PERCEPCIONES DE LAS VÍCTIMAS Y SUS REPRESENTANTES JUDICIALES

FRENTE AL INCIDENTE DE REPARACIÓN INTEGRAL DE LAS VÍCTIMAS DE MAMPUJÁN Y SAN CAYETANO EN EL MARCO DE LA LEY DE JUSTICIA Y PAZ: LEY 975 DE 2005 DE COLOMBIA

\author{
LUIS ALBERTO BONILLA CÁRDENAS \\ JHON BYRON TAMAYO VERA
}

UNIVERSIDAD SANTO TOMAS

FACULTAD DE PSICOLOGÍA

POSGRADOS EN PSICOLOGÍA JURÍDICA

MAESTRÍA EN PSICOLOGÍA JURÍDICA

BOGOTÁ, D.C. Ï COLOMBIA, SEPTIEMBRE - 2014. 
PERCEPCIONES DE LAS VÍCTIMAS DE MAMPUJÁN Y SAN CAYETANO Y SUS REPRESENTANTES JUDICIALES FRENTE A LA REPARACIÓN INTEGRAL EN LA LEY DE JUSTICIA Y PAZ

PERCEPCIONES DE LAS VÍCTIMAS Y SUS REPRESENTANTES JUDICIALES

FRENTE AL INCIDENTE DE REPARACIÓN INTEGRAL DE LAS VÍCTIMAS DE MAMPUJÁN Y SAN CAYETANO EN EL MARCO DE LA LEY DE JUSTICIA Y PAZ: LEY 975 DE 2005 DE COLOMBIA

LUIS ALBERTO BONILLA CÁRDENAS JHON BYRON TAMAYO VERA

Trabajo de grado para obtener el título de:

MAGISTER EN PSICOLOGIA JURÍDICA

ÁNGELA TÁPIAS SALDAÑA ${ }^{1}$

UNIVERSIDAD SANTO TOMAS

FACULTAD DE PSICOLOGÍA POSGRADOS EN PSICOLOGÍA JURÍDICA MAESTRÍA EN PSICOLOGÍA JURÍDICA BOGOTÁ, D.C. İ COLOMBIA, SEPTIEMBRE - 2014.

${ }^{1}$ Directora de la investigación. 
PERCEPCIONES DE LAS VÍCTIMAS DE MAMPUJÁN Y SAN CAYETANO Y SUS REPRESENTANTES JUDICIALES FRENTE A LA REPARACIÓN INTEGRAL EN LA LEY DE JUSTICIA Y PAZ

\section{Dedicatoria}

Esta investigación es el resultado del compromiso adquirido con las víctimas de Mampuján y

San Cayetano, de la colaboración de sus participantes y comunidades en general, de muchas lecturas y escritos, momentos de angustia y tensión, de la formación recibida en la Universidad Santo Tomas, acompañamiento y apoyo de amigos, colegas, familiares y a nuestras respectivas parejas, a todas estas personas nuestros más sinceros agradecimientos.

Los Autores 
PERCEPCIONES DE LAS VÍCTIMAS DE MAMPUJÁN Y SAN CAYETANO Y SUS REPRESENTANTES JUDICIALES FRENTE A LA REPARACIÓN INTEGRAL EN LA LEY DE JUSTICIA Y PAZ

\section{Tabla de Contenido}

Introducción

Objetivos .......

Objetivo general. 20

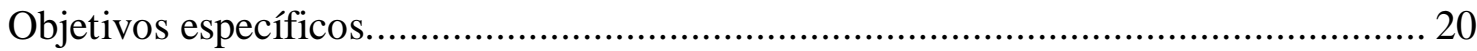

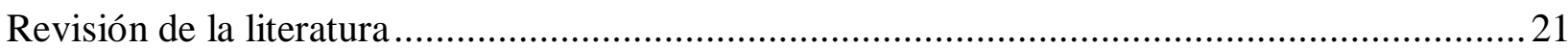

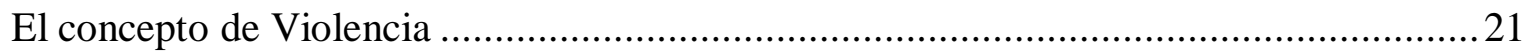

Víctimas del conflicto armado interno y normatividades nacionales para protegerlas ......22

Decisiones: Orden y Exhorto (Resuelve de reparación) .....................................................34

Macrovictimización de Mampuján y San Cayetano y Conflicto Armado Interno...............35

Causas de la macrovictimización de Mampuján y San Cayetano y del Conflicto Armado

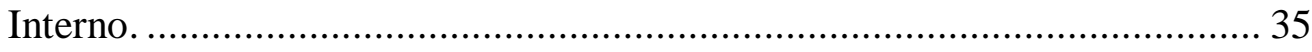

Hechos victimizantes y daños generados por la macrovictimización de Mampuján y San

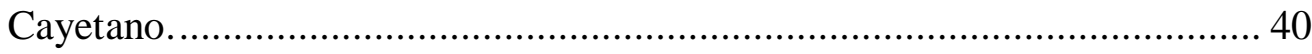

Victimización primaria y secundaria de las víctimas de Mampuján y San Cayetano... 50

Organizaciones e instituciones relevantes en el proceso de Justicia y Paz de las víctimas de

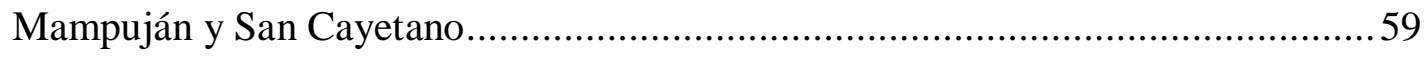

Comisión Nacional de Reparación y Reconciliación (CNRR).......................................59

Misión de Apoyo al Proceso de Paz en Colombia de la Organización de los Estados

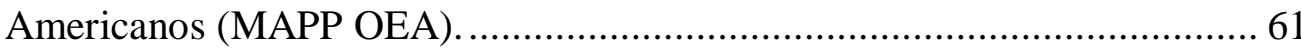


PERCEPCIONES DE LAS VÍCTIMAS DE MAMPUJÁN Y SAN CAYETANO Y SUS REPRESENTANTES JUDICIALES FRENTE A LA REPARACIÓN INTEGRAL EN LA LEY DE JUSTICIA Y PAZ

Programa de las Naciones Unidas para el Desarrollo (PNUD).................................... 62

Departamento de Justicia de los Estados Unidos en Colombia.......................... 63

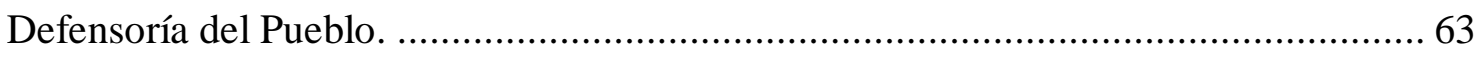

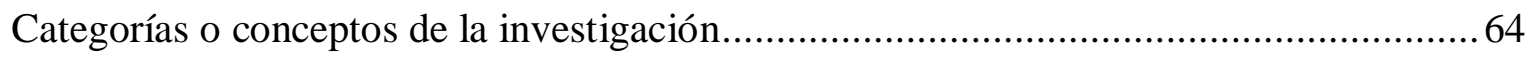

Victimología y tipos de victimización. Campo de acción de la investigación. .............. 64

Los conceptos de Percepción y Percepción Social. ........................................................ 67

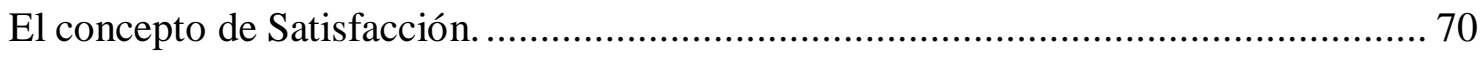

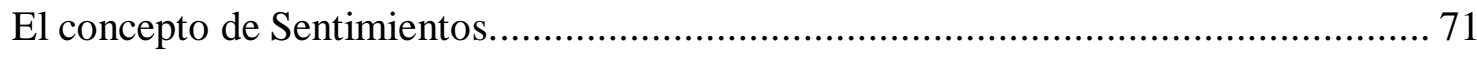

El concepto de Estigma o Estigmatizaciones. ………............................................... 73

Los conceptos de Empoderamiento y Resiliencia........................................................ 75

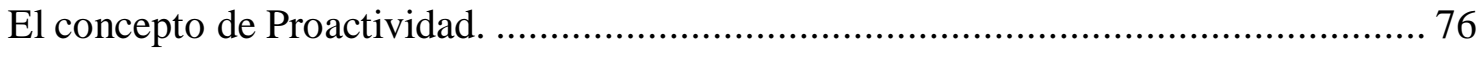

Conflicto Armado Interno y Psicología Jurídica. ....................................................... 77

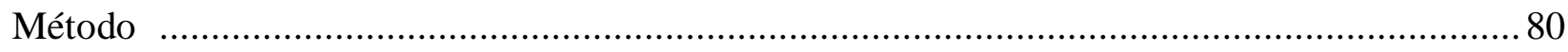

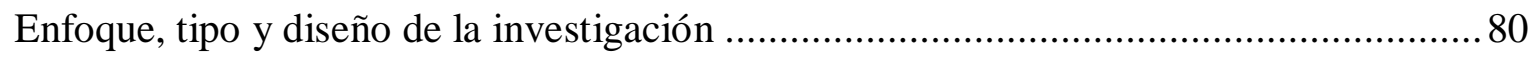

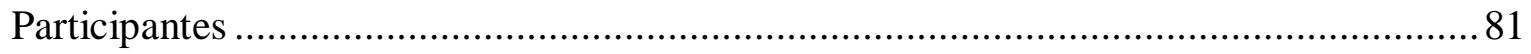

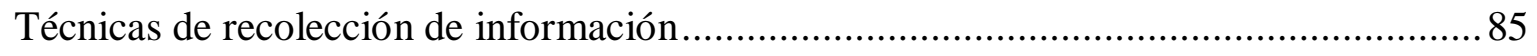

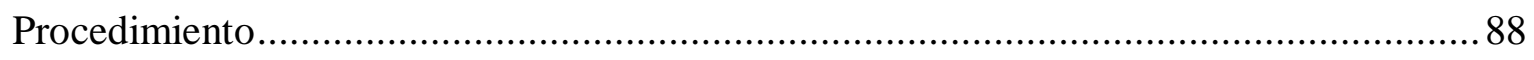

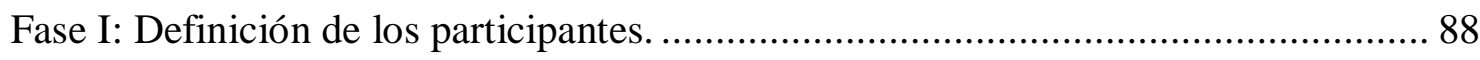

Fase II: Diseño del contenido de las técnicas de recolección de información................ 90

Fase III: Aplicación de las técnicas de recolección de información............................... 90 
PERCEPCIONES DE LAS VÍCTIMAS DE MAMPUJÁN Y SAN CAYETANO Y SUS REPRESENTANTES JUDICIALES FRENTE A LA REPARACIÓN INTEGRAL EN LA LEY DE JUSTICIA Y PAZ

Fase IV: Transcripción y análisis de la información......................................................95

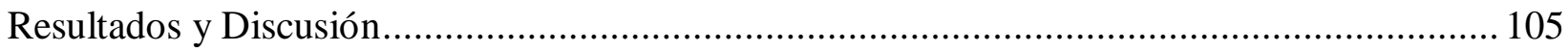

Causas de la macrovictimización de Mampuján y San Cayetano y del Conflicto Armado

Interno

Hechos victimizantes cometidos en la macrovictimización de Mampuján y San Cayetano

Daños generados en las víctimas por la macrovictimización de Mampuján y San Cayetano o por el incidente de reparación integral

Revictimizaciones de las víctimas de Mampuján y San Cayetano.

Procesos jurídicos desacertados en el marco de la Ley de Justicia y Paz adelantados con las víctimas de Mampuján y San Cayetano

Procesos jurídicos acertados en el marco de la Ley de Justicia y Paz adelantados con las víctimas de Mampuján y San Cayetano

Pretensiones de reparación integral de las víctimas de Mampuján y San Cayetano que faltaron por incluirse en el incidente de reparación dado en segunda instancia..... 164

Incumplimientos por parte de la institucionalidad de los Resuelve emitidos por la Corte Suprema de Justicia en el fallo de segunda instancia frente a la reparación integral de las víctimas de Mampuján y San Cayetano

Incumplimientos por parte de los postulados de los Resuelve emitidos por la Corte Suprema de Justicia en el fallo de segunda instancia frente a la reparación integral de las víctimas de Mampuján y San Cayetano 178 
PERCEPCIONES DE LAS VÍCTIMAS DE MAMPUJÁN Y SAN CAYETANO Y SUS REPRESENTANTES JUDICIALES FRENTE A LA REPARACIÓN INTEGRAL EN LA LEY DE JUSTICIA Y PAZ

Insatisfacción de las pretensiones de las víctimas de Mampuján y San Cayetano con el resultado del incidente de reparación dado en la segunda instancia

Satisfacción de las pretensiones de las víctimas de Mampuján y San Cayetano con el resultado del incidente de reparación dado en segunda instancia. 185

Sentimientos presentes o generados en las víctimas de Mampuján y San Cayetano 195

No contribución del incidente de reparación de Mampuján y San Cayetano a la reparación integral de las victimas 198

Contribución del incidente de reparación de Mampuján y San Cayetano a la reparación integral de las víctimas

Contribución del primer incidente de reparación de Justicia y Paz para futuros procesos

Acciones para alcanzar la reparación integral de las víctimas de Mampuján y San Cayetano. Empoderamiento y Resiliencia de las víctimas .203

Agradecimientos para algunas instituciones por parte de algunos participantes .205

Enseñanzas del proceso de Justicia y Paz o del incidente de reparación integral de Mampuján y San Cayetano. 206

Sugerencias de los participantes. .221

Conclusiones y Recomendaciones .233

Referencias 245

APÉNDICES .257 
PERCEPCIONES DE LAS VÍCTIMAS DE MAMPUJÁN Y SAN CAYETANO Y SUS REPRESENTANTES JUDICIALES FRENTE A LA REPARACIÓN INTEGRAL EN LA LEY DE JUSTICIA Y PAZ

\section{Lista de Tablas}

Tabla 1. Daño psíquico en víctimas de delitos violentos. 46

Tabla 2. Actividades adelantadas durante la fase de recolección de información con los líderes y víctimas de Mampuján y San Cayetano. 91

Tabla 3. Actividades adelantadas durante la fase de recolección de información con los representantes judiciales de víctimas de Mampuján y San Cayetano.

Tabla 4. Documentos Primarios y Categorías............................................................ 105

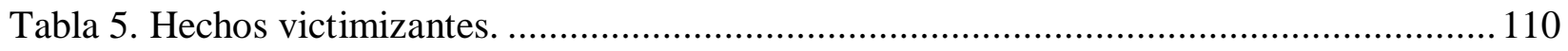

Tabla 6. Ejemplos relevantes de los Daños causados a las víctimas de Mampuján y San Cayetano 
PERCEPCIONES DE LAS VÍCTIMAS DE MAMPUJÁN Y SAN CAYETANO Y SUS REPRESENTANTES JUDICIALES FRENTE A LA REPARACIÓN INTEGRAL EN LA LEY DE JUSTICIA Y PAZ

\title{
Percepciones de las víctimas y sus representantes judiciales frente al incidente de reparación integral de las víctimas de Mampuján y San Cayetano en el marco de la Ley de Justicia y Paz: Ley 975 de 2005 de Colombia
}

\author{
Luis Alberto Bonilla Cárdenas y Jhon Byron Tamayo Vera \\ Ángela Tápias Saldaña ${ }^{2}$
}

\begin{abstract}
Resumen
Correspondió establecer sí el incidente de reparación de Mampuján y San Cayetano en el marco de la Ley 975 de 2005 contribuyó a la reparación integral de las víctimas, por la macrovictimización y hechos victimizantes generados el 10 y 11 de marzo del año 2000, por alias ñJuancho Diqueò y ñDiego Vecinoò, excomandantes de un grupo de las Autodefensas Unidas de Colombia. Para ello, se aplicaron técnicas de recolección de información propias de la psicología como entrevistas semiestructuradas con cuatro líderes-víctimas de estas comunidades, dos de sus representantes judiciales dentro del proceso y grupos focales con diecinueve víctimas de ambas comunidades. Mediante la utilización de conceptos de la Psicología Jurídica, en el proceso investigativo se obtuvieron las percepciones de los participantes frente al incidente de reparación integral, especialmente respecto al fallo de segunda instancia emitido por la Corte Suprema de Justicia. Esta investigación cualitativa de tipo exploratorio, enmarcada en el campo de la victimología y de diseño fenomenológico estuvo soportada por el software Atlas. ti 6.2., que permitió concluir mediante el análisis de las percepciones, que el primer incidente en Justicia y Paz, no logró la reparación integral a las víctimas, debido a que el fallo de segunda instancia no incorporó algunas pretensiones de las víctimas, no hubo cumplimiento total por parte de los postulados y la institucionalidad a las órdenes y exhortos del fallo y no todas las víctimas quedaron satisfechas con el resultado del incidente de reparación ni con el proceso de Justicia y Paz.

Palabras clave: Percepción - Social-, Pretensiones, Reparación, Cumplimiento Sentencia y Satisfacción.
\end{abstract}

\begin{abstract}
Corresponded to establish if the incident Mampuján's and San Cayetano's repair under Law 975 of 2005 contributed to the integral repair of the victims, by the macro victimization and victimizing events generated on 10th and 11th March 2000, by alias "Juancho Dique " and "Diego Vecino" ex commanders of a group the United Self Defense Forces of Colombia. For this, recollection techniques of information typical of psychology were applied as semi-structured interviews with four leaders of these communitiesvictims and two of their judicial representatives inside the process, and focus groups with nineteen victims of both communities. By filling using concepts of Legal Psychology, in the research process participants' perceptions versus incident integral reparation, especially regarding the second instance ruling issued by the Supreme Court is obtained. This exploratory qualitative research, framed in the field of victimology and phenomenological design was supported by the Atlas software. 6.2 you., which revealed by analysis of perceptions that the first incident in Justice and Peace, failed integral reparation to the victims because the judgment on appeal claims not incorporate some of the victims, no compliance Total by the postulates and institutional orders and exhortations of the fault and not all victims were satisfied with the outcome or repair the incident or the Justice and peace process.
\end{abstract}

Key words: Perception, Social Perception, Victims, Integral Repair, Compliance Statement and Satisfaction.

${ }^{2}$ Directora de la investigación. 
PERCEPCIONES DE LAS VÍCTIMAS DE MAMPUJÁN Y SAN CAYETANO Y SUS REPRESENTANTES JUDICIALES FRENTE A LA REPARACIÓN INTEGRAL EN LA LEY DE JUSTICIA Y PAZ

\section{Introducción}

La población colombiana padece desde el siglo pasado un conflicto armado interno que en su desarrollo ha dejado millones de víctimas, si se cuantifican en su balance las personas que han venido padeciendo los rigores del desplazamiento forzado. Este conflicto armado atraviesa la geografía y la historia de Colombia completando así un sombrío panorama de graves violaciones a los Derechos Humanos e infracciones al Derecho Internacional Humanitario caracterizadas por la ocurrencia de hechos victimizantes como homicidios, desapariciones forzadas, torturas, secuestros, despojo de tierras y de bienes y otros delitos que han dejado profundas huellas en las personas que han sido sus víctimas.

El padecimiento de esos hechos, ocasionan graves impactos en la población y sociedad en general, dejando entre sus efectos, no solamente pérdidas materiales sino consecuencias que se manifiestan en el daño psicosocial, en el desarraigo de poblaciones enteras, miedo y zozobra entre los pobladores, familias fragmentadas, intenso sufrimiento emocional e incertidumbre frente al futuro, dificultades de adaptación y en la elaboración de los duelos ante las pérdidas materiales y humanas, ruptura del tejido social, desesperanza, soledad, desesperación, aislamiento, estigmatización y en general cambios drásticos en las expectativas sobre los proyectos de vida de la población.

Lo anterior se constituye solo en una muestra de las dificultades a las que se ven enfrentadas las personas, las familias, las comunidades y la misma sociedad por causa del conflicto armado interno, que lejos de solucionarse, se profundiza y se complejiza más, negando a los ciudadanos de Colombia como a las futuras generaciones, del más elemental derecho que tiene todo ser humano a una vida digna, en paz y con justicia social. 
PERCEPCIONES DE LAS VÍCTIMAS DE MAMPUJÁN Y SAN CAYETANO Y SUS REPRESENTANTES JUDICIALES FRENTE A LA REPARACIÓN INTEGRAL EN LA LEY DE JUSTICIA Y PAZ

El conflicto armado interno en Colombia se ha caracterizado porque en este han intervenido varios actores con intereses diversos y también con razones diferentes que justifican su existencia, es así como las guerrillas desde la década de los años sesenta surgen como respuesta al proceso de exclusión política que se dio con la implementación del frente nacional, como una manera de ponerle punto final a la lucha entre liberales y conservadores.

Dicha exclusión, combinada con la represión violenta por parte del Estado a las aspiraciones de vastos sectores de la población para acceder a la participación política y a la reivindicación social de sus aspiraciones para mejorar sus condiciones de vida, respaldaron la opción de acceder a la toma del poder a través de las armas en nombre del pueblo.

Por otra parte, los llamados grupos paramilitares o las Autodefensas Unidas de Colombia (AUC) surgieron como respuesta por parte de sectores terratenientes, elites políticas regionales, militares, ganaderos, empresarios y personas del común, para contrarrestar el asedio de las guerrillas comunistas, las cuales eran vistas como una amenaza a la estabilidad política y económica del país.

Por último, el Estado se constituye en sí mismo como otro interviniente dentro del conflicto armado interno, a través, de sus fuerzas regulares (Fuerza Pública) que constitucionalmente tienen la obligación de garantizar la seguridad de los ciudadanos, el cuidado y defensa de la soberanía nacional y la estabilidad de las instituciones, ya que en algunos casos sus actuaciones perdieron legitimidad al establecer alianzas con actores armados ilegales, como los paramilitares, visibles en acciones donde han operado de forma conjunta y han tenido un impacto importante en la violación de los derechos de la población civil.

Han sido muchos los intentos de acercamiento entre los gobiernos y los distintos grupos armados ilegales, sin embargo, ninguno había alcanzado un punto más avanzado en cuanto a que 
PERCEPCIONES DE LAS VÍCTIMAS DE MAMPUJÁN Y SAN CAYETANO Y SUS REPRESENTANTES JUDICIALES FRENTE A LA REPARACIÓN INTEGRAL EN LA LEY DE JUSTICIA Y PAZ

el proceso de desarme y desmovilización viniese acompañado por un componente de alternatividad penal como el que se dio en el año 2005 con la promulgación, por parte del gobierno de ese entonces de la Ley 975 (procedimiento vía judicial), denominada la Ley de Justicia y Paz; por la cual en el Diario Oficial No. 45.980 de 25 de julio de 2005 del Congreso de Colombia, se dictan disposiciones para la reincorporación de miembros de grupos armados organizados al margen de la ley, que contribuyan de manera efectiva a la consecución de la paz nacional y se dictan otras disposiciones para acuerdos humanitarios. A través de esta Ley se les brindaba a los comandantes y miembros de las Autodefensas, la posibilidad de desmovilizarse, entregar las armas, confesar sus delitos, pedir perdón, reparar a las víctimas, comprometerse con no volver a delinquir y obtener una pena alternativa de hasta ocho años de prisión.

De igual forma, este marco normativo, en su desarrollo permitió que algunos miembros pertenecientes a la guerrilla, de manera individual, pudieran acceder a las condiciones y beneficios de esta norma.

A partir de la promulgación de la Ley muchos fueron los comandantes y los bloques de las autodefensas que se desmovilizaron y que con la aceptación del gobierno nacional adquirieron el estatus de postulados, elemento necesario para acceder a los beneficios propuestos por esta normatividad; por otra parte, la población que había sufrido las victimizaciones, resultado del accionar de los grupos paramilitares y guerrilleros, en muchas regiones del país tuvieron la oportunidad de romper su silencio y denunciar los hechos de los que habían sido víctimas para configurarse como intervinientes y partes interesadas en lo que posteriormente se dio por llamar los procesos de Justicia y Paz.

Si se hace un balance hasta la fecha, solo se han dictado unas pocas sentencias en firme, siendo la primera de ellas la emitida en contra de Edward Cobos Téllez alias ñDiego Vecinoò, 
PERCEPCIONES DE LAS VÍCTIMAS DE MAMPUJÁN Y SAN CAYETANO Y SUS REPRESENTANTES JUDICIALES FRENTE A LA REPARACIÓN INTEGRAL EN LA LEY DE JUSTICIA Y PAZ

comandante del bloque Montes de María y Uber Enrique Banquez Martínez, alias ñJuancho Diqueò, miembro del frente canal del Dique, de ese mismo bloque de las Autodefensas Unidas de Colombia ï AUC $\ddot{i}$, por homicidio, hurto y desplazamiento forzado de muchas familias de las zonas de Mampuján y San Cayetano de la Región de María la baja en el Departamento de Bolívar en hechos ocurridos entre el 10 y 11 de marzo del año 2000.

Con esa sentencia se establecieron las órdenes para que se iniciara el proceso de reparación integral a las víctimas de Mampuján y San Cayetano por parte de ese grupo paramilitar y de manera subsidiaria por parte del Estado Colombiano. Es de anotar que, la operatividad de la ley, estuvo puesta en entre dicho debido a su incapacidad de materializar la reparación otorgada por parte de los victimarios, y donde, por ejemplo, la verdad que ofrecían los postulados no permitía ser escrutada por el aparato judicial de forma eficaz.

Es por lo anterior, que se hizo necesario verificar la efectividad del proceso a través de la exploración de las percepciones que tuvieron los grupos de participantes: víctimas, sus líderes, quienes también son víctimas, y representantes judiciales, sobre los resultados obtenidos en el fallo de sentencia de segunda instancia establecido por la Corte Suprema de Justicia en el marco del incidente de reparación integral de las víctimas de Mampuján y San Cayetano, en aplicación de la Ley 975 de 2005. Más teniendo en cuenta que esta Ley, que a pesar de llevar más de ocho años en vigencia, ha mostrado que los resultados en cuanto a la garantía de los derechos de las víctimas a la verdad, la justicia y la reparación integral han quedado en entredicho si se hace un recuento de los procesos que se han ejecutoriado a partir de ella.

Además, teniendo en cuenta que el fallo de sentencia dado en el incidente de reparación a las víctimas de Mampuján y San Cayetano ha sido el primero en el marco de la aplicación de la Ley de Justicia y Paz, este resulta paradigmático en el sentido que marca un camino por el cual 
PERCEPCIONES DE LAS VÍCTIMAS DE MAMPUJÁN Y SAN CAYETANO Y SUS REPRESENTANTES JUDICIALES FRENTE A LA REPARACIÓN INTEGRAL EN LA LEY DE JUSTICIA Y PAZ

tendrán que seguir los otros procesos que se están llevando a cabo u otros en materia de reparación integral de las víctimas del conflicto armado interno.

Realizar un análisis de estos resultados, a través de las percepciones de los participantes, es el aporte que la Psicología y de manera específica, la Psicología Jurídica, hace a la comprensión de los resultados obtenidos en la aplicación de instrumentos de Justicia Transicional como lo es la Ley de Justicia y Paz, lo cual permite no solo a la institucionalidad sino también a la sociedad en general y a las víctimas en particular, conocer y reconocer las dificultades, limitaciones y logros del proceso, lo que servirá para poder incidir de manera favorable sobre futuros procesos de Justicia y Paz, haciendo eficiente y eficaz para las victimas la aplicación de estos.

La psicología jurídica en este contexto, no solo tiene para aportar el conocimiento construido a través de las técnicas para la valoración del daño producido a las víctimas afectadas por las acciones de los paramilitares y que permiten tasar esos daños para que la magistratura dictamine en los distintos fallos las medidas que deben aplicarse tanto por parte de los postulados como por el Estado Colombiano para reparar a las víctimas, sino que también puede aportar su saber en cuanto a la investigación empírica para abordar los procesos psicológicos que se presentan por los distintos intervinientes dentro del ámbito forense como los dados en los juicios de Justicia y Paz. Arce y Fariña (1994) plantean que concretamente, la justicia ña protagonizanò personas y las personas (jueces, víctimas, victimarios, abogados, testigos o jurados) en sus percepciones (visiones de hechos, juicios) están influenciadas por sus antecedentes, sobretodo políticos, sociales, económicos y de género. Es así que la visión que puedan tener las víctimas sobre el resultado del incidente de reparación integral dado en el fallo de segunda instancia por la Corte Suprema de Justicia resulta un gran aporte por parte de la psicología jurídica para entender cuál 
PERCEPCIONES DE LAS VÍCTIMAS DE MAMPUJÁN Y SAN CAYETANO Y SUS REPRESENTANTES JUDICIALES FRENTE A LA REPARACIÓN INTEGRAL EN LA LEY DE JUSTICIA Y PAZ

fue el balance general del incidente de reparación y si dicho balance se acerca a las expectativas y pretensiones que fijaron las víctimas como requisitos para sentirse reparadas.

De acuerdo a lo anterior, resulta imperativo para el aparato judicial conocer la visión que tienen las víctimas sobre el resultado del proceso judicial y es cuando se hace vigente la pregunta planteada por Sobral, Arce y Prieto (1994): ¿podría ignorar el legislador la ñnaturalezaò de aquellos a quienes van dirigidas sus normas y prescripciones? Es obvio que no la puede ignorar, ya que ese primer incidente, ese primer esfuerzo para reparar a las víctimas, donde el ideal es que pueda ser de forma integral, es la primera experiencia que se da en el marco de la justicia transicional que comienza a hacer carrera en Colombia, y de lo que se aprenda de esta experiencia dependerán los resultados de los demás incidentes que se den en el marco de la Ley de Justicia y Paz.

Por ende, resulta importante señalar que en el año 2010 se realizó el juicio contra Edwar Cobos Téllez, alias ñDiego vecinoò, y Uber Enrique Banquez Martínez, alias ñJuancho Diqueò, comandantes del bloque Montes de María y frente canal del Dique respectivamente, de las Autodefensas Unidas de Colombia ï AUCï . En este proceso ï el que se considera como el primer incidente de reparación en Justicia y Paz ï, como factor que motivó esta investigación, uno de los autores de la presente investigación participó como perito experto (psicojurídico) y en el mes de Abril de 2010 una comisión conformada por 11 representantes judiciales de las víctimas, un perito económico, dos psicólogos jurídicos y una psicóloga forense estuvieron en San Cayetano y Mampuján como Defensoría del Pueblo para realizar la preparación de las víctimas para su participación en el incidente de reparación, acopiar la documentación necesaria para la representación judicial dentro del incidente y realizar las entrevistas, aplicar instrumentos y realizar los periciales a fin de establecer el daño psicológico a algunas de las personas que habían 
PERCEPCIONES DE LAS VÍCTIMAS DE MAMPUJÁN Y SAN CAYETANO Y SUS REPRESENTANTES JUDICIALES FRENTE A LA REPARACIÓN INTEGRAL EN LA LEY DE JUSTICIA Y PAZ

sido victimizadas por los postulados; frente a ello, es preciso señalar que aunque se elaboraron los respectivos informes y se entregaron a la Magistrada presidente del Tribunal, los peritajes respectivos como elementos probatorios para la estimación del daño psicológico, fueron tomados como pruebas documentales que no fueron presentadas en las audiencias, ya que el interés del Tribunal era orientar el fallo hacia una reparación en Equidad y no en Derecho, este aspecto desvirtuó desde la entrada el sentido del incidente, debido a que se esperaba que en este se pudieran presentar los distintos elementos probatorios para que cada caso fuera presentado y analizado teniendo en cuenta el impacto generado en las víctimas, el daño ocasionado y así poder establecer la tasación para la reparación, siguiendo el principio de que la reparación judicial debe ser proporcional al daño ocasionado.

De esta forma, el tribunal Administrativo de Cundinamarca procedió a fallar en lo que se denominó ñfallo en equidadò, idéntico para todas las víctimas, desconociendo las diferencias en la ocurrencia de los hechos, los impactos producidos, las medidas de afrontamiento utilizadas por las víctimas, y la incidencia de las victimizaciones en sus proyectos de vida, aspectos fundamentales para la tasación de un daño y la definición de la respectiva reparación judicial. De esta forma, se dio la sentencia respectiva el 29 de junio del 2010 por parte del Tribunal Administrativo de Cundinamarca que fue apelada por los representantes judiciales de las víctimas de la Defensoría del Pueblo, por las razones descritas anteriormente y porque no se habían tenido en cuenta, por parte del Tribunal, las pretensiones de reparación de estas personas, que no solo estaban planteadas en términos de indemnización, sino que también contemplaban otros mecanismos como la rehabilitación, la restitución, medidas de satisfacción y garantías de no repetición, aspectos que el Tribunal no tuvo en cuenta en su totalidad. 
PERCEPCIONES DE LAS VÍCTIMAS DE MAMPUJÁN Y SAN CAYETANO Y SUS REPRESENTANTES JUDICIALES FRENTE A LA REPARACIÓN INTEGRAL EN LA LEY DE JUSTICIA Y PAZ

Dicha sentencia fue apelada ante la sala de Casación de la Corte Suprema de Justicia, la que dio su fallo en segunda instancia el 27 de Abril de 2011 y que, entre otros aspectos, resolvió reparar a las víctimas en Derecho y no en Equidad, en sentido opuesto a lo planteado por el Tribunal de Cundinamarca en la primera instancia, lo que determinó que las víctimas fueran reparadas de manera particular, dependiendo del daño ocasionado por el hecho victimizante.

Estos antecedentes revelan las deficiencias y contradicciones en los resultados que ha mostrado la Ley, tanto así que según los medios de comunicación, el 16 de septiembre de 2011, la Fiscal General de la Nación presentó un proyecto de Ley de reforma de esta normatividad para que fuera mucho ñmás ágil y eficazò, tras ser aprobada la Ley 1592 de 2012, se ñeliminóò el incidente de reparación dentro del proceso de Justicia y Paz, el cual pasó por un tiempo, gracias a la Sentencia C-180 de 2014, a ser denominado como incidente de identificación de afectaciones, llevando a la reparación a ser resuelta por la Ley 1448 de 2011, equiparando los montos de la reparación por vía judicial a los montos establecidos para la vía administrativa, generándose nuevamente reparaciones en equidad.

Lo anteriormente descrito, resulta de gran importancia para la comprensión de los resultados y el impacto producido por el primer incidente de reparación en el marco de la Ley de Justicia y Paz en las víctimas, y es precisamente que con la aplicación de conceptos, instrumentos y métodos para generar conocimiento provenientes de la Psicología Jurídica, este trabajo de investigación rescata por una parte la visión de las víctimas y, por otra, la de algunos representantes judiciales como intervinientes fundamentales en el incidente de reparación integral, donde sus percepciones podrían ser tenidas en cuenta en futuros procesos de Justicia y Paz, así como en otros incidentes o procesos de reparación de víctimas. 
PERCEPCIONES DE LAS VÍCTIMAS DE MAMPUJÁN Y SAN CAYETANO Y SUS REPRESENTANTES JUDICIALES FRENTE A LA REPARACIÓN INTEGRAL EN LA LEY DE JUSTICIA Y PAZ

Los temas tratados en el presente trabajo de investigación, como las violaciones a los Derechos Humanos de víctimas del Conflicto Armado Interno como las de Mampuján y San Cayetano, sus participaciones en el primer incidente de reparación integral que se da en el país en el marco de la Ley 975 de 2005 y el fallo de segunda instancia instaurado por la Corte Suprema de Justicia, facilitan un terreno abonado para que el profesional en Psicología Jurídica pueda hacer sus aportes a partir de sus análisis y elementos conceptuales, lo que permitirá un posicionamiento de su papel en estos escenarios. Esto necesariamente conlleva al planteamiento de diversas cuestiones con las víctimas de Mampuján y San Cayetano como: ¿El trato que se viene proporcionando a las víctimas por parte de las instituciones y los postulados es apropiado y acorde a sus demandas, a sus necesidades y a sus derechos? ¿Es posible que los trámites, procedimientos y tratos que vienen brindando las diferentes instituciones y postulados ocasionen más daño a las víctimas?, ¿El proceso de atención y reparación a las víctimas se basó o basa en la restitución de la dignidad y los derechos humanos vulnerados a partir del incidente de reparación en el marco de la Ley de Justicia y Paz?, ¿Existió respeto por la subjetividad de las víctimas?, ¿Cómo puede la psicología jurídica contribuir en la prevención de los efectos psicosociales de la victimización secundaria?. Interrogantes que se irán resolviendo en el transcurso de este informe de investigación cualitativa y que obligan, por ejemplo, al Psicólogo Jurídico indagar más a fondo sobre las formas cómo se viene abordando desde la institucionalidad a las víctimas del conflicto armado interno, poniendo énfasis en metodologías y procedimientos de atención que estén basados en la prevención de la victimización secundaria y la protección de la salud mental de estas personas. 
PERCEPCIONES DE LAS VÍCTIMAS DE MAMPUJÁN Y SAN CAYETANO Y SUS REPRESENTANTES JUDICIALES FRENTE A LA REPARACIÓN INTEGRAL EN LA LEY DE JUSTICIA Y PAZ

Por todo lo anterior, se optó por establecer sí el incidente de reparación de Mampuján y San Cayetano contribuyó a la reparación integral de las víctimas, aspecto que se indagó a través del análisis y sistematización de las percepciones de los participantes.

Para ello, fue necesario que se agotara las instancias de apelación respectivas por los representantes judiciales de las víctimas y una vez establecido el fallo de segunda instancia por parte de la Corte Suprema de Justicia, responder los siguientes interrogantes o preguntas de investigación:

1. ¿Faltaron por incluirse pretensiones de reparación de las víctimas de Mampuján y San Cayetano dentro del incidente de reparación dado en la segunda instancia, cuáles?

2. ¿Fueron cumplidas, por parte de la institucionalidad y los postulados, las órdenes y exhortos emitidos por la Corte Suprema de Justicia en la parte resolutiva del fallo de segunda instancia frente a la reparación integral de las víctimas de Mampuján y San Cayetano?

3. ¿Fueron satisfechas las pretensiones de las víctimas de Mampuján y San Cayetano con el resultado del incidente de reparación dado en segunda instancia?

Las anteriores, porque se consideró que la relación pretensiones de reparación más cumplimiento de los Resuelve de reparación conllevan a establecer la satisfacción de las pretensiones de las víctimas y, por consiguiente, saber sí el incidente de reparación de Mampuján y San Cayetano contribuyó a la reparación integral de estas personas. Se determina esta contribución si se sienten satisfechas las víctimas. 
PERCEPCIONES DE LAS VÍCTIMAS DE MAMPUJÁN Y SAN CAYETANO Y SUS REPRESENTANTES JUDICIALES FRENTE A LA REPARACIÓN INTEGRAL EN LA LEY DE JUSTICIA Y PAZ

\section{Objetivos}

\section{Objetivo general.}

Establecer sí el incidente de reparación de Mampuján y San Cayetano contribuyó a la reparación integral de las víctimas.

\section{Objetivos específicos.}

- Conocer si faltaron por incluirse pretensiones de reparación integral de las víctimas de Mampuján y San Cayetano dentro del incidente de reparación dado en segunda instancia

- Determinar si hubo cumplimiento por parte de la institucionalidad y los postulados de las órdenes y exhortos (Resuelve) emitidos por la Corte Suprema de Justicia en el fallo de segunda instancia frente a la reparación integral de las víctimas de Mampuján y San Cayetano.

- Identificar si fueron satisfechas las pretensiones de las víctimas de Mampuján y San Cayetano con el resultado del incidente de reparación dado en segunda instancia. 
PERCEPCIONES DE LAS VÍCTIMAS DE MAMPUJÁN Y SAN CAYETANO Y SUS REPRESENTANTES JUDICIALES FRENTE A LA REPARACIÓN INTEGRAL EN LA LEY DE JUSTICIA Y PAZ

\section{Revisión de la literatura}

\section{El concepto de Violencia}

Considerando los hechos violentos que serán expuestos más adelante y que cometieron los postulados alias ñJuancho Diqueò y ñDiego Vecinoò con las víctimas de Mampuján y San Cayetano, y apoyados en los planteamientos que sobre la violencia hacen Anderson y Bushman citados por García (2012), en la que se ha definido como una conducta agresiva que tiene la intención de causar daño físico o psicológico, siendo el componente de la intención lo que diferencia a la violencia de otras conductas agresivas o incluso de los daños causados de manera accidental. Martín-Baró (2003) reconoció tres formas de violencia que se distinguían en la vida social de El Salvador: La primera, la violencia delincuencial que afecta de manera diversa a la sociedad y que se origina en el deterioro económico estimulando el robo y la prostitución juvenil y generada por el hambre y la desesperación de muchos al no poder satsifacer sus necesidades básicas; una segunda forma de violencia es la de la represión política en la que los perpetradores son los cuerpos de seguridad, cuerpos policiales, fuerzas combinadas del ejército o simplemente bandas paramilitaes vinculadas a los mismos cuerpos de seguridad o que operan con su apoyo y connivencia esta violencia, donde las víctimas pertenecen a todos los sectores sociales, aunque los obreros y campesinos llevan la peor parte, y una tercera forma de violencia es aquella de la guerra formal misma que a medida que se va intensificando los combates han sido más mortíferos y la destrucción humana y material ha alcanzado dimensiones trágicas.

Según lo anterior, la segunda forma de violencia fue generada en contra de los habitantes de Mampuján y San Cayetano. Así, la violencia desencadenada contra las víctimas de Mampuján y San Cayetano reviste un triple carácter: es brutal, exterior y dolorosa. Lo que la define es el uso material de la fuerza, la rudeza intencional cometida en detrimento de alguien y que genera en las 
PERCEPCIONES DE LAS VÍCTIMAS DE MAMPUJÁN Y SAN CAYETANO Y SUS REPRESENTANTES JUDICIALES FRENTE A LA REPARACIÓN INTEGRAL EN LA LEY DE JUSTICIA Y PAZ

víctimas no solo daños materiales sino también daños inmateriales que desde la perspectiva de la psicología se ubican en los daños psicológicos o daños morales.

\section{Víctimas del conflicto armado interno y normatividades nacionales para protegerlas}

Ahora, para aclarar el concepto de víctima del conflicto armado interno se recurre a la Ley 975 de 2005 y a la Ley 1448 de 2011, leyes que dan contexto a temas sociales, políticos y jurídicos de gran importancia para el país, ya que reconocen que hay conflicto armado en Colombia y en donde se propone verdad y/o justicia y/o reparación para las víctimas.

Por su parte, la Ley 975 de 2005 es aquella por la cual se dictan disposiciones para la reincorporación de miembros de grupos armados organizados al margen de la ley, que contribuyan de manera efectiva a la consecución de la paz nacional y en donde se dictan otras disposiciones para acuerdos humanitarios. Aunque brinda medidas de verdad, justicia y reparación a las víctimas, han sido fuertemente criticadas en cuanto a su efectividad por varios grupos de opositores en el país, como las organizaciones de víctimas, porque, como se puede observar en esta definición, fue pensada principalmente para la reincorporación de sus postulados (desmovilizados de grupos organizados armados ilegales que se acogieron a esta Ley para obtener, por ejemplo, beneficios de reducción de penas), dejando entre dicho su efectividad en reparación de las víctimas si se hace un recuento de los procesos que se han adelantado al respecto.

Mientras que, la Ley 1448 de 2011, la cual fue reglamentada por el Decreto Nacional 4800 de 2011, es la normatividad por la cual se dictan medidas propiamente de atención, asistencia y reparación integral a las víctimas del conflicto armado interno y se dictan otras disposiciones. Siendo su mayor dificultad la imposibilidad de generar reparación en Derecho por no ser un proceso judicial como el de la Ley 975 de 2005, lo que significa que el país actualmente no 
PERCEPCIONES DE LAS VÍCTIMAS DE MAMPUJÁN Y SAN CAYETANO Y SUS REPRESENTANTES JUDICIALES FRENTE A LA REPARACIÓN INTEGRAL EN LA LEY DE JUSTICIA Y PAZ

cuenta con una herramienta efectiva de reparación judicial de víctimas del conflicto armado interno.

Ahora bien, según el Art. 5 de la Ley 975 de 2005, se entiende por víctima (abarca a las víctimas de Mampuján y San Cayetano) la persona que individual o colectivamente haya sufrido daños directos tales como lesiones transitorias o permanentes que ocasionen algún tipo de discapacidad física, psíquica y/o sensorial (visual y/o auditiva), sufrimiento emocional, pérdida financiera o menoscabo de sus derechos fundamentales. Los daños deberán ser consecuencia de acciones que hayan transgredido la legislación penal, realizadas por grupos armados organizados al margen de la ley.

También comprende por víctima al cónyuge, compañero o compañera permanente, y familiar en primer grado de consanguinidad, primero civil de la víctima directa, cuando a esta se le hubiere dado muerte o estuviere desaparecida.

En esta Ley, la condición de víctima se adquiere con independencia de que se identifique, aprehenda, procese o condene al autor de la conducta punible y sin consideración a la relación familiar existente entre el autor y la víctima.

Igualmente considera como víctimas a los miembros de la Fuerza Pública que hayan sufrido lesiones transitorias o permanentes que ocasionen algún tipo de discapacidad física, psíquica y/o sensorial (visual o auditiva), o menoscabo de sus derechos fundamentales, como consecuencia de las acciones de algún integrante o miembros de los grupos armados organizados al margen de la ley.

Asimismo, entiende como víctimas al cónyuge, compañero o compañera permanente y familiares en primer grado de consanguinidad, de los miembros de la fuerza pública que hayan perdido la vida en desarrollo de actos del servicio, en relación con el mismo, o fuera de él, como 
PERCEPCIONES DE LAS VÍCTIMAS DE MAMPUJÁN Y SAN CAYETANO Y SUS REPRESENTANTES JUDICIALES FRENTE A LA REPARACIÓN INTEGRAL EN LA LEY DE JUSTICIA Y PAZ

consecuencia de los actos ejecutados por algún integrante o miembros de los grupos organizados al margen de la ley.

Por su parte, en la Ley 1448 de 2011, a partir de su Art. 3, se consideran víctimas aquellas personas que individual o colectivamente hayan sufrido un daño por hechos ocurridos a partir del $1^{\circ}$ de enero de 1985, como consecuencia de infracciones al Derecho Internacional Humanitario o de violaciones graves y manifiestas a las normas internacionales de Derechos Humanos, ocurridas con ocasión del conflicto armado interno.

Para esta, también son víctimas el cónyuge, compañero o compañera permanente, parejas del mismo sexo y familiar en primer grado de consanguinidad, primero civil de la víctima directa, cuando a esta se le hubiere dado muerte o estuviere desaparecida. Sin embargo, a falta de estas, lo serán los que se encuentren en el segundo grado de consanguinidad ascendente.

De la misma forma, se consideran víctimas las personas que hayan sufrido un daño al intervenir para asistir a la víctima en peligro o para prevenir la victimización.

La condición de víctima se adquiere con independencia de que se individualice, aprehenda, procese o condene al autor de la conducta punible y de la relación familiar que pueda existir entre el autor y la víctima.

Sin embargo, cuando los miembros de la Fuerza Pública sean víctimas en los términos del presente artículo, su reparación económica corresponderá por todo concepto a la que tengan derecho de acuerdo al régimen especial que les sea aplicable. De la misma forma, tendrán derecho a las medidas de satisfacción y garantías de no repetición señaladas en la presente ley.

Los miembros de los grupos armados organizados al margen de la ley no serán considerados víctimas, salvo en los casos en los que los niños, niñas o adolescentes hubieren sido desvinculados del grupo armado organizado al margen de la ley siendo menores de edad. 
PERCEPCIONES DE LAS VÍCTIMAS DE MAMPUJÁN Y SAN CAYETANO Y SUS REPRESENTANTES JUDICIALES FRENTE A LA REPARACIÓN INTEGRAL EN LA LEY DE JUSTICIA Y PAZ

Para los efectos de la presente ley, el o la cónyuge, compañero o compañera permanente, o los parientes de los miembros de grupos armados organizados al margen de la ley serán considerados como víctimas directas por el daño sufrido en sus derechos en los términos del presente artículo, pero no como víctimas indirectas por el daño sufrido por los miembros de dichos grupos.

Para los efectos de la definición contenida en el presente artículo, no serán considerados como víctimas quienes hayan sufrido un daño en sus derechos como consecuencia de actos de delincuencia común.

Las personas que hayan sido víctimas por hechos ocurridos antes del 1 de enero de 1985 tienen derecho a la verdad, medidas de reparación simbólica y a las garantías de no repetición previstas en la presente ley, como parte del conglomerado social y sin necesidad de que sean individualizadas.

La definición de víctima contemplada en el presente artículo, en ningún caso podrá interpretarse o presumir reconocimiento alguno de carácter político sobre los grupos terroristas y/o armados ilegales, que hayan ocasionado el daño al que se refiere como hecho victimizante la presente ley, en el marco del Derecho Internacional Humanitario y de los Derechos Humanos, de manera particular de lo establecido por el artículo tercero $\left(3^{\circ}\right)$ común a los Convenios de Ginebra de 1949. El ejercicio de las competencias y funciones que le corresponden en virtud de la Constitución, la ley y los reglamentos a las Fuerzas Armadas de combatir otros actores criminales, no se afectará en absoluto por las disposiciones contenidas en la presente ley.

Como se ve, ambas normatividades discrepan en que la Ley 1448 de 2011 establece una fecha límite para considerarse victima con derecho a la reparación económica, además, contempla que a falta de sus principales beneficiarios, lo serán quienes se encuentren en el 
PERCEPCIONES DE LAS VÍCTIMAS DE MAMPUJÁN Y SAN CAYETANO Y SUS REPRESENTANTES JUDICIALES FRENTE A LA REPARACIÓN INTEGRAL EN LA LEY DE JUSTICIA Y PAZ

segundo grado de consanguinidad ascendente en los casos muerte o desaparición. A su vez, la Ley 1448 contempla a diferencia de la Ley 975 de 2005 que los miembros de la Fuerza Pública recibirán su reparación económica correspondiente por todo concepto a la que tengan derecho de acuerdo al régimen especial que les sea aplicable, etcétera.

De cualquier modo, las victimas a partir de la Ley 975 de 2005 tienen derecho a una reparación contemplada en el Art. 2, donde se dice que los miembros de los grupos armados que resulten beneficiados con las disposiciones previstas en esta ley (recordemos que les brinda a los postulados, con condiciones, reducción de penas no mayores a 8 años de prisión) tienen el deber de reparar a las víctimas de aquellas conductas punibles por las que fueren condenados mediante sentencia judicial.

Igualmente, cuando no se haya logrado individualizar al sujeto activo pero se compruebe el daño y el nexo causal con las actividades del Grupo Armado Ilegal beneficiario por las disposiciones de la presente ley, el Tribunal directamente o por remisión de la Unidad de Fiscalía, ordenará la reparación a cargo del Fondo de Reparación.

Entonces, será el Tribunal Superior de Distrito Judicial quien al proferir sentencia, ordenará la reparación a las víctimas y fijará las medidas pertinentes, según el Art. 43. Artículo que había sido derogado en su momento por el Art. 41 de la Ley 1592 de 2012.

Entre los actos de reparación, a partir del Art. 44 de la Ley 975 de 2005, y que fue modificado en su momento por el Art. 29 de la Ley 1592 de 2012, están los deberes de restitución, indemnización, rehabilitación y satisfacción, porque recordemos que se había modificado el proceso de reparación transfiriéndolo al contemplado administrativamente por parte del Estado en la Ley 1448 de 2011, volviendo a sus orígenes con la Sentencia C-180 de 2014 donde la Corte Constitucional determinó que la supresión del incidente de reparación 
PERCEPCIONES DE LAS VÍCTIMAS DE MAMPUJÁN Y SAN CAYETANO Y SUS REPRESENTANTES JUDICIALES FRENTE A LA REPARACIÓN INTEGRAL EN LA LEY DE JUSTICIA Y PAZ

integral a las víctimas por la vía judicial penal del régimen de transición de Justicia y Paz generado por la Ley 1592 de 2012, vulnera el derecho fundamental de acceso a la administración de justicia y a un recurso judicial efectivo para lograr dicha reparación.

Desde la Ley 975 de 2005 para tener derecho a gozar del beneficio de la libertad a prueba, el condenado debe proveer al Fondo para la Reparación de las Víctimas los bienes destinados para tal fin; realizar satisfactoriamente los actos de reparación que se le hayan impuesto; colaborar con el Comité Nacional de Reparación y Reconciliación o suscribir un acuerdo con el Tribunal Superior de Distrito Judicial que asegure el cumplimiento de sus obligaciones de reparación.

A partir de esta normatividad, son actos de reparación integral los siguientes:

- La entrega al Estado de bienes para la reparación de las víctimas.

- La declaración pública que restablezca la dignidad de la víctima y de las personas más vinculadas con ella.

- El reconocimiento público de haber causado daños a las víctimas, la declaración pública de arrepentimiento, la solicitud de perdón dirigida a las víctimas y la promesa de no repetir tales conductas punibles.

- La colaboración eficaz para la localización de personas secuestradas o desaparecidas y la localización de los cadáveres de las víctimas.

- La búsqueda de los desaparecidos y de los restos de personas muertas, y la ayuda para identificarlos y volverlos a inhumar según las tradiciones familiares y comunitarias.

Son las víctimas de los grupos armados al margen de la ley las que pueden obtener reparación acudiendo al Tribunal Superior de Distrito judicial, en relación con los hechos que sean de su conocimiento, pero nadie podrá recibir dos veces reparación por el mismo concepto (Art. 45, que fue derogado en su momento por el Art. 41 de la Ley 1592 de 2012). 
PERCEPCIONES DE LAS VÍCTIMAS DE MAMPUJÁN Y SAN CAYETANO Y SUS REPRESENTANTES JUDICIALES FRENTE A LA REPARACIÓN INTEGRAL EN LA LEY DE JUSTICIA Y PAZ

Por su parte, la restitución implica la realización de los actos que propendan por la devolución a la víctima a la situación anterior a la violación de sus derechos. Incluye el restablecimiento de la libertad, el retorno a su lugar de residencia y la devolución de sus propiedades (Art. 46, el cual había sido modificado por el Art. 30 de la Ley 1592 de 2012).

La rehabilitación deberá incluir la atención médica y psicológica para las víctimas o sus parientes en primer grado de consanguinidad de conformidad con el Presupuesto del Fondo para la Reparación de las Víctimas (Art. 47, el cual había sido derogado por el Art. 41 de la Ley 1592 de 2012).

Artículo que fue declarado exequible por la Corte Constitucional mediante Sentencia C-029 de 2009, en el entendido de que los mismos se aplican también al cónyuge, compañero o compañera permanente $y$, en las mismas condiciones, a los integrantes de la pareja del mismo sexo.

Por otro lado, a partir del Art. 48 de la Ley 975 y que había sido derogado en su momento por la Ley 1592 de 2012, entre las medidas de satisfacción y garantías de no repetición, adoptadas por las distintas autoridades directamente comprometidas en el proceso de reconciliación nacional, deberán estar:

- La verificación de los hechos y la difusión pública y completa de la verdad judicial, en la medida en que no provoque más daños innecesarios a la víctima, los testigos u otras personas, ni cree un peligro para su seguridad.

- La búsqueda de los desaparecidos o de las personas muertas y la ayuda para identificarlas y volverlas a inhumar según las tradiciones familiares y comunitarias. Tarea que se encuentra principalmente a cargo de la Unidad Nacional de Fiscalías para la Justicia y la Paz. 
PERCEPCIONES DE LAS VÍCTIMAS DE MAMPUJÁN Y SAN CAYETANO Y SUS REPRESENTANTES JUDICIALES FRENTE A LA REPARACIÓN INTEGRAL EN LA LEY DE JUSTICIA Y PAZ

- La decisión judicial que restablezca la dignidad, reputación y derechos de la víctima y las de sus parientes en primer grado de consanguinidad.

- La disculpa, que incluya el reconocimiento público de los hechos y la aceptación de responsabilidades.

- La aplicación de sanciones a los responsables de las violaciones, todo lo cual estará a cargo de los órganos judiciales que intervengan en los procesos de que trata la presente ley.

- La sala competente del Tribunal Superior de Distrito judicial podrá ordenar conmemoraciones, homenajes y reconocimiento a las víctimas de los grupos armados al margen de la ley. Adicionalmente, la Comisión Nacional de Reconciliación y Reparaciones podrá recomendar a los órganos políticos o de gobierno de los distintos niveles, la adopción de este tipo de medidas.

- La prevención de violaciones de derechos humanos.

- La asistencia a cursos de capacitación en materia de derechos humanos a los responsables de las violaciones. Esta medida podrá ser impuesta a los condenados por la sala competente Tribunal Superior de Distrito Judicial.

Artículo que fue declarado exequible por la Corte Constitucional mediante Sentencia C-029 de 2009, en el entendido de que los mismos se aplican también al cónyuge, compañero o compañera permanente $y$, en las mismas condiciones, a los integrantes de la pareja del mismo sexo.

En cuanto a los programas de reparación colectiva contemplados en el Art. 49 y que había sido derogado en su momento por el Art. 41 de la Ley 1592 de 2012, el Gobierno, siguiendo las recomendaciones la Comisión Nacional de Reconciliación y Reparaciones, deberá implementar 
PERCEPCIONES DE LAS VÍCTIMAS DE MAMPUJÁN Y SAN CAYETANO Y SUS REPRESENTANTES JUDICIALES FRENTE A LA REPARACIÓN INTEGRAL EN LA LEY DE JUSTICIA Y PAZ

un programa institucional de reparación colectiva que comprenda acciones directamente orientadas a recuperar la institucionalidad propia del Estado Social de Derecho particularmente en las zonas más afectadas por la violencia; a recuperar y promover los derechos de los ciudadanos afectados por hechos de violencia, y a reconocer y dignificar a las víctimas de la violencia.

Según el Art. 50 de la Ley 975 de 2005 antes de ser derogado por el Art. 208 de la Ley 1448 de 2011, y que fue lo que acogió a las víctimas de Mampuján y San Cayetano, era la Comisión Nacional de Reparación y Reconciliación, integrada por el Vicepresidente de la República o su delegado, quien la presidiera; el Procurador General de la Nación o su delegado; el Ministro del Interior y de justicia o su delegado; el Ministro de Hacienda y Crédito Público o su delegado; Defensor del Pueblo, dos Representantes de Organizaciones de Víctimas y el Director de la Red de Solidaridad Social, quien desempeñaría la Secretaría Técnica. El Presidente de la República debía designar como integrantes de esta Comisión a cinco personalidades, dos de las cuales, al menos, debían ser mujeres. Esta Comisión tenía una vigencia de 8 años.

Dentro de sus funciones estaban:

- Garantizar a las víctimas su participación en procesos de esclarecimiento judicial y la realización de sus derechos.

- Presentar un informe público sobre las razones para el surgimiento y evolución de los grupos armados ilegales.

- Hacer seguimiento y verificación a los procesos de reincorporación y a la labor de las autoridades locales a fin de garantizar la desmovilización plena de los miembros de grupos armados organizados al margen de la ley, y el cabal funcionamiento de las 
PERCEPCIONES DE LAS VÍCTIMAS DE MAMPUJÁN Y SAN CAYETANO Y SUS REPRESENTANTES JUDICIALES FRENTE A LA REPARACIÓN INTEGRAL EN LA LEY DE JUSTICIA Y PAZ

instituciones en esos territorios. Para estos efectos la Comisión Nacional Reparación y Reconciliación podía invitar a participar a organismos o personalidades extranjeras.

- Hacer seguimiento y evaluación periódica de la reparación de que trata la presente ley y señalar recomendaciones para su adecuada ejecución.

- Presentar, dentro del término de dos años, contados a partir de la vigencia de la presente ley, ante el Gobierno Nacional y las Comisiones de Paz de Senado y Cámara, de Representantes, un informe acerca del proceso de reparación a las víctimas de los grupos armados al margen de la ley.

- Recomendar los criterios para las reparaciones de que trata la presente ley, con cargo al Fondo de Reparación a las Víctimas.

- Coordinar la actividad de las Comisiones Regionales para la Restitución de Bienes.

- Adelantar acciones nacionales de reconciliación que buscaran impedir la reaparición de nuevos hechos de violencia que perturbaran la paz nacional.

Entonces, para la reparación de las víctimas se creó a partir del Art. 54 de la Ley 975 de 2005 el Fondo para la Reparación de las Víctimas, como una cuenta especial sin personería jurídica, cuyo ordenador del gasto era en su momento el Director de la Red de Solidaridad Social.

El Fondo estará integrado por todos los bienes o recursos que a cualquier título se entreguen por las personas o grupos armados organizados ilegales a que se refiere la presente ley, por recursos provenientes del presupuesto nacional y donaciones en dinero o en especie, nacionales o extranjeras. Teniendo claro el entendido de que todos y cada uno de los miembros del grupo armado organizado al margen de la ley, responderán con su propio patrimonio para indemnizar a cada una de las víctimas de los actos violatorios de la ley penal por los que fueren condenados; y también responderán solidariamente por los daños ocasionados a las víctimas por otros miembros 
PERCEPCIONES DE LAS VÍCTIMAS DE MAMPUJÁN Y SAN CAYETANO Y SUS REPRESENTANTES JUDICIALES FRENTE A LA REPARACIÓN INTEGRAL EN LA LEY DE JUSTICIA Y PAZ

del grupo armado al cual pertenecieron. Los recursos administrados por este Fondo estarán bajo la vigilancia de la Contraloría General de la República. El Gobierno reglamentó el funcionamiento de este Fondo y, en particular, lo concerniente a la reclamación y entrega de bienes respecto de terceros de buena fe.

Ahora bien, en cuanto a la reparación integral (Art. 25), la Ley 1448 de 2011 contempla que las víctimas tienen derecho a ser reparadas de manera adecuada, diferenciada, transformadora y efectiva por el daño que han sufrido como consecuencia de las violaciones de que trata el artículo 3 de esta Ley, pero no permite valorar el daño para tasar el monto de la indemnización (reparación económica) como si lo debe hacer la Ley 975 de 2005 por ser de vía judicial, generándose solo reparaciones administrativas en equidad a partir de los hechos victimizantes.

Lo anterior, debido a que la reparación por la Ley 1448 de 2011 comprende las medidas de restitución, indemnización, rehabilitación, satisfacción y garantías de no repetición, en sus dimensiones individual, colectiva, material, moral y simbólica, pero cada una de estas medidas será implementada a favor de la víctima dependiendo de la vulneración en sus derechos y las características del hecho victimizante.

Las medidas de asistencia adicionales consagradas en esta ley propenden por la reparación integral de las víctimas y se consideran complementarias a las medidas de reparación al aumentar su impacto en la población beneficiaria. Por lo tanto, se reconoce el efecto reparador de las medidas de asistencia establecidas en la presente ley, en la medida en que consagren acciones adicionales a las desarrolladas en el marco de la política social del Gobierno Nacional para la población vulnerable, incluyan criterios de priorización, así como características y elementos particulares que responden a las necesidades específicas de las víctimas. 
PERCEPCIONES DE LAS VÍCTIMAS DE MAMPUJÁN Y SAN CAYETANO Y SUS REPRESENTANTES JUDICIALES FRENTE A LA REPARACIÓN INTEGRAL EN LA LEY DE JUSTICIA Y PAZ

No obstante, este efecto reparador de las medidas de asistencia, no sustituyen o reemplazan a las medidas de reparación. Por lo tanto, el costo o las erogaciones en las que incurra el Estado en la prestación de los servicios de asistencia, en ningún caso serán descontados de la indemnización administrativa o judicial a que tienen derecho las víctimas.

La ayuda humanitaria definida en los términos de esta ley no constituye reparación y en consecuencia tampoco será descontada de la indemnización administrativa o judicial a que tienen derecho las víctimas.

Las víctimas de las violaciones (Art. 28) contempladas en el artículo 3 de la Ley 1448 de 2011, tendrán entre otros los siguientes derechos:

- Derecho a la verdad, justicia y reparación.

- $\quad$ Derecho a acudir a escenarios de diálogo institucional y comunitario.

- Derecho a ser beneficiario de las acciones afirmativas adelantadas por el Estado para proteger y garantizar el derecho a la vida en condiciones de dignidad.

- Derecho a solicitar y recibir atención humanitaria.

- Derecho a participar en la formulación, implementación y seguimiento de la política pública de prevención, atención y reparación integral.

- Derecho a que la política pública de que trata la presente ley, tenga enfoque diferencial.

- Derecho a la reunificación familiar cuando por razón de su tipo de victimización se haya dividido el núcleo familiar.

- Derecho a retornar a su lugar de origen o reubicarse en condiciones de voluntariedad, seguridad y dignidad, en el marco de la política de seguridad nacional. 
PERCEPCIONES DE LAS VÍCTIMAS DE MAMPUJÁN Y SAN CAYETANO Y SUS REPRESENTANTES JUDICIALES FRENTE A LA REPARACIÓN INTEGRAL EN LA LEY DE JUSTICIA Y PAZ

- Derecho a la restitución de la tierra si hubiere sido despojado de ella, en los términos establecidos en esta Ley.

- Derecho a la información sobre las rutas y los medios de acceso a las medidas que se establecen en la presente Ley.

- Derecho a conocer el estado de procesos judiciales y administrativos que se estén adelantando, en los que tengan un interés como parte o intervinientes.

- Derecho de las mujeres a vivir libres de violencia.

En este orden de cosas, ambas normatividades nacionales actualmente hacen parte de, a partir de Van Zyl (2008), la Justicia Transicional en Colombia, la cual se entiende como el esfuerzo por construir paz sostenible tras un período de conflicto, violencia masiva o violación sistemática de los derechos humanos. El objetivo de la justicia transicional implica llevar a juicio a los perpetradores, revelar la verdad acerca de crímenes pasados, brindar reparaciones a las víctimas, reformar las instituciones abusivas y promover la reconciliación. Lo anterior exige un conjunto incluyente de estrategias diseñadas para enfrentar el pasado así como para mirar hacia el futuro con el fin de evitar la recurrencia del conflicto y las violaciones. Sin embargo, lo paradójico de ello es que en Colombia se esté adelantando un proceso de Justicia Transicional en medio de un conflicto armado interno que aún permanece y deja sus huellas como las generadas por la macrovictimización de Mampuján y San Cayetano.

\section{Decisiones: Orden y Exhorto (Resuelve de reparación)}

Ahora bien, por el hecho haber sido víctimas del conflicto armado interno pobladores de Mampuján y San Cayetano, se generó con ellos el incidente de reparacion judicial en el marco de la Ley 975 de 2005, donde al fallarse en segunda instancia se emplearon los conceptos de exhorto y orden en los Resuelve de la sentencia que deben llevar a cabo los postulados y las instituciones 
PERCEPCIONES DE LAS VÍCTIMAS DE MAMPUJÁN Y SAN CAYETANO Y SUS REPRESENTANTES JUDICIALES FRENTE A LA REPARACIÓN INTEGRAL EN LA LEY DE JUSTICIA Y PAZ

para reparar a las víctimas; conceptos que requieren definiciones precisas para compresión del lector.

A partir de Quisbert (2010):

Por un la lado, se puede definir el Exhorto como un acto procesal de juez plasmada en una petición librada por él, en proceso que se tramita por ante el juzgado a su cargo, y dirigida a otro juez de su misma categoría pero diferente competencia territorial a fin de que practique alguna diligencia (notificación, embargo, recepción de declaración de testigo) que deba realizarse en la competencia territorial de éste (CPC, 114, 123, 389, 561).

Como un tipo, existe el llamado Exhorto Suplicatorio, que es el exhorto al extranjero, aunque la ley simplemente lo llama exhorto. "....Si tuviera que encomendarse a una autoridad del exterior, se hará mediante exhorto." (CPC, 114).

Por otro lado, una Orden Instruida es un acto procesal del juez plasmado en una orden librada por él dirigida a otro juez pero inferior y de diferente competencia territorial a fin de que practique alguna diligencia judicial (CPC, 114).

\section{Macrovictimización de Mampuján y San Cayetano y Conflicto Armado Interno}

\section{Causas de la macrovictimización de Mampuján y San Cayetano y del Conflicto}

\section{Armado Interno.}

Entonces, la macrovictimización se produce cuando un número indeterminado de personas sufren secuelas de diversa índole originados por una criminalidad en masa, es decir, un conjunto indefinido de víctimas, derivadas de una masificación de violencia, que han sufrido daños en gran escala (Castañón, 2012).

A menudo se identifica el terrorismo (las víctimas de Mampuján y San Cayetano fueron afectadas por este flagelo por parte de alias Juancho Dique y Diego Vecino con colaboración de 
PERCEPCIONES DE LAS VÍCTIMAS DE MAMPUJÁN Y SAN CAYETANO Y SUS REPRESENTANTES JUDICIALES FRENTE A LA REPARACIÓN INTEGRAL EN LA LEY DE JUSTICIA Y PAZ

algunos de sus subalternos e integrantes del Estado) con el término macrovictimización puesto que se entiende que este tipo de violencia genera una extensa y severa victimación, con un indefinido número de víctimas directas e indirectas. Algunos autores consideran que el móvil terrorista es ante todo un móvil político, en el sentido en que los actos terroristas tienen el objetivo principal de cambiar las estructuras políticas o sociales. La víctima de estos delitos no es un fin en sí mismo, sino un medio para atacar al Estado. Por ello, se puede afirmar que el terrorismo da lugar a una muy extensa victimización (López y Arrojo, 1983, citados por Castañón, 2012), más intensa y extensa. Intensa porque la víctima directa llega a sentirse utilizada y desvalorada socialmente (de seguir con vida) y extensa porque el terrorismo genera muchas víctimas indirectas que, aunque no han sido objeto directo del acto terrorista, son sometidas al terror o a la resignación, por miedo a posibles represalias. Conviene, por tanto, hablar más que de víctima, en singular, de víctimas, en plural, ya que cada crimen terrorista causa varias víctimas, la directa y muchas más indirectas. En esta misma línea, Castañón (2012) citando a García (1984) afirma que el terrorismo afecta a un amplio sector de la población, a las víctimas y a los familiares de las mismas, pero también al resto de ciudadanos que se conmueven ante la indiferencia de muchos de los atentados, sufren las molestias ocasionadas por la intervención policial (en los casos de identificaciones, controles generalizados, etcétera) o son víctimas del miedo al terrorismo.

Estas últimas difícilmente pueden ser indemnizadas por el Estado, ya que éste se encuentra imposibilitado para evaluar los efectos padecidos por ellas, solamente estando a su alcance la posibilidad de recompensarlas mediante refuerzos salariales, etcétera. No obstante, con frecuencia, las estadísticas acerca de las víctimas de los delitos terroristas no siempre hacen 
PERCEPCIONES DE LAS VÍCTIMAS DE MAMPUJÁN Y SAN CAYETANO Y SUS REPRESENTANTES JUDICIALES FRENTE A LA REPARACIÓN INTEGRAL EN LA LEY DE JUSTICIA Y PAZ

justicia, distorsionando la realidad al referirse sólo a las víctimas directas, olvidándose de las indirectas, que suelen ser inabarcables: familiares, amigos, vecinos, etcétera.

Además, la violencia terrorista afecta no sólo a bienes jurídicos concretos de víctimas específicas (vida, integridad física, etcétera), sino que también lesiona bienes jurídicos de titularidad difusa (Castañón, 2012), como pueden ser la seguridad ciudadana; de ahí que se califique como pluriofensiva la macrovictimización causada por el terrorismo, ya que multiplica los efectos enervantes del delito: el intenso miedo a la victimización amenaza a enormes sectores, desvitalizando las relaciones sociales, profesionales y económicas (Beristain, 1994; citado por Castañón, 2012).

Por todo ello, conviene proclamar que todos los delitos de terrorismo son de una trágica gravedad, mayor que los similares delitos comunes. De ahí que sus víctimas se han venido denominando macrovíctimas, sin poder equipararse con las víctimas de cualquier otro delito (Beristain, 2005, p.34 y ss; citado por Castañón, 2012): la violencia terrorista crea ñseres deshumanizados, programados, encadenados al círculo del terrorò (Herrera, 1996; citado por Castañón, 2012).

Es así como en algunos casos, según Masón (2000), las Fuerzas Armadas del Estado, y los grupos paramilitares que éstas toleran, representaron una amenaza directa a la seguridad individual en la guerra militarizada contra las drogas y en las campañas contra la insurgencia. En otros, la incapacidad del gobierno central de proteger a la población civil ha expuesto a los pobladores a la violencia de la guerrilla, ataques a pueblos, terrorismo, reclutamientos forzados, extorsiones y secuestros, mientras que estos grupos buscan consolidar su control territorial y financiar su guerra contra el Estado. 
PERCEPCIONES DE LAS VÍCTIMAS DE MAMPUJÁN Y SAN CAYETANO Y SUS REPRESENTANTES JUDICIALES FRENTE A LA REPARACIÓN INTEGRAL EN LA LEY DE JUSTICIA Y PAZ

Por actos tanto de omisión, entendida como la inhabilidad de proteger sus ciudadanos de las masacres de criminales, la guerrilla y los paramilitares; y comisión como las violaciones a los derechos humanos cometidas por el Ejército colombiano, Colombia ha perdido el monopolio del uso legítimo de la fuerza. De otro lado, extensas áreas del país no cuentan con presencia del Gobierno Central ni con protección policial, mientras que los productores de drogas, las fuerzas guerrilleras y los paramilitares compiten violentamente por el control de regiones estratégicas (Masón, 2000).

Pero la cosa empeora aun, alparecer y según López y Sevillano (2008), a diferencia de lo que se percibía inicialmente, porque la parapolítica no fue un escándalo limitado a congresistas de la Costa Atlántica por beneficiarse electoralmente del apoyo de paramilitares. Hoy está establecido que la parapolítica es, o fue un fenómeno nacional de captura masiva de la representación política y el poder público por parte del narcotráfico y el paramilitarismo a través de políticos y otros servidores públicos a nivel local, regional y nacional.

Para entender mejor el panorama, los mismos autores, consideran que para tener una idea de la dimensión de penetración y captura, hasta el 2008 basta decir que la Fiscalía General de la Nación adelantaba alrededor de 334 investigaciones a nivel nacional por procesos de parapolítica. Investigaciones en las que están involucrados desde políticos nacionales, regionales y locales, hasta contratistas y miembros de la fuerza pública.

Como hemos observado, prevalece como una causa del conflicto armado interno el interés particular y el beneficio económico de algunos particulares. Por ende y según Valencia (2009), el conflicto armado interno colombiano se ha convertido en un tema cada vez más recurrente en la agenda de investigaciones económicas nacionales. La razón de tan creciente interés se debe a que éste fenómeno político afecta, entre otras cosas, gran parte de las variables económicas; como por 
PERCEPCIONES DE LAS VÍCTIMAS DE MAMPUJÁN Y SAN CAYETANO Y SUS REPRESENTANTES JUDICIALES FRENTE A LA REPARACIÓN INTEGRAL EN LA LEY DE JUSTICIA Y PAZ

ejemplo, el producto interno bruto, el bienestar social, la inversión privada, el gasto público y el consumo de las familias.

Es decir, citando a Gutiérrez y Sánchez (2006), el conflicto armado interno en Colombia perdió el componente netamente político que lo caracterizaba antes de 1990, ahora Colombia está ante un conflicto ñmás económico, más criminal y más políticoò. Una idea parecida apoyada por Ramírez (2006) y Pizarro (2004), para quienes el conflicto interno armado ha dado un gran giro en la década reciente: antes, las armas se utilizaban con el fin de resolver problemas políticos, ideológicamente comunistas, respaldados por el gobierno norteamericano cuando se dio la Guerra Fría; ahora bien, desde los comienzos del decenio de 1990, el uso de las armas tiene un fin económico, además del político. Y peor aún, señalan los investigadores, el Estado mismo, a través de sus Fuerzas Militares, se unió con grupos paramilitares para lograr el enriquecimiento económico de particulares a costa de macrovictimizaciones como la de Mampuján y San Cayetano, según inferencias y señalamientos obtenidos a partir de la aplicación de las técnicas de recolección de información, respaldando las informaciones de medios de comunicación al respecto obtenidas en investigaciones como la parapolítica.

Pero ahora, como fue señalado por participantes de la investigación y como se detallará en los resultados y discusiones, el paramilitarismo en Colombia ha mutado, no ha desaparecido como lo dice el Estado colombiano con la promulgación de la Ley 975 de 2005 que permitió la desmovilización de los mismos, se denominan ahora Bandas Criminales (BACRIM), unas llamadas ñUrabeñosò, otras ñRastrojosò, entre otros; aunque de acuerdo con la Policía Nacional Intervención de la Policía Nacional. Acta de la Mesa de Estudios Permanente, que tuvo lugar el 12 de diciembre de 2012, pp.1-3. Información recolectada como parte de la inspección judicial ordenada por medio del auto 052 de 2013 - , citada por el AUTO 119 DE 2013, ñas BACRIM 
PERCEPCIONES DE LAS VÍCTIMAS DE MAMPUJÁN Y SAN CAYETANO Y SUS REPRESENTANTES JUDICIALES FRENTE A LA REPARACIÓN INTEGRAL EN LA LEY DE JUSTICIA Y PAZ

son estructuras de crimen organizado, especializadas en narcotráfico, poseen niveles de hostilidad, vinculados a rentas ilícitas y con alcance nacional y trasnacional [pero] carecen de ideología política y contrainsurgente (é ) su propósito es el control de la cadena productiva del narcotráficoò. En esa medida, si bien en las BACRIM pueden concurrir algunas de las características que son propias del conflicto armado, bajo este concepto no se las puede considerar como actores del mismo al no presentarse la ñexistencia de factores ideológicos o políticos para fundamentar su actuaciónò, son ahora grupos posdesmovilizados.

\section{Hechos victimizantes y daños generados por la macrovictimización de Mampuján y}

\section{San Cayetano.}

Los hechos victimizantes generados por la macrovictimización de Mampuján y San Cayetano y manifestados por participantes de la investigación, a saber: Desplazamiento forzado, principalmente de tipo colectivo, Homicidios, Torturas, Secuestro y Hurto; se relacionan con el informe emitido por el Comité Internacional de la Cruz Roja (2010), donde informaba que la población civil de las regiones afectadas por los enfrentamientos armados en Colombia seguían estando expuestas a actos de violencia como homicidios, ataques directos, secuestros y reclutamientos forzados. Muchas personas se ven obligadas a huir y abandonar sus pertenencias.

Sin embargo, estos delitos se pueden definir de forma general, a partir de los delitos por los que fueron condenados los postulados Edwar Cobos Téllez y Uber Enrique Baquez Martínez y que es expuesto en la sentencia de segunda instancia en su apartado ñ̃ROVIDENCIA IMPUGNADAò, a saber: como coautores de los delitos de homicidio agravado; deportación, expulsión, traslado o desplazamiento forzoso de la población civil; secuestro simple; hurto calificado y agravado; utilización ilegal de uniformes e insignias y fabricación, tráfico y porte de armas y municiones de uso privativo de las fuerzas armadas, en concurso homogéneo y sucesivo, 
PERCEPCIONES DE LAS VÍCTIMAS DE MAMPUJÁN Y SAN CAYETANO Y SUS REPRESENTANTES JUDICIALES FRENTE A LA REPARACIÓN INTEGRAL EN LA LEY DE JUSTICIA Y PAZ

donde adicionalmente a Edwar Cobos Téllez se le condenó por el punible de concierto para delinquir agravado (Corte Suprema de Justicia Sala de Casación Penal, República de Colombia, 2011); y lo contemplado en el Código Penal Colombiano (Ley 599 de 2000) de forma literal, como:

- Artículo 103. Homicidio. El que matare a otro, incurrirá en prisión de doscientos ocho (208) a cuatrocientos cincuenta (450) meses. Artículo 104. Circunstancias de agravación. La pena será de cuatrocientos (400) a seiscientos (600) meses de prisión, si la conducta descrita en el artículo anterior se cometiere: 1. En los cónyuges o compañeros permanentes; en el padre y la madre de familia, aunque no convivan en un mismo hogar, en los ascendientes o descendientes de los anteriores y los hijos adoptivos; y en todas las demás personas que de manera permanente se hallaren integradas a la unidad doméstica.

- Artículo 159. Deportación, expulsión, traslado o desplazamiento forzado de población civil. El que, con ocasión y en desarrollo de conflicto armado y sin que medie justificación militar, deporte, expulse, traslade o desplace forzadamente de su sitio de asentamiento a la población civil, incurrirá en prisión de ciento sesenta (160) a trescientos sesenta (360) meses, multa de mil trescientos treinta y tres punto treinta y tres (1.333.33) a tres mil (3000) salarios mínimos legales mensuales vigentes, e inhabilitación para el ejercicio de derechos y funciones públicas de ciento sesenta (160) a trescientos sesenta (360) meses.

- $\quad$ Artículo 168. Secuestro simple. El que con propósitos distintos a los previstos en el artículo siguiente, arrebate, sustraiga, retenga u oculte a una persona, incurrirá en 
PERCEPCIONES DE LAS VÍCTIMAS DE MAMPUJÁN Y SAN CAYETANO Y SUS REPRESENTANTES JUDICIALES FRENTE A LA REPARACIÓN INTEGRAL EN LA LEY DE JUSTICIA Y PAZ

prisión de ciento noventa y dos (192) a trescientos sesenta (360) meses y multa de ochocientos (800) a mil quinientos (1500) salarios mínimos legales mensuales vigentes.

- Artículo 239. Hurto. El que se apodere de una cosa mueble ajena, con el propósito de obtener provecho para sí o para otro, incurrirá en prisión de treinta y dos (32) a ciento ocho (108) meses. La pena será de prisión de dieciséis (16) a treinta y seis (36) meses cuando la cuantía no exceda de diez (10) salarios mínimos legales mensuales vigentes.

- Artículo 240. Hurto calificado. La pena será de prisión de seis (6) a catorce (14) años, si el hurto se cometiere:

1. Con violencia sobre las cosas.

2. Colocando a la víctima en condiciones de indefensión o inferioridad o aprovechándose de tales condiciones.

3. Mediante penetración o permanencia arbitraria, engañosa o clandestina en lugar habitado o en sus dependencias inmediatas, aunque allí no se encuentren sus moradores.

4. Con escalonamiento, o con llave sustraída o falsa, ganzúa o cualquier otro instrumento similar, o violando o superando seguridades electrónicas u otras semejantes.

La pena será de prisión de ocho (8) a dieciséis (16) años cuando se cometiere con violencia sobre las personas. 
PERCEPCIONES DE LAS VÍCTIMAS DE MAMPUJÁN Y SAN CAYETANO Y SUS REPRESENTANTES JUDICIALES FRENTE A LA REPARACIÓN INTEGRAL EN LA LEY DE JUSTICIA Y PAZ

Las mismas penas se aplicarán cuando la violencia tenga lugar inmediatamente después del apoderamiento de la cosa y haya sido empleada por el autor o partícipe con el fin de asegurar su producto o la impunidad.

- Artículo 346. Utilización ilegal de uniformes e insignias. El que sin permiso de autoridad competente importe, fabrique, transporte, almacene, distribuya, compre, venda, suministre, sustraiga, porte o utilice prendas, uniformes, insignias o medios de identificación reales, similares o semejantes a los de uso privativo de la fuerza pública o de los organismos de seguridad del Estado, incurrirá en prisión de cuarenta y ocho (48) a ciento ocho (108) meses y multa de sesenta y seis punto sesenta y seis (66.66) a mil quinientos (1.500) salarios mínimos legales mensuales vigentes.

- Artículo 366. Fabricación, tráfico y porte de armas, municiones de uso restringido, de uso privativo de las fuerzas armadas o explosivos. El que sin permiso de autoridad competente importe, trafique, fabrique, transporte, repare, almacene, conserve, adquiera, suministre, porte o tenga en un lugar armas o sus partes esenciales, accesorios esenciales, municiones de uso privado de las Fuerzas Armadas o explosivos, incurrirá en prisión de once (11) a quince (15) años. La pena anteriormente dispuesta se duplicará cuando concurran las circunstancias determinadas en el inciso 3o del artículo anterior.

- Artículo 340. Concierto para delinquir. Cuando varias personas se concierten con el fin de cometer delitos, cada una de ellas será penada, por esa sola conducta, con prisión de cuarenta y ocho (48) a ciento ocho (108) meses.

Cuando el concierto sea para cometer delitos de genocidio, desaparición forzada de personas, tortura, desplazamiento forzado, homicidio, terrorismo, tráfico de drogas 
PERCEPCIONES DE LAS VÍCTIMAS DE MAMPUJÁN Y SAN CAYETANO Y SUS REPRESENTANTES JUDICIALES FRENTE A LA REPARACIÓN INTEGRAL EN LA LEY DE JUSTICIA Y PAZ

tóxicas, estupefacientes o sustancias sicotrópicas, secuestro, secuestro extorsivo, extorsión, enriquecimiento ilícito, lavado de activos o testaferrato y conexos, o Financiamiento del Terrorismo y administración de recursos relacionados con actividades terroristas, la pena será de prisión de ocho (8) a dieciocho (18) años y multa de dos mil setecientos (2700) hasta treinta mil (30000) salarios mínimos legales mensuales vigentes.

La pena privativa de la libertad se aumentará en la mitad para quienes organicen, fomenten, promuevan, dirijan, encabecen, constituyan o financien el concierto para delinquir.

- Adicionalmente, artículo 137. Tortura en Persona Protegida. El que, con ocasión y en desarrollo de conflicto armado, inflija a una persona dolores o sufrimientos [graves] 33, físicos o síquicos, con el fin de obtener de ella o de un tercero información o confesión, de castigarla por un acto por ella cometido o que se sospeche que ha cometido, o de intimidarla o coaccionarla por cualquier razón que comporte algún tipo de discriminación, incurrirá en prisión de ciento sesenta (160) a trescientos sesenta (360) meses, multa de seiscientos sesenta y seis punto sesenta y seis (666.66) a mil quinientos (1500) salarios mínimos legales mensuales vigentes, e inhabilitación para el ejercicio de derechos y funciones públicas de ciento sesenta (160) a trescientos sesenta (360) meses.

No obstante, hay que dejar claro que por tratarse de postulados acogidos a la Ley 975 de 2005 estos solo fueron condenados a penas no superiores a 8 años de prisión, según el beneficio que los acogió enmarcado de Justicia Transicional en la mencionada Ley. 
PERCEPCIONES DE LAS VÍCTIMAS DE MAMPUJÁN Y SAN CAYETANO Y SUS REPRESENTANTES JUDICIALES FRENTE A LA REPARACIÓN INTEGRAL EN LA LEY DE JUSTICIA Y PAZ

Ahora bien, estos hechos victimizantes o delitos generaron daños en las victimas de Mampuján y San Cayetano que no se han podido subsanar de forma completa, los cuales se obtuvieron del análisis de los discursos o percepciones de las víctimas y demás participantes de la investigación. A saber:

- El Lucro Cesante: es una variante del Daño o Perjuicio Material, entendido como aquel que modifica la situación pecuniaria del perjudicado-demandante, véase García y Parra (2013); sin embargo, siguiendo la terminología del Art. 1106 del Código Civil, es la ganancia que se haya dejado de obtener por consecuencia del hecho del que se es responsable. Si concebimos como daño cualquier lesión de un interés, sea patrimonial o no, el concepto de lucro cesante se circunscribe a la lesión de un interés patrimonial consistente en la pérdida de un incremento patrimonial neto (esto es, deducidos costes) que se haya dejado de obtener como consecuencia del incumplimiento contractual por el deudor o bien del acto ilícito que se imputa a un tercero (Carrasco, s.f.). Es la disminución de las perspectivas favorables de lucro; representa la utilidad no recibida.

- El Daño Emergente: también es una variante del Daño o Perjuicio Materialé (García y Parra, 2013). Concretamente es la pérdida que representa para el acreedor el verse privado del objeto propio de la obligación, representando éste el dinero de la contraprestación (Medellín, et al., 2000), es la disminución del patrimonio existente por el daño.

- El Daño Moral: se refiere a bienes inmateriales como son el honor, sentimientos, afectos o reputación, cuyo daño causado es en el ámbito de lo moral por ser derechos de la personalidad (Villanueva, 2004). 
PERCEPCIONES DE LAS VÍCTIMAS DE MAMPUJÁN Y SAN CAYETANO Y SUS REPRESENTANTES JUDICIALES FRENTE A LA REPARACIÓN INTEGRAL EN LA LEY DE JUSTICIA Y PAZ

- La Pérdida de Chances: es la pérdida de oportunidades. Es la desaparición de la probabilidad seria y real de un evento favorable (Torrealba, s.f.).

- El Daño Colectivo: en un sentido amplio, daño colectivo es el que afecta a varias personas, simultanea o sucesivamente. En un sentido estricto, en cambio, se denomina daño colectivo al que experimenta un conjunto de personas a raíz de la lesión a un interés grupal o social (Compiani, 2001).

- El Daño Psicológico: se refiere, por un lado, a las lesiones psíquicas agudas producidas por un delito violento, que, en algunos casos, pueden remitir con el paso del tiempo y por el apoyo social o un tratamiento psicológico adecuado; y, por otro, a las secuelas emocionales que persisten en la persona de forma crónica como consecuencia del suceso sufrido y que interfieren negativamente en su vida cotidiana. En uno y otro caso el daño psíquico o psicológico es la consecuencia de un suceso negativo que desborda la capacidad de afrontamiento y de adaptación de la víctima a la nueva situación (Pynoos, Sorenson y Steinberg, 1993).

\section{Tabla 1.}

Daño psíquico en víctimas de delitos violentos.

(Esbec, 2000, modificado; citado por Echeburúa et al., 2002).

- Sentimientos negativos: humillación, vergüenza, culpa o ira

- Ansiedad

- Preocupación constante por el trauma, con tendencia a revivir el suceso

- Depresión

- Pérdida progresiva de confianza personal como consecuencia de los sentimientos de 
PERCEPCIONES DE LAS VÍCTIMAS DE MAMPUJÁN Y SAN CAYETANO Y SUS REPRESENTANTES JUDICIALES FRENTE A LA REPARACIÓN INTEGRAL EN LA LEY DE JUSTICIA Y PAZ

indefensión y desesperanza experimentados

- Disminución de la autoestima

- Pérdida del interés y de la concentración en actividades anteriormente gratificantes

- Cambios en el sistema de valores, especialmente la confianza en los demás y la creencia en un mundo justo

- Hostilidad, agresividad, abuso de drogas

- Modificación de las relaciones (dependencia emocional, aislamiento)

- Aumento de la vulnerabilidad, con temor a vivir en un mundo peligroso, y pérdida de control sobre la propia vida

- Cambio drástico en el estilo de vida, con miedo a acudir a los lugares de costumbre; necesidad apremiante de trasladarse de domicilio

- Alteraciones en el ritmo y el contenido del sueño

- Disfunción sexual

Lo que genera habitualmente daño psicológico suele ser la amenaza a la propia vida o a la integridad psicológica, una lesión física grave, la percepción del daño intencionado, la pérdida violenta de un ser querido y la exposición al sufrimiento de los demás, más aún si se trata de un ser querido o de un ser indefenso (Green, 1990). El daño suele ser mayor si las consecuencias del hecho delictivo son múltiples o variadas.

El daño psicológico cursa habitualmente en fases. En una primera etapa suele surgir una reacción de sobrecogimiento, con un cierto enturbiamiento de la conciencia y con un embotamiento general, caracterizado por lentitud, un abatimiento general, unos pensamientos de 
PERCEPCIONES DE LAS VÍCTIMAS DE MAMPUJÁN Y SAN CAYETANO Y SUS REPRESENTANTES JUDICIALES FRENTE A LA REPARACIÓN INTEGRAL EN LA LEY DE JUSTICIA Y PAZ

incredulidad y una pobreza de reacciones. En una segunda fase, a medida que la conciencia se hace más penetrante y se diluye el embotamiento producido por el estado de ñshockò, se abren paso vivencias afectivas de un colorido más dramático: dolor, indignación, rabia, impotencia, culpa, miedo, que alteran con momentos de profundo abatimiento. Y, por último, hay tendencia a reexperimentar el suceso, bien espontáneamente o bien en función de algún estimulo concreto asociado (como un timbre, un ruido, un olor, etcétera) o de algún estimulo más general: una película violenta, el aniversario del delito, la celebración de la Navidad, etcétera (Echeburúa et al., 2002). Por ende, la valoración del daño se hace con arreglo a las categorías de discapacidad y minusvalía (Esbec, 2000).

Entonces, la lesión psíquica, siendo parte del Daño Psicológico, se refiere a una alteración clínica aguda que sufre una persona como consecuencia de haber sufrido un delito violento y que le incapacita significativamente para hacer frente a los requerimientos de la vida ordinaria a nivel personal, laboral, familiar o social. Este concepto de lesión psíquica, que es medible por medio de los instrumentos de evaluación adecuados, ha sustituido al de daño moral, que es un concepto más impreciso, subjetivo y que implica una percepción personal más de perjuicio a los bienes inmateriales del honor o de la libertad que de sufrimiento psíquico propiamente dicho (Echeburúa et al., 2002).

También, hay que aclarar que el Daño Psicológico está de la mano y comprende el Daño a la vida de relación, el cual también es conocido como Daño Fisiológico o Perjuicio del Placer, debido a que se define como el daño que una persona física padece a causa de una lesión de su integridad psicofísica o de la salud, y que consiste en la disminución de las posibilidades del sujeto de ejercer normalmente su personalidad en el medio social. Se trata, por tanto de un aspecto del daño a la salud. Sin embargo, es considerado también cuando su fuente se encuentra 
PERCEPCIONES DE LAS VÍCTIMAS DE MAMPUJÁN Y SAN CAYETANO Y SUS REPRESENTANTES JUDICIALES FRENTE A LA REPARACIÓN INTEGRAL EN LA LEY DE JUSTICIA Y PAZ

en otro bien de la personalidad como la reputación, en casos de calumnia o difamación (García y Parra, 2013).

No obstante, hay que aclarar que dentro del documento se deja el Daño Moral y Daño a la vida de relación por aparte, sin integrarse al Daño Psicológico, porque este último no fue utilizado en el incidente de reparación integral de las víctimas de Mampuján y San Cayetano, en las sentencias de primera y segunda instancia; en estas solo se utilizó el termino psicológico para referirse a medidas de reparación de rehabilitación. Lo que sugiere que para la época había mayor necesidad de utilización de la Psicología Jurídica para ahondar en el tema, generar conocimiento importante para esta área de la psicología y la sociedad en general, y para ser aprovechado por el aparato de justicia. Pero, es el término de Daño Psicológico el que será de referencia para los investigadores, toda vez que se considera abarca a los otros dos conceptos.

Para continuar, las lesiones psíquicas más frecuentes son los trastornos adaptativos (con estado de ánimo deprimido o ansioso), el trastorno de estrés postraumático o la descompensación de una personalidad anómala. Más en concreto, a un nivel cognitivo, la víctima puede sentirse confusa y tener dificultades para tomar decisiones, con una percepción profunda de indefensión, de estar a merced de todo tipo de peligros y de incontrolabilidad, de carecer de control sobre su propia vida y su futuro; a nivel psicofisiológico, puede experimentar sobresaltos continuos; y, por último, a nivel conductual, puede mostrarse apática y con dificultades para retomar la vida cotidiana (Acierno, Kilpatrick y Resnick, 1999).

Mientras que, las secuelas emocionales se refieren a la estabilización del daño psíquico o psicológico, es decir, a una discapacidad permanente que no remite con el paso del tiempo ni con un tratamiento adecuado. Se trata, por tanto, de una alteración irreversible en el funcionamiento 
PERCEPCIONES DE LAS VÍCTIMAS DE MAMPUJÁN Y SAN CAYETANO Y SUS REPRESENTANTES JUDICIALES FRENTE A LA REPARACIÓN INTEGRAL EN LA LEY DE JUSTICIA Y PAZ

psicológico habitual o, dicho en términos legales más imprecisos conceptualmente, de un menoscabo de la salud mental (Echeburúa et al., 2002).

Las secuelas psíquicas más frecuentes en las víctimas de delitos violentos se refieren a la modificación permanente de la personalidad (CIE 10, F62.0), es decir, a la aparición de rasgos de personalidad nuevos, estables e inadaptativos, por ejemplo, dependencia emocional, suspicacia, hostilidad, etcétera, que se mantienen durante al menos 2 años y que llevan a un deterioro de las relaciones interpersonales y a una falta de rendimiento en la actividad laboral (Esbec, 2000).

Esta transformación de la personalidad puede ser un estado crónico o una secuela irreversible de un trastorno de estrés postraumático (F43.1) que puede surgir como consecuencia de haber sufrido un delito violento (Echeburúa et al., 2000).

Por consiguiente, cabe recordar que en Colombia, según la Ley 446 de 1998, en su Artículo 16. VALORACIÓN DE DAÑOS: Dentro de cualquier proceso que se surta ante la Administración de Justicia, la valoración de daños irrogados a las personas y a las cosas, atenderá los principios de reparación integral y equidad y observará los criterios técnicos actuariales. Es decir, un proceso judicial, en este caso en específico en Colombia como los de Justicia y Paz, debería implicar la valoración de los daños, para generarse la respectiva reparación integral, buscando la equidad para las personas, no dentro de sus reparaciones, porque deberían ser en Derecho, sino desde el goce efectivo de derechos para todos.

\section{Victimización primaria y secundaria de las víctimas de Mampuján y San Cayetano.}

Por lo tanto, antes de exponer propiamente la revictimizaciones de las víctimas de ambas comunidades, hay que empezar aclarando que a las víctimas de Mampuján y San Cayetano se les vulneraron Derechos Humanos (DDHH), victimizaciones primarias, contemplados en la 
PERCEPCIONES DE LAS VÍCTIMAS DE MAMPUJÁN Y SAN CAYETANO Y SUS REPRESENTANTES JUDICIALES FRENTE A LA REPARACIÓN INTEGRAL EN LA LEY DE JUSTICIA Y PAZ

Convención Americana sobre Derechos Humanosï Pacto de San José (1969), el cual Colombia ratificó el 31 de julio de 1973 bajo la Ley Aprobatoria: Ley 16 de 1972, D.O. 33.780; Depositario: O.E.A.; en relación con la macrovictimización de Mampuján y San Cayetano, el mismo proceso judicial de Justicia y Paz (primera y segunda instancia) que adelantaron las víctimas o por parte del Estado. Entre estos, los señalados en los artículos:

- $\quad$ Artículo 4. Derecho a la Vida: 1. Toda persona tiene derecho a que se respete su vida. Este derecho estará protegido por la ley y, en general, a partir del momento de la concepción. Nadie puede ser privado de la vida arbitrariamente; ubicado en el Capítulo II - DERECHOS CIVILES Y POLITICOS.

- $\quad$ Artículo 5. Derecho a la Integridad Personal: 1. Toda persona tiene derecho a que se respete su integridad física, psíquica y moral; 2. Nadie debe ser sometido a torturas ni a penas o tratos crueles, inhumanos o degradantes. Toda persona privada de libertad será tratada con el respeto debido a la dignidad inherente al ser humano. Ubicados en el Capítulo II - DERECHOS CIVILES Y POLITICOS.

- Artículo 7. Derecho a la Libertad Personal: 1. Toda persona tiene derecho a la libertad y a la seguridad personales. 2. Nadie puede ser privado de su libertad física, salvo por las causas y en las condiciones fijadas de antemano por las Constituciones Políticas de los Estados Partes o por las leyes dictadas conforme a ellas. Ubicados en el Capítulo II - DERECHOS CIVILES Y POLITICOS.

- Artículo 10. Derecho a Indemnización: Toda persona tiene derecho a ser indemnizada conforme a la ley en caso de haber sido condenada en sentencia firme por error judicial. Ubicado en el Capítulo II - DERECHOS CIVILES Y POLITICOS. 
PERCEPCIONES DE LAS VÍCTIMAS DE MAMPUJÁN Y SAN CAYETANO Y SUS REPRESENTANTES JUDICIALES FRENTE A LA REPARACIÓN INTEGRAL EN LA LEY DE JUSTICIA Y PAZ

- Artículo 17. Protección a la Familia: 1. La familia es el elemento natural y fundamental de la sociedad y debe ser protegida por la sociedad y el Estado. Ubicado en el Capítulo II - DERECHOS CIVILES Y POLITICOS.

- Artículo 19. Derechos del Niño: Todo niño tiene derecho a las medidas de protección que su condición de menor requieren por parte de su familia, de la sociedad y del Estado. Ubicado en el Capítulo II - DERECHOS CIVILES Y POLITICOS.

- $\quad$ Artículo 21. Derecho a la Propiedad Privada: 1. Toda persona tiene derecho al uso y goce de sus bienes. La ley puede subordinar tal uso y goce al interés social. Ubicado en el Capítulo II - DERECHOS CIVILES Y POLITICOS.

- Artículo 22. Derecho de Circulación y de Residencia: 1 . Toda persona que se halle legalmente en el territorio de un Estado tiene derecho a circular por el mismo y, a residir en él con sujeción a las disposiciones legales. Ubicado en el Capítulo II DERECHOS CIVILES Y POLITICOS.

- $\quad$ Artículo 25. Protección Judicial: 1. Toda persona tiene derecho a un recurso sencillo y rápido o a cualquier otro recurso efectivo ante los jueces o tribunales competentes, que la ampare contra actos que violen sus derechos fundamentales reconocidos por la Constitución, la ley o la presente Convención, aun cuando tal violación sea cometida por personas que actúen en ejercicio de sus funciones oficiales. 2. Los Estados Partes se comprometen: c) a garantizar el cumplimiento, por las autoridades competentes, de toda decisión en que se haya estimado procedente el recurso. Ubicados en el Capítulo II - DERECHOS CIVILES Y POLITICOS. 
PERCEPCIONES DE LAS VÍCTIMAS DE MAMPUJÁN Y SAN CAYETANO Y SUS REPRESENTANTES JUDICIALES FRENTE A LA REPARACIÓN INTEGRAL EN LA LEY DE JUSTICIA Y PAZ

Toda vez que se vulneraron Derechos Humanos, contemplados en el Pacto Internacional de Derechos Económicos, Sociales y Culturales (1966), ratificado por Colombia el 29 de octubre de 1969 bajo la Ley Aprobatoria: Ley 74 de 1968, Depositario: O.N.U. Los cuales están contemplados en los artículos:

- Artículo 1: 1. Todos los pueblos tienen el derecho de libre determinación. En virtud de este derecho establecen libremente su condición política y proveen asimismo a su desarrollo económico, social y cultural. 2. Para el logro de sus fines, todos los pueblos pueden disponer libremente de sus riquezas y recursos naturales, sin perjuicio de las obligaciones que derivan de la cooperación económica internacional basada en el principio de beneficio recíproco, así como del derecho internacional. En ningún caso podrá privarse a un pueblo de sus propios medios de subsistencia.

- $\quad$ Artículo 3: Los Estados Partes en el presente Pacto se comprometen a asegurar a los hombres y a las mujeres igual título a gozar de todos los derechos económicos, sociales y culturales enunciados en el presente Pacto.

- Artículo 6: 1. Los Estados Partes en el presente Pacto reconocen el derecho a trabajar, que comprende el derecho de toda persona a tener la oportunidad de ganarse la vida mediante un trabajo libremente escogido o aceptado, y tomarán medidas adecuadas para garantizar este derecho.

- Artículo 11: 1. Los Estados Partes en el presente Pacto reconocen el derecho de toda persona a un nivel de vida adecuado para sí y su familia, incluso alimentación, vestido y vivienda adecuados, y a una mejora continua de las condiciones de existencia. Los Estados Partes tomarán medidas apropiadas para asegurar la 
PERCEPCIONES DE LAS VÍCTIMAS DE MAMPUJÁN Y SAN CAYETANO Y SUS REPRESENTANTES JUDICIALES FRENTE A LA REPARACIÓN INTEGRAL EN LA LEY DE JUSTICIA Y PAZ

efectividad de este derecho, reconociendo a este efecto la importancia esencial de la cooperación internacional fundada en el libre consentimiento.

- $\quad$ Artículo 13: 1. Los Estados Partes en el presente Pacto reconocen el derecho de toda persona a la educación. Convienen en que la educación debe orientarse hacia el pleno desarrollo de la personalidad humana y del sentido de su dignidad, y debe fortalecer el respeto por los derechos humanos y las libertades fundamentales. Convienen asimismo en que la educación debe capacitar a todas las personas para participar efectivamente en una sociedad libre, favorecer la comprensión, la tolerancia y la amistad entre todas las naciones y entre todos los grupos raciales, étnicos o religiosos, y promover las actividades de las Naciones Unidas en pro del mantenimiento de la paz.

Desde el ámbito del Derecho Internacional Humanitario (DIH), a las víctimas de Mampuján y San Cayetano se les vulneraron derechos humanos (victimizaciones primarias) con la macrovictimización en estos territorios, relacionados con artículos del Protocolo Adicional a los Convenios de Ginebra del 12 de agosto de 1949 relativo a la protección de las víctimas de los conflictos armados sin carácter internacional (Protocolo II) (1949), hecho en Ginebra el 8 de Junio de 1977. Este Convenio fue aprobado en Colombia mediante la disposición 58 transitoria de la Constitución Política y promulgado mediante el Decreto 509 de 1996, publicado en el Diario Oficial No. 42.746 de 18 de marzo de 1996. Estos artículos son:

- Artículo 4: Garantías fundamentales: 1. Todas las personas que no participen directamente en las hostilidades, o que hayan dejado de participar en ellas, estén o no privadas de libertad, tienen derecho a que se respeten su persona, su honor, sus convicciones y sus prácticas religiosas, por ejemplo, las víctimas de Mampuján y San 
PERCEPCIONES DE LAS VÍCTIMAS DE MAMPUJÁN Y SAN CAYETANO Y SUS REPRESENTANTES JUDICIALES FRENTE A LA REPARACIÓN INTEGRAL EN LA LEY DE JUSTICIA Y PAZ

Cayetano que eran civiles debieron ser respetados por parte de los grupos armadas sin entrar a desplazarlos forzadamente, lo que afectó en ellos el honor, sus convicciones y prácticas religiosas, debido a que son personas muy creyentes y devotas a la religión cristiana evangélica y tuvieron que dejar abandonado sus lugares de culto en la antigua Mampuján. Debieron ser tratadas con humanidad en toda circunstancia, sin ninguna distinción de carácter desfavorable. Queda prohibido ordenar que no haya supervivientes. 2. Sin perjuicio del carácter general de las disposiciones que preceden, están y quedarán prohibidos en todo tiempo y lugar con respecto a las personas a que se refiere el párrafo 1: a) los atentados contra la vida, la salud y la integridad física o mental de las personas, en particular el homicidio y los tratos crueles tales como la tortura y las mutilaciones o toda forma de pena corporal; b) los castigos colectivos; c) la toma de rehenes; d) los actos de terrorismo. 3. Se proporcionarán a los niños los cuidados y la ayuda que necesiten y, en particular: b) se tomarán las medidas oportunas para facilitar la reunión de las familias temporalmente separadas.

- Artículo 7: Protección y asistencia: 1. Todos los heridos, enfermos y náufragos, hayan o no tomado parte en el conflicto armado, serán respetados y protegidos. 2. En toda circunstancia serán tratados humanamente y recibirán, en toda la medida de lo posible y en el plazo más breve, los cuidados médicos que exija su estado. No se hará entre ellos distinción alguna que no esté basada en criterios médicos. Las víctimas de Mampuján y San Cayetano eran civiles a los que se les debía protección.

- Artículo 8: Búsqueda: Siempre que las circunstancias lo permitan, y en particular después de un combate, se tomarán sin demora todas las medidas posibles para buscar 
PERCEPCIONES DE LAS VÍCTIMAS DE MAMPUJÁN Y SAN CAYETANO Y SUS REPRESENTANTES JUDICIALES FRENTE A LA REPARACIÓN INTEGRAL EN LA LEY DE JUSTICIA Y PAZ

y recoger a los heridos, enfermos y náufragos a fin de protegerlos contra el pillaje y los malos tratos y asegurarles la asistencia necesaria, y para buscar a los muertos, impedir que sean despojados y dar destino decoroso a sus restos. Por ejemplo, en Mampuján y San Cayetano hubo personas desaparecidas forzadamente.

- Artículo 13: Protección de la población civil: 1. La población civil y las personas civiles gozarán de protección general contra los peligros procedentes de operaciones militares. Para hacer efectiva esta protección, se observarán en todas las circunstancias las normas siguientes. 2. No serán objeto de ataque la población civil como tal, ni las personas civiles. Quedan prohibidos los actos o amenazas de violencia cuya finalidad principal sea aterrorizar a la población civil. 3. Las personas civiles gozarán de la protección que confiere este Título, salvo si participan directamente en las hostilidades y mientras dure tal participación.

- Artículo 14: Protección de los bienes indispensables para la supervivencia de la población civil: Queda prohibido, como método de combate, hacer padecer hambre a las personas civiles. En consecuencia, se prohíbe atacar, destruir, sustraer o inutilizar con ese fin los bienes indispensables para la supervivencia de la población civil, tales como los artículos alimenticios y las zonas agrícolas que los producen, las cosechas, el ganado, las instalaciones y reservas de agua potable y las obras de riego.

- Artículo 16: Protección de los bienes culturales y de los lugares de culto: Sin perjuicio de las disposiciones de la Convención de La Haya del 14 de mayo de 1954 para la Protección de los Bienes Culturales en caso de Conflicto Armado, queda prohibido cometer actos de hostilidad dirigidos contra los monumentos históricos, las obras de arte o los lugares de culto que constituyen el patrimonio cultural o espiritual 
PERCEPCIONES DE LAS VÍCTIMAS DE MAMPUJÁN Y SAN CAYETANO Y SUS REPRESENTANTES JUDICIALES FRENTE A LA REPARACIÓN INTEGRAL EN LA LEY DE JUSTICIA Y PAZ

de los pueblos, y utilizarlos en apoyo del esfuerzo militar. Las víctimas de Mampuján, por ejemplo, tuvieron que dejar abandonos sus lugares de culto de la religión cristiana evangélica que practicaban y predicaban en la antigua Mampuján.

- Artículo 17: Prohibición de los desplazamientos forzados: 1. No se podrá ordenar el desplazamiento de la población civil por razones relacionadas con el conflicto, a no ser que así lo exijan la seguridad de las personas civiles o razones militares imperiosas. Si tal desplazamiento tuviera que efectuarse, se tomarán todas las medidas posibles para que la población civil sea acogida en condiciones satisfactorias de alojamiento, salubridad, higiene, seguridad y alimentación. 2. No se podrá forzar a las personas civiles a abandonar su propio territorio por razones relacionadas con el conflicto.

Por consiguiente, cabe preguntarse por los efectos que esto puede generar en las víctimas de Mampuján y San Cayetano, reconociendo que esta situación empeora con revictimizaciones (victimizaciones secundarias), que serán expuestas más adelante en los resultados y discusiones, como las ejecutadas con ellas por parte de postulados (alias Juancho Dique y Diego Vecino), las instituciones con obligaciones contempladas en la sentencia de segunda instancia y la comunidad circundante a las víctimas o sociedad en general.

Para dar respuesta, primero se cita a Gutiérrez de Piñeres et al. (2009), cuando afirman que muchos autores, coinciden en definir la victimización secundaria como las consecuencias psicológicas, sociales, jurídicas y económicas negativas que dejan las relaciones de la víctima con el sistema jurídico penal. Supone, un choque frustrante entre las legítimas expectativas de la víctima y la realidad institucional, involucrando una pérdida de comprensión acerca del sufrimiento psicológico y físico que ha causado el hecho delictivo, dejándolas desoladas e 
PERCEPCIONES DE LAS VÍCTIMAS DE MAMPUJÁN Y SAN CAYETANO Y SUS REPRESENTANTES JUDICIALES FRENTE A LA REPARACIÓN INTEGRAL EN LA LEY DE JUSTICIA Y PAZ

inseguras y generando una pérdida de fe en la habilidad de la comunidad, los profesionales y las instituciones para dar respuesta a las necesidades de las mismas (Kreuter, 2006) (Soria, 1998) y (Landrove, 1998). Asimismo, se entiende como una segunda experiencia victimal que resulta con alguna frecuencia siendo más negativa que la primaria, y puede llevar a incrementar el daño causado por el delito con otros de dimensión psicológica o patrimonial (Berril y Herek, 1992), (Beristain, 1995, 1999), (García-Pablos, 2003), (Landrove, 1998), (ONU, 1999), (Wemmers, 1996).

A su vez, Gutiérrez de Piñeres et. al., 2009), citando a Beristain (1996) considera que la victimización secundaria hace referencia a la mala o inadecuada atención que recibe la víctima una vez entra en contacto con el sistema de justicia.

Entonces, es cuando podemos afirmar que la victimización secundaria, siendo un tipo de revictimización, son repetidas situaciones por las que tienen que pasar las víctimas después de haber sido afectadas por algún delito ante los organismos judiciales, viéndose obligadas a testificar un número infinito de veces, perjudicándose psicológica y emocionalmente de manera más profunda y traumática a la víctima. ñA partir de la denuncia, las víctimas de cualquier delito, deben enfrentar numerosas situaciones en el ámbito de la justicia, que las hace sufrir. Largas esperas y/o en los pasillos, interminables recorridos por diversas oficinas, nuevas citaciones que con frecuencia las llevan a arrepentirse de haber hecho la denunciaò Rozanski (2003), citado por Gutiérrez de Piñeres et al. (2009).

Sumado a lo anterior, apoyándose en estos mismos autores que citan a Kreuter (2006), la experiencia de la victimización secundaria intensifica las consecuencias del hecho criminal, prolongando o agravando el trauma de la víctima; actitudes, comportamientos, actos u omisiones pueden dejar a las víctimas sintiéndose alienadas. 
PERCEPCIONES DE LAS VÍCTIMAS DE MAMPUJÁN Y SAN CAYETANO Y SUS REPRESENTANTES JUDICIALES FRENTE A LA REPARACIÓN INTEGRAL EN LA LEY DE JUSTICIA Y PAZ

Sin embargo, para no confundir al lector, se hace necesario precisar que, la victimización primaria deriva directamente del hecho delictivo; mientras que la secundaria de la relación posterior establecida entre la víctima y el sistema jurídico-penal (policía, sistema judicial, entre otros) o unos servicios sociales defectuosos. El maltrato institucional contribuye a agravar el daño psicológico de la víctima y funciona, según la terminología expuesta anteriormente, como una concausa posterior (Echeburúa, de Corral y Amor, 2002).

Para terminar, los efectos de las victimizaciones secundarias no solo son a nivel emocional o psicológico, debido a que muchas víctimas deben solicitar constantemente permisos en sus trabajos para asistir a las diligencias judiciales, lo que trae como consecuencia la pérdida del empleo, que refleja una incomprensión social por los daños causados a estas (Correia y Vala, 2003), citados por Gutiérrez de Piñeres et al. (2009).

\section{Organizaciones e instituciones relevantes en el proceso de Justicia y Paz de las víctimas de}

\section{Mampuján y San Cayetano}

\section{Comisión Nacional de Reparación y Reconciliación (CNRR).}

Dentro de este reporte de investigación se mencionaron, por parte de los participantes, instituciones u organizaciones representativas dentro del proceso de reparación judicial adelantado con las víctimas de Mampuján y San Cayetano, a saber: CNRR, MAPP OEA, PNUD, Departamento de Justicia de los Estados Unidos en Colombia y Defensoría del Pueblo, las cuales requieren descripciones misionales para comprensión del lector.

A partir de www.vicepresidencia.gov.co $(2014,13$ de agosto) la Comisión Nacional de Reparación y Reconciliación ï CNRR - fue creada en el marco de la Ley de Justicia y Paz, cuyo objetivo es facilitar los procesos de paz y la reincorporación individual o colectiva a la vida civil 
PERCEPCIONES DE LAS VÍCTIMAS DE MAMPUJÁN Y SAN CAYETANO Y SUS REPRESENTANTES JUDICIALES FRENTE A LA REPARACIÓN INTEGRAL EN LA LEY DE JUSTICIA Y PAZ

de miembros de grupos armados al margen de la ley, garantizando los derechos de las víctimas a la verdad, la justicia y la reparación.

En ese contexto, la CNRR se encarga de recomendar al Gobierno la implementación de un programa institucional de reparación colectiva que permita recuperar la institucionalidad del Estado Social de Derecho, restablecer y promover los derechos de los ciudadanos afectados por hechos de violencia, y a reconocer y dignificar a las víctimas. Todas las víctimas de los grupos armados ilegales, tanto de la guerrilla como de las autodefensas, serán objeto de atención de la CNRR.

La CNRR está integrada por un delegado del Vicepresidente de la República (quien la preside); cinco representantes de la sociedad civil; dos representantes de las organizaciones de víctimas, el Procurador General de la Nación o su delegado; un delegado del Ministro del Interior y de Justicia o su delegado; el Ministro de Hacienda y Crédito Público o su delegado; el Defensor del Pueblo; y el director de la Agencia Presidencial para la Acción Social y la Cooperación Internacional, quien ejerce las funciones de Secretaría Técnica. Como cabeza de la comisión, el Vicepresidente lidera a nivel nacional la representación del Gobierno Nacional ante las víctimas para acercarlas a las políticas de reparación y reconciliación.

En el caso de Mampuján y San Cayetano la mayoría de las víctimas acudieron a esta organización y algunas brindan sus agradecimientos por los apoyos recibidos en cuanto al acompañamiento y colaboración con recursos económicos para poder asistir, por ejemplo, a una de las audiencias que se realizaron en la ciudad de Barranquilla del departamento de Atlántico Colombia. 
PERCEPCIONES DE LAS VÍCTIMAS DE MAMPUJÁN Y SAN CAYETANO Y SUS REPRESENTANTES JUDICIALES FRENTE A LA REPARACIÓN INTEGRAL EN LA LEY DE JUSTICIA Y PAZ

\section{Misión de Apoyo al Proceso de Paz en Colombia de la Organización de los Estados Americanos (MAPP OEA).}

Por su parte, a partir de www.oas.org (2014, 13 de agosto), la Organización de los Estados Americanos (OEA) es el organismo regional más antiguo del mundo, cuyo origen se remonta a la Primera Conferencia Internacional Americana, celebrada en Washington, D.C., de octubre de 1889 a abril de 1890. En esta reunión, se acordó crear la Unión Internacional de Repúblicas Americanas y se empezó a tejer una red de disposiciones e instituciones que llegaría a conocerse como ñsistema interamericanoò, el más antiguo sistema institucional internacional.

La OEA fue creada en 1948 cuando se subscribió, en Bogotá, Colombia, la Carta de la OEA que entró en vigencia en diciembre de 1951. Posteriormente, la Carta fue enmendada por el Protocolo de Buenos Aires, suscrito en 1967, que entró en vigencia en febrero de 1970; por el Protocolo de Cartagena de Indias, suscrito en 1985, que entró en vigencia en noviembre de 1988; por el Protocolo de Managua, suscrito en 1993, que entró en vigencia en enero de 1996, y por el Protocolo de Washington, suscrito en 1992, que entró en vigor en septiembre de 1997.

La Organización fue fundada con el objetivo de lograr en sus Estados Miembros, como lo estipula el Artículo 1 de la Carta, "un orden de paz y de justicia, fomentar su solidaridad, robustecer su colaboración y defender su soberanía, su integridad territorial y su independencia". Para lograr sus más importantes propósitos, la OEA se basa en sus principales pilares que son la democracia, los derechos humanos, la seguridad y el desarrollo, y específicamente para Colombia se creó la MAPP OEA que significa ñMisión de Apoyo al Proceso de Paz en Colombia".

Esta organización fue decisiva para algunas víctimas de la investigación porque, como se podrá ver en los resultados y discusión, de esta tienen un recuerdo muy agradable, la consideran una amiga que interactuó junto con ellos en el proceso de reparación integral judicial de Justicia y 
PERCEPCIONES DE LAS VÍCTIMAS DE MAMPUJÁN Y SAN CAYETANO Y SUS REPRESENTANTES JUDICIALES FRENTE A LA REPARACIÓN INTEGRAL EN LA LEY DE JUSTICIA Y PAZ

Paz, se sintieron defendidas por esta organización y de la cual esperan mucho más, por ejemplo, para el cumplimiento de los Resuelve de la sentencia de segunda instancia.

\section{Programa de las Naciones Unidas para el Desarrollo (PNUD).}

A partir de www.pnud.org.co $(2014,13$ de agosto), el Programa de las Naciones Unidas para el Desarrollo (PNUD) es la red de las Naciones Unidas que coopera con pueblos y Estados de todo el mundo para atender las necesidades del desarrollo y forjar una vida mejor. Presente en 166 países, el PNUD trabaja con gobiernos e instituciones nacionales y regionales, la sociedad civil, el sector privado, los medios de comunicación y muchos otros aliados para ayudar a encontrar soluciones propias a los retos del desarrollo humano.

Por formar parte del Sistema de las Naciones Unidas, el PNUD es una organización neutral que realiza su trabajo con base en el respeto por el control que cada país tiene sobre su propio futuro. El compromiso con el desarrollo hace del PNUD un permanente promotor del cambio y el conocimiento, en una presencia amplia y descentralizada que lo mantiene próximo a temas, procesos, ideas y recursos relacionados con el desarrollo.

El PNUD Colombia es un organismo líder en cooperación técnica, asesoramiento de políticas, apoyo para la generación de medios de vida sostenibles y gestión del conocimiento. En coordinación con el Sistema de las Naciones Unidas, las entidades públicas y privadas, las organizaciones de la sociedad civil, los medios de comunicación y todos sus aliados, contribuye al desarrollo humano, el fortalecimiento de la democracia, la lucha contra la pobreza y la inequidad, así como a la construcción colectiva de procesos incluyentes de desarrollo. Al compartir el sueño de una Colombia en paz, el PNUD apoya la difusión del conocimiento y la potencialidad de las capacidades locales, regionales y nacionales para lograr una sociedad más democrática, equitativa y reconciliada. 
PERCEPCIONES DE LAS VÍCTIMAS DE MAMPUJÁN Y SAN CAYETANO Y SUS REPRESENTANTES JUDICIALES FRENTE A LA REPARACIÓN INTEGRAL EN LA LEY DE JUSTICIA Y PAZ

En apoyo de todo el Estado y de la sociedad, y con un énfasis en desarrollo local y una óptica basada en los derechos humanos, el PNUD concentra sus acciones en los siguientes ámbitos: Desarrollo local; gobernabilidad democrática; los objetivos de desarrollo del milenio; el programa de reconciliación y desarrollo, redes; medio ambiente y desarrollo sostenible; desarrollo humano; equidad de género; acción en las regiones; y las alianzas estratégicas.

De este organismo, por ejemplo, un líder de Mampuján expresa agradecimientos, como para la MAPP OEA y el Departamento de Justicia de los Estados Unidos en Colombia, por ser instituciones que interactuaron, asesoraron y acompañaron a las víctimas de Mampuján y San Cayetano en todo el proceso que adelantaron de Justicia y Paz, es decir, en el marco de la Ley 975 de 2005. Instituciones de las cuales las víctimas de Mampuján y San Cayetano esperan más acompañamiento.

\section{Departamento de Justicia de los Estados Unidos en Colombia.}

Brinda asistencia integral para el sector de la Justicia en Colombia, con énfasis especial en la Fiscalía General de la Nación. Aprovecha la profundidad y amplitud de los conocimientos especializados del Departamento de Justicia de los EE.UU. para contribuir a los esfuerzos de Colombia por fortalecer su sistema de justicia y sus capacidades para combatir las graves amenazas que plantean los grupos terroristas, las organizaciones criminales, el crimen violento, el tráfico de estupefacientes, los crímenes de derechos humanos y la corrupción (http://spanish.bogota.usembassy.gov/doj.html; 2014, 13 de agosto).

\section{Defensoría del Pueblo.}

Por último, a partir de www.defensoria.gov.co (2014, 13 de agosto), la Defensoría del Pueblo es la institución del Estado colombiano responsable de impulsar la efectividad de los 
PERCEPCIONES DE LAS VÍCTIMAS DE MAMPUJÁN Y SAN CAYETANO Y SUS REPRESENTANTES JUDICIALES FRENTE A LA REPARACIÓN INTEGRAL EN LA LEY DE JUSTICIA Y PAZ

derechos humanos de los habitantes del territorio nacional y de los colombianos en el exterior, en el marco del Estado Social de Derecho democrático, participativo y pluralista, mediante las siguientes acciones integradas:

- $\quad$ Promover, ejercer y divulgar los derechos humanos.

- $\quad$ Proteger y defender los derechos humanos y prevenir sus violaciones.

- Fomentar la observancia del derecho internacional humanitario.

- Atender, orientar y asesorar en el ejercicio de sus derechos.

- $\quad$ Proveer el acceso a la administración de justicia, en los casos señalados en la Ley.

Institución de la cual las victimas agradecen su participación porque recibieron acompañamiento hasta el final del proceso de Justicia y Paz, a través de sus Defensores Públicos fueron los precursores de la generación de la sentencia en segunda instancia, la cual generó reparaciones en Derecho y no en Equidad, es decir, reparaciones a partir del daño sufrido.

\section{Categorías o conceptos de la investigación}

\section{Victimología y tipos de victimización. Campo de acción de la investigación.}

Como se puede inferir, el campo de acción de esta investigación fue la Victimología. Por cuanto, en base a Tamarit (2006), esta puede definirse hoy como la ciencia multidisciplinar que se ocupa del conocimiento de los procesos de victimación y desvictimación, es decir del estudio del modo en que una persona deviene víctima, de las diversas dimensiones de la victimación (primaria, secundaria y terciaria) y de las estrategias de prevención y reducción de la misma, así como del conjunto de respuestas sociales, jurídicas y asistenciales tendientes a la reparación y reintegración social de la víctima. 
PERCEPCIONES DE LAS VÍCTIMAS DE MAMPUJÁN Y SAN CAYETANO Y SUS REPRESENTANTES JUDICIALES FRENTE A LA REPARACIÓN INTEGRAL EN LA LEY DE JUSTICIA Y PAZ

También puede ser, orientada hacia una descripción desde una perspectiva jurídica, a partir de la Declaración sobre los Principios Fundamentales de Justicia para las víctimas de delitos y del abuso del poder, adoptadas por la Asamblea General de las Naciones Unidas en su Resolución 4034 del 29 de noviembre de 1985, una definición de estas víctimas, como ñas personas que, individual o colectivamente, hayan sufrido daños, inclusive lesiones físicas o mentales, sufrimiento emocional, pérdida financiera o menoscabo sustancial de los derechos fundamentales, como consecuencia de acciones u omisiones que violen la legislación penal vigente en los Estados miembros, incluida la que proscribe el abuso de poderò(UN, 1985).

Teniendo en cuenta lo anterior, la Declaración plantea que podrá considerarse víctima a una persona, independientemente de que se identifique, aprehenda, enjuicie o condene al perpetrador, e incluye, igualmente, en su caso, a los familiares o personas a cargo que tengan relación inmediata con la victima directa y a las personas que hayan sufrido daños al intervenir para asistir a las víctimas en peligro o para prevenir la victimización.

Cabe precisar que estos conceptos fueron incorporados en la legislación colombiana, a través de la promulgación de las Leyes 975 de 2005 (Ley de Justicia y Paz) y 1448 de 2011 (Ley de Víctimas y de Restitución de Tierras).

A este concepto de víctima, fuera de lo penal o criminal, se añade algo más: lo que distingue las víctimas directas, que designan a los sujetos expuestos directamente al evento traumático, de las víctimas indirectas, constituidas por las personas que han sido testigos directos del trauma sin haber sido, a pesar de ello, afectados personalmente. Las víctimas indirectas pueden tener grados diferentes de relación con la víctima directa; así, pueden ser familiares, amigos o vecinos o pueden estar implicados profesionalmente en el acontecimiento: policías, bomberos, personal sanitario o de emergencias, entre otros (Baca, Cabanas y Baca-García, 2003). 
PERCEPCIONES DE LAS VÍCTIMAS DE MAMPUJÁN Y SAN CAYETANO Y SUS REPRESENTANTES JUDICIALES FRENTE A LA REPARACIÓN INTEGRAL EN LA LEY DE JUSTICIA Y PAZ

Lo que se plantea es que la victimización, como aquellas padecidas por víctimas de Mampuján y San Cayetano, es el proceso por el que una persona sufre las consecuencias de un hecho traumático o violatorio de sus derechos. En el estudio del proceso de victimación hay que considerar dos dimensiones: los factores que intervienen en la precipitación del hecho delictivo o (en la versión extendida del concepto de víctima) traumatizante, y, por otra parte, los factores que determinan el impacto de tal hecho sobre la víctima. En este sentido se establece la distinción entre víctimas de riesgo (aquella persona que tiene más probabilidad de ser víctima) y víctima vulnerable (aquella que, cuando ha sufrido una agresión, queda más afectada por lo ocurrido en función de una situación de precariedad material, personal, emocional, entre otros). La literatura victimológica clásica se centró en la primera dimensión, y de ahí su interés en el desarrollo de las tipologías victímales, hoy objeto de un cierto descrédito. Con posterioridad, la Victimología se ha orientado a un concepto de victimación que lo entiende como experiencias individual, subjetiva y relativa culturalmente. Así, el estudio de la victimación, en tanto que fenómeno complejo, obliga a considerar los factores (individuales, sociales, culturales) que condicionan o modulan el modo de vivir la experiencia referida (Domínguez, 2003).

El carácter complejo del proceso de victimización explica que sea habitual distinguir entre victimización primaria, secundaria y terciaria. La victimización primaria recae sobre quien padece el hecho víctimal directamente. El término Victimización Secundaria, como se ha dicho, fue acuñado por Kühne (1986) para referirse a todas las agresiones psíquicas (no deliberadas pero efectivas) que la víctima recibe en su relación con los profesionales de los servicios sanitarios, policiales, o de la judicatura (interrogatorios, reconstrucción de los hechos, asistencia a juicios, identificaciones de acusados, lentitud y demora de los procesos, entre otros), así como los efectos del tratamiento informativo del suceso por parte de los medios de comunicación 
PERCEPCIONES DE LAS VÍCTIMAS DE MAMPUJÁN Y SAN CAYETANO Y SUS REPRESENTANTES JUDICIALES FRENTE A LA REPARACIÓN INTEGRAL EN LA LEY DE JUSTICIA Y PAZ

La victimización terciaria es el conjunto de costes de la penalización sobre quien la soporta personalmente o sobre terceros, y la literatura existente documenta los efectos sobre los internos en centros penitenciarios, sobre los hijos de personas encarceladas, o sobre los efectos de las órdenes de alejamiento en casos de violencia de pareja, bien sobre los ofensores, como sobre las víctimas o su descendencia. La desvictimación, también fenómeno complejo en el que intervienen diversos factores y actores sociales, consiste entonces en el proceso de reparación, entendida no sólo como indemnización de perjuicios, sino como reconocimiento social, asistencia y reintegración social (Domínguez, 2003).

Sin embargo, la gravedad de estos tipos de victimizaciones dependerá de las percepciones y significaciones que las victimas hagan alrededor de los hechos victimizantes, la atención de las instituciones, etcétera.

\section{Los conceptos de Percepción y Percepción Social.}

Entonces, siendo las percepciones de los participantes el pilar de esta investigación, tradicionalmente se han definido como el proceso cognitivo de la conciencia que consiste en el reconocimiento, interpretación y significación para la elaboración de juicios en torno a las sensaciones obtenidas del ambiente físico y social, en el que intervienen procesos psíquicos entre los que se encuentran el aprendizaje, la memoria y la simbolización. Sin embargo, hay sensaciones que también llegan a la mente y son procesadas en forma inconsciente (Montes, Cordero, Acuña, Peláez, Matienzo y Villiarolo, 2010).

En el proceso de la percepción se ponen en juego referentes ideológicos y culturales que reproducen y explican la realidad y que son aplicados a las distintas experiencias cotidianas para ordenarlas y transformarlas. Cabe resaltar aquí a uno de los elementos importantes que definen a la percepción, el reconocimiento de las experiencias cotidianas. El reconocimiento es un proceso 
PERCEPCIONES DE LAS VÍCTIMAS DE MAMPUJÁN Y SAN CAYETANO Y SUS REPRESENTANTES JUDICIALES FRENTE A LA REPARACIÓN INTEGRAL EN LA LEY DE JUSTICIA Y PAZ

importante involucrado en la percepción, porque permite evocar experiencias y conocimientos previamente adquiridos a lo largo de la vida con los cuales se comparan las nuevas experiencias, lo que permite identificarlas y aprehenderlas para interactuar con el entorno. De esta forma, a través del reconocimiento de las características de los objetos se construyen y reproducen modelos culturales e ideológicos que permiten explicar la realidad con una cierta lógica de entre varias posibles, que se aprende desde la infancia y que depende de la construcción colectiva y del plano de significación en que se obtiene la experiencia y de donde ésta llega a cobrar sentido (Montes et al., 2010).

De acuerdo con los referentes del acervo cultural lo percibido es identificado y seleccionado, sea novedoso o no, adecuándolo a los referentes que dan sentido a la vivencia, haciéndola comprensible de forma que permita la adaptación y el manejo del entorno. Al respecto, MerleauPonty (1985) ha señalado que la percepción no es un añadido de eventos a experiencias pasadas sino una constante construcción de significados en el espacio y en el tiempo.

Desde un punto de vista antropológico, la percepción es entendida como la forma de conducta que comprende el proceso de selección y elaboración simbólica de la experiencia sensible, que tienen como límites las capacidades biológicas humanas y el desarrollo de la cualidad innata del hombre para la producción de símbolos. A través de la vivencia la percepción atribuye características cualitativas a los objetos o circunstancias del entorno mediante referentes que se elaboran desde sistemas culturales e ideológicos específicos construidos y reconstruidos por el grupo social, lo cual permite generar evidencias sobre la realidad (Vargas M., 1995).

En términos generales y según Oviedo (2004) la labor de la percepción consiste en un intento de agrupación de la información circundante dentro de unidades simples que le permitan a la conciencia adquirir noción de objeto y con ello afinar su capacidad abstracta. La percepción es 
PERCEPCIONES DE LAS VÍCTIMAS DE MAMPUJÁN Y SAN CAYETANO Y SUS REPRESENTANTES JUDICIALES FRENTE A LA REPARACIÓN INTEGRAL EN LA LEY DE JUSTICIA Y PAZ

entendida como un permanente acto de conceptualización. Los eventos del mundo externo son organizados a través de juicios categoriales que se encargan de encontrar una cualidad que represente de la mejor manera posible a los objetos.

Estos juicios categoriales en ocasiones son compartidos por otras personas, por parte o una comunidad de forma general, generando con ello Percepciones Sociales, en este caso, frente a la macrovictimización de Mampuján y San Cayetano y sobre el incidente de reparación integral en el marco de la Ley de Justicia y Paz, lo que implicó y generó.

Es por eso que se hace necesario aclarar que, a partir de Banchs (1986), las Percepciones Sociales aluden a la categorización que hace parte o la sociedad sobre personas u objetos. Los estudios de Percepción Social se centran en los mecanismos de respuestas sociales y sus procesamientos de la informacióné

Asimismo, Dorsch (1994) considera que el término hace referencia al condicionamiento parcial y al cambio de orientación en el entorno mediante interacciones sociales en el pasado y el presente, y mediante expectativas de acontecimientos sociales. Mientras que la percepción social para Doron y Parot (2007) es empleada a veces para designar los factores sociales de la percepción, donde esta expresión se utiliza más comúnmente para calificar la percepción del ambiente social.

El estudio de la percepción social según Álvaro y Garrido (2003) fue una de las grandes líneas de investigación a las que dio lugar la introducción de los principios de la Escuela de la Gestalt en Psicología Social durante los años 50(é ) el estudio de la percepción social por parte de los psicólogos sociales encuadrados bajo esta orientación, descansó sobre el supuesto de que las leyes que los psicólogos de la Gestalt habían enunciado para explicar la percepción de los 
PERCEPCIONES DE LAS VÍCTIMAS DE MAMPUJÁN Y SAN CAYETANO Y SUS REPRESENTANTES JUDICIALES FRENTE A LA REPARACIÓN INTEGRAL EN LA LEY DE JUSTICIA Y PAZ

objetos físicos eran aplicables igualmente a la percepción de las personas y del comportamiento social.

Ahora bien, dichas percepciones sociales se construyen mediante: percepciones individuales o particulares compartidas, representaciones y valores, conocimientos y creencias (cultura), experiencia individual, experiencia compartida, hábitos adquiridos, comportamientos aprendidos y actitudes (Montes et al., 2010).

Cuando las personas (participantes de la investigación) hacen referencia a los objetos sociales (macrovictimización de Mampuján y San Cayetano y su incidente de reparación integral de Justicia y Paz), los clasifican, los explican y, además, los evalúan, es porque tienené (Montes et al., 2010) una Percepción Social de ese objeto.

Es así como, la teoría de las Percepciones Sociales, parece ser una alternativa de argumentación, donde la macrovictimización de Mampuján y San Cayetano y su incidente de reparación de Justicita y Paz sería un objeto social representable, al que se le asignó unos sentidos y significados sociales por parte de los participantes de la investigación: víctimas, líderes y representantes judiciales; porque el concepto de percepción (individual), por si solo, queda limitado cuando se trata de explicar los fenómenos subyacentes en el proceso de percepción de las víctimas respecto a la reparación definida por una instancia judicial como la Corte Suprema de Justicia. En dicho contexto se reconoce la intervención de factores sociales que resultan determinantes por las relaciones entre los individuos dentro de una comunidad, por cuanto se hace necesario recurrir al concepto de Percepción Social.

\section{El concepto de Satisfacción.}

Teniendo en cuenta que en el trabajo de investigación se hace referencia como objetivo específico, el identificar si fueron satisfechas las pretensiones de las víctimas de Mampuján y San 
PERCEPCIONES DE LAS VÍCTIMAS DE MAMPUJÁN Y SAN CAYETANO Y SUS REPRESENTANTES JUDICIALES FRENTE A LA REPARACIÓN INTEGRAL EN LA LEY DE JUSTICIA Y PAZ

Cayetano con el resultado del incidente de reparación dado en segunda instancia, se hace necesario definir el concepto de Satisfacción.

Por ello, se puede entender la Satisfacción como una valoración cognitiva personal que realiza una persona de la vida y de los dominios de la misma, atendiendo a la calidad de su vida, a las expectativas y aspiraciones, a los objetivos conseguidos, basada en los propios criterios de la persona y que se realiza de forma favorable (Clemente, Molero y González, 2000).

Los mismos autores consideran que la Satisfacción se ve influenciada por múltiples variables, tanto de índole social y cultural, señalando entre las más relevantes el nivel socioeconómico y el nivel cultural de las personas, como por variables de tipo personal, entre las que cabe citar como una de las más importantes la edad, además de otras como el sexo, e incluso las mismas características y rasgos de personalidad, que pueden condicionar la valoración de la vida o de un aspecto de la misma como más o menos satisfactorio.

También, se considera que, al igual que el termino Felicidad, la Satisfacción alude a estados de ánimo positivos en los que se encuentra el individuo en un momento concreto de su vida, es decir, es de carácter pasajero; un estado que se experimenta en un tiempo concreto, pero que no es estable, algo fundamentalmente afectivo. Hay que otorgarle un carácter más afectivo a la Satisfacción y uno más cognitivo a la Felicidad, puesto que esta última proviene de una comparación que el sujeto establece entre lo que posee en su vida y lo que desea de la misma; de tal forma que si posesión y deseo coinciden, el sujeto estará en situación de felicidad (CuervoArango, 1993).

\section{El concepto de Sentimientos.}

Al ser macrovictimizados los pobladores de Mampuján y San Cayetano se generó en ellos una serie de sentimientos que pueden definirse o explicarse a partir de Castilla del Pino (2000), 
PERCEPCIONES DE LAS VÍCTIMAS DE MAMPUJÁN Y SAN CAYETANO Y SUS REPRESENTANTES JUDICIALES FRENTE A LA REPARACIÓN INTEGRAL EN LA LEY DE JUSTICIA Y PAZ

como: los sentimientos, instrumentos del sujeto, son instrumentos de que dispone el sujeto para la relación emocional, afectiva, tanto con personas, animales y cosas, cuanto consigo mismo, es decir, con sus pensamientos, fantasías, deseos, impulsos, incluso con sus propios sentimientos, a todos ellos los denominamos genéricamente ñobjetosò, si bien los primeros son objetos externos y los segundos internos. Los sentimientos sirven 1) para la vinculación eficaz, interesada, con tales objetos, para ñatarseò a ellos mediante un ñazoò precisamente afectivo; y 2) para la organización jerarquizada de los valores, una organización singular, exclusiva de cada sujeto, por tanto egocéntrica.

Lo que confiere subjetividad al modo de relación de cada persona con la realidad y con los objetos que la constituyen, así como al valor que al objeto se le adjudica, es la singular relación afectiva para con él. Sin la singularidad de los sentimientos de cada cual, con solo el instrumento cognitivo, la realidad sería prácticamente análoga en todos los seres humanos: se trataría de seres en última instancia a-sociales, aunque con los mimos instrumentos sensoperceptivos, representacionales y mnémicos: prácticamente robots, ordenadores, máquinas.

En el orden psicológico hay muchas diferencias en la esfera cognitiva de los seres humanos, que se traducen en variaciones de nuestras aptitudes y capacidades intelectuales, pero los sentimientos son los que nos distinguen en tanto sujetos para una relación irrepetible (Castilla del Pino, 2000).

Por otro lado, los sentimientos, estados del sujeto, además de instrumentos del sujeto para la relación con los objetos del entorno y consigo mismo, los sentimientos, se ha dicho en las formulaciones clásicas y tradicionales, son estados del sujeto, porque lo cualifican y lo modifican en cierto sentido. Son estados del ñYoò. Los sentimientos son un instrumento para el uso e instrumento que al ser usado modifica al sujeto (Castilla del Pino, 2000). 
PERCEPCIONES DE LAS VÍCTIMAS DE MAMPUJÁN Y SAN CAYETANO Y SUS REPRESENTANTES JUDICIALES FRENTE A LA REPARACIÓN INTEGRAL EN LA LEY DE JUSTICIA Y PAZ

A su vez, a partir del mismo autor, los sentimientos, estados del organismo, dan a entender que sentir es un proceso que tiene dos partes: la experiencia cognitivaï emocional que el objeto provoca, y los efectos que dicha experiencia desencadena en el organismo, incluido en ese subsistema que es el sujeto. El sentimiento no es solo la experiencia mental sino también la de las alteraciones que el sujeto percibe en el resto de su organismo, como el llanto, el sudor, taquicardia, etcétera. Los sentimientos, pues, afectan no solo al sistema del sujeto sino a la totalidad del organismo. La experiencia de un sentimiento altera el estado del organismo, que reacciona con una serie de síntomas o signos.

No hay sentimientos sin síntomas, pues la homeostasis provocada debe dar señales al sistema para que elabore la respuesta de adaptación. El conjunto de los síntomas constituye un síndrome, une la experiencia mental y la experiencia fisiológica del sentimiento. Cuando el síndrome desborda los límites de las posibilidades adaptativas del organismo surge la crisis, el estrés.

Y cuando sucede la crisis, por ejemplo, se podría afectar la percepción de satisfacción de las víctimas de Mampuján y San Cayetano con el resultado del incidente de reparación judicial integral, y aquellas relacionadas con sus pretensiones y cumplimientos de reparación. La relación sentimientos y percepción = satisfacción o insatisfacción, es innegable.

\section{El concepto de Estigma o Estigmatizaciones.}

Empezando, hay que recordar que las víctimas de Mampuján y San Cayetano fueron estigmatizadas por parte de sus comunidades circundantes y de la sociedad, al señalarlos de colabores de la guerrilla, señalamiento que justificó el accionar paramilitar del cual fueron víctimas y que puede generar afectaciones psicológicas en las victimas, como el sentirse rechazadas y por consiguiente aislamiento, violencia, desconfianza, etcétera. 
PERCEPCIONES DE LAS VÍCTIMAS DE MAMPUJÁN Y SAN CAYETANO Y SUS REPRESENTANTES JUDICIALES FRENTE A LA REPARACIÓN INTEGRAL EN LA LEY DE JUSTICIA Y PAZ

A partir de Goffman (1963), acerca de la naturaleza del estigma se podría resumir en las siguientes premisas: a) el estigma es una marca o señal negativa que es atribuida a individuos; b) una marca que implica un juicio o evaluación negativa; c) la estigmatización tiene consecuencias negativas para el estigmatizado; d) consecuencias negativas que son legitimadas por un sistema de creencias compartidas acerca de los atributos (virtualmente atribuidos) de la persona estigmatizada. Respecto a esto, es necesario hacer referencia a la distinción que hace este autor entre identidad social real de la persona e identidad social virtual. Se habla de virtual en cuanto que ésta identidad es ï ñuna imputación hecha con una mirada retrospectiva en potenciaò. Es decir, es virtual porque solo representa nuestra propia caracterización del estigmatizado, pero no la identidad social real de éste.

Ahora bien, la idea fundamental que deberíamos mantener es que, de acuerdo con Pérez (2013) citando a los siguientes autores:

Goffman (1986, p.3), un estigma es un atributo que desacredita a un individuo, que lo reduce de una persona completa y común a una marcada y disminuida. La estigmatización ocurre cuando una persona posee o cree poseer alguna característica que le confiere una identidad social que es devaluada en un contexto social particular (Crocker et al., 1998, p.505). En otras palabras, la estigmatización está aparejada con una devaluación de la persona en cierto contexto social. Tanto los individuos estigmatizados como los demás miembros de la sociedad comparten la idea de que los primeros poseen un atributo (o marca) que los distingue de los demás y una creencia de que dicho atributo los desvaloriza en comparación con los demás. De acuerdo con Major y OâBrien (2005, p.395), el o los atributos del estigma indican que quienes los tienen: a) son socios poco fiables en el intercambio social; b) son portadores de alguna enfermedad infecciosa, y/o c) son miembros de un grupo que puede ser 
PERCEPCIONES DE LAS VÍCTIMAS DE MAMPUJÁN Y SAN CAYETANO Y SUS REPRESENTANTES JUDICIALES FRENTE A LA REPARACIÓN INTEGRAL EN LA LEY DE JUSTICIA Y PAZ

explotado en beneficio de los miembros del grupo dominante. Asimismo, Goffman (1986, p.5) señala que las sociedades comúnmente construyen una teoría del estigma para explicar la inferioridad de quienes son estigmatizados, muchas veces en función del riesgo que representan para la sociedad. Los miembros de la sociedad justifican la exclusión y la desconfianza hacia ciertos individuos marcados (contaminados) (Major y O’Brien, 2005, p.396).

\section{Los conceptos de Empoderamiento y Resiliencia.}

Al presentarse procesos de Empoderamiento y Resiliencia en víctimas de Mampuján y San Cayetano respecto a sus macrovictimizaciones y al incumplimiento de los Resuelve de la sentencia dada en segunda instancia de Justicia y Paz, se hace necesario recordar que, a partir de Pilonieta (2002), el empoderamiento se propone como algo más que el simple hecho de abrir el acceso a la toma de decisiones, debe consistir en introducir dentro del proceso de la toma de decisiones a las personas que se encuentran fuera del mismo; también debe incluir los procesos que llevan a las personas a percibirse con la capacidad y el derecho a ocupar esos espacios decisorios, a asumirse como sujetos éticos frente a todas y cada una de sus acciones; como la posibilidad de reconocer el poder en todos los seres humanos, y la consiguiente capacidad de convertirlo en una fuerza motivante positiva y no en una elemento de opresión.

A su vez, San Pedro (2006), entiende el Empoderamiento como un proceso de transformación por el cual el individuo va adquiriendo poder y control para tomar decisiones y alcanzar sus propios objetivos. El empoderamiento puede ser un medio para alcanzar un fin como la reducción de la pobreza o la prevención de conflictos, o se puede considerar un fin en sí mismo (un individuo que se empodera). Esta interpretación considera que el proceso parte del individuo 
PERCEPCIONES DE LAS VÍCTIMAS DE MAMPUJÁN Y SAN CAYETANO Y SUS REPRESENTANTES JUDICIALES FRENTE A LA REPARACIÓN INTEGRAL EN LA LEY DE JUSTICIA Y PAZ

y solo a través de su propio entendimiento de la realidad consigue cambiar las estructuras de poder.

Asimismo, este autor considera que el empoderamiento contribuye a la conformación de individuos autosuficientes que saben cómo dirigir su propio desarrollo, como participar en el proceso de toma de decisiones en coordinación con los diferentes niveles de gobierno (local, regional y nacional), y con capacidad para demandar políticas inclusivas. En suma, considera que el empoderamiento es la capacidad del individuo para escoger una opción dentro de varias alternativas siendo consciente de las (opciones) existentes.

Por tanto, lo concibe como un proceso progresivo de aprendizaje en el que se asciende de un estado a otro aumentando el abanico de posibilidades. Inevitablemente, este desarrollo personal implica una ruptura de las estructuras de poder existentes y la eliminación de las construcciones sociales negativas. Para ello, deben existir instituciones abiertas, inclusivas y transparentes, capaces de satisfacer las demandas de los individuos y de la sociedad en su conjunto.

Por otro lado, la Resiliencia puede ser considerada como el fenómeno del desarrollo exitoso de una persona bajo condiciones adversas (Braverman, 1999) o, como propone Masten (1999), considerarla un rasgo relativamente global de la personalidad que le permite a la persona una mejor adaptación a la vida. Sin embargo, la definición más aceptada de resiliencia es la de Garmezy (1991) que la define como ña capacidad para recuperarse y mantener una conducta adaptativa después del abandono o la incapacidad inicial al iniciarse un evento estresanteò.

\section{El concepto de Proactividad.}

Por otra parte, víctimas de Mampuján y San Cayetano también desarrollaron procesos de Proactividad en relacion a los hechos victimizantes que padecieron. A partir de Fernández (1999), una definición simplificada de la proactividad sería el desarrollo autoconsciente de acciones 
PERCEPCIONES DE LAS VÍCTIMAS DE MAMPUJÁN Y SAN CAYETANO Y SUS REPRESENTANTES JUDICIALES FRENTE A LA REPARACIÓN INTEGRAL EN LA LEY DE JUSTICIA Y PAZ

creativas para la generación de las mejores oportunidades posibles, con sometimiento permanente de todo el proceso a la más razonable, rigurosa y eficaz refutación.

\section{Conflicto Armado Interno y Psicología Jurídica.}

En definitiva, siendo esta investigación orientada por la Psicología Jurídica, hay que definir esta area de la psicología, la cual trata de los supuestos psicológicos en que se fundamentan las leyes y quienes las aplican, bien sean juristas bien psicólogos, con el fin de explicar, predecir e intervenir (Martín, Palleja y Alonso, 2006), o es un área de la Psicología encargada de describir, explicar, predecir e intervenir sobre el comportamiento humano que tiene lugar en el contexto jurídico, con la finalidad de contribuir a la construcción y práctica de sistemas jurídicos objetivos y justos.

Desde esta perspectiva, el comportamiento humano se concibe como un conjunto que incluye no solo la conducta fácilmente observable, sino también los procesos cognoscitivos y emocionales, y las creencias y actitudes de las personas. Interesan dentro de esta área el comportamiento de diversos actores como los delincuentes, las víctimas, los administradores y procuradores de justicia, demandantes, demandados, testigos, guardias, policías y sociedad en general en el marco de la ley y de los sistemas de Justicia (Morales y García, 2010).

Ahora bien, citando a Rodríguez (2014), desde las diferentes instituciones encargadas de atender a las víctimas del conflicto armado como en organizaciones no gubernamentales que trabajan al servicio de los Derechos Humanos, teniendo en cuenta sus áreas de aplicación, un Psicólogo Jurídico podría desempeñarse como:

- Asesor: de las víctimas a quienes puede dar orientación legal con respecto a las entidades competentes, instancias o rutas de atención que puede seguir para el restablecimiento de derechos. Por su parte, también puede asesorar a los 
PERCEPCIONES DE LAS VÍCTIMAS DE MAMPUJÁN Y SAN CAYETANO Y SUS REPRESENTANTES JUDICIALES FRENTE A LA REPARACIÓN INTEGRAL EN LA LEY DE JUSTICIA Y PAZ

profesionales de las instituciones para la toma de decisiones en los diferentes procesos que se adelantan con víctimas. Se espera que el resultado de esta investigación pueda retroalimentar a la institucionalidad, replantear su quehacer, asesorando futuras prácticas

- Consultor de la norma: el psicólogo jurídico puede asesorar a funcionarios de la rama legislativa y ejecutiva para la creación de políticas públicas que respondan a la atención de las víctimas, teniendo en cuenta, por ejemplo, investigaciones como esta donde se indagó las percepciones de las víctimas de Mampuján y San Cayetano frente al incidente de reparación de Justicia y Paz para que puedan hacer eco y repercusión en las decisiones legislativas, entre otras. Es decir, un psicólogo jurídico puede interesarse por la eficacia e impacto de la norma y esto es lo que pretende esta investigación, a través de la percepción de los participantes sobre el incidente de reparación y, de forma general, sobre la Ley 975 de 2005.

- Perito: El psicólogo jurídico puede emitir informes periciales de las víctimas como punto de partida para la medida de rehabilitación dentro de la reparación integral que contempla la ley 1448 de 2011 o para el proceso judicial de la Ley 975 de 2005 en el incidente de identificación de afectaciones.

- Mediador: Con las víctimas se pueden adelantar procesos de mediación con el fin de hacer manejo de los conflictos antes de buscar resolución en instancias judiciales. Estos procesos contribuyen a la descongestión del aparato judicial, lo que conlleva a un beneficio de doble vía: por una parte las victimas podrán satisfacer con mayor efectividad sus necesidades y/o derechos, lo que a su vez generará una mejor percepción de la institucionalidad y minimizará la aparición de sintomatología 
PERCEPCIONES DE LAS VÍCTIMAS DE MAMPUJÁN Y SAN CAYETANO Y SUS REPRESENTANTES JUDICIALES FRENTE A LA REPARACIÓN INTEGRAL EN LA LEY DE JUSTICIA Y PAZ

psicológica que agravaría la salud mental. La segunda vía es que las instituciones tendrían menos h̃̃acinamientoò y una baja importante de casos que si se abordan preventiva y adecuadamente puede solucionarse en términos más sencillos, lo que permitiría priorizar la atención de aquellos casos que requieran un trato especial, al tiempo que los funcionarios también conseguirían adelantar su trabajo más eficazmente, disminuyendo la carga laboral y por ende el estrés y demás afectaciones, dado al contacto diario que tienen con las historias desgarradoras de los usuarios(as), lo que Smtih y Álvarez (2007), citados por Rodríguez (2014) desde el contexto costarricense pretenden establecer:

(é ) cómo en la práctica, aparte de la víctima tradicional del delito, existe otra víctima silenciosa del proceso penal, constituido por el equipo de investigadores, fiscales, jueces y peritos, que día a día convive con el dolor ajeno. El problema se agrava por la carencia de conciencia y decisión política, sensibilidad por parte del sistema y jerarquías del Poder Judicial para conformar una oficina o entidad encargada de abordar preventivamente la problemática del empleado judicial, sino también porque respecto de la víctima del proceso, no se cumplen a cabalidad las garantías que se crearon en el Código Procesal Penal en cuanto a la atención integral que debe recibir una víctima. 
PERCEPCIONES DE LAS VÍCTIMAS DE MAMPUJÁN Y SAN CAYETANO Y SUS REPRESENTANTES JUDICIALES FRENTE A LA REPARACIÓN INTEGRAL EN LA LEY DE JUSTICIA Y PAZ

\section{Método}

\section{Enfoque, tipo y diseño de la investigación}

La investigación se caracterizó por ser de enfoque Cualitativo de tipo exploratorio. Cualitativo en tanto se basó en métodos de recolección de datos no estandarizados ni completamente determinados, propiamente no se efectuó una medición numérica como en las investigaciones cuantitativas, por lo que el análisis no fue estadístico en el proceso de interpretación (Hernández, Fernández y Baptista, 2010), lo que no quiere decir que, dentro del mismo no se pueda utilizar datos numéricos; además, es cualitativo porque no siguió una secuencia estricta en su desarrollo, lo que es recomendable para ser utilizado en investigaciones que tienen como finalidad básica iniciar un proceso de análisis y de investigación novedoso consistente en reconstruir la realidad tal y como lo observan y lo perciben los protagonistas de un proceso, como es el caso de las víctimas de Mampuján y San Cayetano, sus líderes y los abogados, actores Judiciales de la Defensoría del Pueblo, quienes las representaron en el incidente de reparación dado en segunda instancia, iniciando desde la primera instancia. Fue de tipo exploratorio por cuanto aún hay pocos antecedentes de estudios relacionados con el resultado, a través de la percepción de unos participantes, de un incidente de reparación integral en el marco de la Ley de Justicia y Paz; es decir, los estudios exploratorios se realizan cuando el objetivo consiste en examinar un tema poco estudiado (Hernández, Fernández y Baptista, 2010).

Por otro lado, el diseño fenomenológico fue utilizado en esta exploración porque su finalidad fue indagar sobre el significado, estructura y esencia de una experiencia vivida (incidente de reparación integral y macrovictimización de Mampuján y San Cayetano) por una persona (individual), grupo (grupal) o comunidad (colectiva) - participantes de esta investigación respecto a un fenómeno: lo que gira en torno al incidente de reparación y la macrovictimización 
PERCEPCIONES DE LAS VÍCTIMAS DE MAMPUJÁN Y SAN CAYETANO Y SUS REPRESENTANTES JUDICIALES FRENTE A LA REPARACIÓN INTEGRAL EN LA LEY DE JUSTICIA Y PAZ

(Patton, 2002, citado por Hernández, Fernández y Baptista, 2006, p.712). Lo que distingue a este diseño de otros diseños cualitativos es la o las experiencias del participante o participantes como centro de indagación (Hernández et al. 2006, p.712). Por lo tanto, experiencias, significados y percepciones de los participantes de esta investigación respecto al incidente de reparación de Mampuján y San Cayetano, fueron el centro de indagación, teniendo en cuenta que el incidente de reparación integral dado en segunda instancia por la Ley 975 de 2005, presentó falencias que afectan a las víctimas en sus derechos. Lo cual, requiere investigaciones de este tipo que ayude a mejorar futuras intervenciones y procesos con víctimas, y que aporte información que guie la toma de decisiones para futuras reformas estructurales de la Ley si así se desea, por ejemplo, con sustento en la percepción de los participantes de una investigación como esta.

\section{Participantes}

La selección de los participantes para aplicar las técnicas de recolección de información, se hizo sin importar cantidades o sus características etarias, étnicas, educativas, políticas, socioeconómicas, entre otras, solo se preguntaron algunos de estos últimos datos para fines de identificación. Lo cual obedece a que en los estudios cualitativos, según Hernández et al.(2010), el tamaño de la muestra (en este caso Grupos de Participantes) no es importante desde una perspectiva probabilística, pues el interés de los investigadores no es generalizar los resultados de este estudio a una población más amplia, se buscó profundizar sobre conceptos o percepciones de unos participantes que ayudaron a entender el fenómeno de estudio y a responder las preguntas de investigación o interrogantes de forma profunda y solo desde la opinión de ellos, de tal manera que sirva para futuros procesos.

No existieron parámetros definidos para la cantidad de participantes, porque hacerlo iba claramente contra la propia naturaleza de la indagación cualitativa, el principal factor o necesidad 
PERCEPCIONES DE LAS VÍCTIMAS DE MAMPUJÁN Y SAN CAYETANO Y SUS REPRESENTANTES JUDICIALES FRENTE A LA REPARACIÓN INTEGRAL EN LA LEY DE JUSTICIA Y PAZ

en las personas seleccionadas fue que proporcionaran un sentido de comprensión profunda del ambiente y de los interrogantes, estas selecciones de participantes, no son utilizadas para representar a una población, el objetivo primordial es la riqueza, profundidad y la calidad de la información, no la cantidad ni la estandarización.

Fue seleccionado entonces, un número reducido de participantes o líderes de víctimas y representantes judiciales, debido a que fueron los casos que los investigadores pudieron manejar de manera realista, de acuerdo con los recursos disponibles y de disponibilidad de tiempo de las partes, tanto de los participantes como de los investigadores.

Se pensó, para dar un ejemplo, en convocar más representantes judiciales de víctimas, pero los invitados no contaban con el tiempo suficiente para participar en la investigación; de la comunidad de San Cayetano se pensó convocar otro líder, pero la persona entrevistada es la única en esa población con la calidad de líder que acompañó a las víctimas en el incidente de reparación integral. Además, porque las personas seleccionadas, son aquellas que tenían información vasta y suficiente para responder las preguntas de investigación.

A partir de la consulta que se realizó, Hernández et al. (2010), lo importante era obtener datos (que se convirtieron en información) de personas (participantes) sobre percepciones en profundidad, en las propias ñformas de expresiónò de cada una de ellas. Estas personas participaron de forma voluntaria en la investigación, y algunos de ellos lo hicieron de forma autoseleccionada, ya que algunas de las personas se propusieron como participantes en el estudio sin necesidad de recibir la invitación.

Los participantes seleccionados fueron:

- Cuatro líderes de las comunidades de Mampuján y San Cayetano, quienes acompañaron a las víctimas durante todo el proceso y también son víctimas. 
PERCEPCIONES DE LAS VÍCTIMAS DE MAMPUJÁN Y SAN CAYETANO Y SUS REPRESENTANTES JUDICIALES FRENTE A LA REPARACIÓN INTEGRAL EN LA LEY DE JUSTICIA Y PAZ

Específicamente, fueron seleccionados tres líderes de Mampuján y una persona líder de San Cayetano.

- Dos abogados que laboran en la Defensoría del Pueblo y que participaron en el incidente de reparación, en calidad de representantes judiciales de las víctimas tanto de Mampuján como de San Cayetano y, para ello, se tuvo en cuenta que en el proceso, hubieran apelado la sentencia en primera instancia y hayan culminado con su participación en la sentencia de segunda instancia.

- Diecinueve personas que fueron reconocidas como víctimas en el incidente de reparación de segunda instancia de Mampuján y San Cayetano, que fueron representadas judicialmente por abogados (representantes judiciales) de la Defensoría del Pueblo, y que se encontraban viviendo en las zonas de Mampuján y San Cayetano al momento de la aplicación de las técnicas de recolección de información. Es decir, nueve víctimas de Mampuján (víctimas de Desplazamiento Forzado Urbano ï siete- y Rural Ï dos-) y diez de San Cayetano (también, víctimas de Desplazamiento Forzado).

Hombres y mujeres mayores de edad al momento de recoger la información para la investigación.

Cabe precisar que, para la participación de las personas descritas anteriormente, como se dijo, se realizó de manera voluntaria, pero bajo consentimiento informado (ver Apéndice A. Modelo consentimiento informado participantes), teniendo en cuenta lo establecido en la Ley 1090 de 2006 que reglamenta la práctica profesional del Psicólogo en Colombia y dicta el Código Deontológico y Bioético y otras disposiciones, y lo señalado en la Resolución No 008430 de 1993, por la cual se establecen las normas científicas, técnicas y administrativas para la investigación en salud. No obstante, antes de firmar el consentimiento informado, los 
PERCEPCIONES DE LAS VÍCTIMAS DE MAMPUJÁN Y SAN CAYETANO Y SUS REPRESENTANTES JUDICIALES FRENTE A LA REPARACIÓN INTEGRAL EN LA LEY DE JUSTICIA Y PAZ

participantes pudieron observar la certificación que acreditaba a los investigadores como estudiantes de la Maestría en Psicología Jurídica de la Universidad Santo Tomas, Bogotá D.C. ï Colombia.

Los investigadores ante todo, como aspecto ético de investigaciones con seres humanos, respetaron a los participantes, propiciando que narraran sus experiencias, percepciones o puntos de vista sin enjuiciarlos o criticarlos. Utilizaron una postura reflexiva, sensible, abierta, pero procurando minimizar la influencia que sobre los participantes y el ambiente pudiera ejercer sus creencias, fundamentos, condiciones o experiencias de vida asociadas con el problema de estudio, como ejemplo, hay que señalar que los investigadores, al momento de la recolección de la información, trabajaban en la Defensoría del Pueblo, pero se les recordó a los participantes la necesidad de que fueran vistos como investigadores, que los visualizaran sin que la calidad de trabajadores de esa institución influenciara sus respuestas, hubo atenta nota y cuidado frente a posibles respuestas influenciadas, atreviéndonos a decir, que estas son ausentes por completo. En la recolección de la información, a través, de las técnicas y, en general, en todo el proceso de investigación, perdimos nuestra calidad de trabajadores o funcionarios de la Defensoría del Pueblo.

También, como principios éticos, los investigadores invitaron a buscar la resiliencia a los líderes y víctimas de Mampuján y San Cayetano que participaron en el proceso de recolección de información. La idea no era solo conseguir información en cuanto a las percepciones de las víctimas y líderes de Mampuján y San Cayetano, que permitieran el desarrollo de esta investigación y alcanzar los objetivos de la misma, sino dejar un aporte que contribuyera al mejoramiento de su calidad de vida, donde buscaran la capacidad de superar las condiciones 
PERCEPCIONES DE LAS VÍCTIMAS DE MAMPUJÁN Y SAN CAYETANO Y SUS REPRESENTANTES JUDICIALES FRENTE A LA REPARACIÓN INTEGRAL EN LA LEY DE JUSTICIA Y PAZ

adversas que los aquejan y embargan, lo cual, ha venido dándose gracias a la espiritualidad, ambas comunidades manifestaron poseer gran devoción y fe en la religión.

Por lo tanto, para la intervención de los participantes de la investigación, se tuvo en cuenta lo contemplado en la Resolución No 008430 de 1993 sobre investigaciones en seres humanos. Para ello, en esta investigación en la que el ser humano fue el sujeto de estudio a partir de sus percepciones, prevaleció el criterio de respeto a la dignidad de los participantes y la protección de sus derechos y su bienestar (Art. 5). A su vez, la investigación se ajustó a principios científicos y éticos propios de la psicología jurídica que la justifican (Art. 6 a.); en esta prevaleció la seguridad de los beneficiarios y se expresó claramente los riesgos (mínimos) de la investigación (Art. 6 d.); contó con el consentimiento informado y por escrito del sujeto (participantes) de la investigación (Art. 6 e.), entendiéndose por este el acuerdo por escrito, mediante el cual los participantes autorizaron su participación en la investigación, con pleno conocimiento de la naturaleza de los procedimientos, beneficios y riesgos a que se sometían, con la capacidad de libre elección y sin coacción alguna (Art. 14); se llevó a cabo tras obtener la autorización de la Universidad Santo Tomas quien asesoró y representó la investigación (Art. 6 g.); y se protegió la privacidad del individuo, sujeto de investigación, evitando colocar sus datos de identificación dentro del reporte investigativo porque así fue la voluntad de ellos (Art. 8).

\section{Técnicas de recolección de información}

Para esta investigación se utilizaron dos tipos de ñécnicas de recolección de informaciónò para acopiar información de percepción de los participantes y para responder las preguntas de investigación, o reconocer dificultades, limitaciones y logros de este incidente de reparación en cuanto a sí contribuyó a la reparación integral de las víctimas o, por el contrario, si se constituyó en un elemento de revictimización. 
PERCEPCIONES DE LAS VÍCTIMAS DE MAMPUJÁN Y SAN CAYETANO Y SUS REPRESENTANTES JUDICIALES FRENTE A LA REPARACIÓN INTEGRAL EN LA LEY DE JUSTICIA Y PAZ

Estas técnicas son: Entrevista Semiestructurada y Grupo Focal. Por una parte se realizaron entrevistas semiestructuradas de forma individual con los cuatro líderes de las víctimas de las comunidades de Mampuján (3) y San Cayetano (1) y, por otra, con los dos representantes judiciales de las víctimas de las dos comunidades, que laboran en la Defensoría del Pueblo y que participaron en el incidente de reparación integral ante el Tribunal Administrativo de Cundinamarca, que posteriormente interpusieron recursos de apelación al fallo de primera instancia y sustentaron ante la Corte Suprema de Justicia los argumentos para que se diera un fallo más favorable para las víctimas.

Las entrevistas semiestructuradas, se realizaron teniendo en cuenta que es una herramienta utilizada para la obtención de información, la cual puede ser aplicada de manera grupal o individual. Dispone de una guía que aborda los ejes temáticos que se deben tratar a lo largo de la entrevista; sin embargo, el orden en el que se desarrollan los distintos tópicos y la forma en que se realizan las preguntas se dejan a la libre decisión y valoración del entrevistador, de acuerdo a la dinámica que se genere en la relación con el entrevistado.

En el marco de esta investigación, se aplicaron las entrevistas semiestructuradas de forma individual, los investigadores plantearon la conversación a libre decisión, efectuando las preguntas que creyeron oportunas y haciéndolo en términos de conveniencia para recolectar la información suficiente, profunda y sin afectar a los entrevistados, por ejemplo, con revictimizaciones. Sí se realizó una guía de preguntas, pero con el fin de aclararlas o explicar el significado de cada una de las respuestas, se dio o se le pidió a los entrevistados aclaraciones cuando no se entendía algún punto y que profundizaran en algún extremo cuando se veía necesario, se establecieron estilos propios y personales de conversación en la entrevistas, los 
PERCEPCIONES DE LAS VÍCTIMAS DE MAMPUJÁN Y SAN CAYETANO Y SUS REPRESENTANTES JUDICIALES FRENTE A LA REPARACIÓN INTEGRAL EN LA LEY DE JUSTICIA Y PAZ

cuales estaban basados en las particularidades discursivas de conjugación de los entrevistados y entrevistadores.

Lo anterior, se refuerza con las aseveraciones de Hernández et al. (2010), cuando se considera que las entrevistas semiestructuradas se basan en una guía de asuntos o preguntas y el entrevistador tiene la libertad de introducir preguntas adicionales para precisar conceptos $\mathrm{u}$ obtener mayor información sobre los temas deseados (es decir, no todas las preguntas están predeterminadas). Las preguntas se hicieron de forma abierta y neutral, ya que con las entrevistas cualitativas se pretende obtener información sobre perspectivas, percepciones, experiencias y opiniones detalladas de los participantes en su propio lenguaje.

En cuanto a las diecinueve víctimas de las comunidades de Mampuján y San Cayetano, se utilizó la técnica de Grupo Focal, un Grupo Focal con las nueve víctimas de Mampuján y otro con las diez víctimas de San Cayetano, es decir, en total se desarrollaron dos grupos focales separados con el total de este tipo de participantes, de a uno por cada grupo (de Mampuján o San Cayetano) de víctimas.

Según Prieto y March (2002), el grupo focal es una técnica de investigación cualitativa, consiste en una entrevista grupal dirigida por un moderador a través de un guión de temas o de entrevista. Se busca la interacción entre los participantes como método para generar información. El Grupo Focal lo constituyen un número limitado de personas: entre 4 y 10 participantes, un moderador y, si es posible, un observador.

A través de este se consigue información en profundidad sobre lo que las personas opinan y hacen, explorando los porqués y los cómos de sus opiniones y acciones. No se obtienen cifras ni datos que nos permitan medir aspecto alguno. Se trabaja con la información que se expresa en los discursos y conversaciones de los grupos. 
PERCEPCIONES DE LAS VÍCTIMAS DE MAMPUJÁN Y SAN CAYETANO Y SUS REPRESENTANTES JUDICIALES FRENTE A LA REPARACIÓN INTEGRAL EN LA LEY DE JUSTICIA Y PAZ

La investigación basada en grupos focales ha sido tradicionalmente entendida como ñuna forma de recolectar datos cualitativos, la cual, esencialmente, implica involucrar a un pequeño conjunto de personas en una(s) discusión(es) de grupo informal(es), œ́nfocadaôhacia un tema o una serie de temas específicosò(Wilkinson, 2004).

Los investigadores en ciencias sociales en general, y los investigadores cualitativos en particular, frecuentemente confían en los grupos focales para recolectar datos de varios individuos de forma simultánea; asimismo, los grupos inquietan menos a los participantes, generando un ambiente que ayuda a que hablen de sus percepciones, ideas, opiniones y pensamientos (Krueger y Casey, 2000).

\section{Procedimiento}

Para adelantar la investigación se estableció un procedimiento definido en cuatro fases a saber:

\section{Fase I: Definición de los participantes.}

Consistió en la definición de las personas que participaron en la investigación. En esta fase del trabajo de investigación, los investigadores desarrollaron todos los elementos para garantizar que las personas definidas previamente para la recolección de la información pudieran estar informadas sobre el propósito de la misma y se obtuviera su aceptación para participar, ya sea como líder o representante judicial entrevistado o como participantes de los grupos focales. Como el trabajo de recolección de información estuvo orientado hacia las víctimas (incluyendo a sus líderes, quienes también son víctimas) y sus representantes judiciales, se optó por establecer de manera prioritaria y en primera instancia el contacto con los líderes de Mampuján y San Cayetano, los contactos se hicieron por vía telefónica y se les explicó el objeto de la investigación y la necesidad que tenía el equipo de investigación de obtener sus apoyos, en primer momento, 
PERCEPCIONES DE LAS VÍCTIMAS DE MAMPUJÁN Y SAN CAYETANO Y SUS REPRESENTANTES JUDICIALES FRENTE A LA REPARACIÓN INTEGRAL EN LA LEY DE JUSTICIA Y PAZ

para lograr que ellos concedieran las entrevistas, en una segunda etapa, lograr identificar algunas víctimas de Mampuján y San Cayetano para que participaran en los grupos focales.

Una vez obtenidos los correos electrónicos de los líderes, se les envió la información por escrito y se les sugirió las fechas en que posiblemente el equipo investigador estaría en la región. Así, fue que se definió el sábado 29 y el domingo 30 de septiembre de 2012 para adelantar las entrevistas semiestructuradas a los líderes y desarrollar los Grupos Focales en Mampuján y San Cayetano.

De igual forma, los representantes judiciales de las víctimas fueron convocados e informados de la investigación vía telefónica y personalmente. Se definió conjuntamente el día 22 de marzo de 2013 para realizar con ellos las Entrevistas Semiestructuradas en la ciudad de Bogotá D.C.

Pero antes de ser convocados los participantes, se definió que fueran seleccionados según lo expuesto en detalle en el apartado ñParticipantesò del título ñMétodoò de esta investigación. A grosso modo, sin importar cantidades o sus características etarias, étnicas, educativas, políticas, socioeconómicas, entre otras. El principal factor en las personas seleccionadas era que pudieran proporcionar un sentido de comprensión profunda del ambiente y de las preguntas de investigación.

Por ende, para dar respuesta a los objetivos e interrogantes de la investigación, se realizó una visita a las víctimas y sus líderes en Mampuján y San Cayetano, el requisito para su participación en la investigación era encontrase incluidos dentro del incidente de reparación de segunda instancia, así mismo se contactaron a dos representantes judiciales de las víctimas en Bogotá y el requisito para su participación era que hubiesen apelado el fallo del incidente de reparación 
PERCEPCIONES DE LAS VÍCTIMAS DE MAMPUJÁN Y SAN CAYETANO Y SUS REPRESENTANTES JUDICIALES FRENTE A LA REPARACIÓN INTEGRAL EN LA LEY DE JUSTICIA Y PAZ

integral proferido en primera instancia por el Tribunal Administrativo de Cundinamarca ante la Corte Suprema de Justicia.

\section{Fase II: Diseño del contenido de las técnicas de recolección de información.}

Durante esta fase se realizó la elaboración de las preguntas para las entrevistas semiestructuradas, tanto de los líderes de las víctimas como de los representantes judiciales, y la definición, en una primera instancia, de los ejes temáticos para el desarrollo de los grupos focales a víctimas, posteriormente se realizó la redacción de las preguntas definitivas que sirvieron de guía para el desarrollo de los grupos focales. Dichas preguntas fueron construidas con el apoyo y asesoría de la Directora de la Investigación, quien acompañó a los investigadores en la revisión de la redacción, pertinencia y construcción apropiada de las preguntas, de tal manera que sí dieran respuesta a los interrogantes de esta investigación (ver Apéndice B. Preguntas guías de las técnicas de recolección de información).

Aquí conviene detenerse un momento a fin de observar que a los líderes sólo se les aplicó la entrevista semiestructurada. A pesar de ser también víctimas, no fueron convocados para participar en el desarrollo de los grupos focales, debido a dos razones, la primera, porque ya habían brindado información suficiente a través de las entrevistas semiestructuradas y, segundo, porque se buscó evitar la influencia o incidencia que ellos pudieran tener como líderes en las respuestas de los asistentes de los grupos focales.

\section{Fase III: Aplicación de las técnicas de recolección de información.}

Tal como estuvo previsto y según lo acordado con los líderes de Mampuján y San Cayetano, el equipo de investigación (investigadores) se trasladó a la zona de Montes de María, llegando por Cartagena el 28 de septiembre de 2012, lo cual posibilitó que estuvieran en el asentamiento 
PERCEPCIONES DE LAS VÍCTIMAS DE MAMPUJÁN Y SAN CAYETANO Y SUS REPRESENTANTES JUDICIALES FRENTE A LA REPARACIÓN INTEGRAL EN LA LEY DE JUSTICIA Y PAZ

donde se encuentran las víctimas de Mampuján, en el Municipio de María la Baja denominado por ellos ñ́Mampujancitoò, desde las 9:00 a.m. del 29 de septiembre, y desde ese momento poder seguir el cronograma definido para la recolección de la información. A continuación se presenta una tabla con la información sobre las actividades realizadas por el equipo de investigación en el proceso de recolección de información con las víctimas de Mamujan y San Cayetano y sus líderes.

Tabla 2.

Actividades adelantadas durante la fase de recolección de información con los líderes y víctimas de Mampuján y San Cayetano.

\begin{tabular}{llll}
\hline \multicolumn{1}{c}{ Fecha } & Descripción de la actividad & Lugar \\
\hline 29 Sep. 2012 & Entrevista semiestructurada a líder & Mampujáncito ï María La Baja \\
& TR de Mampuján & \\
\hline 29 Sep. 2012 & Entrevista semiestructurada a líder & Mampujáncito ï María La Baja \\
& AV de Mampuján & \\
\hline 29 Sep. 2012 & Entrevista semiestructurada a líder & Mampujáncito ï María La Baja \\
& GP de Mampuján & \\
\hline 29 Sep. 2012 & Grupo Focal a víctimas de & Mampujáncito ï María La Baja \\
& Mampuján & \\
\hline 30 Sep. 2012 & Entrevista semiestructurada a líder & San Cayetano ï San Juan de \\
& LM de San Cayetano & Nepomuceno & \\
\hline 30 Sep. 2012 & Grupo Focal a víctimas de San & San Cayetano ï San Juan de \\
& Cayetano & Nepomuceno & \\
\hline
\end{tabular}


PERCEPCIONES DE LAS VÍCTIMAS DE MAMPUJÁN Y SAN CAYETANO Y SUS REPRESENTANTES JUDICIALES FRENTE A LA REPARACIÓN INTEGRAL EN LA LEY DE JUSTICIA Y PAZ

Avanzando en los temas, luego hubo un encuentro con los representantes judiciales de las víctimas de Mampuján y San Cayetano, con ellos se desarrolló las entrevistas semiestructuradas el 22 de marzo de 2013 en la ciudad de Bogotá D.C., ciudad de residencia de estos abogados, desde las 10:10 a.m. Llegado a este momento se pudo seguir un cronograma definido para la recolección de la información, el cual se presenta en la siguiente tabla con la información sobre las actividades realizadas con estas personas.

\section{Tabla 3.}

Actividades adelantadas durante la fase de recolección de información con los representantes judiciales de víctimas de Mampuján y San Cayetano.

\begin{tabular}{|c|c|c|}
\hline Fecha & Descripción de la actividad & Lugar \\
\hline \multirow[t]{4}{*}{22 Marzo 2013} & semiestructurada & Bogotá D.C. ï Oficina personal \\
\hline & representante judicial JS de las & del Representante Judicial. \\
\hline & víctimas de Mampuján y San & \\
\hline & Cayetano & \\
\hline \multirow[t]{4}{*}{22 Marzo 2013} & semiestructurada & Bogotá D.C. ï Cafetería Oma \\
\hline & representante judicial LV de las & \\
\hline & víctimas de Mampuján y San & \\
\hline & Cayetano & \\
\hline
\end{tabular}

Cabe precisar que, la aplicación de las Entrevistas Semiestructuradas, con los líderes de las víctimas como con los representantes judiciales, se llevó a cabo de forma individual, con una duración aproximada de una hora. La realización de cada Grupo Focal tuvo una duración aproximada de dos horas. Antes de la aplicación de cada una de estas técnicas, hubo presentación 
PERCEPCIONES DE LAS VÍCTIMAS DE MAMPUJÁN Y SAN CAYETANO Y SUS REPRESENTANTES JUDICIALES FRENTE A LA REPARACIÓN INTEGRAL EN LA LEY DE JUSTICIA Y PAZ

de los asistentes, saludo de bienvenida y agradecimientos por la participación, se le explicó a los participantes el fin de la investigación, objetivos y metodología de la aplicación de las técnicas, donde se les pedía, por ejemplo, la autorización para gravar la información aportada; además, se les preguntó si estaban interesados en participar en el proceso, al obtener una respuesta positiva, el paso a seguir fue el de firmar el consentimiento informado por cada uno de ellos.

Las técnicas de recolección de información fueron aplicadas de forma adecuada leyendo una a una las preguntas en la secuencia establecida en las guías de preguntas, tomando apunte y gravando las conversaciones, explicando las dudas pero en ningún caso sesgando o incitando las respuestas; además, hubo ampliación y solicitud de clarificación de las respuestas para enriquecer el contenido de la información. En ningún caso las guías de preguntas fueron auto diligenciadas por los participantes o dejado para ser completado por ellos, ya que se hubiera perdido el sentido de una Entrevista y de un Grupo Focal, donde requiere de entrevistadores o moderadores que estén atentos a las respuestas.

De otra parte, aunque los investigadores laboran en la Defensoría del Pueblo, fueron insistentes con los participantes, antes, durante y después del proceso de recolección de información, en el hecho que dentro de la investigación solo debían ser vistos y actuarían como estudiantes de la Maestría en Psicología Jurídica de la Universidad de Santo Tomas Bogotá D.C. Y por ende, perdían la calidad de trabajadores de esta entidad del Ministerio Público durante la investigación; lo anterior con el fin de ser objetivos con la información que se recogió y con la forma de realizar esta actividad, dónde los participantes no confundieran los roles de los investigadores.

También, los investigadores precisaron y aclararon a los participantes sus nombres y datos de identificación, los objetivos de la investigación, sus fines, la metodología a utilizar para 
PERCEPCIONES DE LAS VÍCTIMAS DE MAMPUJÁN Y SAN CAYETANO Y SUS REPRESENTANTES JUDICIALES FRENTE A LA REPARACIÓN INTEGRAL EN LA LEY DE JUSTICIA Y PAZ

recoger la información, sus procedencias; acciones necesarias para la transparencia del proceso. Y leyeron a su vez el consentimiento informado, el cual fue firmado por todos los participantes como señal de aprobación de participación dentro de la investigación.

Por lo tanto, los investigadores realizaron actividades o señalamientos de encuadre con los participantes antes de la aplicación de las técnicas de recolección de información. Se señaló a los participantes la importancia de una participación activa para responder las preguntas, apagar o poner los teléfonos tipo celular en modo silencio para no afectar la escucha de los demás asistentes durante las intervenciones; en tanto que a los grupos focales se les insistió en la necesidad de ser tolerantes con las diferentes opiniones de los participantes, levantar la mano como señal de solicitud para dar un aporte u opinión, la libertad de opinar en las respuestas que así lo desearan, entre otras.

Es necesario resaltar que, al final de cada técnica de recolección de información aplicada, se leyó a los participantes la información recogida por uno de los relatores, investigador que tomó apunte de las respuestas de los participantes, con el fin de tener aceptación por parte de ellos con la información acopiada; y finalmente, se dieron los agradecimientos pertinentes para los participantes por la colaboración en la investigación.

Con todo y lo anterior, se alcanzaron los objetivos propuestos obedeciendo a principios éticos profesionales desde la Psicología Jurídica, como se observará al final de este documento, donde al identificarse una población afectada y vulnerada psicológica y legalmente se recurrió a la asesoría psicojurídica de algunos temas, pudiendo ser un campo de acción de esta área de la psicología. Frente a ello, se realizaron precisiones a los participantes: líderes y víctimas de Mampuján y San Cayetano, frente a las diferencias normativas entre el proceso judicial (Ley 975 de 2005) y los administrativos (Decreto 1290 de 2008 y Ley 1448 de 2011); estas precisiones, en 
PERCEPCIONES DE LAS VÍCTIMAS DE MAMPUJÁN Y SAN CAYETANO Y SUS REPRESENTANTES JUDICIALES FRENTE A LA REPARACIÓN INTEGRAL EN LA LEY DE JUSTICIA Y PAZ

cuanto a beneficiarios, derechos y procedimientos, se hicieron solo al final de las entrevistas semiestructuradas y los grupos focales para no afectar las respuestas de los participantes, no afectar la percepción en ellos.

Lo anterior, con el fin último de invitar a las víctimas, incluidos los líderes, a rendir la declaración por la Ley 1448 de 2011, buscando la obtención de los beneficios que contempla esta normatividad: atención, asistencia y reparación integral, a través, de las cinco medidas de reparación integral que son: indemnización, satisfacción, rehabilitación, garantías de no repetición y restitución, aunque la indemnización ya se había cubierto con lo obtenido por la sentencia de segunda instancia del proceso de Justicia y Paz, y soliciten el acompañamiento, orientación y asesoría, frente a los procesos administrativos, de la Defensoría del Pueblo, por medio de la Defensoría Delegada de Orientación y Asesoría a Víctimas del Conflicto Armado Interno.

Como consecuencia de esto, los investigadores sugirieron a los participantes hacer buen uso de los medios de participación ciudadana, como el voto, pues una indebida administración municipal puede obedecer a la venta y regalo de votos.

Cabe invitar a la consulta de los fragmentos de textos de transcripciones ï tal cual como fueron grabadas, respetando su formulacion original - de las técnicas de recolección de información, Citas desde el Atlas. ti 6.2, basadas en precisiones o percepciones de los entrevistados durante la aplicación de estas técnicas. Estas citas serán encontradas de forma detallada en los resultados y discusión de este reporte de investigación.

\section{Fase IV: Transcripción y análisis de la información.}

Ahora bien, con la aplicación de las técnicas de recolección de información se pudo obtener datos que fueron transcritos en Word y analizados a través del Atlas. ti 6.2, software para el 
PERCEPCIONES DE LAS VÍCTIMAS DE MAMPUJÁN Y SAN CAYETANO Y SUS REPRESENTANTES JUDICIALES FRENTE A LA REPARACIÓN INTEGRAL EN LA LEY DE JUSTICIA Y PAZ

análisis cualitativo de datos, lo que generó insumos para la emisión de los resultados y las respectivas discusiones, conclusiones y recomendaciones de la investigación.

Por consiguiente, esta fase consiste en la transcripción de los archivos de audio y en el análisis de la información recogida, teniendo en cuenta las sugerencias de Hernández et al. (2010) para hacer el análisis detallado de los datos; transcripción que se llevó a cabo entre los días 24 y 30 de junio de 2013. Para esto, se contrató una mujer profesional, ñfilóloga Hispanistaò de la Universidad de Antioquia de la ciudad de Medellín Antioquia (Colombia), que conocía y tenía experiencia en las normas APA y la forma de transcribir audios a una hoja de Word, una persona que comprendió la necesidad de que esa transcripción trajera consigo el principio de confidencialidad, lo cual hizo, por ejemplo, sustituyendo en la transcripción el nombre verdadero de los participantes por seudónimos y comprometiéndose por escrito con la confidencialidad de la información, también, con este consentimiento informado, la digitadora se comprometió el 24 de junio verbalmente y por escrito a participar en la transcripción, lo cual en ningún momento la hace autora, coautora o integrante de la investigación; la confidencialidad de la información hace referencia a salvaguardar la identidad de los participantes y asegurando la no utilización indebida de la información, la cual, solo podría ser utilizada con autorización de los investigadores (ver Apéndice C. Modelo consentimiento informado digitadora). Además, esta persona utilizó un formato con márgenes amplias en la transcripción (por si los investigadores veían la necesidad de hacer anotaciones o comentarios), separó las intervenciones a espacio doble y señalando con precisión, por ejemplo, en las Entrevistas Semiestructuradas, las intervenciones del entrevistador y del entrevistado; en los Grupos Focales, las intervenciones del conductor (moderador) y de cada participante, señalando quién hacia cada intervención. 
PERCEPCIONES DE LAS VÍCTIMAS DE MAMPUJÁN Y SAN CAYETANO Y SUS REPRESENTANTES JUDICIALES FRENTE A LA REPARACIÓN INTEGRAL EN LA LEY DE JUSTICIA Y PAZ

Según lo escrito en Presentación - filología (s.f.), un profesional Filólogo Hispanista posee competencias para desempeñarse en el diseño, dirección y ejecución de procesos de investigación, y en actividades relacionadas con el lenguaje, la lengua, el idioma, la literatura y, en general, con la cultura. En el campo del lenguaje y la lengua puede desempeñar funciones como: investigador de fenómenos idiomáticos; analista y asesor lingüístico, redactor y corrector de textos en editoriales, medios de comunicación e instituciones culturales; analista y productor de discursos institucionales; lexicógrafo y terminólogo para la confección de diccionarios, glosarios y vocabularios especializados; asesor lingüístico de programas de procesamiento y análisis automatizado de textos; asesor lingüístico en el diseño de programas interactivos para medios electrónicos y de páginas web. En el campo literario puede tener desempeños como: investigador y ensayista literario; co-investigador en estudios de carácter histórico y cultural; animador y promotor de talleres; analista, crítico, asesor de traducción, reseñista, jurado y editor; escritor o asesor en la escritura de guiones; asesor de políticas de desarrollo de la literatura y de ediciones literarias o culturales.

Por tal razón, esta persona fue escogida para la transcripción de los audios, ya que, además, tiene competencias en el campo investigativo, literario, del lenguaje y la lengua, lo que hizo que viera la necesidad $і ̈$ acertadamente -, por ejemplo, de transcribir todas las palabras, sonidos y elementos paralingüísticos de los audios: muecas, interjecciones, tales como: ¡ehhhhh!, ¡ahhh no!, ¡ajaaa!, ¡pa@̂a!, etcétera, propios del gentilicio de la población de Mampuján y San Cayetano o de las intervenciones de los investigadores, ya que en cada país o región, hay expresiones propias de la cultura local. También, la digitadora indicó pausas o silencios, expresiones significativas, entre otras señales. 
PERCEPCIONES DE LAS VÍCTIMAS DE MAMPUJÁN Y SAN CAYETANO Y SUS REPRESENTANTES JUDICIALES FRENTE A LA REPARACIÓN INTEGRAL EN LA LEY DE JUSTICIA Y PAZ

Posteriormente, las transcripciones fueron releídas por los investigadores, junto con las anotaciones, con el fin de explorar el sentido general de los datos y poder recordar casos o vivencias que faltaron por incluirse para el análisis de la información. Luego, se decidió organizar los datos y sus relaciones o concurrencias por categorías de análisis, utilizando el Software de análisis de datos cualitativos: Atlas. ti $6.2 \mathbb{R}$, el cual es una marca registrada de ATLAS.ti Scientific Software Development GmbH, Berlin (2003-2010).

El autor de esta herramienta tiene en cuenta que el trabajo analítico de una investigación cualitativa, implica elementos tangibles: el material de investigación precisa trabajo a destajo, montaje, elaboración, planes complejos, y un manejo un tanto especial de la información. Una caja de herramientas como el Atlas. ti, bien surtida, por ejemplo, con transcripciones, audios, fotografías, etcétera, proporciona los instrumentos necesarios para analizar y evaluar en profundidad, buscar y consultar en sus datos, capturar, visualizar y compartir los resultados (Friese, S., 2010).

Según Muñoz (2005), Atlas. ti es una herramienta informática cuyo objetivo es facilitar el análisis cualitativo de, principalmente, grandes volúmenes de datos textuales, archivos de sonido, imagen o vídeo, entre otros archivos. Puesto que su foco de atención es el análisis cualitativo, no pretende automatizar el proceso de análisis, sino simplemente ayudar al intérprete humano agilizando considerablemente muchas de las actividades implicadas en el análisis cualitativo y la interpretación, como por ejemplo, la segmentación del texto (unidades de análisis o documentos primarios) en pasajes o citas, la codificación (categorías de análisis), o la escritura de comentarios y anotaciones; es decir, todas aquellas actividades que, de no disponer del programa, se podría realizar con ayuda de otras herramientas como papel, lápices de colores, tijeras, fichas, fotocopias, entre otros, las cuales podrían llevar a los investigadores a errores u omitir categorías 
PERCEPCIONES DE LAS VÍCTIMAS DE MAMPUJÁN Y SAN CAYETANO Y SUS REPRESENTANTES JUDICIALES FRENTE A LA REPARACIÓN INTEGRAL EN LA LEY DE JUSTICIA Y PAZ

de análisis valiosas para la investigación, ya que implicaría una tarea ardua de concentración, atención y organización que depende de las condiciones del documento de análisis, contexto y del sujeto.

Hacer el análisis de la información cualitativa recogida de las víctimas de Mampuján y San Cayetano (incluyendo sus líderes) y sus representantes judiciales, sin ayuda del Atlas. ti 6.2, habría generado dificultades, evidentemente, porque el volumen de la información era bastante, en este caso la dificultad para manejarla, organizarla y lo que más dispendioso parecía, relacionar las categorías de análisis o acceder a recuperar información. Gracias a este programa se pudo, entre otras cosas, integrar toda la información que se tenía, ya sean los datos, las transcripciones de los audios de las técnicas de recolección de información, las anotaciones o comentarios, facilitando su organización, su búsqueda y recuperación, y por ende, la generación de los resultados y discusiones de la investigación.

Entonces, con las transcripciones y análisis de la información con ayuda del Atlas. ti 6.2., permitiendo la organización de la información, se obtuvieron los resultados de la investigación, los cuales aplican hasta las fechas de aplicación de las técnicas de recolección de información, debido a que las percepciones de los participantes pueden variar con el tiempo y con los avances de las medidas de reparación integral que vayan recibiendo, es un proceso subjetivo. Por ende, los resultados y discusiones de esta investigación se basan solo en las percepciones de los participantes, el trabajo no busca contrastarlas con la realidad, por ejemplo, con el cumplimiento real de las medidas de reparación integral a través de consultas con la Unidad de Justicia y Paz de la Fiscalía General de la Nación u órganos de control, por ejemplo, del Ministerio Público u otros, lo cual podría implicar una nueva investigación. Para mayor comprensión, se invita al 
PERCEPCIONES DE LAS VÍCTIMAS DE MAMPUJÁN Y SAN CAYETANO Y SUS REPRESENTANTES JUDICIALES FRENTE A LA REPARACIÓN INTEGRAL EN LA LEY DE JUSTICIA Y PAZ

lector a buscar los conceptos y las definiciones del término Percepción que se utilizaron en la Revisión de la Literatura para sustentar este trabajo de investigación.

Dicho análisis de la información con Atlas. ti 6.2., se hizo con el proceso de codificación de las citas o creación de categorías (códigos), los cuales son los temas de discusión de la investigación; a partir de este software o herramienta de análisis de datos cualitativos, que, como ya se ha dicho, minimiza el margen de omisión de Categorías, debido a que facilita su identificación, organización, agrupación y extracción para los resultados de una forma más ágil y sin dejarlo a la organización basada solo en el ojo humano.

Como dato que confirma la existencia y aplicación de unas técnicas de recolección información con los participantes, transcribiendo sus opiniones o percepciones exactamente como fueran dichas, se incluyó este en este reporte de investigación las citas más relevantes de los participantes, las cuales son fragmentos de textos de las transcripciones de los audios de la aplicación de las técnicas de recolección de información o de apuntes en medio de estas actividades.

En estas citas se omite el nombre de los participantes por cuestiones de seguridad y porque así fue la voluntad de ellos, donde exponer sus identidades podría acarrear dificultades por un tema tan complejo como es el del Conflicto Armado Interno, con señalamientos directos a personas e instituciones; solo se resolvió dejar los nombres de los investigadores, los nombres de los participantes fueron reemplazados con seudónimos.

A su vez, se hace indispensable recordar que fue abundante la información recogida y transcripta, siendo manejada de forma controlada por el proceso de concurrencia de citas entre las categorías de análisis, reduciéndose la utilización de estas dentro del escrito. La concurrencia 
PERCEPCIONES DE LAS VÍCTIMAS DE MAMPUJÁN Y SAN CAYETANO Y SUS REPRESENTANTES JUDICIALES FRENTE A LA REPARACIÓN INTEGRAL EN LA LEY DE JUSTICIA Y PAZ

podría denominarse, a partir del Atlas. ti 6.2. y según los investigadores, como la conjugación y limitación o disminución de citas, basadas en la coincidencia de estas para explicar las categorías.

Lo anterior, surgió de las unidades de análisis o documentos primarios, es decir, las transcripciones en documentos tipo Word ${ }^{\circledR}$, que se rescataron de dos grupos focales, uno por cada grupo de víctimas de Mampuján y San Cayetano, y las seis entrevistas semiestructuradas aplicadas a dos representantes judiciales de las víctimas, tres líderes de víctimas de Mampuján y a la persona líder de San Cayetano.

Para ello, se escogieron unas citas o fragmentos de texto de las transcripciones, a las cuales se les definió de a una categoría (código), es decir, un significado. La creación de estos códigos terminó cuando se agotaron las posibilidades de significados de los fragmentos de texto de todas las transcripciones; algunas de estas requirieron creación de comentarios que aluden a diferentes anotaciones o interpretaciones de los investigadores que ayudaron a generar los resultados y las discusiones de la investigación. En consecuencia, una categoría hace relación a un tema de discusión en específico.

Para mayor comprensión de estos conceptos y del Software Atlas. ti 6.2, se invita al lector a consultar fuentes primarias para las ampliaciones conceptuales al respecto. También, se hace claridad sobre el Software que viene configurado, entre otras, con una característica definida así: por defecto, idioma inglés; donde al momento de plasmar los resultados en este reporte de investigación, se tomó la tarea de traducir las palabras o frases del programa a idioma español para una mayor comprensión del lector.

\section{Documentos primarios utilizados para el análisis.}

Nueve (9)

- P1: Transcripción entrevista semiestructurada a líder AV de Mampuján 
PERCEPCIONES DE LAS VÍCTIMAS DE MAMPUJÁN Y SAN CAYETANO Y SUS REPRESENTANTES JUDICIALES FRENTE A LA REPARACIÓN INTEGRAL EN LA LEY DE JUSTICIA Y PAZ

- P2: Transcripción entrevista semiestructurada a líder GP de Mampuján

- $\quad$ P3: Transcripción entrevista semiestructurada a líder TR de Mampuján

- P4: Transcripción entrevista semiestructurada a líder LM de San Cayetano

- P5: Transcripción entrevista semiestructurada a Representante Judicial JS delas víctimas de Mampuján y San Cayetano

- $\quad$ P6: Transcripción entrevista semiestructurada a Representante Judicial LV de las víctimas de Mampuján y San Cayetano

- $\quad$ P7: Transcripción grupo focal a víctimas de Mampuján

- $\quad$ P8: Transcripción prólogo del grupo focal a víctimas de San Cayetano (el audio de este grupo focal quedó dividido en dos, porque no se quería dejar información sin registrar, así fuera, por ejemplo, de las conversaciones llevadas a cabo antes de aplicar el grupo focal, porque entre estas existió información que aportó a los resultados y objetivos de la investigación).

- P9: Transcripción grupo focal a víctimas de San Cayetano

De los documentos primarios, por un proceso de desfragmentación de las transcripciones, se determinaron 19 códigos o categorías de análisis, los cuales fueron discutidos en esta investigación; a saber:

\section{Categorías o Códigos (Temas de análisis y discusión).}

1. Causas de la macrovictimización de Mampuján y San Cayetano y del Conflicto Armado Interno

2. Hechos victimizantes cometidos en la macrovictimización de Mampuján y San Cayetano

3. Daños generados por la macrovictimización de Mampuján y San Cayetano 
PERCEPCIONES DE LAS VÍCTIMAS DE MAMPUJÁN Y SAN CAYETANO Y SUS REPRESENTANTES JUDICIALES FRENTE A LA REPARACIÓN INTEGRAL EN LA LEY DE JUSTICIA Y PAZ

4. Revictimizaciones de las víctimas de Mampuján y San Cayetano

5. Procesos jurídicos desacertados en el marco de la Ley de Justicia y Paz adelantados con las víctimas de Mampuján y San Cayetano

6. Procesos jurídicos acertados en el marco de la Ley de Justicia y Paz adelantados con las víctimas de Mampuján y San Cayetano

7. Pretensiones de reparación integral de las víctimas de Mampuján y San Cayetano que faltaron por incluirse en el incidente de reparación dado en segunda instancia

8. Incumplimientos por parte de la institucionalidad de los Resuelve emitidos por la Corte Suprema de Justicia en el fallo de segunda instancia frente a la reparación integral de las víctimas de Mampuján y San Cayetano

9. Incumplimientos por parte de los postulados de los Resuelve emitidos por la Corte Suprema de Justicia en el fallo de segunda instancia frente a la reparación integral de las víctimas de Mampuján y San Cayetano

10. Insatisfacción de las pretensiones de las víctimas de Mampuján y San Cayetano con el resultado del incidente de reparación dado en la segunda instancia

11. Satisfacción de las pretensiones de las víctimas de Mampuján y San Cayetano con el resultado del incidente de reparación dado en segunda instancia

12. Sentimientos presentes o generados en las víctimas de Mampuján y San Cayetano

13. No contribución del incidente de reparación de Mampuján y San Cayetano a la reparación integral de las víctimas

14. Contribución del incidente de reparación de Mampuján y San Cayetano a la reparación integral de las víctimas 
PERCEPCIONES DE LAS VÍCTIMAS DE MAMPUJÁN Y SAN CAYETANO Y SUS REPRESENTANTES

JUDICIALES FRENTE A LA REPARACIÓN INTEGRAL EN LA LEY DE JUSTICIA Y PAZ

15. Contribución del primer incidente de reparación de Justicia y Paz para futuros procesos

16. Acciones para alcanzar la reparación integral de las víctimas de Mampuján y San Cayetano. Empoderamiento y Resiliencia de las víctimas

17. Agradecimientos para algunas instituciones por parte de algunos participantes

18. Enseñanzas del proceso de Justicia y Paz o del incidente de reparación integral de Mampuján y San Cayetano

19. Sugerencias de los participantes

Entonces, con la información anterior para sacar o definir los resultados y generar las discusiones de esta investigación, se recuperaron las citas o fragmentos de texto de las transcripciones de las técnicas de recolección de información que sirven como soporte de cada uno de los temas (Códigos) tratados. Por lo tanto, se expone a continuación las transcripciones o descripciones narrativas de los resultados (soportes de los códigos o categorías: citas), las cuales se discutieron, generándose conclusiones y recomendaciones en esta investigación. 
PERCEPCIONES DE LAS VÍCTIMAS DE MAMPUJÁN Y SAN CAYETANO Y SUS REPRESENTANTES JUDICIALES FRENTE A LA REPARACIÓN INTEGRAL EN LA LEY DE JUSTICIA Y PAZ

\section{Resultados y Discusión}

Informe basado en las consultas del Atlas. ti 6.2., realizadas del 01 al 19 de septiembre de 2013. Nueve (9) documentos primarios en la consulta.

\section{Tabla 4.}

Documentos Primarios y Categorías.

\section{Documentos Primarios \\ Categorías o Códigos}

- P1: Transcripción entrevista semiestructurada a líder AV de Mampuján

- P2: Transcripción entrevista semiestructurada a líder GP de Mampuján

- P3: Transcripción entrevista semiestructurada a líder TR de Mampuján

- P4: Transcripción entrevista semiestructurada a líder LM de San Cayetano

- P5: Transcripción entrevista semiestructurada a Representante Judicial JS delas víctimas de Mampuján y San Cayetano

- P6: Transcripción entrevista semiestructurada a Representante Judicial LV de las víctimas de Mampuján y San Cayetano

- P7: Transcripción grupo focal a víctimas de Mampuján

- P8: Transcripción prólogo del grupo focal a víctimas de San Cayetano (el audio de este grupo focal quedó dividido en dos, porque no se quería dejar información sin registrar, así fuera, por ejemplo, de las conversaciones llevadas a cabo antes de aplicar el grupo
1. Causas de la macrovictimización de Mampuján y San Cayetano y del Conflicto Armado Interno

2. Hechos victimizantes cometidos en la macrovictimización de Mampuján y San Cayetano

3. Daños generados por la macrovictimización de Mampuján y San Cayetano

4. Revictimizaciones de las víctimas de Mampuján y San Cayetano

5. Procesos jurídicos desacertados en el marco de la Ley de Justicia y Paz adelantados con las víctimas de Mampuján y San Cayetano

6. Procesos jurídicos acertados en el marco de la Ley de Justicia y Paz adelantados con las víctimas de Mampuján y San Cayetano

7. Pretensiones de reparación integral de las víctimas de Mampuján y San Cayetano que faltaron por incluirse en 
PERCEPCIONES DE LAS VÍCTIMAS DE MAMPUJÁN Y SAN CAYETANO Y SUS REPRESENTANTES

focal, porque entre estas existió información que aportó a los resultados y objetivos de la investigación).

- P9: Transcripción grupo focal a víctimas de San Cayetano el incidente de reparación dado en segunda instancia

8. Incumplimientos por parte de la institucionalidad de los Resuelve emitidos por la Corte Suprema de Justicia en el fallo de segunda instancia frente a la reparación integral de las víctimas de Mampuján y San Cayetano

9. Incumplimientos por parte de los postulados de los Resuelve emitidos por la Corte Suprema de Justicia en el fallo de segunda instancia frente a la reparación integral de las víctimas de Mampuján y San Cayetano

10. Insatisfacción de las pretensiones de las víctimas de Mampuján y San Cayetano con el resultado del incidente de reparación dado en la segunda instancia

11. Satisfacción de las pretensiones de las víctimas de Mampuján y San Cayetano con el resultado del incidente de reparación dado en segunda instancia

12. Sentimientos presentes o generados en las víctimas de Mampuján y San Cayetano

13. No contribución del incidente de reparación de Mampuján y San Cayetano a la reparación integral de las víctimas 
PERCEPCIONES DE LAS VÍCTIMAS DE MAMPUJÁN Y SAN CAYETANO Y SUS REPRESENTANTES JUDICIALES FRENTE A LA REPARACIÓN INTEGRAL EN LA LEY DE JUSTICIA Y PAZ

14. Contribución del incidente de
reparación de Mampuján y San
Cayetano a la reparación integral de las
víctimas
15. Contribución del primer incidente de
reparación de Justicia y Paz para futuros
procesos
16. Acciones para alcanzar la reparación
integral de las víctimas de Mampuján y
San Cayetano. Empoderamiento y
Resiliencia de las víctimas
17. Agradecimientos para algunas
instituciones por parte de algunos
participantes de
18. Enseñanzas del proceso de Justicia y
Paz o del incidente de reparación
integral de Mampuján y San Cayetano
19. Sugerencias de los participantes

\section{Causas de la macrovictimización de Mampuján y San Cayetano y del Conflicto Armado} Interno

El líder AV de las víctimas de Mampuján, percibió: ñé eso no fue solo un tema de, Juancho Dique y de Diego Vecino y de las para; el el, el ejército, la fuerza pública también participóé ò $(P 1: 01)^{3}$, como causa de la macrovictimización de esta comunidad y parte del Conflicto Armado Interno, es decir, a las afectaciones o vulneraciones por la participación, bien sea en omisión o acción, de las fuerzas de seguridad y defensa del Estado colombiano en hechos victimizantes o

\footnotetext{
${ }^{3}$ Cuando se encuentre, por ejemplo: (P1:01), significa: el (P1) primer Documento Primario y el segundo número (01) la primera cita del primer documento primario.
} 
PERCEPCIONES DE LAS VÍCTIMAS DE MAMPUJÁN Y SAN CAYETANO Y SUS REPRESENTANTES JUDICIALES FRENTE A LA REPARACIÓN INTEGRAL EN LA LEY DE JUSTICIA Y PAZ

macrovictimizaciones. Consideró que lo sucedido con la comunidad de Mampuján, en cuanto al desplazamiento forzado colectivo, los homicidios en San Cayetano, entre los otros delitos, no fue solo un tema de alias ñJuancho Diqueò, ñDiego Vecinoò o de los paramilitares (AUC); la Fuerza Pública (integrantes del Ejército Nacional de Colombia) también participó, permitiendo o colaborando con los hechos victimizantes; infiriendo, como una de las posibilidades, con el fin de recibir algún tipo de beneficio a cambio, manifestándose alianza entra la Fuerza Pública y el paramilitarismo.

Del mismo modo, considera que con el incidente de reparación integral de las víctimas de Mampuján y San Cayetano, en el marco de la Ley de Justicia y Paz:

é se descubrió la parapolítica, un montón de funcionarios y el Estado mismo podrido, gracias a eso, encontramos que Colombia no estaba tan sana, como se decía a nivel internacional y nacional, en cada medio, gracias a eso, creo que hoy entendemos que no éramos locos diciendo, que la sanidad en Colombia solo se basaba en intimidación y matar a otrosé (P1:02).

Es decir, gracias al incidente se descubrió gran parte de la parapolítica en Colombia, donde funcionarios del Estado o políticos estaban aliados con grupos armados al margen de la Ley denominados paramilitares, buscando el enriquecimiento económico a costa de generar victimizaciones o macrovictimizaciones con el argumento de estar combatiendo a la guerrilla, señalan los investigadores. Es por esto que con el incidente se visibilizó, a nivel nacional e internacional, la situación del país en relación al Conflicto Armado Interno, donde las voces estaban silenciadas por las intimidaciones o amenazas, también por los homicidios, entre otros hechos victimizantes. 
PERCEPCIONES DE LAS VÍCTIMAS DE MAMPUJÁN Y SAN CAYETANO Y SUS REPRESENTANTES JUDICIALES FRENTE A LA REPARACIÓN INTEGRAL EN LA LEY DE JUSTICIA Y PAZ

Al mismo tiempo y en el desarrollo de esta discusión, el representante judicial LV de las víctimas de Mampuján y San Cayetano en medio de la entrevista semiestructurada, consideró que por:

é la productividad que tiene la tierra en determinadas partes del país y que es inmensa, hay mucha compañía extranjera, y muchos colombianos a través de determinadas sociedades, muchas personas de renombre público, que son miembro de esas sociedades, y que les interesa más el enriquecimiento o el pequeño particular que el interés general de la comunidad, y por eso pudieron hacer masacres que se han producidoé (P6:01).

Dicho en otros términos, por la productividad que tiene la tierra en determinadas regiones del país, que podría usarse fácilmente para el cultivo ilícito o la minería, infieren los investigadores, se considera que algunas compañías extranjeras y particulares colombianos de renombre público, a través, de determinadas sociedades, buscan el enriquecimiento económico personal a costa de macrovictimizaciones como la de Mampuján y San Cayetano, imperando el interés del pequeño particular sobre el interés general.

En resumen, según las percepciones de los participantes mencionados anteriormente, entre las causas de la macrovictimización de Mampuján y San Cayetano y parte del Conflicto Armado Interno, están: las 1) afectaciones o vulneraciones por la participación, bien sea en omisión o acción, de las Fuerzas Públicas del Estado (Ejército Nacional) en hechos victimizantes o macrovictimizaciones; 2) alianza delictiva entre Políticos, funcionarios del Estado y Grupos Armados Ilegales, buscando el enriquecimiento económico; y el hecho de que 3) impere el interés del pequeño particular sobre el interés general, es decir, la búsqueda del enriquecimiento personal (compañías extranjeras y particulares colombianos de renombre público) a costa de 
PERCEPCIONES DE LAS VÍCTIMAS DE MAMPUJÁN Y SAN CAYETANO Y SUS REPRESENTANTES JUDICIALES FRENTE A LA REPARACIÓN INTEGRAL EN LA LEY DE JUSTICIA Y PAZ

victimizaciones o macrovictimizaciones, aprovechando la productividad de las tierras de algunas regiones del país.

\section{Hechos victimizantes cometidos en la macrovictimización de Mampuján y San Cayetano}

Primero, es de traer a colación lo expuesto en la sentencia de segunda instancia en su apartado ñPROVIDENCIA IMPUGNADAò respecto a que la Sala de Justicia y Paz del Tribunal Superior de Bogotá condenó a los postulados Edwar Cobos Téllez y Uber Enrique Banquez Martínez a 468 y 462 meses de prisión, respectivamente, como coautores de los delitos de homicidio agravado; deportación, expulsión, traslado o desplazamiento forzoso de la población civil; secuestro simple; hurto calificado y agravado; utilización ilegal de uniformes e insignias y fabricación, tráfico y porte de armas y municiones de uso privativo de las fuerzas armadas, en concurso homogéneo y sucesivo. A Edwar Cobos Téllez, adicionalmente se le condenó por el punible de concierto para delinquir agravado (Corte Suprema de Justicia Sala de Casación Penal, República de Colombia, 2011). Aunque luego, los postulados fueron acogidos por los beneficios de reducción de penas, no superando penas de 8 años de prisión, tal cual como lo contempla la Ley 975 de 2005, tras colaborar con el proceso judicial, la verdad para las víctimas y sus respectivas reparaciones, a sabiendas de que existen criticas frente a ello por parte de participantes de la investigación.

Sin embargo, las víctimas de Mampuján y/o San Cayetano padecieron los siguientes hechos victimizantes, según algunos participantes:

\section{Tabla 5.}

Hechos victimizantes.

Desplazamiento forzado, principalmente de tipo colectivo (siendo, por ejemplo, en las 
PERCEPCIONES DE LAS VÍCTIMAS DE MAMPUJÁN Y SAN CAYETANO Y SUS REPRESENTANTES JUDICIALES FRENTE A LA REPARACIÓN INTEGRAL EN LA LEY DE JUSTICIA Y PAZ

propias palabras de la líder LM de San Cayetano ñEl efecto victimizante que me afectó más, fueé bueno en primera instancia fue el desplazamiento, é ò $(P 4: 01))$. Homicidios

Torturas

Al compararse la información aportada por participantes frente a los hechos victimizantes con lo plasmado en la sentencia de segunda instancia en su apartado ñ̃ROVIDENCIA IMPUGNADAò, se pudo notar que hizo falta un hecho importantísimo, nombrado por el representante judicial LV de las víctimas de Mampuján y San Cayetano, por incluirse en la sentencia en el apartado mencionado: Tortura en Persona Protegida; lo cual se asevera cuando precisó como hechos victimizantes de las víctimas: ñHomicidio, tortura y desplazamiento forzadoò (P6:02). Este delito no está incluido en la sentencia en el señalado, desconociendo las razones, y por ende, pudiera estar ocasionando insatisfacción en las victimas, dato que infortunadamente no se alcanzó a confirmar dentro de la investigación, debido a la abundancia de información que se tuvo que manejar. Es en Persona Protegida porque toda aquella victima inmersa en el desarrollo del Conflicto Armado está protegida por normas Nacionales e Internacionales de Derechos Humanos y del Derecho Internacional Humanitario como se expuso en la Revisión de la Literatura.

Daños generados en las víctimas por la macrovictimización de Mampuján y San Cayetano o por el incidente de reparación integral

Por otro lado, a partir de las descripciones de algunos participantes, entre los daños generados por los hechos victimizantes en las víctimas de Mampuján y/o San Cayetano o por el 
PERCEPCIONES DE LAS VÍCTIMAS DE MAMPUJÁN Y SAN CAYETANO Y SUS REPRESENTANTES JUDICIALES FRENTE A LA REPARACIÓN INTEGRAL EN LA LEY DE JUSTICIA Y PAZ

incidente de reparación integral, y que serán expuestos con ejemplificaciones, recordando que sus definiciones están en el apartado de la Revisión de la Literatura, se encontraron los siguientes: Lucro Cesante, Daño Emergente, Daño Moral, Pérdida de Chances, Daño Colectivo (por las afectaciones al bien común o a las costumbres de ambas comunidades por los hechos victimizantes) y Daño Psicologico (considerado, por el Representante Judicial JS, como el daño que más se presentó en las comunidades afectadas por dichos hechos, y que además, está relacionado con el Daño a la vida de relacion). Para confirmar esto, ver algunas de las percepciones de participantes:

- $\quad$ Líder GP de Mampuján: ñEhh, la Corte reconoce el daño emergente y el lucro cesante, cosa que en primera instancia se había fallado por igualdadé ò $(P 2: 01)$.

- $\quad$ Representante Judicial JS de las víctimas de Mampuján y San Cayetano: a) ñé unos daños materiales, unos daños inmateriales, un daño moral, un daño a la vida de relacióné ò (P5:01). b) ñé los hechos, y a los daños que sufrieron las víctimas que en este daño la mayoría eran daños de tipo psicológicoò (P5:02).

- Señora 1 del grupo focal aplicado a las víctimas de San Cayetano: ñé por ejemplo en mi caso todos mis hijos quedaron brutos, porque ya yo no, desde que salieron de allá del pues de la vereda cuando estaban en el colegio, acá ya fue diferente, entonces ellos ya ya no estudiaroné ò (P9:01). Relacionado con el daño de Pérdida de Chances.

- Grupo focal de las víctimas de Mampuján: ñé pero que lo más difícil de reconstruir de pronto, no son ni las escuelas, ni los hospitales, pese a que 
PERCEPCIONES DE LAS VÍCTIMAS DE MAMPUJÁN Y SAN CAYETANO Y SUS REPRESENTANTES JUDICIALES FRENTE A LA REPARACIÓN INTEGRAL EN LA LEY DE JUSTICIA Y PAZ

son parte fundamental para nosotros, pero la pregunta que, que yo me hago personalmente es, donde queda el tejido social (Daño Colectivo). Y todos esos daños ehh, espirituales que la violencia causó en nuestras vidas (Daño Moral)ò (P7:01).

Sin embargo, para afirmar estos daños, deben ser confirmados por peritos en cada una de las áreas, solo se hizo un intento de clasificación para orientar al lector; no obstante, conociendo los posibles daños y teniendo como referente lo sucedido con la sentencia de primera instancia frente a la reparación en equidad, lo que debería ser claro es que un proceso judicial, en este caso en específico en Colombia como los de Justicia y Paz, debería implicar la valoración de los daños, para generarse la respectiva reparación integral, buscando la equidad para las personas, no dentro de sus reparaciones, porque deberían ser en Derecho, sino desde el goce efectivo de derechos para todos.

De todas maneras, no se puede desconocer que la actitud ambivalente, inconsistente y confusa del Estado, por medio de sus sucesivos gobiernos e instituciones permanentes, le fue funcional al proyecto paramilitar en sus diferentes facetas y modalidades, estableciendo un nivel de responsabilidad estatal que se debe analizar y asumir, por encima de los casos concretos de acción u omisión de algunos funcionarios (Pena, 2005). Cabe recordar que los daños que sufren las personas como consecuencia del conflicto armado interno son imputables al Estado, cuando se demuestra que se causan por una falla del servicio de la administración o por el riesgo creado por este. Como se ha dicho, en el caso de Mampuján y San Cayetano, algunos participantes de la investigación manifestaron la contribución de la Fuerza Pública (Ejército Nacional), por acción u omisión, en la macrovictimización de Mampuján y San Cayetano, lo que debería generar investigaciones judiciales efectivas y respectivas sanciones. 
PERCEPCIONES DE LAS VÍCTIMAS DE MAMPUJÁN Y SAN CAYETANO Y SUS REPRESENTANTES JUDICIALES FRENTE A LA REPARACIÓN INTEGRAL EN LA LEY DE JUSTICIA Y PAZ

Entonces, como ejemplos relevantes, existen o existieron daños con considerables consecuencias en las vidas de las víctimas de Mampuján y San Cayetano por la macrovictimización que padecieron o por el incidente de reparación integral. Estos son: 
PERCEPCIONES DE LAS VÍCTIMAS DE MAMPUJÁN Y SAN CAYETANO Y SUS REPRESENTANTES JUDICIALES FRENTE A LA REPARACIÓN INTEGRAL EN LA LEY DE JUSTICIA Y PAZ

\title{
Tabla 6.
}

Ejemplos relevantes de los Daños causados a las víctimas de Mampuján y San Cayetano.

\section{Daños (ejemplos relevantes)}

\section{Citas relacionadas o percepciones de los participantes}

\author{
Interrupción de la relación que tenían las víctimas de ñé se interrumpe, la relación, con, con la tierra,é se crea \\ Mampuján y San Cayetano con la tierra, donde un gran un malestar ehh, económico, sobretodo porque tu forma de \\ número se dedicaba a la agricultura, se afectó la forma de producción está allá y te vienes pa'ca,é (P1:03). \\ producción económica de estas comunidades. Cuando se \\ desplazaron forzadamente llegaron a lugares que les \\ impedía desarrollar sus actividades laborales habituales \\ (Relacionado con los Daños: Lucro cesante y/o Pérdidas de \\ Chances). \\ Pérdida de documentos de las propiedades, entre otros, de los ñé digamos que se debió tener más en cuenta esta \\ líderes o víctimas de Mampuján y San Cayetano, a causa del situación de las víctimas, algunos les tocó salir corriendo \\ desplazamiento forzado, donde por el temor de ser asesinados por sus vidas, perdieron documentos, si de pronto tenían \\ salieron huyendo de sus hogares, abandonándolos (Daño documentos de vacunación, de los animales, no pudieron \\ Emergente y/o Lucro Cesante). demostrarlo porque, porque eso ser perdió, é ò (P2:02).
}


PERCEPCIONES DE LAS VÍCTIMAS DE MAMPUJÁN Y SAN CAYETANO Y SUS REPRESENTANTES JUDICIALES FRENTE A LA REPARACIÓN INTEGRAL EN LA LEY DE JUSTICIA Y PAZ

Hacinamientos familiares de las víctimas de Mampuján y ñK: é ya no corríamos en el patio ya no andábamos a pies

San Cayetano, muchos no cuentan con viviendas dignas y descalzos porque el contexto no nos lo permitía porque amplias para albergar a sus integrantes (Daño Emergente). vivíamos en un hacinamiento porque en un cuarto vivían hasta 6 personas, 5 familias, entonces... ò (P7:02).

Víctimas de Mampuján y San Cayetano se encuentran pagando ñSEÑOR: Tanta pérdida, porque ajá, yo dure 9 años arriendos por la pérdida de sus viviendas con el desplazamiento pagando arriendo, $\quad$ y sé yo no voy a ser digamos forzado $\mathrm{y}$, en ocasiones, deben vender propiedades, como beneficiado en ese gasto que tuve, y vendí un animal para animales, para cubrir esos gastos (Daño: Lucro Cesante). pagar un arriendo en una casa ajena, y por eso se pone uno malò (P7:03).

Pérdida o deterioro de bienes muebles e inmuebles, ñ BYRON: Qué tipo de pérdidas. J: Pérdidas materiales, especialmente con el desplazamiento forzado (Daños: como de mis animales, mi casa, tenía dos ***é ò (P7:04). Lucro Cesante, Pérdida de Chances, Daño Emergente y/o ñé por ejemplo en el caso de los desplazamiento y de las Daño Colectivo) casas que fueron abandonadas, de las casas que se destruyeron, de los cultivos que se perdieron, é ò (P5:03). ñé.hacerse por ejemplo la reparación de vías, ehh escuelas, ehh etcétera, etcétera, é ò (P5:04). ñé una 
reparación de vías, reconstrucción de escuelas, de hospitales, de puestos de salud,é ò (P5:05).

Interrupciones de los procesos de educación de algunas víctimas, ñSEÑORAl: $\quad$ No, pero yo digo que por ejemplo especialmente de los hijos víctimas menores de edad. Los bajos perjudicaron en los hijos de uno ya, por ejemplo en mi caso recursos económicos generados por el desplazamiento forzado y todos mis hijos quedaron brutos, porque ya yo no, desde la baja cantidad de reparacion económica recibida, percibida de que salieron de allá del pues de la vereda cuando estaban esta manera por participantes del grupo focal de San Cayetano, en el colegio, acá ya fue diferente, entonces ellos ya ya no no permitió que los padres continuaran con los procesos estudiaroné LUIS: No volvieron a estudiaré SEÑORA1: educativos de sus hijos (Daño: Pérdida de Chances). uhm uhm Mis hijos quedaron todos, toditos quedaron, quedaron brutos mis hijos, no más 2 no mas que me han terminado el bachillerato aquí en el pueblo, por eso, yo digo que en ese caso si, bastante y la cómo la reparación mía fue muy bajita ya, pa ese campo que cuándo me va a alcanzar eso pa darles estudios a ellos, esos \$13.000.000é ò. (P9:02).

Desubicación y reajuste de las víctimas en relación al ñé ENTREVISTADO: Bueno, en estos casos de



REPARACIÓN INTEGRAL EN LA LEY DE JUSTICIA Y PAZ

desplazamiento forzado, sobretodo porque llegan a un desplazamiento masivo, se pierde lo del tejido social, eh se contexto que no es el propio, el cual implica nuevas pierde, se tiende a maltratar o a perder la cultura innata costumbres, culturas, relaciones interpersonales, formas que tenía un pueblo, eh, entonces en ese aspecto pienso que de trabajo, entre otras (Daño Psicológico y/o Daño a la deben haber unas medidas aún más profundas para vida de relación y/o Daño Colectivo). Hubo afectación y recuperar ese tejido, pienso de que deben haber unas consecuencias en los hábitos y costumbres de estas medidas de protección haciaé o o, unas medidas de personas, se afectó lo cultural, se maltrató y se tiende a recuperación de esa cultura, de esa forma de ser del ser perder la cultura innata, el tejido social de un pueblo humano en esas, en esas eh comunidades, hay que recordar (según líder de Mampuján); por ejemplo, las costumbres o que nosotros éramos unas personas, ehh con unas tradiciones alimenticias han venido cambiando, al igual costumbres muy particulares. ENTREVISTADOR: Cuáles. que el hábito de decirle ñtíoò a todo a quien que se ENTREVISTADO: Ehhh.. con esa forma de alimentarnos consideraba mayor, mayor que el emisor del mensaje, diferente, con esa forma de saludar a nuestros vecinos posiblemente personas de tercera edad. La invitación o diferente, con esa forma de llegar todas las mañanas donde sugerencia de parte de algunos participantes es que debió una cantidad de gente y tomarnos un tinto, con eso de, eh haber unas medidas aún más profundas, para recuperar ese decirle ñtíoò a todo a quien considero mayor de edad, y tejido social de las víctimas de Mampuján y San eso de decir tío a una persona que no es ni siquiera mi 

REPARACIÓN INTEGRAL EN LA LEY DE JUSTICIA Y PAZ

Cayetano, dentro del incidente de reparación dado en primo, ni mi tío, ni mi familia, eso es, eso es un valor primera y segunda instancia.

agregado a la vida, porque eso es un aspecto que refleja respeto, que refleja sencillez, que refleja humildad; entonces, todas esas costumbres que no las he mencionado todas, porque ya ustedes se imaginarán para dónde quiero ir, ehh, se pierden, y se pierdené ò (P3:01).

Temor en las víctimas al referirse a los seudónimos de ñENTREVISTADOR: De Participar en ese proceso. alias ñJuancho Diqueò y ñDiego Vecinoò, en general, al ENTREVISTADO: Con los, con personas que sólo referirse a los grupos armados ilegales. Debido a que conocíamos de nombre, y que, ese nombre indicada mucho algunos participantes de la investigación perciben que los daño, é ò (P1:04). ñENTREVISTADO: é cuando vamos a la postulados, aún siguen o pueden seguir delinquiendo, audiencia de reparación había temor; de hecho es la tienen aliados que les rinden fidelidad y obediencia, aun primera vez que nos vamos a sentar, frente a frente con si están en las cárceles (Daño Psicológico).

alguien, a quien nosotros sabemos que pese a estar en Bogotá y preso tiene injerencia sobre el territorio, tiene soldados, tiene gente que le son fieles y él lo demuestra así después, entonces digamos que si el tigre nos manda a 

REPARACIÓN INTEGRAL EN LA LEY DE JUSTICIA Y PAZ

matar para él es fácilé ò (P1:05).

Temor de volver al campo, de retornar (Daño Psicológico). ñé nuestro temor de volver al campoé ò (P1:06).

Miedo en algunas víctimas de Mampuján y San Cayetano frente ñé muchas veces cuando estamos en lugares como que no a lugares desconocidos y cuando escuchan sonidos fuertes, creen conocemos mucho sentimos miedo, si vivimos con miedo que sucederá algo ñmaloò como lo sucedido en las constante, si sentimos que cualquier sonido fuerte, creemos macrovictimizaciones de Mampuján y San Cayetano. Lo cual que es algo malo, cuando hay personas que quedaron puede estar relacionado con síndrome de estrés postraumático sufriendo de nervios, de cosas así que de pronto no se (Daño Psicológico). sufría antesé ò (P7:05).

Temor en algunas víctimas de Mampuján y San Cayetano de que ñé de pronto, se dice que, eso ya no va a volver a ocurrir, vuelvan a ser víctimas del conflicto armado interno (Daño pero ajá caramba no estamos como seguros, no estamos Psicológico y/o Daño Colectivo). como seguros sentimos algo, sentimos miedo, oyó, y ojale no se vuelva a repetir, oyó, contamos con las leyes, con las promesas o todo lo que se ha firmado, se puede decir que a favor de nosotrosé ò (P7:06).

Pérdida de seres queridos por los homicidios (Daño Psicológico ñé por ejemplo para dar todo, la la, el respaldo a la y/o Daño Moral). familia, a los dolientes de la persona muerta,é ò (P7:07). 
PERCEPCIONES DE LAS VÍCTIMAS DE MAMPUJÁN Y SAN CAYETANO Y SUS REPRESENTANTES JUDICIALES FRENTE A LA REPARACIÓN INTEGRAL EN LA LEY DE JUSTICIA Y PAZ

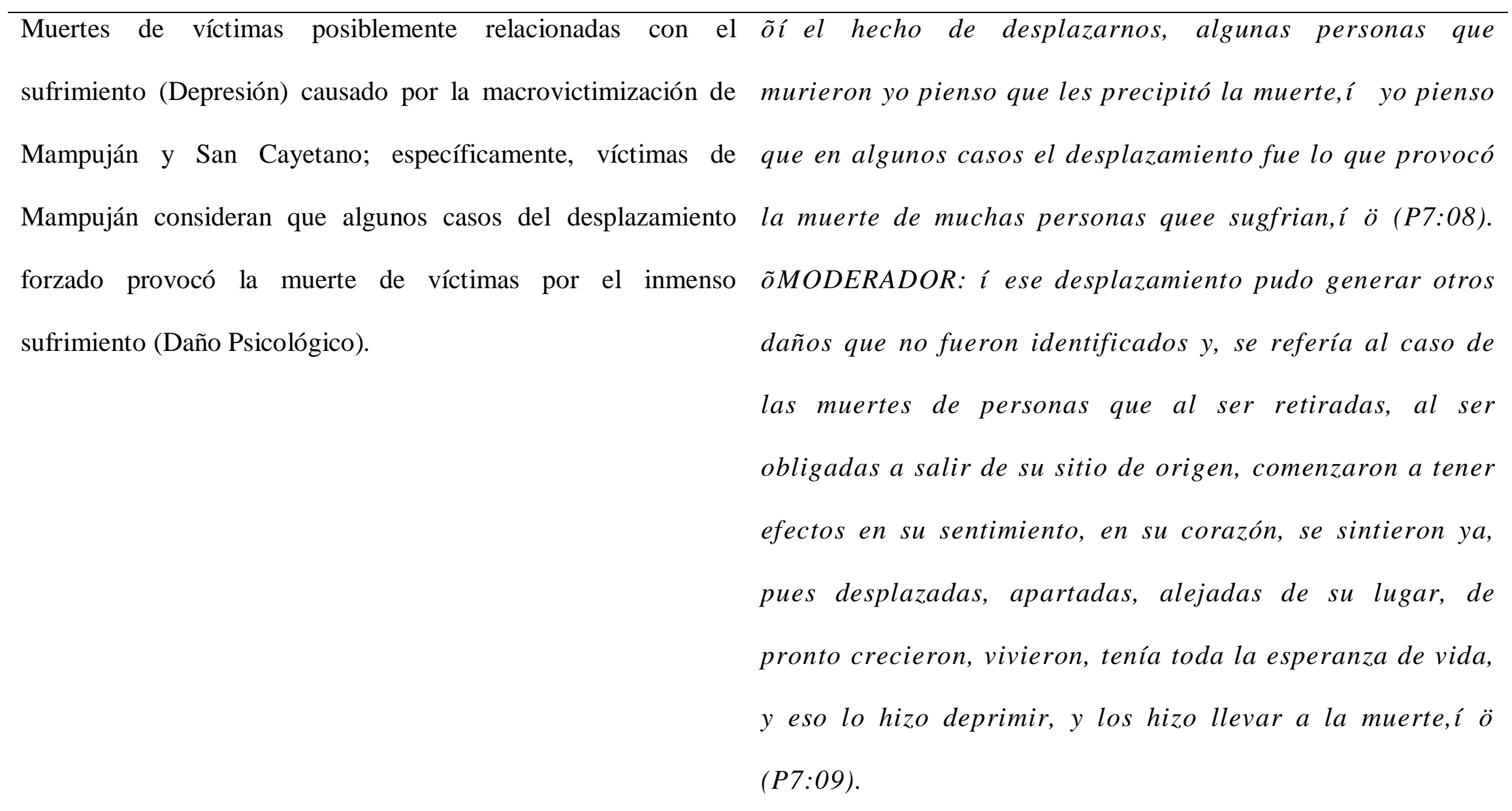

Afectaciones de los procesos de niñez y adolescencia que ñK: é es difícil uno llegar a un contexto que no conoce y
adelantaban víctimas menores de edad de Mampuján y empezar a construir nuevas relaciones, de pronto en medio
San Cayetano antes, por ejemplo, del desplazamiento del estigma de ser desplazados, en medio de la


PERCEPCIONES DE LAS VÍCTIMAS DE MAMPUJÁN Y SAN CAYETANO Y SUS REPRESENTANTES JUDICIALES FRENTE A LA REPARACIÓN INTEGRAL EN LA LEY DE JUSTICIA Y PAZ

forzado (Daño Psicológico y/o Daño a la vida de relación).

discriminación, crear amigos es bastante complejo. $Y$, y de pronto acostumbrarte a que tus amigos no están, o si están están demasiados lejos donde no pueden hablar no pueden jugar. Yo salí a la edad de los 7 años, hoy tengo 19, he vivido la mayoría del tiempo acá, pero lo que en realidad a mi me hizo feliz, lo que hizo de mi una niña feliz lo vivi allá, lo que vivo acá es intentando reconstruir mi vida alrdedor que el contexto permita es como que todoò. (P7:10). ก̃SEÑORA1: Eso también afectó bastante eso la salida de allá, había mucho niños que se corrompieron,é ò (P9:03).

Con la macrovictimización de Mampuján y San Cayetano, ñé con el desplazamiento forzado, que hubo, ehh muchas específicamente con el desplazamiento forzado, varios muchas personas sufrieron ehh este tipo de daño, muchas integrantes de las comunidades empezaron a presentar familias se acabaron, hubo, se presentaron una cantidad de problemas relacionados con drogadicción o consumo de problemas de tipo social y encontramos que hubo sustancias psicoactivas, alcoholismo, separación de drogadicción, hubo matrimonios que se acabaron, hubo 
PERCEPCIONES DE LAS VÍCTIMAS DE MAMPUJÁN Y SAN CAYETANO Y SUS REPRESENTANTES JUDICIALES FRENTE A LA REPARACIÓN INTEGRAL EN LA LEY DE JUSTICIA Y PAZ

cónyuges o compañeros permanentes, y prostitución. La prostitución, hubo alcoholismo, entonces todo ese tipo de mayoría de los daños ocasionados a las poblaciones de daños nosotros buscar la forma de que fueran Mampuján y San Cayetano son de tipo psicológico (Daño reparadosé ò (P5:06).

Psicológico y/o Daño a la vida de relación).

Temor en las víctimas de participar, en un principio, en el ñENTREVISTADO: é empezamos en el incidente eehhh.... proceso de Justicia y Paz, en el incidente de reparación es decir que versiones libres y esas cosas no asistimos, integral (Daño Psicológico y/o Daño Moral). porque era complicadoé, sobretodo el temor que había en la gente. ENTREVISTADOR: De Participar en ese proceso. ENTREVISTADO: Con los, con personas que sólo conocíamos de nombre, y que, ese nombre indicada mucho daño,é ò (P1:07).

Efectos emocionales en los representantes judiciales que ñé Uno no puede desligarse, del sufrimiento de estas personas representaron a las víctimas de Mampuján y San Cayetano. El porque de verdad si le llega, a uno lo tocaé ò (P5:07). representante judicial JS de las víctimas de Mampuján y San Cayetano manifestó de alguna manera que el sufrimiento de estas personas los afecta emocionalmente, sufrimiento que también es 

REPARACIÓN INTEGRAL EN LA LEY DE JUSTICIA Y PAZ

generado por grupos guerrilleros, no solo por parte de los grupos

que fueron comandados por alias ñJuancho Diqueò y ñDiego

Vecinoò (Daño Psicológico y/o Daño Moral).

Desesperación e insatisfacción de las víctimas de Mampuján y ñé ya que Mampuján, ha sido un pueblo que hemos, en San Cayetano, generadas en un principio por la algún momento hemos de pronto desesperado, pero hemos macrovictimización de las comunidades pero incrementadas por sido pacientes, bastante, ehhh hay, hay momentos, hubieron la lentitud de los procesos adelantados de Justicia y Paz, por el momentos en los cuales quisimos tirar la toalla, oo, o incumplimiento de los exhortos del incidente de reparación hacer cosas por la vía violenta, pero, una de las cosas que integral dado en segunda instancia, en momentos, por ejemplo, caracterizó a Mampuján, y lo ha caracterizado es la víctimas de Mampuján han querido tirar la toalla o hacer cosas manera pacífica como ha hecho las cosas, é ò (P7:11).

por la vía violenta pero han sabido ser pacientes (Daño

Psicológico y/o Daño Moral).

La idea de parte del líder AV de Mampuján, y que comparten ñé desde la enfermedad que nos crearon esto, hasta el día otros participantes, de que ñé nada los ayudará a ser o vivir de hoy; porque nada nos ayudara a ser mejor de lo que mejor de lo que vivían en sus comunidades, antes del fuimos alláé ò (P1:08). desplazamiento forzadoò. Sería diferente que dijeran que 
PERCEPCIONES DE LAS VÍCTIMAS DE MAMPUJÁN Y SAN CAYETANO Y SUS REPRESENTANTES JUDICIALES FRENTE A LA REPARACIÓN INTEGRAL EN LA LEY DE JUSTICIA Y PAZ

ñnada les devolverá sus vivencias y estilos de vida que tenían y llevaban en Mampuján y San Cayetanoò; el factor resiliencia es importante en la resignificación de conceptos, percepciones o ideas frente a situaciones adversas, lo que podría llevar a una comunidad a vivir de mejor manera (Daño Psicológico y/o Daño Moral).

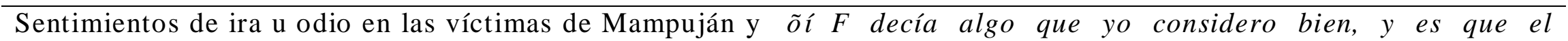
San Cayetano con los postulados y grupos armados desplazamiento crea en nosotros, ehh tantas cosas, ilegales y la misma comunidad por sus estigmatizaciones nosotros sufrimos estigma, sufrimos sentimientos que, que, (Daño Psicológico y/o Daño Moral). de pronto, de odio, de rechazo, de miedo, de temor, y de pronto desconfianza, tantos sentimientos que el desplazamiento ehh, ehh, nos proporciona a nosotros, é ò (P7:12).

Participación agresiva de las víctimas pero sin violencia, ñé entonces, pues llegamos a ese escenario creyendo que al principio, en el incidente de reparación integral de iba a ser de riñas, de peleas, hubieron unas primeras Mampuján y San Cayetano (Daño Psicológico). intervenciones, que de hecho fueron fuertes, porque la 

REPARACIÓN INTEGRAL EN LA LEY DE JUSTICIA Y PAZ

hacen las personas de San Juan, M.P.; Y, W, y ellos tienen unas afectaciones sentimentalesé ò (P1:09).

Desconfianza de las víctimas en la institucionalidad, en el ñé hubo un aislamiento al momento del desplazamiento, no Estado y sus funcionarios públicos, lo cual afectó, en un confiábamos en nadie puesto que fueron instituciones del principio, la relación con sus representantes judiciales Estado las que permitieron y en algunos casos participaron dentro del proceso de Justicia y Paz. Las víctimas, en los en el desplazamiento,é ò (P2:03). ñé muchas de las primeros momentos del proceso, según el representante víctimas se dieron reticente a acercarse a nosotros a judicial JS, no confiaban en los Representantes judiciales conversar lo primero que tuvimos que hacer es nosotros fue de la Defensoría del Pueblo y en el proceso de Justicia y ganarnos la confianza de la gente, acercarnos a ellos y Paz, lo cual obedece a la participación del Estado, por posteriormente mediante varias charlas y visitas que se le omisión o acción, a través, de algunas de sus instituciones hizo al Corregimiento de Mampuján, explicarles en qué o representantes, en la macrovictimización de Mampuján consistían nuestra participación en el en el procesoé ò y San Cayetano (Daño Psicológico y/o Daño a la vida de (P5:08). relación).

Discriminaciones o estigmatizaciones de la sociedad con ñK: é no es fácil cuando uno llega a una comunidad las víctimas de Mampuján y San Cayetano, referentes a la extraña y se ve discriminado, y se ve que te tratan mal 

REPARACIÓN INTEGRAL EN LA LEY DE JUSTICIA Y PAZ

creencia de que eran colaboradores de la guerrilla y que porque, como si el simple hecho de ser desplazado como si por esa situación las AUC (paramilitares) los habían el ser desplazado es un pecado o es un delito mortal o es hecho desplazar forzadamente. Y, por ende, no sé qué cosa, como si fuéramos culpables de lo que pasó naturalización de la sociedad colombiana con las y no somos culpables, simplemente somos víctimasé ò acciones, existencia y presencia de los grupos armados (P7:13). ñé es difícil uno llegar a un contexto que no ilegales, ya muchos ni se inmutan (Daño Moral, Daño conoce y empezar a construir nuevas relaciones, de pronto Psicológico y/o Daño Colectivo). en medio del estigma de ser desplazados, en medio de la discriminacióné ò $(P 7: 14)$. ñé pues uno queda como que, que desubicada, sobretodo porque llega a un contexto que no es el nuestro, y porque llega bajo el estigma de, de la sociedad, de que si te sacaron fue por algo, algo tenía que ver, sobre todo cuando, cuando la razón era que, ee el medio informático, es que somos colaboradores de, de la guerrilla, entonces la sociedad por casi siempre no tiende a defender a a, a ese paisano sino a creer lo que el medio publicó porque si lo publica el medio eso es verídico, é ò 

REPARACIÓN INTEGRAL EN LA LEY DE JUSTICIA Y PAZ

\section{$(P 1: 10)$}

Por los problemas económicos generados por la ñé un ejemplo muy concreto de las fosas, cuanta gente no macrovictimización de Mampuján y San Cayetano, tenía como enterrar sus muertos, no tenía recursos para especialmente por el desplazamiento forzado, varias víctimas enterrar sus muertos, y ahí estaría una línea de reparación tuvieron que enterrar a sus seres queridos asesinados en fosas por ejemplo para dar todo, la la, el respaldo a la familia, a comunes. De lo cual no se ha generado procesos de exhumación los dolientes de la persona muerta, para que sea enterrada para enterrar los restos en condiciones dignas y ajustadas a las en términos de dignidad, en términos de de, de respeto a la creencias de los dolientes (Daño Psicológico y/o Daño Moral). memoria, a la dignidad de esa persona, é ò (P7:15).

Se fragmentaron las familias y relaciones interpersonales ñé vemos que eso tiene unas connotaciones sumamente de las víctimas de Mampuján y San Cayetano. Hubo grandes, no sólo es perder la dignidad con la sociedad, es afectaciones o consecuencias psicológicas o psicosociales la parte económica que que, que se fragmenta, la familia en las víctimas, por ejemplo, por la difícil situación de misma, ehh ehh, la afectación psicológica, psicosocial que vivienda que poseen las víctimas de Mampuján, o como se viene sobre la gente, las reacciones ya no son las maltratos intrafamiliares, los cambios en las formas de mismas, las formas de hablares, de actuar cambian, la relación con familiares (cambios de roles) y con otros comunidad ha cambiado, é ò (P1:11). ñé esa amistad se integrantes de la comunidad, por ejemplo, la rompió con el desplazamiento debido a que nos tuvimos 

REPARACIÓN INTEGRAL EN LA LEY DE JUSTICIA Y PAZ

recriminación que hicieron las víctimas de Mampuján y que distanciar unos para un lado otros para otroé ò San Cayetano, en algún momento, a sus líderes por la idea (P7:16). ñé a Mampuján lo cambiaron, porque Mampuján de que tenían algo que ver con la lentitud e era una comunidad afectiva, amorosa, amigable, gente con incumplimiento de las fechas informadas de los procesos mucho respeto, con culturas definida,é ò (P1:12). de indemnización, a pesar de que era una orden y no un ñé Entonces son casos, donde tu llegas y te da pena que exhorto dentro de la sentencia de segunda instancia. A su alguien llegue y te vea en una carpita, pero eso es lo único vez, se rompieron los lazos de amistad de algunas que tienes, llega alguien y te ve el fogón apagado, eso es, víctimas (Daño Psicológico, Daño a la vida de relación y/o como que eso te deprime, si, yo creo que de alguna manera Daño Colectivo). moral, psicológica, eso afecta todo, todos los ángulosé ò (P1:13). ñé nos complicaron un tanto la vida, sobre todo a nosotros porque algunas veces las comunidades no entienden que eso no lo defino yo, osea yo vengo aquí con... ENTREVISTADOR: Osea las comunidades responsabilizan a los voceros sobre eso y... ENTREVISTADO: Si, si, la gente reclama. ENTREVISTADOR: ¿y les reclaman es a ustedes? 
ENTREVISTADO: Si, algunas veces hay palabras, que intentan incluso en vez de motivar a uno, de sentar a uno y pensar que estamos luchando por una comunidad que no valoran mucho esfuerzo, y que nosotros peleamos con quienes saben mucho de leyes; y cuando venimos en vez de recibir aplausos y felicitaciones, encontramos una comunidad que quiere pelear con nosotros también, porque a él no lo metieron;é ò (P1:14).

Se alteró el proyecto de vida de las víctimas con los ñé se daña el proyecto de vida, uno viene preparado para, hechos victimizantes, especialmente con el para soñar y esos sueños tienen pasos, una vez que le desplazamiento forzado (Daño: Pérdida de Chances y/o Daño pasaé que le interrumpen ese proceso, pues uno queda Colectivo). como que, que desubicada, sobretodo porque llega a un contexto que no es el nuestro,é entonces creemos que, que eso interrumpe ese proyecto de vida, ese modelo de vida que se trae,é ò $(P 1: 15)$.

Dificultades de orden público en la comunidad de ñé antes de comenzar el proceso, ya estando aquí, 
PERCEPCIONES DE LAS VÍCTIMAS DE MAMPUJÁN Y SAN CAYETANO Y SUS REPRESENTANTES JUDICIALES FRENTE A LA REPARACIÓN INTEGRAL EN LA LEY DE JUSTICIA Y PAZ

Mampuján después del desplazamiento forzado y antes de Mampuján se descompuso mucho, mucho, mucho, mucho, comenzar el proceso de Justicia y Paz (Daño a la vida de é, orden público, los pelados se volvieron...ò (P1:16). relación). 
PERCEPCIONES SOBRE LA MACROVICTIMIZACIÓN DE MAMPUJÁN Y SAN CAYETANO Y SU REPARACIÓN INTEGRAL EN EL MARCO DE LA LEY 975 DE 2005.

\section{Revictimizaciones de las víctimas de Mampuján y San Cayetano}

Como consencuencia, los daños expuestos en el apartado anterior empeoran con revictimizaciones. Sin embargo, necesario es precisar que, ampliando la definición de Echeburúa, de Corral y Amor (2002), la revictimización a la cual se hace referencia dentro de este apartado es la victimización secundaria. Ésta se deriva, como se ha dicho, de las relaciones de las víctimas con las instituciones sociales o de servicios sociales, sanitarios, medios de comunicación, jurídicos, personas naturales o jurídicas, sujetos colectivos, entre otros.

Es por eso, que la definición de revictimización en esta investigación tiene lugar a que existen personas de Mampuján y San Cayetano que fueron víctimas de alias ñJuancho Diqueò y ñDiego Vecinoò, por lo cual sufrieron unos daños y, posteriormente, fueron revictimizadas (victimizadas secundariamente) por algunas instituciones, postulados y parte de la sociedad, en donde claramente se está evidenciando relacionados y nuevos episodios de violación de derechos y, por lo tanto, de revictimizaciones.

Es así como el líder AV de las víctimas de Mampuján percibe como no contribución del incidente de reparación dado en segunda instancia, a la asistencia y, por consecuencia, a la reparación integral de las víctimas de Mampuján, las afectaciones o vulneraciones de las instituciones con esta comunidad. A partir del líder AV, el hecho, por ejemplo, que víctimas de Mampuján, hayan pasado por el hecho de que ñé nos sacaron del colegio donde estábamos y quedamos en la condición de que no se pagaron los albergues hasta el día, se comprometió pero no alcanzaba, é ò (P1:17); es decir, hayan sido sacadas de un colegio, institución educativa, donde estaban siendo albergadas como consecuencia del desplazamiento forzado, con el argumento de que luego iban a ser reubicadas en nuevos albergues, pero los compromisos y obligaciones de la administración municipal del momento en esta materia no 
PERCEPCIONES SOBRE LA MACROVICTIMIZACIÓN DE MAMPUJÁN Y SAN CAYETANO Y SU REPARACIÓN INTEGRAL EN EL MARCO DE LA LEY 975 DE 2005.

fueron llevados a cabo, desprotegió a las víctimas y las revictimizó, las cuales estaban en condiciones de vulnerabilidad, la mayoría no contaban con los recursos económicos suficientes para subsistir ni para pagar arriendos; el desplazamiento forzado, generado por el grupo armado al margen de la Ley: bloque ñMontes de Maríaò y por omisión o acción de la Fuerza Pública del Estado, los había desterrado, aparte de sus residencias, de sus lugares de trabajo, necesitando el apoyo del Estado.

El líder AV de las víctimas de Mampuján percibe al mismo tiempo, como victimización secundaria, las necesidades o pretensiones no cumplidas o llevabas a cabo de algunas víctimas de Mampuján respecto a asistir a las audiencias de versiones libres que se adelantaban con los postulados, alias ñDiego Vecinoò y alias ñJuancho Diqueò, lo cual puede corroborarse cuando señaló que:

é empezamos en el incidente eehhh....es decir que versiones libres y esas cosas no asistimos, porque era complicado para ese entonces la economía, sobretodo el temor que había en la gente. ENTREVISTADOR: De Participar en ese proceso. ENTREVISTADO: Con los, con personas que sólo conocíamos de nombre, y que, ese nombre indicada mucho daño,é (P1:18).

Lo anterior, con el fin de esclarecer y obtener la verdad alrededor de los hechos victimizantes que padecieron, pero con la posibilidad de controvertir o escuchar directamente las versiones de los postulados; no obstante, no contaron con el apoyo económico suficiente para asistir a estas audiencias, sumado a esto, existía el temor que había en la gente de hacer contacto con los postulados, el cual pudo haber sido contrarrestado con acompañamientos más efectivos, por ejemplo, psicojurídicos, que mitigaran esta consecuencia de la macrovictimización de Mampuján y San Cayetano, preparándolas para las audiencias. 
PERCEPCIONES SOBRE LA MACROVICTIMIZACIÓN DE MAMPUJÁN Y SAN CAYETANO Y SU REPARACIÓN INTEGRAL EN EL MARCO DE LA LEY 975 DE 2005.

Es más, siendo el incumplimiento de parte de algunas instituciones una parte de las revictimizaciones, por ejemplo, con su obligación constitucional de defensa y protección de los ciudadanos colombianos, como lo es el de la Fuerza Pública: Policía Nacional, pone al descubierto revictimizaciones, afectaciones o vulneraciones que está cometiendo esta institución con las víctimas de Mampuján, privándolos o limitándolos del goce efectivo de las ñgarantías de no repeticiónòde hechos victimizantes. Es decir, el líder AV de Mampuján percibe que:

é donde hay tanto policía, y usted viene a decir que esa es la seguridad, y yo pienso que cuando hicieron el proyecto de seguridad, pensaron que era satisfacción de esa víctima, y viene la víctima y dice hoy aquí, es que no se siente segura aquí;é la gente se molesta y termina diciendo, es que ustedes son desagradecidosé (P1:19).

Lo que sugiere que hay víctimas de Mampuján que no se sienten seguras con las acciones de las Fuerzas Policivas del Estado porque no han sido definidos conjuntamente, entre víctimas y esta institución, los proyectos de seguridad para la comunidad, lo cual les genera intranquilidad e insatisfacción, sienten desconfianza institucional, más si se recuerda que una de estas instituciones de la Fuerza Pública como el Ejército Nacional, ha sido participe, por omisión o acción, de hechos victimizantes relacionados con el Conflicto Armado Interno, entre ellos, los llamados: Falsos Positivos, los cuales consisten en la victimización (asesinatos) de un sujeto individual o colectivo inocente por parte, en este caso específico, del Ejército Nacional, con el argumento de que pertenecía a la Guerrilla; muertos en supuestos combates dentro del marco del conflicto armado interno que vive el país.

Por consiguiente, se victimiza secundariamente a las víctimas de Mampuján y no se logra la reparación integral de estas personas, cuando hay incumplimiento del incidente de reparación 
PERCEPCIONES SOBRE LA MACROVICTIMIZACIÓN DE MAMPUJÁN Y SAN CAYETANO Y SU REPARACIÓN INTEGRAL EN EL MARCO DE LA LEY 975 DE 2005.

integral, dado en segunda instancia, por parte de las instituciones o los postulados. Según la percepción del líder TR de las víctimas de Mampuján:

é no puede ser reparada una comunidad con una sentencia que le haga invitación al Estado al cumplimiento, o que lo exhorte a que lo cumpla, y que no se den en esas sentencias unas órdenes taxativas, para que se pueda juzgar con toda la libertad del caso, sino es cumplida, entonces yo pienso que ahí falló mucho la corte suprema y sería una de las críticas que yo podría haceré (P3:02).

En otras palabras, las comunidades no pueden ser reparadas integralmente y son revictimizadas con una sentencia que le hace la invitación al Estado y a las diferentes instituciones, sobre el cumplimiento de lo dictaminado por la Corte Suprema de Justicia en cuanto a la reparación integral de estas personas, es decir, que exhorte y no ordene en su totalidad a las instituciones o postulados lo relacionado a la reparación.

Piensa que el hecho de que se exhorte y no se le ordene en su totalidad a la institucionalidad o postulados, en el incidente de reparación integral, dado en segunda instancia, lo relacionado a la reparación integral de las víctimas de Mampuján, es una grave vulneración de derechos de parte de la Corte Suprema de Justicia con las víctimas, no las benefició en cuanto a la reparación integral y, además, impide realizar seguimiento o monitoreo al cumplimiento de lo dictaminado por la Corte, en relación a límites de tiempo. Sin límites temporales definidos, la institucionalidad o los postulados revictimizan a las víctimas.

De igual forma, la persona líder LM de las víctimas de San Cayetano manifestó:

Nooo, osea no las llenó todas porque es una sentencia que tiene muchos vacíos, ehhh, como ya le manifestéé primero un vacío muy grande que las órdenes las cambió a exhortos, osea, ese es el peor que hay porque es que ahí nadie quiere 
PERCEPCIONES SOBRE LA MACROVICTIMIZACIÓN DE MAMPUJÁN Y SAN CAYETANO Y SU REPARACIÓN INTEGRAL EN EL MARCO DE LA LEY 975 DE 2005.

cumplir, ahí cuando se le menciona el Ministerio de Agricultura dice que él no tiene facultad para cumplir con eso, la gobernación dice entonces que el ministerio dice eso yo me voy detrás de lo que dice el ministerio y el municipio dice pues yo me voy detrás de lo que dice la gobernación, entonces nadie cumplimos, osea eso ya lo hemos dialogado de esa manera, porque si el Ministerio de Agricultura dice no poder apoyar a los agricultores, porque dice que el que puede ayudar es vivienda, que para eso está el Ministerio de vivienda, qué va a hacer un Ministerio de Agricultura apoyando en vivienda si lo de ellos es agricultura. ENTREVISTADOR: Lo que pasa es que dentro de los programas del Ministerio de Agricultura está el tema de vivienda rural, o sea eso es competencia del ministerio y no del fondoé del Ministerio de Vivienda digamos, sería de pronto ese el sentido. ENTREVISTADA: Pero si nosotros le pedimos es proyectos productivos, nosotros no le estamos pidiendo vivienda. ENTREVISTADOR: Vivienda rural. ENTREVISTADA: Osea, yo supongo que eso hace parte de su competencia, siempre y cuando las personas, las comunidades les manifiesten esa necesidad, pero si mi necesidad es cultivaré osea, yo vivo del cultivo, de la producción agrícola, dígame, si yo le pido que me apoye en volver a ser una productora agrícola en mi finca, ehh cómo me va a decir, no, no puedo porque esa no es mi competencia. Osea, esa sí es su competencia, pienso yo que sí es su competencia porque por eso se llama Ministerio de Agricultura o si no hay que cambiarle el nombre y ponerle el que por lo menos se relacione con lo que ellos tienen que cumpliré (P4:02). 
PERCEPCIONES SOBRE LA MACROVICTIMIZACIÓN DE MAMPUJÁN Y SAN CAYETANO Y SU REPARACIÓN INTEGRAL EN EL MARCO DE LA LEY 975 DE 2005.

Lo que sugiere que, los exhortos en el incidente de reparación dado en segunda instancia, juegan con la dignidad de las personas, de las víctimas de Mampuján y San Cayetano, por ejemplo, en cuanto al tema de proyectos productivos para la recuperación de la capacidad productiva de las víctimas, algunas de ellas desean generar proyectos productivos relacionados con la agricultura y no lo han podido hacer, debido a que entre instituciones como el Ministerio de Agricultura y el de Vivienda, la Gobernación y Alcaldías de la región, entre otras instituciones, se han rebotado las responsabilidades en materia de reparación integral, a sabiendas que el Ministerio de Agricultura es el de mayor competencia al respecto; lo cual no contribuye a la reparación integral de las víctimas de San Cayetano, genera en ellas insatisfacción de las pretensiones de reparación con el resultado del incidente de reparación dado en la segunda instancia.

Con estos exhortos de la sentencia del incidente de reparación integral de las víctimas de Mampuján y San Cayetano, dado en segunda instancia, casi ninguna institución está cumpliendo lo dictaminado por la Corte Suprema de Justicia. Debido a que esta sentencia modificó el numeral séptimo de la parte resolutiva del fallo impugnado en primera instancia, en el sentido de aclarar que todas aquellas medidas de rehabilitación, satisfacción, no repetición y colectivas por medio de las cuales se imparten órdenes a las diversas autoridades estatales se deben entender como exhortaciones para su cumplimiento (Corte Suprema de Justicia Sala de Casación Penal, República de Colombia, 2011).

Excepción hecha de las medidas de satisfacción de carácter simbólico y de no repetición contempladas en los apartados 358 (En ceremonia de recordación a las víctimas de los hechos ocurridos, el día 10 de marzo de 2011, con la presencia del Gobierno Nacional, Departamental y Municipal, se hará un acto de reconocimiento público de los abusos cometidos por las 
PERCEPCIONES SOBRE LA MACROVICTIMIZACIÓN DE MAMPUJÁN Y SAN CAYETANO Y SU REPARACIÓN INTEGRAL EN EL MARCO DE LA LEY 975 DE 2005.

autodefensas en las poblaciones de San Cayetano y Mampuján; esta medida será coordinada por la Comisión Nacional de Reparación y Reconciliación y dará informe a la Sala trimestralmente, de los preparativos), 359 (Ordenar que se haga un documental de una hora que tenga como guión la presente sentencia, con entrevistas a víctimas y victimarios y que contenga un acto público de perdón por Uber Enrique Banquez Martínez y Edward Cobos Téllez. Este acto deberá transmitirse en una franja horaria de máxima audiencia, por uno de los canales de mayor cobertura del País. La coordinación del documental estará a cargo de la Sala Administrativa del Consejo Superior de la Judicatura y la Comisión Nacional de Reparación y Reconciliación, quienes deberán rendir informe de lo avanzado dentro de los tres meses siguientes a la ejecutoria de la sentencia), 360 (Toda vez que los aquí postulados ofrecieron como medida de reparación, la construcción de un monumento de recordación por los hechos del 10 y 11 de marzo de 2000 en San Cayetano y Mampuján, la Sala ordena que a cargo de los señores Banquez Martínez y Cobos Téllez, con la coordinación previa de la Comisión Nacional de Reparación y Reconciliación (quienes deberán consultar con la población de San Cayetano y Mampuján los detalles del monumento, especificaciones, lugar donde debe quedar ubicado y demás) se fabrique, antes de la ceremonia de recordación que tendrá lugar el 10 de marzo de 2011) y 362 (se solicitó dentro del incidente de reparación integral que los centros educativos que se construyan lleven un nombre conmemorativo de estos hechos, la Sala dispone que una vez estos Colegios sean edificados, será la Comisión Nacional de Reparación y Reconciliación quien coordine este aspecto con los habitantes de San Cayetano y Mampuján y las autoridades locales y Regionales). Por la misma razón, se revocaron los plazos establecidos para el cumplimiento de las obras públicas y programas ordenados (Corte Suprema de Justicia Sala de Casación Penal, República de Colombia, 2011). 
PERCEPCIONES SOBRE LA MACROVICTIMIZACIÓN DE MAMPUJÁN Y SAN CAYETANO Y SU REPARACIÓN INTEGRAL EN EL MARCO DE LA LEY 975 DE 2005.

A su vez, porque exhortó al Gobierno Nacional para que en la forma indicada en la parte motiva del proveído [acápite 2.3. (b)], diseñe e implemente las políticas necesarias para concretar el restablecimiento de la capacidad laboral de las víctimas de los hechos tema del proceso (Corte Suprema de Justicia Sala de Casación Penal, República de Colombia, 2011).

También, porque en la sentencia de primera instancia, sin ser refutada por la segunda, se detalló que: 337. No tiene conocimiento la Sala sobre ocupación de tierras, luego del desplazamiento; por tanto no hay ningún pronunciamiento de restitución de inmuebles. Sin embargo, como parte de esta medida se ordena proceder a la formalización de los títulos sobre los predios, que ostentaban los habitantes de San Cayetano y Mampuján, cuando fueron sacados de su territorio: propiedad, posesión, tenencia, etcétera (Tribunal Superior del Distrito Judicial de Bogotá Sala de Justicia y Paz, 2010).

Lo más claro es que, la sentencia de segunda instancia revocó la cuantificación de las reparaciones ñen equidadò, para proceder a tasarlas en derecho. Y modificó el numeral sexto de la parte resolutiva de la sentencia de primera instancia, para fijar la indemnización de perjuicios ocasionados por los delitos objeto de este proceso con los criterios y cuantías definidos en esta determinación, los cuales comportan la inclusión y exclusión de las víctimas, corrección de los nombres precisamente indicados en la parte motiva y la revocatoria del plazo otorgado al Fondo de Reparación para hacer efectivas las indemnizaciones (Corte Suprema de Justicia Sala de Casación Penal, República de Colombia, 2011).

No obstante, el líder TR de las víctimas de Mampuján manifestó que las víctimas de su comunidad frente a que:

é el Estado no cumpleé ya nosotros comenzamos a hacer derecho de petición, en cumplimiento de los exhortos, yo aspiro, que a pesar de que esto ya es cosa 
PERCEPCIONES SOBRE LA MACROVICTIMIZACIÓN DE MAMPUJÁN Y SAN CAYETANO Y SU REPARACIÓN INTEGRAL EN EL MARCO DE LA LEY 975 DE 2005.

juzgada, cuando ya han habido unos compromisos, de las instituciones, de las alcaldías, de la gobernación, de los ministerios, del DPS, han habido unos compromisos que están consagrados en una mesa, que se instaló oficialmente, de la cual hacemos reuniones periódicas todos los meses, eso se convierte entonces sí en un compromiso, porque ya dentro de esas mesas oficiales, hay unos compromisos y hay unas pautas dadas por de esas instituciones, entonces, dentro de esos compromisos y ligado a los exhortos, ya nosotros comenzamos a hacer los primeros derechos de petición, y esperamos entonces sí, que cuando esos derechos de petició no tengan respuesta, entonces el tribunal, que es el encargado de hacer el seguimiento, pueda hacerlos cumplir a través de una orden,é (P3:03).

Es decir, víctimas de Mampuján han sabido contrarrestar esta situación de vulneración de derechos del incidente de reparación integral, dado en segunda instancia, a través de mecanismos de protección de los Derechos Humanos o acciones constitucionales, como el ñDerecho de Peticiónò, con el cual solicitan información y el cumplimiento de los exhortos. Un procedimiento de las víctimas de Mampuján es la conformación de mesas oficiales de trabajo o de seguimiento a las instituciones que tienen compromisos a partir de la sentencia dada en segunda instancia, en estas reuniones periódicas pactan, posiblemente por escrito, unos tiempos de cumplimiento que no están contemplados dentro de la sentencia, para luego solicitarle a la institucionalidad, por medio del Derecho de Petición, el cumplimiento a partir de límites temporales; por ejemplo, han pactado compromisos con instituciones con responsabilidades e inmersas en el incidente de reparación integral dado en segunda instancia, como la Gobernación y Alcaldías regionales, con los Ministerios y el Departamento Administrativo para la Prosperidad Social (DPS). 
PERCEPCIONES SOBRE LA MACROVICTIMIZACIÓN DE MAMPUJÁN Y SAN CAYETANO Y SU REPARACIÓN INTEGRAL EN EL MARCO DE LA LEY 975 DE 2005.

Por lo que se aclara que, también a la fecha de aplicación de las técnicas de recolección de información, el mismo líder de víctimas de Mampuján percibió ñé que el Estado ha venido cumpliendo, las medidas de reparación simbólicas, pero donde quiera que hay que invertir recursos, ha, han habido muchas falencias y muchas vacilaciones, é ò (P3:04). Lo que sugiere que, el Estado a través de sus instituciones, ha venido cumpliendo las medidas de reparación simbólica, pero donde quiera que haya que invertir recursos económicos, como las medidas de reparación colectiva: construcción de vías, mejoramiento de acueductos y alcantarillados, entrega de viviendas, entre otras, existen vacilaciones institucionales. Por lo tanto, es importante resaltar que existe revictimizaciones institucionales que hacen que las víctimas de Mampuján no se sientan atendidas, asistidas y reparadas integralmente.

Aunque, y según la persona líder LM de las víctimas de San Cayetano, a pesar de ser la reparación Colectiva la que más ha tenido tropiezos u obstáculos para llevarse a cabo, revictimizandolas, se ha presentado que el Ministerio de Educación ha cumplido parte de los exhortos con la construcción de escuelas, como la de Arroyo Hondo (Bolívar, María la Baja, Colombia), la cual contó con facilidad de predio para su construcción. Pero la misma suerte no ha ocurrido con la escuela de la vereda Aguas Blancas, donde ha faltado más gestión institucional para la adquisición de los terrenos, donde los particulares o grandes compradores de tierras han adquirido esos predios y pretenden venderlos en sumas muy elevadas de dinero, donde las Administraciones Municipales no pueden comprar por la posibilidad de entrar a cometer un aparante peculado, o desisten totalmente de la venta por falta de voluntad, sin importar el bien común sobre el particular.

Lo anterior, puede corroborarse con lo manifestado por el líder LM en medio de la entrevista semisestructurada, a saber: 
PERCEPCIONES SOBRE LA MACROVICTIMIZACIÓN DE MAMPUJÁN Y SAN CAYETANO Y SU REPARACIÓN INTEGRAL EN EL MARCO DE LA LEY 975 DE 2005.

é por lo menos el Ministerio deé el Ministerio de, de, de, de Educación, ya de él era su competencia construir las escuelas que quedaron dentro de la sentencia de órdenes y luego exhortos, hemos tenido una inconveniente con la escuela de la vereda de Aguas Blancas, porque por lo menos la escuela de Arroyo Hondo para construirla tenía predio, pero el de Aguas Blancas tuvo su predio pero no fue legalizado en su momento, y luego el predio de la escuela quedó dentro de las ventas masivas de tierras que se vendieron a las personas que compran tierras; entonces fue un problema porque ellos no lo devolvieron y están puesé nadie los puede obligar a dar un predio que es de ellos si ellos no quieren, ehh luego, está el tema que en la sentencia dicen que como ya se había manifestado no teníamos predio para las escuelas, la sentencia daé exhorta al alcalde del municipio a comprar los predios para la construcción de la misma, pero el alcaldeé no sé si es que políticamente no ha tenido la voluntad.. Política que se debería tener para construir, porque en todo lo que usted tiene voluntad tiene solución, cuando usted dice no, pues ahí sí nos estancamos, ENTREVISTADOR: Exacto. ENTREVISTADA: Entonces el predio lo están vendiendo el señor una hectárea de tierra, por 10 millones de pesos, luego se llegó a un acuerdo que se lo vendía en 9 millones de pesos, él manifiesta no poderlo comprar porque estaría cometiendo un peculado, qué se yo, porque que son platas del Estado y el terreno no lo debe pagar más de 5 millones de pesos y puede pensarse que se se queda con la plata. Bueno, por eso, pero yo pienso que si tuviera voluntad lo había hecho, porque con voluntad se hace todo, se había hecho convenio, se habian hecho cosas, se había manifestado, se había pasado un escrito, se había dicho ehh, yo voy a hacer esto, 
PERCEPCIONES SOBRE LA MACROVICTIMIZACIÓN DE MAMPUJÁN Y SAN CAYETANO Y SU REPARACIÓN INTEGRAL EN EL MARCO DE LA LEY 975 DE 2005.

esto para la reparación de las víctimas, osea, él había hecho algo positivo, pero como no ha tenido voluntad sencillamente por eso no se ha cumplido, é (P4:03).

De igual manera, esta persona líder de San Cayetano, manifiesta que existe revictimizaciones (victimizaciones secundarias) institucionales, por ejemplo, por parte de INVÍAS ñCon las víasé pues le toca a Invías una parte, Invías se comprometió, vino, llegó, dijo que iniciaban obras, en oc.., a finales de septiembre o a principios de octubre, é pero nada aúné (P4:04). La cual, a pesar de haber adquirido compromisos en las mesas de trabajo y de seguimiento con las víctimas de Mampuján y San Cayetano, no ha podido construir las carreteras que necesitan estas comunidades, donde específicamente a partir de lo observado por los investigadores cuando estuvieron visitando y aplicando las técnicas de recolección de información en las zonas, las víctimas de Mampuján están en condiciones de vida y sanidad más difíciles, debido a que no poseen alcantarillado, agua potable, andenes, centro de salud, vías pavimentadas, lo que en invierno vuelve, por ejemplo, una ñagunaò a ñMampujáncitoò, nombre que le han dado algunas víctimas de Mampuján al lugar donde actualmente residen, cerca de la antigua Mampuján.

Los problemas son tan angustiantes que el mismo líder afirma que no se cuenta con puentes y pontones, la administración departamental ha argumentado insuficiencia anual presupuestal para llevar a cabo estas construcciones; esta persona líder de víctimas de San Cayetano percibe que a la fecha tendrían que llevar por lo menos un 50 por ciento de las construcciones de la medidas de reparación colectivas, la insatisfacción es absoluta y también expresa que solo va un $10 \%$ de cumplimiento; cuando se pensaba que lo más demorado iba a ser las indemnizaciones, a la fecha de aplicación de las técnicas de recolección de información, ha sido el proceso que más rápido se ha ido presentado con las víctimas de Mampuján y San Cayetano como parte de la 
PERCEPCIONES SOBRE LA MACROVICTIMIZACIÓN DE MAMPUJÁN Y SAN CAYETANO Y SU REPARACIÓN INTEGRAL EN EL MARCO DE LA LEY 975 DE 2005.

reparación integral, lo cual obedece a que esta medida de reparación fue una orden y no un exhorto dentro de la sentencia de segunda instancia.

Lo cual se puede confirmar con el hecho de que opinó que:

é la gobernación que le tocan los puentes y los pontones, pues no, los puentes y los pontones les toca a la Alcaldía, ahí estamos un poquito cojos porque la gobernación manifestó en primera instancia decir que iba a construir porque tiene puentes que construir que sí que tenía el dinero para los puentes y esto, ahora en la mesa pasada que hicimos en junio manifiesta que no, porque, se le vaé es mucho, mucho presupuesto y ellos no lo tenían en el presupuesto de este año, cuando eso ya se había hecho previamente, y dice que sólo puede construir un puente este año y así, entonces eso es insatisfactorio para nosotros porque, primero ya la sentencia lleva mucho tiempo de haber salido y que ya es hora que ya por lo menos hubiera por lo menos un $50 \%$ construido de todo lo que decía en la sentencia, no va ni un 10\%, en lo único que se ha avanzado, en lo que veíamos menos avances era en las reparaciones individuales, en las indemnizaciones y por lo menos fue lo que tuvo un avance más rápido... (P4:05).

Asimismo y continuando con las percepciones de los participantes, la persona líder LM de San Cayetano percibe que:

é la Fiscalía que fue una institución que nos acompañó mucho, que tengan, ósea que tengan claro y que investiguen bien, o sea, que no queden víctimas fuera del incidente de reparación porque genera un caos, acá sucedió y ha sido dramático, quedó mucha gente por fuera del incidente de reparación aun siendo víctimasé $(P 4: 06)$. 
PERCEPCIONES SOBRE LA MACROVICTIMIZACIÓN DE MAMPUJÁN Y SAN CAYETANO Y SU REPARACIÓN INTEGRAL EN EL MARCO DE LA LEY 975 DE 2005.

Es decir, LM piensa que se cometieron victimizaciones secundarias por parte de la Fiscalía General de la Nación, dejando víctimas por fuera, sin ser beneficiadas del incidente de reparación dado en segunda instancia por falta de pruebas, debido a la pérdida de documentos que cometieron ï error procesal - , en relación con otra categoría de análisis, representantes judiciales de víctimas de la Defensoría del Pueblo, lo cual ha generado, en las víctimas de San Cayetano, desconfianza institucional, envidias, desconfianza y rivalidades entre pares y con sus líderes, e insatisfacción con los resultados del incidente de reaparición integral dado en segunda instancia. Invita de alguna manera, a la Fiscalía General de la Nación, específicamente a la Unidad de Justicia y Paz, a que las investigaciones para determinar la calidad de víctima de unas personas y sus daños causados, deben fundarse en el rigor investigativo, buscando mayor valor en la atención a las víctimas que con los victimarios (postulados) o los mismos representantes judiciales, como aquellas personas afectadas por hechos victimizantes, a las cuales se les vulneraron Derechos Humanos y, con las cuales, hubo infracciones al Derecho Internacional Humanitario.

Por otro lado, la participante $K$ del grupo focal realizado con las víctimas de Mampuján, considera que gran parte de las instituciones que están fijadas con responsabilidades de reparación dentro del incidente de segunda instancia, juegan con la dignidad de las víctimas de ambas comunidades al incumplir los exhortos emitidos por la Corte Suprema de Justicia, por ejemplo, en cuanto a la restitución de tierras:

K: Eso se, eso se ha dado parcialmente, primero porque las induciones, yo creo que, que muchas veces jugaron con nuestra dignidad; primero, porque en unos momentos, cuando se dio, la, la, la segunda sentencia, la sentencia de ratificación, la Corte ordenaba la restitución de las tierras, yyy y no,é (P7:17). 
PERCEPCIONES SOBRE LA MACROVICTIMIZACIÓN DE MAMPUJÁN Y SAN CAYETANO Y SU REPARACIÓN INTEGRAL EN EL MARCO DE LA LEY 975 DE 2005.

Para contrarrestar esta situación se ha venido haciendo seguimientos al cumplimiento de la sentencia, la insistencia y perseverancia de las víctimas de Mampuján y San Cayetano ha llevado a la Magistrada Ponente del incidente de reparación dado en segunda instancia a verificar y a exigir a las instituciones el cumplimiento de los exhortos, lo cual ha generado el inicio de acciones institucionales, que avanzan a paso muy lento y con enredos procesales. Para confirmar:

é cuando se hace, la, la la sentencia aquí de los postulados, la sentencia de seguimiento, los postulados en esta comunidad y la jueza ya que se, se empieza a exigirles más a las organizaciones, empiezan a moverse, hoy por hoy las organizaciones se están moviendo, eso ehh.. eso es buenoé (P7:18).

Estas acciones son vistas como una burla institucional por el hecho de que, en las propias palabras de la participante $K$, ñé ponen a las comunidades como si fueran una bola de pim pom, de tirarlas aquí paôallá, y uno a la final no sabe a quién creeré (P7:19), es decir, las instituciones ponen a las comunidades víctimas como una bola de Ping-Pong a tocar innumerables puertas de un lado a otro, sin obtener respuestas satisfactorias y adecuadas para el reclamo de sus derechos como víctimas reconocidas en la sentencia de segunda instancia y del conflicto armado interno, pero gracias a organizaciones colaboradoras y a los líderes de víctimas de Mampuján y San Cayetano, los procesos han tenido inicios de cumplimiento, aunque con gran lentitud, ñé lo que pese a que vimos que se burlaron de nosotros en algún momento, también es por las organizaciones y por los líderes que este proceso hoy está en donde está, ha llegado a dónde estáé ò (P7:20). Las víctimas no deberían estar reclamando sus derechos sino recibirlos oportunamente y sin contratiempos.

Las victimizaciones secundarias por parte de las instituciones con las víctimas de Mampuján y San Cayetano, también son las desacertadas y deficientes acciones de las Administraciones 
PERCEPCIONES SOBRE LA MACROVICTIMIZACIÓN DE MAMPUJÁN Y SAN CAYETANO Y SU REPARACIÓN INTEGRAL EN EL MARCO DE LA LEY 975 DE 2005.

Municipales. La participante Señora 3 del grupo focal de San Cayetano percibe y opina que parte de los dineros de asistencia y reparación integral para las víctimas u otros, no se desvían o pierden desde el mismo Estado colombiano, desde el Distrito Capital en Bogotá, sino desde una de sus ramificaciones como las Administraciones Municipales, son aprovechados por unos particulares a costa de la vulneración de unas poblaciones necesitadas de intervención:

...Por qué sucederá eso, ustedes qué creen, que hacen. SEÑORA: Las malas administraciones. SEÑOR 1: Sabe cómo le voy a decir yo *** porque lo que pasa es que aquí en Colombia, las personas, que tiene el cargo, están pensando en el beneficio personal, todas las personas que tienen cargo, ehh a su, en su poder, están pensando en su beneficio personal, y no piensan en la comunidad. SEÑORA3: Es que yo pienso que eso no se desvía de allá del Estado, se debía de las administraciones, las administraciones son las que descarrilan todo, y ahí se pierde todo. (P9:04).

Asimismo, participantes de ese mismo grupo Focal, consideran que son revictimizaciones, por parte de las Administraciones Municipales, el incumplimiento que se ha venido presentado del exhorto relacionado con la construcción de viviendas dignas para las familias desplazadas de Mampuján y San Cayetano. Los candidatos a las Alcaldías de María la Baja, donde se encontraba ubicado el corregimiento de Mampuján, y de San Juan de Nepomuceno, donde está ubicado el corregimiento de San Cayetano, ambos del departamento de Bolívar en Colombia, prometen la construcción y culminación de viviendas dignas para poblaciones vulnerables, como estas víctimas, pero tan pronto son elegidos, olvidan sus compromisos al respecto y, así sucesivamente, sucede con cada candidato a las administraciones municipales. Estos participantes consideran que administraciones municipales legalizan fraudulentamente acciones de este tipo, yendo, por 
PERCEPCIONES SOBRE LA MACROVICTIMIZACIÓN DE MAMPUJÁN Y SAN CAYETANO Y SU REPARACIÓN INTEGRAL EN EL MARCO DE LA LEY 975 DE 2005.

ejemplo, a visitar los terrenos y las comunidades de Mampuján y San Cayetano, tomando fotografías y presentándolas, a los órganos de control, como gestiones realizadas en materia de construcción de vivienda de interés social, donde son las mismas víctimas con sus indemnizaciones quienes están mejorando sus viviendas. Las víctimas insatisfechas les han reclamado a los Alcaldes, pero han tenido, por parte de algunos mandatarios, respuestas llenas de falta de respeto. Para confirmar lo dicho anteriormente, ver la siguiente Cita:

é SEÑORA3: Porque esto, lo de desplazados, por ejemplo, como somos nosotros, tenemos derecho a un vivienda digna. SEÑORA: El alcalde saliente dijo que las iba a terminar y ahora el de ahora también dijo, que las iba a continuar y no, no terminan. Si si, ya fueron a tomar fotos, por toda, por toda la salida y el cuartico, porque eso es lo que hay. LUIS: Qué harán con esas fotos, ustedes qué creen que harán con esas fotos. SEÑORA1: Para estarlo engañando a uno. SEÑORA3: Yo digo lo contrario, yo digo que ellos toman fotos, es para ellos llevar es su, su paquete bien compuestico allá donde están trabajando, ajá páque ***su sueldo venga que digan, exactamente. Yo digo que es así. Toman fotos para que los miren bien allá, y digan*** Cayó la una, la otra. LUIS: Y dicen que ya construyeron el barrio. SEÑORA3: Que ya todo está bonito, SEÑOR: Echando embustes, no, si vamos a terminar.SEÑORA: El alcalde saliente, nos reunió a nosotros, nos mostró una foto, y yo no sé a qué horas tomaron esa foto dónde digo yo.. Oiga. Más serio, yo no sé en donde tomaron esa foto. Y allá no invitaron y nos dice, No va, ahh tú fuiste, que fuimos 5 te acuerdas, que lo vimos cuando llegamos a planeación con L, con F. Yo, yo miré y me salí de la sala. Me dio rabia porque, porque no me falte al respeto estamos aquí que el venía, y el no llegó, y el no llegó, entonces vamos allá y le vamos reclamando y el salió con una falta de respeto**** (P9:05). 
PERCEPCIONES SOBRE LA MACROVICTIMIZACIÓN DE MAMPUJÁN Y SAN CAYETANO Y SU REPARACIÓN INTEGRAL EN EL MARCO DE LA LEY 975 DE 2005.

Lo cual empeora, cuando al desconocer las rutas de acceso de sus derechos, las victimas entran en procesos repetitivos, equivocados, ineficaces y revictimizantes para solicitarlos, a partir de lo dicho por la líder AV de Mampuján. Sus derechos no deberían ser solicitados sino recibidos sin trámites redundantes y dispendiosos, no deberían estar tocando puertas para ser reparados integralmente, las instituciones deberían pensar más en el beneficio de estas poblaciones vulnerables, como ellos mismos dicen ñé las instituciones deberían humanizarse más, no ser indiferentes con las víctimasé (P1:20)ò, no deberían evadir sus responsabilidades y poner a las víctimas de un lado para el otro a solicitar las medidas de reparación integral, donde les dicen, por ejemplo, esta no es la entidad competente, diríjase a esta otra entidad, cuando la responsabilidad si era de la primera.

\section{Procesos jurídicos desacertados en el marco de la Ley de Justicia y Paz adelantados con las víctimas de Mampuján y San Cayetano}

Aunque se puede tomar las victimizaciones secundarias (revictimizaciones), parte de las pretensiones de reparación integral de las víctimas de Mampuján y San Cayetano que faltaron por incluirse en el incidente de reparación dado en segunda instancia y los incumplimientos de los Resuelve de reparación, contemplados en la sentencia de segunda instancia, los cuales serán expuestos más adelante, de parte de la institucionalidad y los postulados como procesos jurídicos desacertados que afectan a las víctimas en sus procesos de reparación, los participantes señalaron específicamente como procesos jurídicos desacertados de Justicia y Paz adelantados con las víctimas de Mampuján y San Cayetano, encontrándose en un primer momento, el hecho de ordenarse la reparación integral en equidad en el incidente de reparación dado en primera instancia; por ejemplo, el líder AV de Mampuján expresó que: 
PERCEPCIONES SOBRE LA MACROVICTIMIZACIÓN DE MAMPUJÁN Y SAN CAYETANO Y SU REPARACIÓN INTEGRAL EN EL MARCO DE LA LEY 975 DE 2005.

é entonces ella, calla en equidad. Para nosotros en ese momento, fue para agarrar cabeza, y empezamos a luchar y a intentar reversar eso, eso parecía no era posible, luego en la apelación dicen losé todo el mundo no está de acuerdo,é $(P 1: 21)$.

Posteriormente, a partir de lo dicho por el líder AV de Mampuján, que se tratara de limitar las manifestaciones de sentimientos en los procesos de Justicia y Paz, a través, de los aplausos de las víctimas, consideran que existe mucho formalismo al respecto en las audiencias, por ejemplo, en una de la audiencias donde las victimas salieron con un detalle religioso, en este caso una biblia, y con un mensaje para los postulados en un acto de perdón:

é Entonces, cuando eso da ya ustedes saben que en cuestión de evidencias no se puede andar aplaudiendo, entonces es mucho legalismo. ENTREVISTADOR: Mucha formalidadé ENTRTEVISTADO: é cuando dimos el mensaje la gente interrumpió, se rompió el orden, dicen los que están acá que Mampuján duró como que, un espacio de un minuto dando fuerte aplauso caluroso, y aunque decían aguante porque esto es unaé nadie tuvo que ver con eso, porque Mampuján queremos que el aplauso es la evidencia que estamos de acuerdo, nosotros no sabemos pelear, nosotros sabemos vivir en paz, é la Biblia que les dimos de alguna manera ayuda a uno a entender que la fuerza para terminar la guerra es apostando a a, al amor, dando amor, dando perdón a quien ni siquiera lo está pidiendoé (P1:22).

También, podemos señalar la pérdida de documentos aportados por las víctimas para identificar y reconocer sus calidades de victimas (beneficiarios) y las afectaciones o daños causados por la macrovictimización de Mampuján y San 
PERCEPCIONES SOBRE LA MACROVICTIMIZACIÓN DE MAMPUJÁN Y SAN CAYETANO Y SU REPARACIÓN INTEGRAL EN EL MARCO DE LA LEY 975 DE 2005.

Cayetano. Lo cual, afectó a muchas víctimas de estas comunidades en cuanto al recibimiento de la reparación integral, por ejemplo, la indemnización; algunas de ellas estuvieron incluidas en el incidente de primera instancia pero en la segunda instancia no fueron reconocidas, de lo cual no han recibido explicaciones referentes a los criterios de la Corte Suprema de Justicia para la decisión o si la pérdida de documentos fueron las causas de este proceso irresponsable, que les ha traído consecuencias negativas a los líderes de víctimas, debido a que las víctimas los han inculpado o visto como responsables, en ocasiones, de este error procesal; pero, principalmente, el líder TR de Mampuján señala como responsables de esta dificultad a los representantes judiciales de víctimas de la Defensoría del Pueblo, quienes, además, de extraviar documentos de las víctimas, en algunos casos no tramitaron bien las solicitudes de reparación y no las asesoraron bien, por ejemplo, en cuanto a que los familiares de las víctimas secuestradas también tenían derecho a una reparación integral:

é ENTREVISTADOR: $Y$ estaban reconocidos en la primera instancia. ENTREVISTADO: Y estaban reconocidos como delito de desplazamiento, pero cuando hubo la apelación entró la petición de reconocimiento de daño emergente, porque la, la Defensoría del pueblo aprovechó para pedirlo y fue lógicamente aprobado, creo que la misma Defensoría también falla porque no, en todos los casos no hubo unaé no hubo un celo de los abogados que nos representaron para salvaguardar la información, para llevar mis documentos a cabalidad y para presentarlos ante la Corte, y en algunos casos la Corte no consideró que estaban bien tramitados y tampoco, a aprobó los beneficios, otra cosa en la que fuimos 
PERCEPCIONES SOBRE LA MACROVICTIMIZACIÓN DE MAMPUJÁN Y SAN CAYETANO Y SU REPARACIÓN INTEGRAL EN EL MARCO DE LA LEY 975 DE 2005.

mal asesorados también y, y, yel hecho de haber conseguido esos recursos adicionales muy bueno por la Defensoría, pero hubieron casos claves, por ejemplo, hubieron 7 personas secuestradas en el proceso, esas 7 personas según la ley y según la misma sentencia tenían derecho a 30 salarios mínimos adicionales a a, alo de los recursos por desplazamiento, tenían derecho sus papás a esos 30 salarios mínimos también, osea el padre y la madre, y cada hermano tenía derecho a 4 millones de pesos, por, por, por su hermano haber sufrido esa situación, entonces nosotros no teníamos ese conocimiento jurídico, pero sí debían tenerlo los abogados, y los abogados jamás nos preguntaron quién es tu mamá, quién es tu papá, quién es la mamá del secuestrado, ni quiénes son los hermanos, lo que quiere decir que en el caso de mi hermano, que fue secuestrado se perdieron cerca de cien millones de pesosé (P3:05).

Es decir, no se tuvo en cuenta las dificultades de las víctimas de Mampuján y San Cayetano respecto a que perdieron documentos de acreditación de los daños causados, como títulos de semovientes, entre otros, que les impidió demostrar estos daños en el incidente de reparación integral dado en segunda instancia y, por ende, dejaron de recibir, junto a sus familias, la debida reparación al respecto. Documentos que también se perdieron cuando las victimas tuvieron que salir con urgencia de sus residencias o lugares de trabajo por el desplazamiento forzado o cuando algunas casas fueron incendiadas por el grupo armado ilegal con los documentos en el interior, según el líder GP de Mampuján. Para corroborar lo dicho por él:

é digamos que se debió tener más en cuenta esta situación de las víctimas, algunos les tocó salir corriendo, perdieron documentos, si de pronto tenían 
PERCEPCIONES SOBRE LA MACROVICTIMIZACIÓN DE MAMPUJÁN Y SAN CAYETANO Y SU REPARACIÓN INTEGRAL EN EL MARCO DE LA LEY 975 DE 2005.

documentos de vacunación, de los animales, no pudieron demostrarlo porque, porque eso ser perdió, en algunos casos se quemaron, en algunos casos la gente no sabía a qué venían, por lo tanto, no tuvo tiempo de recoger documentosé (P2:04).

Además, a partir del representante judicial JS, la gran mayoría de las víctimas de Mampuján y San Cayetano eran trabajadores independientes, lo cual dificultó demostrar los daños relacionados con el Daño Emergente y Lucro Cesante porque, por ejemplo, no había documentos que soportaran sus ingresos económicos mensuales:

é Es que, cómo la demostramos sencillamente en el caso del desplazamiento, cuando íbamos a a cuantificar los perjuicios, el daño emergente, el núcleo cesante, cómo te digo no teníamos con qué porque no era posible demostrar, cómo ellos eran trabajadores independientesé (P5:09).

Al mismo tiempo, la participante MUJER 2 del grupo focal de las víctimas de San Cayetano ve como posible, pero sin afirmar, infieren los investigadores, que existieron errores en los nombres u otros datos plasmados en las órdenes de las indemnizaciones, evitando que les fueran entregadas a los beneficiarios:

é MUJER 2: é pero él no salió no sé por qué, pero él está disponible por eso, porque él dice que ajá, que por que el no salió, que qué pasó ahí. MUJER 3: De pronto, no sería que el tenía su plata en el bolsillo *** MUJER 2: No, no, todas las copias iban ahí, todo iba grapadito ahí... porque ehh osea, el hijo mayor de él, el hijo mayor de nosotros, de los varones, el tiene el mismo nombre de él. LUIS: Ajá. MUJER 2: Pero es diferente porque él llevaba su registro civil y él llevaba la fotocopia de la cédula. LUIS: Claro. BAYRON: Da los apellidos, pero... 
PERCEPCIONES SOBRE LA MACROVICTIMIZACIÓN DE MAMPUJÁN Y SAN CAYETANO Y SU REPARACIÓN INTEGRAL EN EL MARCO DE LA LEY 975 DE 2005.

MUJER 2: Ajá exacto, porque es que mi marido es $M L$, y mi hijo es MM, entonces el dio su registro, y él su fotocopia de la cédula, así que yo no sé, qué pasó ahí... (P8:01).

A su vez, como proceso desacertado está que el representante judicial LV manifestó que la Fiscalía General de la Nación poseía información valiosa de las víctimas que no compartieron con ellos para facilitar sus procesos de Justicia y Paz y de Reparación Integral. A saber:

é adicionalmente otro inconveniente que se, que se, se presentó al ser el primer incidente era la falta de comunicación institucional, ya que mucha información de la cual era requerida de los representantes judiciales reposaba en las carpetas de la Fiscalía General de la Nación, y en tal sentido hay un poco de celo o ellos manifestaban una especie de reserva sumarial sobre esa documentación, y cuando se hacía presente representantes judiciales al momento del incidente de reparación, hasta ese momento se daba cuenta que esa información la tenía la Fiscalía, pero nunca se no puso presente,é (P6:03).

Igualmente, está el hecho de que la Magistrada Ponente del incidente de reparación integral dado en segunda instancia deba solicitarle a la institucionalidad el cumplimiento de la sentencia, no hay voluntad institucional para cumplir los exhortos sin la presión de la Magistrada, las instituciones dilatan los procesos:

é la jueza ya que se, se empieza a exigirles más a las organizaciones, empiezan a moverse, hoy por hoy las organizaciones se están moviendo, eso ehh.. eso es bueno, es está moviendo y de pronto ya no están con la mismaé burla, por llamarlo así las organizaciones $* * *(P 7: 21)$. 
PERCEPCIONES SOBRE LA MACROVICTIMIZACIÓN DE MAMPUJÁN Y SAN CAYETANO Y SU REPARACIÓN INTEGRAL EN EL MARCO DE LA LEY 975 DE 2005.

También, el hecho que hasta la fecha de aplicación de las técnicas de recolección de información, a las víctimas aún no se le haya solucionado el tema de las viviendas dignas acordes a sus costumbres y estados en que se encontraban antes de los hechos victimizantes, por ejemplo, el líder GP de Mampuján manifestó: ñé nosotros estábamos acostumbrados a unas viviendas amplias, con unos patios donde podíamos tener los animales ehhh, para el consumo y eso, hoy estamos reducidos a unas viviendas de 6 metros por 6 en el mejor de los casosé (P2:05).ò.

Por su parte, la SEÑORA 3 del grupo focal de San Cayetano, opinó que no se han generado las condiciones para las víctimas de Mampuján y San Cayetano que quieren retornar al territorio, por ejemplo, como la adecuación y reconstrucción de las viviendas:

é SEÑORA3: é el gobierno quería que la gente campesina tuvieran a su retorno por eso digo yo que lo inicial habrían sido, vamos a hacerle las viviendas para que todos y después se venga todo lo demásé por lo menos yo no tengo vivienda, eso se cayó, y pádonde voy a coger allá, yo me quedo acá. Uhmmmé (P9:06).

Más, la decisión de exhortar y no ordenar las medidas de reparación integral en su totalidad para las víctimas de Mampuján y San Cayetano en el incidente dado en segunda instancia; especialmente se afecta las reparaciones colectivas. Al parecer, según el representante judicial LV, la Corte Suprema de Justicia exhortó y no ordenó las medidas de reparación integral a las instituciones del Estado con el argumento de que la Rama Judicial no puede obligar al Ejecutivo, posiblemente teniendo en cuenta las dificultades de generación de recursos presupuestales anuales: 
PERCEPCIONES SOBRE LA MACROVICTIMIZACIÓN DE MAMPUJÁN Y SAN CAYETANO Y SU REPARACIÓN INTEGRAL EN EL MARCO DE LA LEY 975 DE 2005.

é Lo primero que toca señalar es que, tal como la Corte Suprema de Justica le hizo el reparo al tribunal, las ramas del poder público no pueden ehh, chocar entre sí, y pues si bien es cierto el tribunal solicitó, en cierta medida obligaba que determinadas entidades de nivel municipal, departamental, y estatal, cumplieran unas medidas en reparación de las víctimas, más que todo en lo que tiene que ver con las medidas de carácter colectivo, la Corte Suprema de Justicia hizo el reparo que uno no puede obligar a las entidades, osea el judicial no puede obligar a las entidades del ente ejecutivo, y obviamente hubo una modificación por simple y llanamente exhortar, y la exhortación no obliga a que la entidad cumpla con esos, é (P6:04).

A su vez, se encontró otro proceso desacertado, según la líder LM de San Cayetano la atención estuvo puesta con mayor fuerza en las victimas de Mampuján que en las de San Cayetano, tanto que las víctimas de esta comunidad junto a su líder, hicieron gestiones para que el proceso adelantado dejara de llamarse solamente ñproceso de Mampujánò, quedando al final ñincidente de reparación de Mampuján y San Cayetanoò, es decir, lograron un reconocimiento de la comunidad como víctimas de alias ñJuancho Diqueò y ñDiego Vecinoò. Para confirmar:

é las instituciones a nosotros en San Cayetano o sea no nos hicieron el acompañamiento adecuado en su momento porque sólo enfocaban a Mampuján, o sea ellos sólo decían que existía Mampuján y luego cuando yo miro que dice el reconocimiento de la Fiscalía que dice Masacre de Mampuján yo empecé a revolver las aguas y a decir: no, es que aquí en Mampuján no hubo masacre, ustedes le están dando reconocimiento sólo a Mampuján, esto no es válido y esto 
PERCEPCIONES SOBRE LA MACROVICTIMIZACIÓN DE MAMPUJÁN Y SAN CAYETANO Y SU REPARACIÓN INTEGRAL EN EL MARCO DE LA LEY 975 DE 2005.

me lo cambian y me lo cambian y me lo cambian, y el Fiscal me dijo eso no se puede, yo le dije sí se puede, ustedes tienen que reconocer que se equivocaron y cambiar el nombre. Entonces luego pusieroné ya le hicieron el reconocimiento a la Masacre de las Brisas y a San Cayetano por lo menos lo ponen en la sentencia de Mampuján - San Cayetano porque no le hacían reconocimiento, sólo a Manpuján... (P4:07).

La persona líder de víctimas de San Cayetano siente que no hubo neutralidad al respecto y hubo demasiado enfoque en las víctimas de Mampuján. La comunidad de Mampuján fue la que más recibió acompañamiento de parte de la institucionalidad, según esta líder. Es más, según esta misma persona, muchas de las víctimas de San Cayetano, incluyéndola a ella, no obtuvieron cupos para asistir a Bogotá D.C. a los procesos adelantados de Justicia y Paz, con el argumento de que era un espacio solo para víctimas de Mampuján:

é por lo menos yo no participé desde Bogotá porque partiendo de ahí de que no nos atendían a todas las víctimas por igual, a mí no me dieron cupos para ir a delegar a Bogotá, yo sólo lo pude hacer desde aquí, desde la videoconferencia, el Chat satélite desde Bogotá porque sólo decían que eran Mampujanos entonces sólo le dieron cupos a las víctimas de Mampuján para estar en eso, é (P4:08).

Lo cierto es que, a partir del líder GP de Mampuján, a pesar de que algunas entidades como la MAPP OEA, PNUD, Comisión Nacional de Reparación y Reconciliación CNRR y personas particulares apoyaron económicamente a las víctimas de Mampuján y San Cayetano, hubo dificultades económicas en las víctimas de estas 
PERCEPCIONES SOBRE LA MACROVICTIMIZACIÓN DE MAMPUJÁN Y SAN CAYETANO Y SU REPARACIÓN INTEGRAL EN EL MARCO DE LA LEY 975 DE 2005.

comunidades para participar en el proceso de Justicia y Paz, por ejemplo, para asistir a las audiencias de versión libre que se realizaron en la ciudad de Barranquilla. A saber: é Bueno yo pienso que las dificultades estuvieron a lo largo del proceso no sólo en el incidente, la víctima no tiene condiciones para participar en el proceso digamos que económicamente, ehh, para llegar a una audiencia que se realiza en Barranquilla en el caso nuestro, no, no todos estábamos en condiciones de ir allá, muchas veces tuvo la MAP OEA que facilitar los recursos, el PNUD u otras personas particulares que, que le apostaron al proceso, entidades como la Comisión Nacional de Reparación; ehh, pero creo que las dificultades estuvieron allí a lo largo del proceso,é (P2:06).

Al mismo tiempo, como proceso desacertado, el representante judicial LV piensa que está el traslado de representantes judiciales radicados en la ciudad de Bogotá a representar víctimas en Mampuján y San Cayetano dentro del proceso de Justicia y Paz: ñé una de las falencias más complicadas, es el hecho de que deban trasladarse representantes judiciales de Bogotá, hasta San Cayetano, hasta Mampuján, todo lo que tiene que ver con esa infraestructura que toca adaptar, é ò (P6:05). Posiblemente, la dificultad radica en que esta situación retrasó procesos con las víctimas, relacionados con la recopilación de documentos que comprobaran los daños causados, estos Defensores Públicos no podían estar en contacto permanente y personal con las víctimas por la lejanía en que se encontraban.

Además, participantes de los grupos focales de las víctimas de Mampuján y San Cayetano ven como desacertado el tema de la ñJusticiaò del proceso de Justicia y Paz para los postulados. No ven gratificante, reparador ni justo que los postulados deban 
PERCEPCIONES SOBRE LA MACROVICTIMIZACIÓN DE MAMPUJÁN Y SAN CAYETANO Y SU REPARACIÓN INTEGRAL EN EL MARCO DE LA LEY 975 DE 2005.

cumplir condenas de entre 5 y 8 años de cárcel mientras las victimas siguen sufriendo las consecuencias de la macrovictimización de Mampuján y San Cayetano, cuando las victimas aún no han sido reparadas integralmente en su totalidad. Para corroborar:

é pensaría que la gente en las cárceles, que los postulados estén en las cárcelesé van a salir pronto y nosotros salimos en las mismas condiciones o peores condiciones en algunos casos, porque quizás en algunos casos que están en peores condiciones, esperando que todavía la reparación se dé, entonces ese es el desequilibrio, que por una parte los postulados cumplen su pena, pero salen prácticamente limpios, sin problema y la comunidad, y las personas siguen con los problemasé (P7:22). é SEÑOR: La, los únicos que salieron beneficiados en esa ley fueron los postulados, é Porque con todo el año que hicieron, para para 8 años de cárcel, eso digoé SEÑORA: Que ya están a punto de salir. SEÑOR: Porque todavía, todavía, todos estando aquí, nos atrevemos a decir que no no hemos recibido el todo como ellosé (P9:07).

Finalmente, está el hecho de que el proceso de ñVerdadò de Justicia y Paz sea construido principal y ñsolamenteò a partir de las versiones de los postulados:

é Bueno yo creo queé lo que no comparto es que sean los postulados los que digan la verdad. La verdad no puede ser contada por alguien que de alguna manera, primero no conoce la historia, y segundo oculta algunos hechos. Creo que la verdad debería ser tenida en cuenta desde las comunidades también, si el postulado admite un hecho, pues la comunidad tuviera la oportunidad de expresar lo que omiten. ̀̀ (P2:07). 
PERCEPCIONES SOBRE LA MACROVICTIMIZACIÓN DE MAMPUJÁN Y SAN CAYETANO Y SU REPARACIÓN INTEGRAL EN EL MARCO DE LA LEY 975 DE 2005.

Frente a ello, el líder AV de Mampuján, considera que deberían ser tenidas en cuenta con mayor magnitud las opiniones, declaraciones y refutaciones de las víctimas en este proceso, debido a que considera que no hubo ñVerdadò de todos los hechos victimizantes, referentes a la macrovictimización de Mampuján y San Cayetano. El mismo líder, considera que no dijeron toda la verdad los postulados, como el encapuchado en los hechos victimizantes que dijeron que no estaba y las victimas decían que sí estaba:

é pues si ellos no dijeron verdad, porque esa satisfacción de ellos; ellos entienden que han pasado cosas que ellos no dijeron,é como el encapuchado que dijeron que no estaba y la gente decía que si estaba y luego yo digo, señor postulado, ehh victimario, pero usted, pero usted no puede apostar que su palabra contradiga la de, la de toda la comunidad, que tiene tan presente ese día como si fuera hoy, porque eso no se puede borrar, el hecho de pasar por donde está fulano. Hasta los rostros si los vemos los conocemos, ahora que viene alguien vestido de cara y de todo, pues eso es inevitable que lo recordemos, y él llega a decir un tono, bueno ayúdenme a recordar; entonces creemos que cuando existen cosas como esas, el entiende que si alterca con la comunidad pues vamos a llegar a unas... él no tiene la razón, la comunidad la tieneé (P1:23).

\section{Procesos jurídicos acertados en el marco de la Ley de Justicia y Paz adelantados con las víctimas de Mampuján y San Cayetano}

Sin embargo, como procesos jurídicos acertados de Justicia y Paz con las víctimas de Mampuján y San Cayetano, es necesario señalar que hubo participación de las víctimas en estos procesos para la construcción de las medidas de reparación: ñé la señora Magistrada que creo que fue muyé muy sobre sobre el balance. 
PERCEPCIONES SOBRE LA MACROVICTIMIZACIÓN DE MAMPUJÁN Y SAN CAYETANO Y SU REPARACIÓN INTEGRAL EN EL MARCO DE LA LEY 975 DE 2005.

ENTREVISTADOR: Muy equilibrada. ENTREVISTADO: Ella equilibró mucho, le dio participación a las víctimas, como justicia y paz lo contempla, creemos que eso fue muy acertado, é ò (P1:24). Es decir, la Magistrada Ponente de la sentencia de segunda instancia fue equilibrada y equitativa con la participación de las partes, según el líder AV de las víctimas de Mampuján. Con lo cual se dio cumplimiento a lo dispuesto en el Art. 51 de la Ley 975 de 2005 (Funciones de la Comisión Nacional de Reparación y Reconciliación. Derogado por el Art. 208 de la Ley 1448 de 2011. La Comisión Nacional de Reparación y Reconciliación cumplirá las siguientes funciones:), numeral 52.1 (Garantizar a las víctimas su participación en procesos de esclarecimiento judicial y la realización de sus derechos).

De igual forma, a partir del representante judicial JS de las víctimas de Mampuján y San Cayetano y otros participantes, se puede señalar la generación de la segunda instancia del incidente de reparación, en cuanto a que permitió órdenes y exhortos de reparación integral a las víctimas en derecho y no en equidad, por ejemplo, las sumas de dinero de las indemnizaciones buscaron estar acordes a los daños causados. En la segunda instancia se tuvo en cuenta los daños causados en las victimas, por ejemplo, se tuvo en cuenta el lucro cesante, daño emergente, daño moral, entre otros; además, se exhortó medidas de rehabilitación física y psicológica para las víctimas que lo requerían; se exhortó medidas de reparación colectiva, como reparación y construcción de vías, reconstrucción y construcción de escuelas, hospitales, puestos de salud, entre otros; al igual se exhortó medidas de ñgarantías de no repeticiónò, como que se les brindara seguridad a las comunidades por parte de la Policía e Infantería de Marina y se crearon unos CAI; se exhortó medidas para capacitar a las víctimas en proyectos productivos y en inversión de los recursos 
PERCEPCIONES SOBRE LA MACROVICTIMIZACIÓN DE MAMPUJÁN Y SAN CAYETANO Y SU REPARACIÓN INTEGRAL EN EL MARCO DE LA LEY 975 DE 2005.

económicos que llegan del Estado, por ejemplo, las indemnizaciones; las anteriores en relación con los daños causados a las víctimas. Para corroborar lo anterior:

é cuando en segunda instancia se falla, pues, todo aquél que demostró haber perdido bienes materiales, pues se le reconoce y por eso. ENTREVISTADOR: En derecho. ENTREVISTADO: En derecho, si,é ò (P2:08). ñé por ejemplo, en primera instancia se falla en diecisiete millones, eso fue un desacierto para nosotros, un desconcierto, porque, de acuerdo a a a, alas perdidas y a las gestiones que se habían hecho de, de, de la Defensoría y de quienes conocían del tema, pues no tenía que ser en equidad, sino un derecho,é ò (P1:25). ñENTREVISTADOR: Uhmm. ENTREVISTADO: Hubo casos en en este fallo en el que un grupo familiar se le indemnizó con cifras de hasta \$980.000.000, una cifra que son elevadas, altas y que nosotros creemos que, que cumplimos, no solo en la parte económica porque también se logró conseguir unas medidas de rehabilitación, nosotros solicitamos asistencia médica y social para las víctimas, una reparación de vías, reconstrucción de escuelas, de hospitales, de puestos de salud, se logró, brindarles seguridad en el sentido en que, que, ehh.. en el sentido que la Infantería de Marina y la Policía iba a prestar seguridad, se crearon unos CAI, ehh... se le prestó, asistencia psicosocial en el sentido de de instruirlos a ellos en proyectos productivos para que el dinero que se, el Estado les dio de indemnización supieran cómo invertirlo para pues para su futuro,é aunque muchos son exhortosé, (P5:10).

En esta línea de argumentación, cabría anotar las percepciones como la aceptación y satisfacción por parte del mismo representante judicial JS de que se haya indemnizado a 
PERCEPCIONES SOBRE LA MACROVICTIMIZACIÓN DE MAMPUJÁN Y SAN CAYETANO Y SU REPARACIÓN INTEGRAL EN EL MARCO DE LA LEY 975 DE 2005.

una gran mayoría de las víctimas de Mampuján y San Cayetano, más del 90\%. Es la medida de reparación que se ha venido cumpliendo casi a cabalidad, porque algunas víctimas aún están a la espera de la indemnización, a pesar de ser una orden dentro del incidente de segunda instancia. Para confirmar lo dicho por el participante:

é La verdad sí creo que que logramos el objetivo, yo creería que, que en un, no tanto en un $100 \%$, pero en una cifra muy alta, más del $90 \%$ porque cómo te dije en Mampuján fueron muchas las visitas que se hicieron a la comunidad, fue muchas las charlas que se tuvieron con ella, y las expectativas que la comunidad tenía con respecto a la, a la indemnización que el Estado en su momento podría darle, pues sobrepasamos esos límites, é (P5:11).

Hasta ahora, está el cumplimiento, de una parte considerable, de las medidas de reparación simbólicas con las víctimas de Mampuján y San Cayetano; según el líder TR de Mampuján: ñé hay que aclarar que el Estado ha venido cumpliendo, las medidas de reparación simbólicas, é ò (P3:06). También, el hecho que las víctimas solicitaron lo justo en cuanto a reparación integral; el representante judicial JS de las víctimas de Mampuján y San Cayetano manifestó que las víctimas pidieron lo justo en cuanto a la reparación integral y que fueron ñhonestas al manifestar los daños causadosò, como la cantidad de semovientes perdidos, entre otros; a saber:

é Él sabe cómo vive la gente, de qué vive la gente, sabe que tiene la gente, sabía también el valor de esos semovientes por ser como lo manifestó un campesino y un oriundo de esa zona, ellos en este caso no refutaron las pruebas que los campesinos exactamente lo que se les perdió, ellos en ese sentido los campesinos eh fueron honestos y solo y pidieron justamente lo que tenían, no pidieron sumas 
PERCEPCIONES SOBRE LA MACROVICTIMIZACIÓN DE MAMPUJÁN Y SAN CAYETANO Y SU REPARACIÓN INTEGRAL EN EL MARCO DE LA LEY 975 DE 2005.

exorbitantes. ENTREVISTADOR: Ujum. ENTREVISTADO: Que en su momento no pudieran decir, que estaban de pronto mintiendo o teniendo un provecho, no ellos sencillamente pidieron los valores, que que lo que tenían y lo que perdieron, entonces por eso yo creo que los postulados en su momento no, no refutaron esas pruebas de la defensaé (P5:12).

Finalmente, se encuentra los procesos de seguimiento al cumplimiento de las medidas de reparación integral contempladas en el incidente de segunda instancia. Según el mismo representante judicial JS, se han hecho tres audiencias de seguimiento acompañadas por la Magistrada Ponente, dos de ellas en Mampuján, con el fin de presionar a las instituciones del Estado, como las Alcaldías deducen los investigadores, en el cumplimiento, especialmente, de las medidas de reparación colectiva, las cuales han avanzado a pasos muy lentos. Para corroborar lo dicho por el participante:

é Nosotros hemos hecho seguimiento a ese a ese fallo, hemos, ya se han hechos 3 audiencias de seguimiento, se hicieron 2 en Mampuján, con la comunidad, con la Magistratura, se les está exigiendo al Estado, pero de verdad el Estado ha sido negligente en ese sentido, y los compromisos, por ejemplo colectivos, que se, que adquirió los ha ido cumpliendo pero muy lentamente, lentamenteé (P5:13).

\section{Pretensiones de reparación integral de las víctimas de Mampuján y San Cayetano que}

\section{faltaron por incluirse en el incidente de reparación dado en segunda instancia}

Recordemos que uno de los objetivos específicos de esta investigación era conocer si faltaron por incluirse pretensiones de reparación integral de las víctimas de Mampuján y San 
PERCEPCIONES SOBRE LA MACROVICTIMIZACIÓN DE MAMPUJÁN Y SAN CAYETANO Y SU REPARACIÓN INTEGRAL EN EL MARCO DE LA LEY 975 DE 2005.

Cayetano dentro del incidente de reparación dado en segunda instancia, desde la percepción de los participantes. Para dar respuesta a ello:

En primera instancia, se encontró como pretensión de reparación integral no incluida dentro del incidente de reparación dado en segunda instancia, el hecho de que las demás medidas de reparación integral, como la indemnización, fueran dadas como ordenes dentro del incidente de reparación dado en segunda instancia y no como exhortos, por la agilidad en sus cumplimientos. El líder AV de las víctimas Mampuján manifiesta que todas las medidas de reparación debieron haber sido dadas como órdenes, debido a que considera que la Reparación Colectiva (exhorto), por ejemplo, beneficia más a la comunidad que el mismo dinero otorgado como indemnización (orden). Es decir, el incidente de reparación dado en segunda instancia debió contener con precisión el cumplimiento rápido - con tiempos definidos - , oportuno y eficaz de las medidas de reparación integral. Para corroborar lo dicho por el participante:

é como la indemnización si es una orden, entonces empiezan a trabajarle a la indemnización, y con lo colectivo que consideramos, que es mucho más, y que beneficia más a la comunidad que lo, que lo, lo monetario, pues, no estaba si no bajo los exhorto y ellos empiezan con la indemnizacióné (P1:26).

Por otra parte, y a pesar de que la mayoría estuvo de acuerdo, el líder TR de Mampuján considera que algunas víctimas estuvieron en desacuerdo con los montos de las indemnizaciones definidos en la sentencia de segunda instancia, debieron ser más altos, acordes a los daños causados a pesar de que no haya existido varias pruebas para demostrarlos, tal y como lo propuso en su momento la Defensoría del Pueblo, a través, de los representante judiciales de las víctimas: ñé Yo creo que hizo falta, porque se aprobaran algunos montos más considerables, tal y como lo propuso eh la Defensoría del Pueblo en su momento, é ò (P3:07). Debido a 
PERCEPCIONES SOBRE LA MACROVICTIMIZACIÓN DE MAMPUJÁN Y SAN CAYETANO Y SU REPARACIÓN INTEGRAL EN EL MARCO DE LA LEY 975 DE 2005.

que, varias víctimas de Mampuján y San Cayetano no tenían como demostrar pérdidas de bienes muebles, como los enceres, semovientes o cosas del hogar, porque perdieron o les fueron extraviados los documentos o fueron incinerados dentro de las casas de las cuales se desplazaron por culpa del Grupo Armado Ilegal:

é Si, algunas personas que demostraron haber perdido ehhh recibieron lógicamente un monto superior, porque por el delito de desplazamiento se reconocieron 17 millones de pesos, pero adicionalmente a esto si la persona demostró haber perdido, eh, algo más, un bien, pues también se lo estaban reconociendo, pero creo que no es completo aún, porque la víctima en esos momentos no tiene o no puede estar demostrando que perdió, se supone que la gente no está en el aire, de hecho si si, si, tenemos un lapso de tiempo en una comunidad, eh debemos tener un patrimonio, pues entonces no tendríamos que demostrarlo, lastimosamente fue un proceso judicial, y hubo que demostrarlo, pero, creo que la víctima debió ser másé digamos que se debió tener más en cuenta esta situación de las víctimas, algunos les tocó salir corriendo, perdieron documentos, si de pronto tenían documentos de vacunación, de los animales, no pudieron demostrarlo porque, porque eso ser perdió, en algunos casos se quemaron, en algunos casos la gente no sabía a qué venían, por lo tanto, no tuvo tiempo de recoger documentosé ò (P2:09).

Lo que quiere decir que, se limitó que se incluyeran todos los daños causados y víctimas de Mampuján y San Cayetano dentro de la sentencia de segunda instancia para su debida reparación integral. No todos gozan del derecho a una reparación integral o equitativa a partir de los daños causados. 
PERCEPCIONES SOBRE LA MACROVICTIMIZACIÓN DE MAMPUJÁN Y SAN CAYETANO Y SU REPARACIÓN INTEGRAL EN EL MARCO DE LA LEY 975 DE 2005.

Por su parte, según el líder TR de Mampuján, hizo falta la pretensión de que el incidente de reparación de Mampuján y San Cayetano dado en segunda instancia o el proceso como tal, abarcara a más víctimas de regiones vecinas. Las cuales, también sufrieron el flagelo de alias ñJuancho Diqueò y ñDiego Vecinoò, debido a que solo cobijó a las víctimas de Mampuján, San Cayetano y parte de las Brisas, entre otras veredas:

é hizo falta que se ampliara un poco más ese proceso, que no solamente fuera con Mampuján y con San Cayetano, sino que con algunas poblaciones más que también fueron víctimas del desplazamiento, supuestamente por los mismos actores, ehh pero, realmente nosotros en ese proceso pudimos lograr que lo que tiene que ver con Mampuján, San Cayetano, las Brisas y las demás veredas, fuera tenido en su gran mayoría, o en casi todos los aspectos, é (P3:08).

A su vez, el líder AV de Mampuján considera que hace falta la construcción de una Casa Museo en su comunidad y no un Monumento como se propuso en el incidente dado en segunda instancia, sin tener en cuenta la opinión y la negativa de las víctimas de Mampuján al respecto, ellas no quieren y manifestaron estar en desacuerdo con la idea, pero no fueron escuchas ni tenidas en cuenta sus oposiciones, ni la sugerencia de invertir el dinero del Monumento en la Casa Museo. El sueño es tener en la Casa Museo unos tapices que representen a unas ñmujeres tejiendo sueños y sabores de pazò y exponer unas fotografías, las cuales han empezado a recopilar, sobre los tiempos antiguos de Mampuján, de sus antepasados, la historia de Mampuján. Para corroborar:

é intentamos que eso que ellos iban a invertir en el monumento, pues se invirtiera para mejorar el museo; o en su momento habíamos pensado, ehh, teníamos unos tapices, hacer como que una casa cultural, ya nuestra, donde reposaran los 
PERCEPCIONES SOBRE LA MACROVICTIMIZACIÓN DE MAMPUJÁN Y SAN CAYETANO Y SU REPARACIÓN INTEGRAL EN EL MARCO DE LA LEY 975 DE 2005.

tapices y un tanto intentar que recoger la memoria pensando en que esos exhortos iban a demorar mucho, entonces teníamos una memoria que para ese entonces recobro mucho sentido, que eran los tapices, las mujeres tejiendo sueños y sabores de paz, teníamos una memoria, unas fotografías que habíamos buscado en el mismo proceso que recuerdan todo ese tiempo viejo de nuestros antepasados, una historia de Mampuján que se construyó en ese mismo proceso y soñábamos con tener una casa donde guardar todo eso hasta el día que se haga una realidad la, el museo de Mampuján;é (P1:27).

Igualmente, hizo falta la inclusión en el incidente de la construcción de un pozo, con el cual víctimas de San Cayetano en el punto del Arroyón puedan surtirse de agua para sus quehaceres diarios, en sus tierras:

é SEÑOR2: é tengo un pedacito de tierra en el punto arroyón, yo he podido construir una vivienda para no tenemos agua, no tenemos todavía no ha podido recuperar nada, entonces eso es lo que yo quiero que el gobierno haga otra ayudita $\mathrm{pa}^{\prime}$ a ver si podemos tener un pozo, tan siquiera para nosotros recoger el aguaé (P9:08).

De igual manera, la persona líder TR de Mampuján considera que hizo falta que se incluyera con claridad y contundencia dentro del incidente de reparación dado en segunda instancia, lo referente al derecho a la educación superior para las víctimas de Mampuján y San Cayetano, donde se definiera claramente beneficiarios, requisitos, beneficios o condiciones, etcétera: ñé hizo falta que se incluyera con mayor contundencia eh, el derecho a la educación superior, aunque en este momento nos están hablando de un programa eh, del DPS tendiente a cubrir esa parte con alguna parte de la población,é ò (P3:09). 
PERCEPCIONES SOBRE LA MACROVICTIMIZACIÓN DE MAMPUJÁN Y SAN CAYETANO Y SU REPARACIÓN INTEGRAL EN EL MARCO DE LA LEY 975 DE 2005.

Al mismo tiempo, un participante del grupo focal de las víctimas de Mampuján piensa que faltó indemnización por los gastos generados por concepto de arriendos de viviendas que han tenido que pagar durante varios años las víctimas de Mampuján y San Cayetano, como consecuencia del desplazamiento forzado; a saber: ñé Tanta pérdida, porque ajá, yo dure 9 años pagando arriendo, y sé yo no voy a ser digamos beneficiado en ese gasto que tuveé ò $(P 7: 23)$.

Por otra parte, para una participante del grupo focal de víctimas de San Cayetano, la dignificación de las comunidades no se hizo eficientemente y acorde a los deseos de muchas víctimas, por ejemplo, siente que los recortes de periódico donde se desmentía que habían sido victimizadas por alias ñJuancho Diqueò y ñDiego Vecinoò por ser colaboradores de la guerrilla, no fue un proceso suficiente porque no les devolvió la dignidad, en sus propias palabras: ñé son papeles que se rompen, se muerené ò (P9:09). Esta intervención debió ser por todos los medios de comunicación y con mayor resonancia, consideran los investigadores. Para corroborar de mejor manera lo dicho:

é SEÑORA: Exactamente, que entregaron un periódico, limpiando el nombre de de nosotros, pero en realizad, osea yo... BYRON: Y eso les parece a ustedes suficiente?... SEÑORA: Eso no es suficiente, porqueé BYRON: Y por qué eso no es suficiente. SEÑORA: Porque un papel se rompe, se muere, se acabó; pero, hasta ahí ya osea que ya ya en lo personalmente estamos sucios porque ya ellos dijeron que eramos guerrilleros, nos asesinaron a nosotros. ò (P9:10).

Finalmente, el líder TR de Mampuján expresó que las medidas de reparación integral incluidas en la sentencia de segunda instancia debieron estas más ajustadas a la identidad de las comunidades, buscando la recuperación del tejido social, la recuperación cultural y de 
PERCEPCIONES SOBRE LA MACROVICTIMIZACIÓN DE MAMPUJÁN Y SAN CAYETANO Y SU REPARACIÓN INTEGRAL EN EL MARCO DE LA LEY 975 DE 2005.

costumbres, como la de decir ñíoò a las personas mayores, acto que refleja respeto y humildad, las particularidades culinarias de las regiones, entre otras. Piensan los investigadores que esto se vio afectado, por ejemplo, al definirse como exhortos medidas de reparación como el retorno, la construcción de viviendas dignas, sin buscar expresamente mantener las costumbres de estas comunidades:

é deben haber unas medidas aún más profundas para recuperar ese tejido, pienso de que deben haber unas medidas de protección haciaé o o, unas medidas de recuperación de esa cultura, de esa forma de ser del ser humano en esas, en esas eh comunidades, hay que recordar que nosotros éramos unas personas, ehh con unas costumbres muy particularesé ENTREVISTADOR: Cuáles. ENTREVISTADO: Ehhh.. con esa forma de alimentarnos diferente, con esa forma de saludar a nuestros vecinos diferente, con esa forma de llegar todas las mañanas donde una cantidad de gente y tomarnos un tinto, con eso de, eh decirle ñtíò̀ a todo a quien considero mayor de edad, y eso de decir tío a una persona que no es ni siquiera mi primo, ni mi tío, ni mi familia, eso es, eso es un valor agregado a la vida, porque eso es un aspecto que refleja respeto, que refleja sencillez, que refleja humildad;é (P3:10).

\section{Incumplimientos por parte de la institucionalidad de los Resuelve emitidos por la Corte}

\section{Suprema de Justicia en el fallo de segunda instancia frente a la reparación integral de las}

\section{víctimas de Mampuján y San Cayetano}

Es necesario recordar que otro de los objetivos específicos de esta investigación era determinar si hubo cumplimiento por parte de los postulados y por parte de la institucionalidad de las órdenes y exhortos (Resuelve) emitidos por la Corte Suprema de Justicia en el fallo de 
PERCEPCIONES SOBRE LA MACROVICTIMIZACIÓN DE MAMPUJÁN Y SAN CAYETANO Y SU REPARACIÓN INTEGRAL EN EL MARCO DE LA LEY 975 DE 2005.

segunda instancia frente a la reparación integral de las víctimas de Mampuján y San Cayetano, desde la percepción de los participantes. De lo cual se puede decir que no hay cumplimiento total de las obligaciones, lo cual no contribuye a la reparación integral de las víctimas.

Aunque se ha venido respondiendo este punto, como respuesta detallada se encontró varios incumplimientos por parte de la institucionalidad señalados por los participantes de la investigación. Entre ellos está, según el líder TR de Mampuján, mejorar las condiciones de vida de las comunidades de Mampuján y San Cayetano donde están residiendo en el momento por el desplazamiento forzado. En cuanto a generar condiciones dignas de vivienda, carreteras pavimentadas para evitar inundaciones o lodo en las calles en épocas invernales, donde tengan agua potable, alcantarillado, entre otros beneficios, especialmente con las víctimas de Mampuján. Para corroborar:

é pero en los exhortos, é por ejemplo el alcantarillado, agua potable, cunetas, bordillos y andenes, nadie nos toca, e insistimos e insistimos, y no hay respuesta positiva, entonces creemos que también hay un juego allí, y como decimos los costeños en el bueno uso de la palabra, ñun vacilónò,é (P3:11).

Es decir, relacionado con lo anterior, el líder LM de San Cayetano considera que no ha existido cumplimiento de las reparaciones colectivas en su totalidad. No se han construido, sobretodo en la comunidad de Mampuján, la cual lo requiere con más prontitud por las observadas difíciles condiciones de vida y salubridad durante la aplicación de las técnicas de recolección de información, carreteras pavimentadas (a cargo de INVÍAS), viviendas dignas (responsabilidad de las Administraciones Municipales), puestos de salud, iglesias cristiana evangélica en Mampuján, religión que la mayoría de la comunidad practica y predica, centros educativos o escuelas en su totalidad, donde todavía falta legalizar el predio para la construcción 
PERCEPCIONES SOBRE LA MACROVICTIMIZACIÓN DE MAMPUJÁN Y SAN CAYETANO Y SU REPARACIÓN INTEGRAL EN EL MARCO DE LA LEY 975 DE 2005.

de la escuela a ubicarse en la vereda de Aguas Blancas, a cargo de la Alcaldía; cunetas, bordillos, andenes, obligaciones de las Alcaldías, sobretodo de donde está ubicada Mampuján para la generación del proyecto de construcción y del Departamento para la Prosperidad Social (DPS) para la construcción; centro de acopio de las comunidades; puentes y pontones a cargo de la Gobernación de Bolívar; acueductos y alcantarillado, especialmente con la comunidad de Mampuján, este último con responsabilidad de la Alcaldía de María la Baja; entre otros compromisos:

é hemos tenido una inconveniente con la escuela de la vereda de Aguas Blancas,é la sentencia daé exhorta al alcalde del municipio a comprar los predios para la construcción de la misma, pero el alcaldeé no sé si es que políticamente no ha tenido la voluntadé Con las víasé pues le toca a Invías una parte, Invías se comprometió, vino, llegó, dijo que iniciaban obras, en oc.., a finales de septiembre o a principios de octubre,é ehhh, la gobernación que le tocan los puentes y los pontones, pues no, los puentes y los pontones les toca a la Alcaldía, ahí estamos un poquito cojos porque la gobernación manifestó en primera instancia decir que iba a construir porque tiene puentes que construir que sí que tenía el dinero para los puentes y esto, ahora en la mesa pasada que hicimos en junio manifiesta que no, porque, se le vaé es mucho, mucho presupuesto y ellos no lo tenían en el presupuesto de este año, cuando eso ya se había hecho previamente, y dice que sólo puede construir un puente este añoé (P4:09).

Lo cual, está desgastando a las víctimas de Mampuján y San Cayetano y genera pérdida de confianza en las entidades del Estado. A partir de un participante del grupo focal de Mampuján, 
PERCEPCIONES SOBRE LA MACROVICTIMIZACIÓN DE MAMPUJÁN Y SAN CAYETANO Y SU REPARACIÓN INTEGRAL EN EL MARCO DE LA LEY 975 DE 2005.

una de sus causas es la falta de definición y eficacia por parte de la institucionalidad en la consecución de terrenos o lotes para empezar las medidas colectivas de reparación:

é Está hablando de de, de, de la reparación colectiva, y yo eso no se ha dado yyy, claro que de pronto yo digo que ellos no tienen quizá mucha culpa, el problema de nosotros aquí, es que no conseguimos los terrenos para construir, ellos. BYRON: Por qué razón. SEÑOR: Porque los propietarios, piden una suma muy elevadaé $(P 7: 24)$.

Por ejemplo, la Alcaldía de María la Baja que cobija a Mampuján no ha logrado gestionar los terrenos para las escuelas, por ende, el Ministerio de Educación no se ha podido encargar de todo el tema metodológico educativo, es decir, de la educación:

é ya se había manifestado no teníamos predio para las escuelas, la sentencia daé exhorta al alcalde del municipio a comprar los predios para la construcción de la mismaé pero el alcaldeé no sé si es que políticamente no ha tenido la voluntadé (P4:10).

A su vez, no se ha priorizado las viviendas dignas para las víctimas (familias) de Mampuján y San Cayetano, llevándolas a gastar los dineros de la indemnización en arriendos, compra de vivienda nueva, usada o en mejoras, dinero que podría ser gastado en otras necesidades, teniendo en cuenta que la vivienda ya es un derecho adquirido por ser desplazados forzadamente:

é tengo que señalar una falencia que también tiene la sentencia, é por ejemplo si yo vivo en una choza, si yo vivo en una casita de bahareque, que en invierno se me resuma, y se me forma un barrial, se me hace muy difícil, siendo de que la vivienda también es una obligación dentro de la sentencia, se me hace muy difícil esperar 2 o 3 años, que me cumplan dándome una vivienda, teniendo yo 30, 40, 
PERCEPCIONES SOBRE LA MACROVICTIMIZACIÓN DE MAMPUJÁN Y SAN CAYETANO Y SU REPARACIÓN INTEGRAL EN EL MARCO DE LA LEY 975 DE 2005.

50, 60 millones de pesos en un banco. Entonces la gente ha tenido la necesidad, parcialmente de utilizar los recursos de la sentencia para hacer vivienda, y esa no es la idea. Yo creo que usted vio almorzando aquí a una cantidad de personas que no son de aquí, usted se ha dado cuando, hay cerca de 50 o 60 personas trabajando construcción, cada quien está haciendo 2 o 3 piezas, está arreglando sus casas y creemos que ahi hay un desgaste porque tranquilamente la gente puede invertir en otras cosas, lo que hoy está invirtiendo en viviendaé (P3:12).

No obstante, la vivienda para poblaciones vulnerables, como las víctimas del conflicto armado, también está contemplado como un derecho constitucional, el cual se utilizó en el incidente de reparación, se pretende reparar a las víctimas con algo que es una obligación constitucional del Estado con los ciudadanos colombianos vulnerables.

Lo que importa es entender la sugerencia de los investigadores que consiste en hacer un seguimiento en los comités de las comunidades al cumplimiento de los exhortos y órdenes del incidente de reparación, donde la secretaria técnica la tiene el DPS: ñé la secretaría técnica del comité, en este caso la ejerce el DPS...ò (P3:13); se debe ser más insistente con las instituciones que tienen responsabilidad al respecto o informar las debidas anormalidades e incumplimientos al Ministerio Público para las respectivas investigaciones y sanciones.

En la misma línea, como incumplimiento institucional, está también el retorno de las víctimas de Mampuján y San Cayetano que así lo desean. Según una participante del grupo focal de las víctimas de San Cayetano, retorno a sus lugares de trabajo y de residencia, antes de que sucediera la macrovictimización de estas comunidades, en especial el desplazamiento forzado; además, de generar las condiciones para ello, tales como, la construcción o reconstrucción de las viviendas: ñé SEÑORA3: é el gobierno quería que la gente campesina tuvieran a su 
PERCEPCIONES SOBRE LA MACROVICTIMIZACIÓN DE MAMPUJÁN Y SAN CAYETANO Y SU REPARACIÓN INTEGRAL EN EL MARCO DE LA LEY 975 DE 2005.

retorno por eso digo yo que lo inicial habrían sido, vamos a hacerle las viviendas para que todos y después se venga todo lo demásé ò (P9:11).

Visto desde otra perspectiva, la persona líder LM de San Cayetano, considera que está la generación y apoyo en la consecución de proyectos productivos para las víctimas de Mampuján y San Cayetano, con el fin de mejorar sus capacidades productivas. Por ejemplo, el Ministerio de Agricultura no ha presentado colaboración y cumplimiento para apoyar a las víctimas en proyectos productivos, confundiéndolas, evadiendo las responsabilidades, argumentando que la obligación es de otras instituciones:

é Pero si nosotros le pedimos es proyectos productivos, nosotros no le estamos pidiendo vivienda. ENTREVISTADOR: Vivienda rural. ENTREVISTADA: Osea, yo supongo que eso hace parte de su competencia, siempre y cuando las personas, las comunidades les manifiesten esa necesidad, pero si mi necesidad es cultivaré osea, yo vivo del cultivo, de la producción agrícola, dígame, si yo le pido que me apoye en volver a ser una productora agrícola en mi finca, ehh cómo me va a decir, no, no puedo porque esa no es mi competencia. Osea, esa sí es su competencia, pienso yo que sí es su competencia porque por eso se llama Ministerio de Agricultura o si no hay que cambiarle el nombre y ponerle el que por lo menos se relacione con lo que ellos tienen que cumpliré (P4:11)

Ahora bien, a partir de la participante $K$ del grupo focal de las víctimas de Mampuján, también se ha incumplido la ejecución de las medidas de rehabilitación física y psicológica o de atención psicosocial para las víctimas de Mampuján y San Cayetano que lo necesitan o solicitan. A su vez, está la restitución de tierras para las víctimas de Mampuján y San Cayetano afectadas. Para corroborar: 
PERCEPCIONES SOBRE LA MACROVICTIMIZACIÓN DE MAMPUJÁN Y SAN CAYETANO Y SU REPARACIÓN INTEGRAL EN EL MARCO DE LA LEY 975 DE 2005.

é $K$ : Bueno ... uhmmm... ahora, cuando hablaban de las preguntas ustedes se sienten reparados, de ahí insistirse que la reparación no se ha dado de manera completa, y si no se ha dado da manera completa no podemos decir que se ha dado de manera integral si, porque la reparación tiene varios elementos si, la indemnización si, la indemnización que es lo material, la parte de la plata, pero hay otra, de la de de componentes como la rehabilitación, como la asistencia psicosocial,é . é primero, porque en unos momentos, cuando se dio, la, la, la segunda sentencia, la sentencia de ratificación, la Corte ordenaba la restitución de las tierras, yyy y no, y y si, no sé si los señores se acuerdan, que se demoró como un periodo ahí como***, sin eh, sin presencia de las organizaciones, de pronto, se burlaban de nosotros y decían, no que el fallo está paốal fecha y después cuando esa fecha llegaba, y decía, no, es que ahora hay que esperar,é $(P 7: 25)$.

Seguimos pues con la observación de lo que se ha incumplido, ahora estamos hablando de las ñgarantías de no repeticiónò con las víctimas de Mampuján y San Cayetano, no hay percepción de seguridad por parte de las víctimas (líder AV de Mampuján):

é y usted viene a decir que esa es la seguridad, y yo pienso que cuando hicieron el proyecto de seguridad, pensaron que era satisfacción de esa víctima, y viene la víctima y dice hoy aquí, es que no se siente segura aquí;é (P1:28).

Y, también, las medidas de satisfacción con las víctimas de ambas comunidades en su totalidad, se ha hecho parcialmente: ñé $K$ : Eso se, eso se ha dado parcialmente, primero porque las induciones, yo creo que, que muchas veces jugaron con nuestra dignidad; primero, porque en unos momentos, é ò (P7:26). Añadido a esto, se encontró que, como 
PERCEPCIONES SOBRE LA MACROVICTIMIZACIÓN DE MAMPUJÁN Y SAN CAYETANO Y SU REPARACIÓN INTEGRAL EN EL MARCO DE LA LEY 975 DE 2005.

mínimo, a un participante, este de San Cayetano, no se le ha cumplido, diferente a las medidas de reparación integral, las ayudas humanitarias por el desplazamiento forzado: ñ..SEÑOR 1: é Ehhh otras cosas que tampoco, yo personalmente no he recibido son las ayudas humanitariasé ò (P9:12).

Al igual que, la indemnización de todas las víctimas de Mampuján y San Cayetano incluidas en la sentencia de segunda instancia; aunque, según el representante judicial JS, se ha indemnizado a alrededor del $65 \%$ de los beneficiarios de ambas comunidades, de alrededor de 1600 víctimas de ambas comunidades, y que hay 400 personas o más que no han recibido los recursos económicos de indemnización: ñé En la parte económica, yo creo que se ha cumplido como por ahí en un 60\%, 65\%, como te digo son más o menos 400 o más víctimas a las que no se les ha entregado recursoé ò (P5:14); pero se demoraron casi un año, después de la sentencia de segunda instancia, para empezar a reparar económicamente a las víctimas, según la líder LM de San Cayetano:

é bueno ustedes saben que el haber dado una sentencia de segunda instancia decía que se le pagara a las víctimas en el tiempo mínimo, incluso menciona en la de primera instancia menciona tres meses, y luego dice que de inmediato, y eso hasta ahora se dio, más de un año, casi año y medio después, oseaé (P4:12).

Esta misma persona líder de San Cayetano considera que específicamente en su comunidad se ha indemnizado alrededor del $63 \%$ de los beneficiarios; indemnizaciones que se dieron en San Cayetano el 26 de agosto de 2012; del mismo año y mes, el 25 con las víctimas de San Juan, el 24 con las víctimas que residen en Cartagena y entre el 27 y 28 con las de Mampuján. Para corroborar: 
PERCEPCIONES SOBRE LA MACROVICTIMIZACIÓN DE MAMPUJÁN Y SAN CAYETANO Y SU REPARACIÓN INTEGRAL EN EL MARCO DE LA LEY 975 DE 2005.

é Si, ya lo han recibido en San Cayetano ummhhh como el 60\%, 63\% más o menos. ENTREVISTADOR: Y en qué épocas recibieron esa indemnización? ENTREVISTADA: El día 26 de agosto de 2012. ENTREVISTADOR: Eso fue para San Cayetano y Mampuján? O solamente en San Cayetano? ENTREVISTADA: No, en San Cayetano se dio el 26, las víctimas de San Juan se dieron el 25, las víctimas que viven en Cartagena la recibieron el 24, en Mampuján se dio el 27 y 28 de agostoé (P4:13).

\section{Incumplimientos por parte de los postulados de los Resuelve emitidos por la Corte Suprema} de Justicia en el fallo de segunda instancia frente a la reparación integral de las víctimas de Mampuján y San Cayetano

El líder AV de Mampuján y un participante del grupo focal de San Cayetano, consideraron como incumplimiento de los Resuelve de la sentencia de segunda instancia, la no confesión de todos los hechos victimizantes de parte de los Postulados, afectándose la dignidad y reconocimiento de reparación integral para todas las víctimas de Mampuján y San Cayetano:

é pues si ellos no dijeron verdad, porque esa satisfacción de ellos; ellos entienden que han pasado cosas que ellos no dijeron, (P1:29). é para que lograr pues la verdad se lleve pues a flote, es decir que se dijera verdad de la verdad, es decir como otra verdad, si me entienden. SEÑOR: Los postulados tienen que hablaré (P9:13).

Por su parte, el líder AV de Mampuján percibe como incumplimientos de parte de los postulados de los Resuelve de la Corte Suprema de Justicia dados en la sentencia de segunda instancia, la construcción de unos monumentos, especialmente en la comunidad de Mampuján, compromiso adquirido por los mismos postulados sin ser solicitados por las víctimas: ñé hay 
PERCEPCIONES SOBRE LA MACROVICTIMIZACIÓN DE MAMPUJÁN Y SAN CAYETANO Y SU REPARACIÓN INTEGRAL EN EL MARCO DE LA LEY 975 DE 2005.

una orden, que es la cuestión de los monumentos, eso es un compromiso que se hicieron ellos mismos, ninguno se lo pidió; eso no se ha hecho,é ò (P1:30), es más, ellas han manifestado estar en desacuerdo con la idea, solicitan en remplazo de los monumentos, construcción de una Casa Museo: ñé ese recurso que iban a invertir en monumentos, porque no nos lo aportaban para conseguir ehh.. un museo, para hacer una casa museo en Mampuján, é ò (P1:31). Sin embargo, desconociendo las causas, ñé en ninguna parte se han hecho los monumentosé ò $(P 1: 32)$, según el mismo líder de Mampuján. Uno de esos monumentos debe realizarse en San Juan de Nepomuceno.

Para realizarse lo anterior, se hace necesaria la entrega de sus bienes o propiedades para pasar al fondo de reparación de las víctimas, en específico, de Mampuján y San Cayetano, entre otras. Los postulados han entregado bienes que sumados no superan los 1.000 millones de pesos, cuando la reparación de las víctimas cuesta alrededor de 36.000 millones. En el caso, por ejemplo, de alias ñJuancho Diqueò entregó una casa valorada en 12.000 millones, por otro lado, alias ñDiego Vecinoò entregó varias fincas, pero alrededor de seis presentaban problemas judiciales, según el representante judicial JS. A saber:

é Las órdenes específicas hacia ellos eran pues fíjate que, para ellos ser postulados ellos tenían que, que, que reparar y reparar era que eh los postulados como tal, el bloque de vía debía entregar. ENTREVISTADOR: Propiedades. ENTREVISTADO: Al fondo unas propiedades, las propiedades que entregaron fueron ínfimas, las propiedades que ellos entregaron escasamente creo que llegan a los \$1.000.000.000, cuando la reparación de las víctimas costó alrededor de $\$ 36.000 .000 .000$, el caso de Juancho Dique por ejemplo, lo que entregó fue una casa valorada en \$12.000.000, que no alcanzan ni para reparar una víctima. 
PERCEPCIONES SOBRE LA MACROVICTIMIZACIÓN DE MAMPUJÁN Y SAN CAYETANO Y SU REPARACIÓN INTEGRAL EN EL MARCO DE LA LEY 975 DE 2005.

Diego Vecino entregó varias fincas, pero, 2 o 3 de las 5 o 6 que entregó tenían problemas judiciales, osea que, en cuanto a los bienes que ellos entregaron para reparar, no, para mí no cumplían con los requisitosé (P5:15).

\section{Insatisfacción de las pretensiones de las víctimas de Mampuján y San Cayetano con el}

\section{resultado del incidente de reparación dado en la segunda instancia}

El último objetivo específico de esta investigación consistía en identificar si fueron satisfechas las pretensiones de las víctimas de Mampuján y San Cayetano con el resultado del incidente de reparación dado en segunda instancia. De lo cual, se pudo obtener varias respuestas puntuales por parte de algunos participantes, pero antes se hace necesario que el lector recuerde la definición de Satisfacción expuesta en la Revisión de la Literatura.

Ahora, respondiendo al objetivo específico, primero es necesario precisar y recordar que las pretensiones a las cuales se hace referencia en este punto no están netamente ligadas con pretensiones de reparación. Abarca un sin número de anhelos de las víctimas de Mampuján y San Cayetano con el resultado del incidente de reparación dado en segunda instancia.

Entonces, a pesar que algunas víctimas de Mampuján y San Cayetano se sienten satisfechas con el proceso de Justicia y Paz o con los resultados del incidente de reparación integral dado en segunda instancia, como se detallará en el siguiente apartado, existen otras que sienten insatisfacción de sus pretensiones.

Por ejemplo, en un primer momento, genera insatisfacción en las víctimas de Mampuján y San Cayetano el incumplimiento de las medidas de reparación integral contempladas en el incidente de reparación dado en segunda instancia. Lo cual no contribuye a la reparación integral de las víctimas. Por ejemplo: 
PERCEPCIONES SOBRE LA MACROVICTIMIZACIÓN DE MAMPUJÁN Y SAN CAYETANO Y SU

REPARACIÓN INTEGRAL EN EL MARCO DE LA LEY 975 DE 2005.

é eso es insatisfactorio para nosotros porque, primero ya la sentencia lleva mucho tiempo de haber salido y que ya es hora que ya por lo menos hubiera por lo menos un 50\% construido de todo lo que decía en la sentencia, no va ni un 10\%, (P4:14). ENTREVISTADOR: Y en la medida de satisfacción, que fueron las orden que se entregó eh eh, ahí en la sentencia, en la realización de cierto tipo de eventos por así decirlo, está mucho más atrasado, porque ahí debía, debía, hacerse por ejemplo la reparación de vías, ehh escuelas, ehh etcétera, etcétera, que no, no se han cumplidoé (P5:16).

Lo cual está en contravía con lo que piensa el representante judicial JS de las víctimas de Mampuján y San Cayetano, donde frente a la pregunta ¿cree que las pretensiones de las víctimas de Mampuján y San Cayetano fueron satisfechas con el resultado del incidente de reparación dado en segundo instancia?, respondió: ñé $S i$, lo que, lo que las víctimas pretendían, yo, yo creo y estoy seguro de que nosotros logramos el objetivo de la reparacióné ò (P5:17).

Además, según un participante del grupo focal de Mampuján, siente insatisfacción porque considera que ningún proceso, ñé con lo que uno ha perdido allá, nunca se repone eso, eso es como una herida muy grande...ò (P7:27), le devolverá lo perdido con la macrovictimización de Mampuján y San Cayetano. Más, cuando otro participante del grupo focal de Mampuján y otros de San Cayetano, perciben que la indemnización recibida o a recibir por la sentencia de segunda instancia es poca, a pesar de que en ésta se ordenó indemnización en Derecho y no en Equidad, indemnización que no es equivalente a lo perdido como víctimas de alias ñ̃uancho Diqueò y ñ̃iego Vecinoò: 
PERCEPCIONES SOBRE LA MACROVICTIMIZACIÓN DE MAMPUJÁN Y SAN CAYETANO Y SU REPARACIÓN INTEGRAL EN EL MARCO DE LA LEY 975 DE 2005.

é Osea, que ese daño que nos hicieron a nosotros, eso no tiene comparación por esto porque uno perdió todo más de lo que tenia y con poquita plata que le dan a uno, que eso se acaba, nunca comparece con lo que uno teníaé, é el dinero se acaba y el daño queda hechoé (P7:28). é LUIS: é la indemnización solamente alcanzó para muy pocas cosas? SEÑORA3: Si señor. SEÑOR1: Para muy pocas cosasé ò (P9:14).

Por ejemplo, la indemnización no ha alcanzado para que las victimas puedan darles estudio a sus hijos, como se ha dicho anteriormente, estudio que abandonaron por la macrovictimización de Mampuján y San Cayetano.

Asimismo, dos participantes de ambos grupos focales concuerdan en considerar que la indemnización recibida o a recibir solo por el desplazamiento forzado, sin sumar los daños causados, a raíz de los resultados del incidente de reparación dado en segunda instancia, es una suma muy baja; aunque el mismo monto se había ordenado en la primera instancia. Considera que 17.000 millones de pesos no son suficientes para reparar a las víctimas del desplazamiento forzado, más cuando han pasado casi 12 años de esperar un incidente de reparación y perdieron bienes muebles de gran envergadura, como cultivos grandes de ñame u otros cultivos, cría de animales, como gallinas, cerdos, semovientes, entre otros, con los cuales subsistían. Para confirmar:

é.tantos sentimientos que el desplazamiento ehh, ehh, nos proporciona a nosotros, que la reparación que \$17.000.000 no son suficientes para reparar a la, a las víctimas de esta comunidad, si nos ponemos a sacar la cuenta son casi 12 años de lucha, bueno son casi no, son12 años de lucha, son 12 años en los que hemos vivido, de pronto en medio del miedo, é (P7:29). é Pero $\$ 17.000 .000$ no es lo que recompensa 12 años deeee de dufrimiento y que uno no podía, no puede 
PERCEPCIONES SOBRE LA MACROVICTIMIZACIÓN DE MAMPUJÁN Y SAN CAYETANO Y SU REPARACIÓN INTEGRAL EN EL MARCO DE LA LEY 975 DE 2005.

trabajar como antes trabajaba, y queeee, las cosas que uno tenía no las ha podido recuperar, en especial esa confianza, el daño uhmm uno, yo sembraba mis ñames, 3000 matas de ñame, mi esposa tenía gallinas, teníaaaa cerdo, habíaaa, de todo, y ella, ella duró casi 6 años que no iba allá,é (P9:15).

No cabe duda que esta molestia genera insatisfacción en una gran mayoría de víctimas de Mampuján y San Cayetano, por el hecho de que no se reparara a algunas víctimas por pérdidas de algunos bienes inmuebles o muebles, como los dejados en los hogares o los despojados por el desplazamiento forzado. Debido a que no se tuvo en cuenta, dentro del incidente de reparación dado en segunda instancia, la pérdida de documentos en medio de la angustia del desplazamiento de las personas o por parte de los representantes judiciales, para acreditar sus calidades de víctimas, las pérdidas o daños causados; se dejaron víctimas por fuera de la sentencia de segunda instancia y algunos daños causados, lo que les limitó la reparación integral recibida o a recibir, entre ellas, la indemnización.

Por otro parte, le insatisface a otro participante del grupo focal de Mampuján, no ver que se estén dando garantías de no repetición para las comunidades afectas por la macrovictimización de Mampuján y San Cayetano, donde puntualmente expresa:

é son 12 años en los que hemos vivido, de pronto en medio del miedo, del temor de que los hechos se vuelvan a repetir pese a que van a dar la garantía de la no repetición, yo creo que las palabras se las lleva el viento, y dicen que el papel lo aguanta todo, pero, también es ver qué tanto aguanta ese papel, porque si viene una gota de agua de seguro se desvanece. Entonces es ver que tan cierto es esa garantía de no repetición, para ver si esto satisface nuestras necesidades, lo que nosotros no vemos que se está dando,é (P7:30). 
PERCEPCIONES SOBRE LA MACROVICTIMIZACIÓN DE MAMPUJÁN Y SAN CAYETANO Y SU REPARACIÓN INTEGRAL EN EL MARCO DE LA LEY 975 DE 2005.

Para terminar, a la participante $K$ del grupo focal de Mampuján no la satisface los 5 u 8 años de cárcel que deben cumplir los postulados que se acogieron a la Ley de Justicia y Paz, en este caso en específico, condena que deben cumplir alias ñJuancho Diqueò y ñDiego Vecinoò. Lo cual, considera no aporta a la reparación integral de las víctimas, por hechos tan atroces que cometieron estos victimarios no solo en Mampuján y San Cayetano, sino que venían haciéndolo desde el territorio Monte Mariano; las masacres no fueron solo en las Brisas, ni desplazamiento en Mampuján o San Cayetano, sino en muchos otros municipios de la región, donde según esta víctima de Mampuján, percibe como injusto que un violador (relacionado con un solo delito sexual) reciba más condena que estos postulados que cometieron delitos tan atroces y en grandes cantidades: de lesa humanidad, crímenes de guerra, genocidios, macrovictimizaciones, entre otros:

é $K$ : é sigue siendo mínimo 8 años de cárcel para unas personas que cometieron hechos tan atroces, y no solo en Mampuján, sino que venían haciéndolo desde lo que fue, en todo lo que fue el territorio Monte Mariano, osea fueron hechos horribles, fueron masacres no solo en Las Brisas, fueron desplazamiento no solo en Mampuján, sino en muchos otros municipios de la región Montemariana, ehh entonces osea, 8 años de cárcel, yo creo que a un violador le dan muchas más años de cárcel, pero le dan algo así parecido o quizá un poquito más, cuanto más una persona que cometió tantos crímenes, a una persona que de pronto desplazó a tantas comunidades, entonces creo que, que la justicia, osea no creo que haya sido la jucticia, la justicia como eficaz en este medio, osea 8 años de cárcel simplemente por la, la ley de Justicia y Paz que son 8 años y la persona aaaa, no me pareceé $(P 7: 31)$. 
PERCEPCIONES SOBRE LA MACROVICTIMIZACIÓN DE MAMPUJÁN Y SAN CAYETANO Y SU REPARACIÓN INTEGRAL EN EL MARCO DE LA LEY 975 DE 2005.

\section{Satisfacción de las pretensiones de las víctimas de Mampuján y San Cayetano con el resultado del incidente de reparación dado en segunda instancia}

Tal como sucedió en el apartado anterior, se hace necesario precisar que las pretensiones a las cuales se hace referencia en este punto no están netamente ligadas con pretensiones de reparación integral. Abarca un sin número de anhelos de las víctimas de Mampuján y San Cayetano con el resultado del incidente de reparación dado en segunda instancia.

Ahora bien, a pesar de que existen insatisfacciones en algunos de los participantes víctimas de Mampuján y San Cayetano frente a sus pretensiones con el resultado del incidente de reparación dado en segunda instancia, por ejemplo, con las indemnizaciones recibidas, como se señaló en el apartado anterior respondiendo, como en este, a uno de los objetivos específicos de esta investigación; existen otras víctimas de ambas comunidades que pretendían o anhelan que con el proceso de Justicia y Paz o el incidente de reparación integral, incluyendo el obtenido en segunda instancia, pudieran sentirse satisfechas, pudieran sentirse reparadas integralmente.

Por ejemplo, el líder TR de Mampuján percibe que el avance en la reparación económica o indemnización, ha devuelto esperanza a las comunidades, les ha ayudado a sentirse mejor respecto a sus condiciones anteriores al desplazamiento forzado colectivo, mejorando sus relaciones interpersonales, el tejido social y, obteniendo así, un mejoramiento de la confianza en el Estado. Expresando que: ñé la gente mejoró un poquito las relaciones interpersonales, mejoró el tejido social, mejoró la confianza en el Estado, por ejemplo ahora que se dio la medida parcial de indemnización individual la gente tiene un nuevo ánimo, é ò (P3:14).

También, el líder AV de Mampuján percibe que gracias al proceso de Justicia y Paz las víctimas escucharon algunas verdades por parte de los postulados sobre los hechos victimizantes, 
PERCEPCIONES SOBRE LA MACROVICTIMIZACIÓN DE MAMPUJÁN Y SAN CAYETANO Y SU REPARACIÓN INTEGRAL EN EL MARCO DE LA LEY 975 DE 2005.

las cuales, al principio, generaban terror dentro de la comunidad, pero luego fue contribuyendo a la reparación. Contribución dada también por el hecho de que pudieron conocer a los postulados (la mayoría por medio televisivo), expresarles sus sentimientos, observar acciones de presunto arrepentimiento por parte de ellos y brindarles expresiones de perdón; generando satisfacción en las víctimas. Para corroborar:

é creemos que, el proceso sirvió, he.. justicia y paz sirvió, gracias a eso escuchamos algunas verdades, que nos hicieron de pronto azararnos tanto, gracias a eso no encontramos con los postulados, a quienes odiábamos por que no los veíamos, gracias a eso pudimos perdonar, gracias a eso pudimos pensar intentar sonarnos nosotros mismos, gracias a eso pudimos ver a esos señores en el pueblo mismo pidiendo perdón, gracias a eso pudimos ver algunos de ellos llorando,é (P1:33).

Otra razón que genera satisfacción en el mismo líder y a su vez en el líder GP de Mampuján y que creen, a otras víctimas, con el proceso de Justicia y Paz o con los resultados del incidente de reparación dado en segunda instancia, es que permitió dignificarlos de alguna forma con la publicación por medios de comunicación escrita, periódicos, donde se decía que las víctimas de Mampuján y San Cayetano no eran colaboradores de la guerrilla, argumento que utilizaron los postulados para victimizarlos $y$, por el cual, muchas comunidades o ciudadanos rechazaban o discriminan a estas víctimas. Estas publicaciones de retratación se basaron en lo dictaminado en la sentencia de segunda instancia, donde debía publicarse por medios locales de Mampuján y San Cayetano que estas personas habían sido víctimas del conflicto armado interno, específicamente por un grupo paramilitar y que esto no había sido por 
PERCEPCIONES SOBRE LA MACROVICTIMIZACIÓN DE MAMPUJÁN Y SAN CAYETANO Y SU REPARACIÓN INTEGRAL EN EL MARCO DE LA LEY 975 DE 2005.

ser presuntos colabores de la guerrilla, que no tenían ningún vínculo con ellos; lo cual se realizó el 18 de agosto de 2011, según el mismo líder de Mampuján:

é gracias a justicia y paz pudimos escuchar y ver en, en, en un documento público, estos que un día sacaron por colaboradores de guerrilla, no son guerrilleros,é (P1:34). é Bueno, yo pienso que todo lo que tiene que ver con papeles se ha avanzado, por ejemplo una publicación que para nosotros es muy significativa dondeé la orden es que se publicase en un medio local queee, que no éramos guerrilleros, ni teníamos ningún vínculo con ellos, eso se realizó el 18 de agosto de 2011, creo queé eso como es un trámite que se hace con periódicos, y, y esoé, creo que es muy importante para nosotros que se haya hecho eso,é (P2:10).

Como consecuencia de esto, genera satisfacción en algunos participantes el hecho de que el proceso en general permitiera descubrir que la macrovictimización de Mampuján y San Cayetano no fue solo un asunto de alias ñJuancho Diqueò y ñDiego Vecinoò. Debido a que, como se ha dicho, según el líder AV de Mampuján, hubo participación de Funcionarios, Fuerza Pública, entidades o instituciones del Estado.

El mismo líder de Mampuján expresa que, además, el resultado del incidente de reparación dado en segunda instancia satisface a las víctimas porque permitió descubrir y mostrar nacional e internacionalmente asuntos como la parapolítica, donde personajes de la vida pública o funcionarios públicos que laboraban o laboran para el Estado, como Senadores, Concejales, Alcaldes, Presidente de la República al momento de los hechos (este último por las sospechas fundadas en el participante por su omisión de reacción frente a los hechos victimizantes o porque posiblemente fue engañado), entre otros, como ya se ha dicho en otros tipos de investigaciones o 
PERCEPCIONES SOBRE LA MACROVICTIMIZACIÓN DE MAMPUJÁN Y SAN CAYETANO Y SU REPARACIÓN INTEGRAL EN EL MARCO DE LA LEY 975 DE 2005.

a través de medios de comunicación, estaban presuntamente implicados, por acción u omisión, en la macrovictimización de Mampuján y San Cayetano o en el mismo Conflicto Armado Interno. Así mismo, piensa que dentro de la perspectiva en el campo nacional e internacional por fin se pudo comprender, de alguna manera, que la aparente armonía, paz, sanidad, que vivía el territorio colombiano se debía al acto de silenciar a las poblaciones por medio de intimidaciones, macrovictimizaciones como la de Mampuján y San Cayetano o hechos victimizantes. Para verificar lo dicho por él:

é eso no fue solo un tema de, Juancho Dique y de Diego Vecino y de las para; el el, el ejército, la fuerza pública también participó, porque hasta ahora teníamos héroes, villanos; pero, aunque no se haya hecho mucho, creo que el solo el hecho de conocer verdades en Colombia, hacen saber que tú no eres un loco diciendo, que yo vi al soldado fulano aquí también;é gracias a eso se descubrió la parapolítica, un montón de funcionarios y el Estado mismo podrido, gracias a eso, encontramos que Colombia no estaba tan sana, como se decía a nivel internacional y nacional, en cada medio, gracias a eso, creo que hoy entendemos que no éramos locos diciendo, que la sanidad en Colombia solo se basaba en intimidación y matar a otros, porque cuando nos dimos cuenta el estado se corrió; y dijimos un día, eso fue muy personal; el presidente no puede ser tan bobo, porque pánosotros ese man es un coco; pero pasan dos cosas, estaba de acuerdo o se lo pasaron por la faja, lo engañaron, osea, no es tan vivo como el cree que es, porque hicieron un montón de cosas en su administración, y hoy dice, no sé, osea si no sabe es porque no eres tan vivo como tú piensas y no eres un coco ni un estratégico, porque en tu mismas barbas, ahí te estaban comiendo, y tú no te diste 
PERCEPCIONES SOBRE LA MACROVICTIMIZACIÓN DE MAMPUJÁN Y SAN CAYETANO Y SU REPARACIÓN INTEGRAL EN EL MARCO DE LA LEY 975 DE 2005.

cuenta. Entonces participó, o no es tan bueno como el público lo cree y como el mismo lo cree;é (P1:35).

De esta misma forma y gracias al incidente de reparación dado en segunda instancia, los líderes AV y TR de Mampuján consideraron que pudieron conocer instituciones de las cuales recibieron apoyo incondicional, conocieron sus derechos como víctimas del conflicto armado interno y la forma democrática y asertiva de defenderlos en nuestro país, por ejemplo, con acciones constitucionales (derechos de petición, acciones de tutela, desacatos, entre otros). Es decir, descubrieron la importancia de expresarse sin violencia, por ejemplo, para solicitar sus derechos, sin generar riñas o peleas, lo cual los satisface:

é gracias a esto confirmamos que la palabra dicha con amor no trae violencia, gracias a esto aprendimos a decir verdades, sin traer peleas y sin lastimar a nadie,é (P1:36). é Ah no, eso fue muy enriquecedor, eh, nos dejó la enseñanza y la experiencia de conocer la Defensoría del Pueblo, cómo se maneja, cómo actúa, los compromisos que, que se tiene, me dejó la enseñanza de conocer todas las instituciones, eh, que tienen que ver con el cumplimento de la ley de víctimas, eh, en este caso la nuestra 965, o sea la ley de aspecto transicional, é (P3:15).

A su vez, el mismo líder AV de Mampuján piensa que algunas víctimas descubrieron que las leyes no son perfectas como la de Justicia y Paz, en temas por ejemplo, como la Verdad y la Justicia, pero de ahí la importancia para ellos de invitar al Estado a aprender de estos errores procesales y legislativos frente a la Ley de Justicia y Paz, para generar o reformar adecuadamente normatividades judiciales o administrativas en beneficio de las víctimas del conflicto armado interno, para que otras puedan beneficiarse de lo que las víctimas de Mampuján y San Cayetano adelantaron o vienen adelantando con el proceso de Justicia y Paz. Muchas de estas víctimas 
PERCEPCIONES SOBRE LA MACROVICTIMIZACIÓN DE MAMPUJÁN Y SAN CAYETANO Y SU REPARACIÓN INTEGRAL EN EL MARCO DE LA LEY 975 DE 2005.

comprendieron que se puede vivir tranquilitamente sin odios y resentimientos, porque todo depende de la manera adecuada de defender sus derechos sin necesidad de recurrir a la violencia; por ejemplo, ñé yo no tengo que ser malo porque otro me convoco a ser maloé (P1:37)ò con sus acciones ilegales, y:

é es tarea, las leyes no son perfectas, luego la puesta en marcha tampoco es perfecta y es tarea de los que vienen, de intentar corregir las flaquezas de ellos, y nosotros dimos un ejemplo de lo que podía ser, lo que no fue, se puede corregir para con otro síé (P1:38).

Él expresó que el incidente dado en segunda instancia sirvió y satisface a las víctimas porque está permitiendo educar a la comunidad sobre que la riqueza o el verdadero tener no está solo en el dinero, en tener mucha plata, sino en aprender a vivir con los recursos conseguidos: ñé la rique, la verdadera riqueza, el verdadero tener, no consiste en tener mucha plata, consiste en tener para las necesidades, del diario vivir y del futuro de aquellos que yo creo que van a seguir detrás de míé ò (P1:39). La ambición puede traer consecuencias como la de generar macrovictimizaciones como la de Mampuján y San Cayetano, donde por la ambición económica y de poder, la gente se puede enceguecer y violentar a otros, como lo hicieron los postulados.

Continuando con el tema, el líder GP de Mampuján considera que a pesar de que la Ley de Justicia y Paz no es una herramienta jurídica hecha para las víctimas sino para los victimarios (postulados) en su gran mayoría, las víctimas pudieron aprovecharse de ésta, haciéndola una herramienta necesaria para el país, para la Verdad, la Justicia y la Reparación Integral de las víctimas: 
PERCEPCIONES SOBRE LA MACROVICTIMIZACIÓN DE MAMPUJÁN Y SAN CAYETANO Y SU REPARACIÓN INTEGRAL EN EL MARCO DE LA LEY 975 DE 2005.

é Yo creo que es una herramienta que aunque no fue hecha para las víctimas nosotros pudimos aprovechar esa ventana que por allí se dio, creo que es una herramienta necesaria para el país, hoy no podríamos estar hablando de esto que estamos hablando si no existiera justicia y paz, creo que Justicia y Paz es como un puente para llegar al otro lado, si no hubiese existido Justicia y Paz yo no le hubiese podido decir a Juancho que la comunidad le perdonaba, yo quería hablar con él pensando en esa comunidad que él destruyó y yo creo que incluso es la herramienta que nos permite acercarnos a la verdad, cuando yo puedo hablar con un postulado acerca de un hecho yo puedo acercarme a la realidad, sin esa herramienta es imposible, y aparte el proceso de reconciliación, aparte de que es un derecho y es algo personal, debería ser algo a nivel nacional... (P2:11).

El componente ñJudicialò y de ñVerdadò de la Ley de Justicia y Paz complementaría las reparaciones integrales administrativas, como el de la Ley 1448 de 2011 o el Decreto 1290 de 2008, entre otras, donde estas últimas no permiten acciones como las versiones libres de los postulados y las expresiones de perdón de las partes en unos procesos de audiencias directamente; por ende, la consecución o construcción de la Verdad y la Justicia, aunque presenten fuertes detractores dentro de las comunidades de víctimas, sin la Ley de Justicia y Paz no se generarían, ni siquiera los procesos de reconciliación entre víctimas y victimarios, como lo dice este líder: ñé la reconciliación entre víctimas, victimarios e incluso la misma sociedad es una necesidad y se encuentra allí plasmada en la Ley 975é ò (P2:12).

Por otro lado, según la intervención del líder TR de Mampuján, el proceso de Justicia y Paz o el resultado del incidente de reparación integral de Mampuján y San 
PERCEPCIONES SOBRE LA MACROVICTIMIZACIÓN DE MAMPUJÁN Y SAN CAYETANO Y SU REPARACIÓN INTEGRAL EN EL MARCO DE LA LEY 975 DE 2005.

Cayetano dado en segunda instancia, satisface a las víctimas porque con ella pudieron mejorar sus relaciones interpersonales, donde trabajando en equipo han guiado y vivenciado el proceso de Justicia y Paz que se ha venido adelantando con las víctimas, ha permitido mejorar la confianza en el Estado. Además, el hecho de que muchas víctimas hayan recibido la indemnización les ha permito una nueva luz de esperanza, ha mejorado sus estados de ánimo. Para confirmar: ñé la gente mejoró un poquito las relaciones interpersonales, mejoró el tejido social, mejoró la confianza en el Estado, por ejemplo ahora que se dio la medida parcial de indemnización individual la gente tiene un nuevo ánimo,é ò (P3:16).

Se encontró de igual forma que, la persona líder LM de San Cayetano percibió que el proceso de Justicia y Paz genera algún tipo de satisfacción en las victimas porque con ella se puede preparar incidentes de reparaciones donde los afectados pueden ser partícipes y presentar unas pretensiones de reparación, hay reparaciones individuales y colectivas, se hace una construcción de la ñVerdadò con la ayuda de los postulados, se reconoce sus calidades de víctimas y se puede generar reparaciones en Derecho y no en Equidad, como si sucede, según la interpretación de los entrevistadores, con las normatividades administrativas como la Ley 1448 de 2011 y el Decreto 1290 de 2008, donde no se repara por el daño causado sino por los hechos victimizantes sufridos, generando reparaciones en Equidad:

é Porque es que por lo menos la ley 975 se haceé se prepara incidentes de reparaciones, se dan fallos, o sea, se hacen cosas y se recogen *** así colectivas e individuales y por lo menos los postulados ahí tienen la opción de reconocernos como víctimas, eehhhé, entonces sí vale la pena justicia y pazé (P4:15). 
PERCEPCIONES SOBRE LA MACROVICTIMIZACIÓN DE MAMPUJÁN Y SAN CAYETANO Y SU REPARACIÓN INTEGRAL EN EL MARCO DE LA LEY 975 DE 2005.

Es decir que, principalmente lo que más satisface a las víctimas de Mampuján y San Cayetano con el incidente de reparación integral dado en segunda instancia, es el hecho de que con este se haya logrado reparaciones en Derecho y no en Equidad. Les satisface que sus procesos de reparación se hayan generado a partir de los daños causados y no solamente a partir de los hechos victimizantes sufridos.

Por otro lado, el representante judicial JS de las víctimas de Mampuján y San Cayetano considera que el incidente de reparación integral dado en segunda instancia sí satisface las pretensiones de las víctimas, porque en su mayoría, sus pretensiones de reparación integral fueron incluidas en este incidente, está seguro que los representantes judiciales, incluyéndose, pudieron lograr el objetivo de la reparación, donde debe ser tenido en cuenta las pretensiones de las víctimas (Ley 975 de 2005, Art. 23. Incidente de reparación integral): ñé Si, lo que, lo que las víctimas pretendían, yo, yo creo y estoy seguro de que nosotros logramos el objetivo de la reparación...ò (P5:18); lo cual está en contravía de lo que piensa el líder TR de Mampuján, cuando manifestó que las víctimas no se sienten satisfechas cuando faltaron por incluirse pretensiones de reparación dentro de la sentencia de segunda instancia, tan importantes como el hecho de que las medidas de reparación integral debieron estas más ajustadas a la identidad de las comunidades, buscando la recuperación del tejido social, la recuperación cultural y de costumbresé :

é pienso que deben haber unas medidas aún más profundas para recuperar ese tejido, pienso de que deben haber unas medidas de protección haciaé o o, unas medidas de recuperación de esa cultura, de esa forma de ser del ser humano en 
PERCEPCIONES SOBRE LA MACROVICTIMIZACIÓN DE MAMPUJÁN Y SAN CAYETANO Y SU REPARACIÓN INTEGRAL EN EL MARCO DE LA LEY 975 DE 2005.

esas, en esas eh comunidades, hay que recordar que nosotros éramos unas personas, ehh con unas costumbres muy particularesé (P3:17).

O cuando existen, como se ha dicho, participantes que expresaron que no fueran incluidas todas las víctimas en la sentencia de segunda instancia, todos los hechos victimizantes para algunas víctimas, como el desplazamiento forzado, y todos los daños que se les causaron a estas personas, como pérdidas de bienes muebles e inmueblesé , afectándose el reconocimiento de la calidad de víctima, las indemnizaciones y procesos de reparación integral.

Sin embargo, a partir del representante judicial LV, un 95\% (la gran mayoría) de la población víctima de estas comunidades se siente satisfecha con el tema de las indemnizaciones, aunque exista algunos detractores, por ejemplo, por temas de no inclusión de algunos daños causados dentro del incidente de reparación o algunas víctimas; no obstante, y aunque esté en contravía por lo dicho por otros participantes de la investigación, en cuanto a la reparación colectiva, que fue donde más se generó exhortos, se están haciendo acciones para que sean cumplidos los dictamines o Resuelves, por ejemplo, se ha presentado solicitudes por parte de la Procuraduría General de la Nación que han generado por parte de la Gobernación de Bolívar y las Alcaldías de María la Baja y de San Juan Nepomuceno, inicios en la implementación de las medidas colectivas de reparación, como los estudios para lograr el saneamiento de las propiedades, construcción de carreteras, acueductos, líneas telefónicas, entre otras; es decir, él considera que tanto las medidas individuales como colectivas de reparación han cumplido las expectativas de las víctimas de Mampuján y San Cayetano y las que tenían los representantes judiciales en cuanto a su inclusión en el incidente, aunque hayan existido errores 
PERCEPCIONES SOBRE LA MACROVICTIMIZACIÓN DE MAMPUJÁN Y SAN CAYETANO Y SU REPARACIÓN INTEGRAL EN EL MARCO DE LA LEY 975 DE 2005.

como la creación de exhortos, son los órganos de control los que ahora deberán velar por el cumplimiento de estos. A saber:

é En lo que tiene que ver con la reparación individual yo creo queee, más del 95\% de las víctimas se encuentran satisfechas, así unas digan que no, y yo lo miro desde el punto de vista objetivo como abogado, y desde el punto de vista de la reparación colectiva hasta lo que tengo entendido, ya que esa solicitud fue presentada por parte de la Procuraduría, en estos momentos el gobierno ya ha empezado, junto con la gobernación, la alcaldía local a implementar medidas que tienen que ver con, saneamiento de propiedades, construcción de carreteras, ehh... acueductos, creación de acueductos, líneas telefónicas, entonces considero que, que esas medidas de carácter colectivo se han venido dando paulatinamente, pero al parecer tanto las de carácter individual como las de carácter colectivo si cumplieron las expectativas que tenían las víctimas, y las que teníamos nosotros como representantes judiciales... (P6:06).

En definitiva, el incidente de reparación dado en segunda instancia satisface a un gran número de víctimas porque con este pudieron ser reconocidas como víctimas de grupos paramilitares, comandados, específicamente, por alias ñJuancho Diqueòy ñDiego Vecinoò, y del Conflicto Armado Interno. Pudieron empezar a recibir una reparación (indemnización), aunque hasta la fecha de aplicación de las técnicas de recolección de información, no ha sido integral por la generación de exhortos y el incumplimiento de las demás medidas de reparación por parte de la institucionalidad y los postulados, es decir, obtuvieron algo que mal o bien no contaban como reparación pero con grandes falencias en su cumplimiento.

\section{Sentimientos presentes o generados en las víctimas de Mampuján y San Cayetano}


PERCEPCIONES SOBRE LA MACROVICTIMIZACIÓN DE MAMPUJÁN Y SAN CAYETANO Y SU REPARACIÓN INTEGRAL EN EL MARCO DE LA LEY 975 DE 2005.

Específicamente por la macrovictimización de Mampuján y San Cayetano hay presentes o se generaron sentimientos de ira y odio en algunas víctimas, especialmente, por el desplazamiento forzado, por ser la mayoría de la población quienes padecieron este hecho victimizante, por ser la mayoría quienes perdieron los hábitos y costumbres de la antigua Mampuján y San Cayetano, perdieron bienes muebles e inmuebles, dejaron abandonadas economías estables relacionadas, por ejemplo, con la agricultura. Les generaba o genera rabia ver que la vida les ha cambiado por la macrovictimización de Mampuján y San Cayetano (líder LM de San Cayetano y un participante del grupo focal de Mampuján). Para corroborar:

é el desplazamiento, me partió la vida en dos en el sentido en que tenía una economía muy estable en la vereda y al trasladarnos acá, eso se derrumbó, entonces yo sentía mucha rabia de ver que la vida nos había cambiado tan drásticamente, sólo porque, yo decía porque unas personas se antojaron de hacer cosas y que ya uno no puede ir más allá,é (P4:16). é y es que el desplazamiento crea en nosotros, ehh tantas cosas, nosotros sufrimos estigma, sufrimos sentimientos que, que, de pronto, de odio, de rechazo, de miedo, de temor, y de pronto desconfianza, tantos sentimientos que el desplazamiento ehh, ehh, nos proporciona a nosotros, é (P7:32).

Al mismo tiempo, existe en algunas víctimas de Mampuján y San Cayetano sentimientos de temor frente a la posibilidad de repetición de los hechos victimizantes, según un participante del grupo focal de Mampuján: ñé son 12 años en los que hemos vivido, de pronto en medio del miedo, del temor de que los hechos se vuelvan a repetiré ò (P7:33). No se sienten seguras, no los convence los planes de seguridad de la Fuerza Pública con la población víctima y 
PERCEPCIONES SOBRE LA MACROVICTIMIZACIÓN DE MAMPUJÁN Y SAN CAYETANO Y SU REPARACIÓN INTEGRAL EN EL MARCO DE LA LEY 975 DE 2005.

demás colombianos, más cuando existen y vivenciaron antecedentes de apoyo, por acción u omisión, de estas (Ejército Nacional), entidades o funcionarios del Estado en la macrovictimización de Mampuján y San Cayetano: ñé donde hay tanto policíaé , pienso que cuando hicieron el proyecto de seguridad, pensaron que era satisfacción de esa víctima, y viene la víctima y dice hoy aquí, es que no se siente segura aquí;é ò (P1:40). Tanto que, existió en algunos participantes sentimientos de temor con la presencia de los investigadores en el proceso de recolección de información, algunas víctimas sintieron temor al referirse a las causas de la macrovictimización de Mampuján y San Cayetano y su implicación de personajes y entidades del Estado, pero gracias a la intervención oportuna y adecuada de los investigadores, estos temores pudieron ser controlados hasta el punto de tener fluidez en los discursos en medio de la aplicación de las técnicas de recolección de información. Para verificar:

é Si hasta el momento, en cierta forma uno le da un poquito de temor, de hablar, osea yo soy sincera y lo voy a decir, osea estas cosas en entrevista y en realidad a uno le genera un poquito de, de miedoé (P9:16).

Al respecto conviene decir que, a partir de lo expresado por un participante del grupo focal de Mampuján, la macrovictimización de Mampuján y San Cayetano ha generado en varios pobladores no víctimas de estas comunidades, sentimientos de rechazo, miedo y desconfianza con estas víctimas de alias ñJuancho Diqueò y alias ñDiego Vecinoò; es decir, estigmatizaciones, asociando a las víctimas como colaboradores de la guerrilla, lo que justificaba las acciones delictivas de las AUC (Paramilitares): ñé pues uno queda como que, que desubicada, sobretodo porque llega a un contexto que no es el nuestro, y porque llega bajo el estigma de, de la sociedad,é ò (P1:41). Es por esto que algunas víctimas manifestaron sentimientos de tristeza y desesperación frente al incumplimiento de las medidas de reparación 
PERCEPCIONES SOBRE LA MACROVICTIMIZACIÓN DE MAMPUJÁN Y SAN CAYETANO Y SU REPARACIÓN INTEGRAL EN EL MARCO DE LA LEY 975 DE 2005.

integral ordenadas y exhortadas en el incidente de reparación integral dado en segunda instancia: ñé en algún momento hemos de pronto desesperado, pero hemos sido pacientes,...ò $(P 7: 34)$.

\section{No contribución del incidente de reparación de Mampuján y San Cayetano a la reparación integral de las victimas}

Ahora bien, dando respuesta al objetivo general de esta investigación: ñEstablecer sí el incidente de reparación de Mampuján y San Cayetano contribuyó a la reparación integral de las víctimasò, se vio la necesidad de establecer dos tipos de respuesta, una de no contribución y otra de contribución (este último discutido en el siguiente apartado) del incidente a la reparación integral de las víctimas de Mampuján y San Cayetano. Es decir, no hubo una completa contribución del incidente a la reparación integral de las víctimas.

Entonces puede afirmarse, a partir de lo dicho por algunos participantes, que el incidente de reparación integral de Mampuján y San Cayetano no contribuyó a la reparación integral de las víctimas por el hecho de que no fueran incluidas todas las víctimas en la sentencia de segunda instancia:

é que no queden víctimas fuera del incidente de reparación porque genera un caos, acá sucedió y ha sido dramático, quedó mucha gente por fuera del incidente de reparación aun siendo víctimas, é a mi me quedó mi hija por fuera del fallo de la sentencia de primera y de segunda instancia, entregando documentos y entregando todo, y personas que por lo menosé incluso ellos conocen hasta esta familia, entonces, o seaé. (P4:17).

$\mathrm{Al}$ igual que, sus pretensiones, todos los hechos victimizantes para algunas víctimas, como el desplazamiento forzado, y todos los daños que se les causaron a estas personas, como pérdidas de 
PERCEPCIONES SOBRE LA MACROVICTIMIZACIÓN DE MAMPUJÁN Y SAN CAYETANO Y SU REPARACIÓN INTEGRAL EN EL MARCO DE LA LEY 975 DE 2005.

bienes muebles e inmuebles, por ejemplo, por la pérdida de los documentos de las víctimas en el mismo acto del desplazamiento forzado o por parte de los representantes judiciales, entre otras causas.

A su vez, por las revictimizaciones que se han cometido con estas personas, por los exhortos de la sentencia de segunda instancia, y por el incumplimiento de las medidas de reparación integral dadas en esta sentencia por parte de la institucionalidad o los postulados, especialmente de las reparaciones colectivas.

\section{Contribución del incidente de reparación de Mampuján y San Cayetano a la reparación integral de las víctimas}

Del incidente de reparación integral, según los líderes AV y GP de Mampuján, contribuye a la reparación integral de las víctimas de Mampuján y San Cayetano, las disculpas públicas que los postulados le otorgaron a las víctimas y los actos de perdón que ellas le brindaron, donde en una de las audiencias de este incidente, una de los líderes de víctimas de Mampuján le otorgó una biblia como gesto de perdón a los postulados, lo cual es un acto simbólico de reconciliación:

é Mampuján creo que ratifica como una comunidad de perdóné é acá dijeron estamos de acuerdo con eso, entonces creemos que esa es la evidencia, de que ese proceso de intentar, no somos psicólogos, pero la Biblia que les dimos de alguna manera ayuda a uno a entender que la fuerza para terminar la guerra es apostando a a, al amor, dando amor, dando perdón a quien ni siquiera lo está pidiendoé (P1:42).

Y, a su vez, las publicaciones por medios escritos, periódicos, donde se desmentía que la población de Mampuján y San Cayetano era colaboradora de la guerrilla: 
PERCEPCIONES SOBRE LA MACROVICTIMIZACIÓN DE MAMPUJÁN Y SAN CAYETANO Y SU REPARACIÓN INTEGRAL EN EL MARCO DE LA LEY 975 DE 2005.

é la orden es que se publicase en un medio local queee, que no éramos guerrilleros, ni teníamos ningún vínculo con ellos, eso se realizó el 18 de agosto de 2011, creo queé eso como es un trámite que se hace con periódicos, é creo que es muy importante para nosotros que se haya hecho esoé (P2:13).

Cabe señalar como contribución a la reparación integral de las víctimas, teniendo en cuenta lo dicho por el líder TR de Mampuján, el que conocieran sus derechos adquiridos con el proceso de Justicia y Paz y la forma de solicitarlos con acciones constitucionales, como el derecho de petición, entre otros: ñé ya nosotros hicimos los primeros derechos de petición y vamos trabajando para que eso sea una realidad, entonces yo sí creo realmente, que yo puedo tener mi reparación individual, yo puedo tener algunas poquitas medidas...ò (P3:18). Al estar informadas las víctimas, sentían seguridad para adelantar los procesos de Justicia y Paz y esto iba contribuyendo a sus reparaciones integrales.

Como es sabido, también contribuye el hecho que se pudiera hablar de procesos de ñVerdadò en las versiones libres (líder GP de Mampuján), aunque no fueron confesados por los postulados todos los hechos victimizantes, según otros participantes. Asimismo, los inicios de reconciliación entre víctimas, victimarios e incluso la misma sociedad, siendo un fin y una necesidad plasmada en la Ley 975 de 2005 (líder GP de Mampuján):

é yo creo que incluso es la herramienta que nos permite acercarnos a la verdad, cuando yo puedo hablar con un postulado acerca de un hecho yo puedo acercarme a la realidad, sin esa herramienta es imposible, y aparte el proceso de reconciliación, aparte de que es un derecho y es algo personal, debería ser algo a 
PERCEPCIONES SOBRE LA MACROVICTIMIZACIÓN DE MAMPUJÁN Y SAN CAYETANO Y SU REPARACIÓN INTEGRAL EN EL MARCO DE LA LEY 975 DE 2005.

nivel nacional. La reconciliación entre víctimas, victimarios e incluso la misma sociedad es una necesidad y se encuentra allí plasmada en la Ley 975... (P2:14).

Y el inicio de las indemnizaciones para las víctimas de Mampuján y San Cayetano.

Como consecuencia de esto e infiriendo, del incidente de reparación contribuye a la reparación integral de las víctimas, lo generado dentro de la sentencia de segunda instancia: órdenes y exhortos, buscando reparación integral en Derecho y no en Equidad, tanto en reparaciones individuales como colectivas: ñé En derecho, si, entonces creo que fue un aciertoé ò (P2:15). Una reparación integral en derecho para las víctimas del conflicto armado interno basada en los daños causados genera efectos reparadores, la reparación en equidad no es ecuánime con el padecimiento de la víctima.

\section{Contribución del primer incidente de reparación de Justicia y Paz para futuros procesos}

El incidente de reparación integral de Mampuján y San Cayetano, en el marco de la Ley de Justicia y Paz, tanto el generado en primera como en segunda instancia con las víctimas de ambas comunidades, es un derrotero por el cual deberían seguir los demás procesos de Justicia y Paz, entre otros.

Porque invitó a estas víctimas del conflicto armado interno a acudir a las diferentes normatividades judiciales o administrativas, utilizando acciones constitucionales cuando no hay cumplimiento de las medidas de reparación integral, acudiendo a la paciencia sin llegar a la inactividad, según un participante del grupo focal de Mampuján: ñé algún momento hemos de pronto desesperado, pero hemos sido pacientes, é ò (P7:35); ilustró que la generación de exhortos ocasionan dificultades de reparación integral a las víctimas del conflicto armado interno, y que el 
PERCEPCIONES SOBRE LA MACROVICTIMIZACIÓN DE MAMPUJÁN Y SAN CAYETANO Y SU REPARACIÓN INTEGRAL EN EL MARCO DE LA LEY 975 DE 2005.

incumplimiento de las medidas de reparación integral, por parte de los postulados o la institucionalidad, genera revictimizaciones y, por ende, la no reparación integral.

A su vez, el incidente de reparación integral de Mampuján y San Cayetano ha motivado a otras víctimas, por ejemplo, de María la Baja, a consultarles a las víctimas de Mampuján y San Cayetano cómo son los procesos de Justicia y Paz. Son alrededor de 10.000 víctimas de María la Baja las que ahora requieren acompañamiento, según el líder TR de Mampuján: ñé entonces nos queda también pendiente el hecho terminar la obra, porque nosotros empezamos con Mampuján como un proyecto piloto, pero en este momento tenemos a cerca de 10.000 víctimas de María la Baja pidiéndonos ayuda, pidiéndonos nuestra intervención, é ò (P3:19). Mostrando la importancia y relevancia para el país de los procesos de reparación integral de las víctimas, no solo en materia administrativa sino judicial; no obstante, es de resaltar los cambios generados en su momento con la reforma de la Ley de Justicia y Paz, la Ley 1592 de 2012, que ñeliminabaò el incidente de reparación de la Ley 975 de 2005, de este proceso judicial, para destinar la reparación integral de las víctimas al proceso vía administrativa generado por la Ley 1448 de 2011, ocasionando reparación en Equidad y no en Derecho; lo cual, violaba, a criterio de los investigadores, el derecho a la igualdad de las demás víctimas del conflicto armado interno que ya tenían adelantados sus procesos de Justicia y Paz, no es posible ni se ve justo que unas víctimas (de Mampuján y San Cayetano) hayan obtenido un incidente de reparación integral por Justicia y Paz y en Derecho y las demás no, vulneraría los derechos de reparación igualitaria de las demás víctimas. 
PERCEPCIONES SOBRE LA MACROVICTIMIZACIÓN DE MAMPUJÁN Y SAN CAYETANO Y SU REPARACIÓN INTEGRAL EN EL MARCO DE LA LEY 975 DE 2005.

\section{Acciones para alcanzar la reparación integral de las víctimas de Mampuján y San}

\section{Cayetano. Empoderamiento y Resiliencia de las víctimas}

Frente a las dificultades que se han venido señalando del proceso de Justicia y Paz y del incidente de reparación integral adelantado con las víctimas de Mampuján y San Cayetano, según la persona líder LM de San Cayetano, han solicitado a la Corte Suprema de Justicia, con respuesta positiva, que se genere una audiencia de ñinclusiónò, en la cual se incluyan los daños causados por la macrovictimización y las víctimas de Mampuján y San Cayetano que faltaron por incluirse en el incidente de reparación integral dado en segunda instancia, procedimiento que debería solicitar la Unidad de Justicia y Paz de la Fiscalía General de la Nación y, a través, de los representantes judiciales de la Defensoría del Pueblo para la representación judicial de las víctimas. A saber:

é Es que por lo menos lo que le pedimos a la sala de la corte una audiencia de inclusión y la sala de la corte nos dijo sí, pero que teníamos que prepararla y que es la Fiscalía quien se la tiene que pedir para que los defensores puedan ser los que representante allá. ENTREVISTADOR: Audiencia de inclusión?. ENTREVISTADA: Si, de inclusión. ENTRAVISTADOR: Ósea esa es la estrategia para poder vincular. ENTREVISTADA: A las personas que quedaron por fuera. Sí, pero lo luchamosé (P4:18).

Lo cual, sería una muestra de empoderamiento y resiliencia de las víctimas de Mampuján y San Cayetano, donde a pesar de las adversidades y las falencias del incidente de reparación dado en segunda instancia, donde se dejó daños y víctimas por fuera de la sentencia, buscan la manera de salir de las dificultades, sin someterse o 
PERCEPCIONES SOBRE LA MACROVICTIMIZACIÓN DE MAMPUJÁN Y SAN CAYETANO Y SU REPARACIÓN INTEGRAL EN EL MARCO DE LA LEY 975 DE 2005.

resignarse a los errores procesales, utilizando en ocasiones, por ejemplo, el derecho de petición.

Empoderamiento y resiliencia que también se puede observar, a partir del desarrollo del grupo focal de Mampuján, por ejemplo, cuando las víctimas de Mampuján y San Cayetano realizaron una marcha o caminata desde sus comunidades o lugares de residencia hacia la ciudad de Cartagena el 12 de diciembre de 2011, donde las víctimas de ambas comunidades solicitaban cumplimiento de las medidas de reparación integral dadas en segunda instancia, especialmente los exhortos:

é en cuanto al cumplimiento de la sentencia, ehh nos pusieron unos plazos y no se nos cumplía, entonces, debido a eso, tuvimos que hacer una caminatas, usted ve qué es fácil, salir de aquí, de este caserío, de este pueblo, salir aquí paôCartagena de pie, no, eso no fue fácil, eso, eso salió de aquí de la comunidad de Mampuján, eso eso nosotros lo hicimos para que pudieran, nos pudieran cumplir, lo que ya, una parte de lo que ya hoy cumplieron. Prácticamente, con esa caminata, ablandó, diríamos nosotros, o creemos que esa caminata aflojó un poquito más lo que fue el cumplimiento de la sentencia, pero no fue justo para nosotros para que nos tuvieran que cumplir, tuviéramos que hacer esa caminata, porque por derecho propio, nosotros nos tenían que cumpliré (P7:36).

Estas víctimas sufrieron la macrovictimización de Mampuján y San Cayetano alrededor de hace 10 años, hechos victimizantes y daños que cambiaron sus vidas, afectaron sus estilos de subsistencia, hábitos y costumbres, y a pesar de ello, casi sin ayuda, han ido sobreponiéndose a esas dificultades y han generado estrategias para 
PERCEPCIONES SOBRE LA MACROVICTIMIZACIÓN DE MAMPUJÁN Y SAN CAYETANO Y SU REPARACIÓN INTEGRAL EN EL MARCO DE LA LEY 975 DE 2005.

corregir los errores de la sentencia de segunda instancia, pero ésta aún no se cumple en su totalidad.

\section{Agradecimientos para algunas instituciones por parte de algunos participantes}

Frente a las adecuadas gestiones y acciones institucionales, de algunas de ellas, antes, durante y después del incidente de reparación integral de Mampuján y San Cayetano con las víctimas, el líder TR de Mampuján expresa agradecimientos a la MAPP OEA, al PNUD y al Departamento de Justicia de los Estados Unidos en Colombia, instituciones que interactuaron, asesoraron y acompañaron a las víctimas de Mampuján y San Cayetano en todo el proceso que adelantaron de Justicia y Paz, es decir, en el marco de la Ley 975 de 2005. Instituciones de las cuales las víctimas de Mampuján y San Cayetano esperan más acompañamiento. Para corroborar:

é nos queda un recuerdo muy agradable de la MAP OEA, nos queda un recuerdo muy agradable del PNUD, nos queda un recuerdo muy agradable también del departamento de justicia de la Embajada Americana, son amigos que han interactuado junto con nosotros, gracias que nos han defendido, y de los que esperamos mucho más, é (P3:20).

A su vez, un participante del grupo focal de Mampuján agradece a la Fiscalía General de la Nación, específicamente, a la Unidad de Justicia y Paz, por el apoyo en las investigaciones: ñé gracias a las organizaciones, de pronto a la Fiscalía por el, el, por el apoyo en la investigación, é ò (P7:37), aunque se hayan presentado errores como el dejar daños y víctimas por fuera del incidente de reparación dado en segunda instancia. 
PERCEPCIONES SOBRE LA MACROVICTIMIZACIÓN DE MAMPUJÁN Y SAN CAYETANO Y SU REPARACIÓN INTEGRAL EN EL MARCO DE LA LEY 975 DE 2005.

Y, agradece a la Defensoría del Pueblo, específicamente, infieren los investigadores, a los representantes judiciales, por haberlas representado y acompañado en el proceso, en el incidente de reparación integral, a pesar de las falencias que presentaron y que ya se han mencionado: ñé gracias aé a la Defensoría, ehh por, por todo ese apoyo en la defensa de nosotros, é porque aquí cada una de las organizaciones, é hizo posible el sueño de esta comunidad por la sentencia de reparacióné ò (P7:38).

\section{Enseñanzas del proceso de Justicia y Paz o del incidente de reparación integral de}

\section{Mampuján y San Cayetano}

Según el líder AV de Mampuján, una enseñanza del proceso de Justicia y Paz o del incidente de reparación de Mampuján y San Cayetano, es que debe realizarse buscando la reconciliación y el perdón, sin violencia en las audiencias y manejando respeto por el otro: ñé usted la tiene que aceptar, que va a participar, ojala no venga bajo la agresión, entonces empezamos a través del respeto y en reconciliación con todos; era el escenario de víctima y victimario, pero no tiene por qué haber peleasé ò (P1:43); con lo cual se podría lograr una reconstrucción del tejido social, el cual fue roto por la violencia. La violencia genera más violencia: ñé creo que el mensaje también es, que se entienda, que la violencia, solo va a generar más violencia, é ò (P1:44).

Por otro lado, el mismo líder opina que las víctimas deben velar, pero en palabras más técnicas, por la Resignificación (adquirir un nuevo significado de una idea o concepto, que se agrega al que ya se tenía o lo cambia en porción o por completo. Específicamente, serian cambios de significados o de percepciones de los hechos victimizantes orientados a la superación del daño) y resiliencia frente a los daños causados (superación a pesar de lo 
PERCEPCIONES SOBRE LA MACROVICTIMIZACIÓN DE MAMPUJÁN Y SAN CAYETANO Y SU REPARACIÓN INTEGRAL EN EL MARCO DE LA LEY 975 DE 2005.

dificultoso de la adversidad); en la medida que esto se logre podrán estar preparadas para sobrellevar lo que implica el proceso de Justicia y Paz: ñé de alguna manera la gente empezó a ver que, ajá yo tengo que cambiar yo tengo.. y eso es parte de mejorar parte del estado en que empecé,é ò (P1:45).

También, como enseñanza observa que los líderes o víctimas no pueden dejarse tentar por las ofertas económicas que surgen en medio de los procesos de Justicia y Paz, pero no señala específicamente quiénes, de qué tipo y con qué fines se generaban esas ofertas; en la medida en que no se acepten se podrá velar por la reparación integral de las víctimas del conflicto armado interno. Para verificar:

é en realidad yo soy grande en la medida en que hago por los demás, yyy, y aprendimos que no hay que venderse, que ofertas de compra, vienen, vinieron, vienen y vendrán para los representantes de las comunidades, porque los que quieren matar el proceso, solo quieren comprar e intentar comprar a quienes hacen esos procesos; el consejo es que cuando uno no se vende, permite que el proceso continué el curso y se va a permitir que las comunidades se beneficien mañana; eso no lo sabíamos, lo aprendimos en esto que la vida nos permitió vivir,é (P1:46).

A su vez, a partir del líder GP de Mampuján, se puede decir que por más hechos violentos o victimizantes que hayan pasado las víctimas, deben organizarse de tal manera que se trabaje conjuntamente, una organización que no tiene que ver con aspectos legales o jurídicos, pero se hace necesario conocerlos, infieren los investigadores, aspectos jurídicos que les permitan defender sus derechos y, así, 
PERCEPCIONES SOBRE LA MACROVICTIMIZACIÓN DE MAMPUJÁN Y SAN CAYETANO Y SU

REPARACIÓN INTEGRAL EN EL MARCO DE LA LEY 975 DE 2005.

continuar con sus planes de vida a través de la reparación integral, resignificación y resiliencia. Para confirmar lo dicho por el participante:

é la reflexión que puedo dar acerca del tema es que por más que sean los hechos violentos lo más importante es continuar organizado y una organización que no tiene que ver con aspectos legales o jurídicos sino que la comunidad sigue en marcha con su plan de vida independientemente de la situación por la cual está atravesando... (P2:16).

Igualmente, el líder AV de Mampuján comenta que, a pesar de la desconfianza de las víctimas de Mampuján y San Cayetano con personajes, particulares o instituciones del Estado, han aprendido a dialogar más, sin tanto temor y desconfianza, medio necesario para llegar a las reconciliaciones y para aprender a solicitar sus derechos: ñé desde el comienzo y con el transcurso del proceso hemos ha prendido a dialogar más; al principio era muy difícil, de pronto, la desconfianza no la hemos ha prendido a matarla toda acerca a quienes trabajan, é ò (P1:47). Lo cual, se logra con el adecuado acompañamiento de líderes de víctimas y la institucionalidad, donde se les trasmita a las víctimas sus derechos y mecanismos para acceder a ellos frente al incumplimiento de órdenes o exhortos de reparación. El proceso de Justicia y Paz generó vocación de liderazgo en algunas víctimas, como sucedió con el líder GP de Mampuján:

é pues ehhh, es una experiencia maravillosa, porque a mí me ha enseñado que es mejor dar que recibir, y mi tío decía que, el que no vive para servir no sirve para vivir, entonces, es una vocación de servicio en virtud de los demás, é (P2:17).

Asimismo, el líder GP de Mampuján comenta que el proceso de Justicia y Paz adelantado con las víctimas de Mampuján y San Cayetano ha permitido la 
PERCEPCIONES SOBRE LA MACROVICTIMIZACIÓN DE MAMPUJÁN Y SAN CAYETANO Y SU REPARACIÓN INTEGRAL EN EL MARCO DE LA LEY 975 DE 2005.

transformación de muchas de estas personas, donde han ampliado las fronteras de adquisición de dinero, donde ya no solo se dedican a la agricultura, sino a otras formas laborales y de liderazgo:

é el proceso también me ha transformado, te dije inicialmente que, que yo era un campesino dedicado a la agricultura solamente, hoy tengo una visión distinta como campesino, pienso en un desarrollo como campesino, pero ehh, eso creo que me lo ha dado el proceso, es muy significativo e importanteé (P2:18).

A su vez, como enseñanza del proceso de Justicia y Paz, según este líder, está la virtud de la perseverancia y la confianza en particulares e instituciones para lograr la reparación integral, puesto que hubo un aislamiento y desconfianza de estas comunidades con el desplazamiento forzado hacia la institucionalidad para buscar apoyo, más cuando participantes de la investigación consideran que el Estado, a través de algunos de sus integrantes, fue partícipe de la macrovictimización de Mampuján y San Cayetano:

é Bueno yo pienso que, la enseñanza es la virtud de la perseverancia, la virtud de la perseverancia, la confianza no sólo en las personas sino en las instituciones, yo creo que eee, es la enseñanza más grande que hemos recibido como comunidad, puesto que hubo un aislamiento al momento del desplazamiento, no confiábamos en nadie puesto que fueron instituciones del Estado las que permitieron y en algunos casos participaron en el desplazamiento, a, al haber participado en este incidente y tener los resultados que tenemos la enseñanza es volver a confiar en las instituciones del Estado... (P2:19). 
PERCEPCIONES SOBRE LA MACROVICTIMIZACIÓN DE MAMPUJÁN Y SAN CAYETANO Y SU REPARACIÓN INTEGRAL EN EL MARCO DE LA LEY 975 DE 2005.

Por su parte, la persona líder TR y un participante del grupo focal de Mampuján consideran que el proceso de Justicia y Paz adelantado con las víctimas de Mampuján y San Cayetano, le permitió a las víctimas conocer institucionalidades de las cuales podían obtener apoyo para la defensa de sus derechos, como la Defensoría del Pueblo: ñé me dejó la enseñanza de conocer todas las instituciones, eh, que tienen que ver con el cumplimento de la ley de víctimasé ò (P3:21). ñé a la Defensoría, ehh por, por todo ese apoyo en la defensa de nosotros, é ò (P7:39), institución del Ministerio Público de Colombia: no es una sola institución que lo conforma, en conjunto son la Procuraduría General de la Nación, la Defensoría del Pueblo y las Personerías municipales, y cada una de ellas es un organismo de control.

A su vez, según el mismo líder TR, les permitió conocer las diferentes normatividades a las cuales podían acudir como víctimas, en especial la Ley 975 de 2005, teniendo en cuenta que está enmarcada en lo que se denomina como Justicia Transicional, es un proceso judicial (investigativo) que puede ser lento y que, por ende, implica paciencia en las víctimas (se da paso a paso). En consecuencia, invita al respeto y humildad por el proceso y sus diferentes actores:

é eh, en este caso la nuestra 965, o sea la ley de aspecto transicional, y nos deja la enseñanza profunda, de que en los procesos como estos, hay unos aspectos que son prioritarios y que nunca deben faltar, y es la paciencia, y es el respeto, y es ehh, la humildad, la humildad como madre de todas las virtudes, é (P3:22).

También, considera que cualquier persona que vaya a emprender una labor tan riesgosa como la que las víctimas de Mampuján y San Cayetano han emprendido con el proceso de Justicia y Paz, posiblemente en relación a los postulados o por 
PERCEPCIONES SOBRE LA MACROVICTIMIZACIÓN DE MAMPUJÁN Y SAN CAYETANO Y SU REPARACIÓN INTEGRAL EN EL MARCO DE LA LEY 975 DE 2005.

retaliaciones, infieren los investigadores, debe estar bien espiritualmente: ñé $e h h, y$ es que también, la parte espiritual, creemos de que cualquier persona que vaya a emprender una labor, tan riesgosa como la que nosotros hemos emprendido, debe estar bien espiritualmente, porque eso trae paz,é ò (P3:23).

Por su parte, también percibe y aprendió que una de las limitaciones más grandes que presenta el Estado colombiano o la institucionalidad es la falta de formación de sus funcionarios públicos o trabajadores, algunos de los funcionarios de las instituciones presentaron un nivel de capacitación muy bajo al momento de adelantar los procesos de Justicia y Paz con las víctimas de Mampuján y San Cayetano, algunos de ellos no conocían en qué consistía la Ley 975 de 2005, no sabían qué era Justicia Transicional, una sentencia, entre otras cosas. Por lo cual, cree que se deben buscar mecanismos para superar esta gran falencia, la cual no se logra con los cambios constantes de trabajadores o funcionarios públicos que se hacen dentro de las instituciones sino brindándoles capacitación, generándoles competencias; los puestos laborales no deberían generarse ni ocuparse por recomendaciones políticas o apalancamientos de otros con influencia, debe ser por competencias, aspecto que tiene atrasado al país respecto a transparencia en estos tipos de procesos y, por ende, infieren los investigadores, en idoneidad en varios de sus casos, más cuando los mismos procesos no pueden llevarse a cabo por la modalidad de Contratistas por Prestación de Servicios que deben padecer muchos trabajadores en Colombia, el término de un contrato obstaculiza, irrumpe o acaba procesos y no brinda garantías laborales. Para corroborar: 
PERCEPCIONES SOBRE LA MACROVICTIMIZACIÓN DE MAMPUJÁN Y SAN CAYETANO Y SU REPARACIÓN INTEGRAL EN EL MARCO DE LA LEY 975 DE 2005.

é hemos entendido que el país tiene unas limitaciones muy grandes, y una de esas limitaciones más grandes está precisamente en el nivel de capacitación de un gran un, de un gran número de funcionarios públicos, creemos que se debe buscar un mecanismo para fortalecer eso, ese cambio en la institucionalidad permanente que existe y esa forma de recomendar a los funcionarios, creemos de que es, de que uno de los aspectos que tiene atrasado al país, si recordamos unas frases anteriores, el 30 de enero cuando nos sentamos por primera vez había un desconocimiento total de los funcionarios de las instituciones, sobre qué era una ley transicional, sobre qué era una sentencia, y sobre qué compromisos tenemos, un ejemplo con el Ministerio de Agricultura, óigase bien, Ministerio de Agricultura,é (P3:24).

Otra enseñanza que se percibe, es que para lograr la reparación integral de las víctimas deben cumplirse a cabalidad y eficazmente las órdenes y exhortos generados en los incidentes de reparación, y generando órdenes y no exhortos dentro de estos. Por su parte, la persona líder LM de San Cayetano percibe que las víctimas dentro de un proceso de Justicia y Paz deben ser participativas, por ejemplo, en la construcción de las medidas de reparación, y vencer el miedo para velar por el cumplimiento de sus derechos y ser reconocidas como víctimas dentro de un incidente de reparación en el marco de la Ley 975 de 2005:

é nos dejó una experiencia que es que hay que apartar el miedo para poder tener lo justo, porque a nosotros el miedo era el que no nos dejaba participar en algunos espacios pero el incidenteé aprendimos con el incidente de reparación que el miedo no le sirve a las personas, nosotros tenemos que ser pues echa' 
PERCEPCIONES SOBRE LA MACROVICTIMIZACIÓN DE MAMPUJÁN Y SAN CAYETANO Y SU REPARACIÓN INTEGRAL EN EL MARCO DE LA LEY 975 DE 2005.

hacia delante, de todas maneras en un momento tenemos mucho temor pero ya ahora las cosas están cambiando, y el gobierno ya nos está acompañando y eso ha marcado la diferenciaé (P4:19).

De igual manera, el líder LM de San Cayetano percibe que las víctimas para poder participar dentro del proceso de Justicia y Paz deben ser activas. No deben esperar a que les den las cosas o sus derechos, hay que tocar puertas, consultar y solicitar apoyo, es decir, deben ser proactivas: ñé para participar hay que estar activos, no podemos esperar que todo nos lo traigan, hay que tocar puertas y preguntar cosas y pedir cosasé ò (P4:20).

Según el representante judicial JS, ve como enseñanza que las macrovictimizaciones como la de Mampuján y San Cayetano no es un tema que afecta solo a las víctimas, sino también a sus representantes judiciales de alguna manera: ñé Uno no puede desligarse, del sufrimiento de estas personas porque de verdad si le llega, a uno lo toca; é ò (P5:19), para lo cual los investigadores sugieren procesos de acompañamiento psicológico para los abogados, para que las problemáticas de las víctimas con las que trabajan no los permee hasta el punto de limitarlos, afectarlos o generarles repercusiones (signos o síntomas) físicas o psicológicas.

También, se puede agregar que al ser el incidente de reparación de Mampuján y San Cayetano pionero dentro de los procesos de Justicia y Paz, debe ser el pilar por el cual se construyan nuevos procesos con víctimas enmarcados en esta normatividad u otras.

A su vez, se debería considerar que el conflicto armado interno de Colombia no es solo un tema de las víctimas, victimarios, representantes judiciales o las instituciones, debe ser una labor de todo el pueblo colombiano, donde con todos se aporte a la solución del conflicto. El desinterés de la sociedad también afecta a las víctimas. 
PERCEPCIONES SOBRE LA MACROVICTIMIZACIÓN DE MAMPUJÁN Y SAN CAYETANO Y SU REPARACIÓN INTEGRAL EN EL MARCO DE LA LEY 975 DE 2005.

Del mismo modo, el representante judicial LV considera que las víctimas del conflicto armado interno se ven en medio de los grupos armado ilegales, sino contribuyen a una de las partes pueden ser victimizadas, más cuando no existe presencia del Estado (Fuerza Pública) para su protección en algunas partes recónditas, veredas o municipios del país. El Estado ha contribuido al conflicto armado interno por omisión o acción. A saber:

é una cosa es estar viviendo en Colombia desde una ciudad capital como Bogotá, y otra cosa muy distinta estar viviendo en Colombia como en un municipio o una vereda de San Cayetano, o Rosa de Mampuján, son realidades muy distintas, lastimosamente la presencia estatal en esos municipios es totalmente mínima y lo que señalan las personas, que en cierta medida tenían que convivir, o bien con los paramilitares, o bien con la guerrilla, era la única opción de vida que tenían porque si no los mataban o sino tenían que desplazarse para las grandes capitalesé (P6:07).

Dejando de lado este panorama, también ve como enseñanza del proceso de Justicia y Paz llevado a cabo con las víctimas de Mampuján y San Cayetano, que existe un nivel de impunidad abrumante dentro de la Rama Judicial, muchos casos terminan archivados o precluidos sin explicación alguna, posiblemente, por el mismo temor de las autoridades judiciales para empoderarse y llevar a cabo los procesos judiciales, donde deban investigarse a personajes (victimarios) con un gran repertorio delincuencial, los cuales ejercen o ejercían un poder político y militar dentro del territorio:

é que el nivel de impunidad de la rama judicial es abrumante, ya que muchos de los casos terminaban archivados o precluidos como tal, por el mismo temor que las autoridades judiciales tenían, para acusar, a esas personas que eran 
PERCEPCIONES SOBRE LA MACROVICTIMIZACIÓN DE MAMPUJÁN Y SAN CAYETANO Y SU REPARACIÓN INTEGRAL EN EL MARCO DE LA LEY 975 DE 2005.

conocidas en la región, y que por obvias razones ejercían el poder político, militar, en esas determinadas partes del paísé (P6:08).

De igual manera, ve como enseñanza del proceso adelantado con estas víctimas, que los verdaderos responsables de la macrovictimización de estas personas aún no están capturados, no han sido procesados; hay muchas personas que en este momento tuvieron que ver con la masacre de San Cayetano y con el desplazamiento forzado de ambas comunidades que no están involucradas en investigaciones judiciales. Para verificar:

é los verdaderamente responsables, deee, esos hechos aún no están capturados, aún no están procesados, hay muchas personas que en este momento tienen que ver con ese masacre por ejemplo de San Cayetano, con el desplazamiento de Mampuján y aún no están involucradosé (P6:09).

Cabe subrayar seguramente porque puntualiza que, por la productividad que tiene la tierra en determinadas partes del país, existen compañías extranjeras y colombianos, a través, de determinadas sociedades y muchas personas de renombre público del país, que le interesa más el enriquecimiento económico personal o el beneficio del pequeño particular que el interés general de la comunidad, generando masacres o macrovictimizaciones como las que han sucedido en medio del conflicto armado interno, entre ellas, la de Mampuján y San Cayetano. No se sabe si lo que vienen a explotar sea la minería o el cultivo de narcóticos, no se puntualizó por parte de los participantes, pero podría ser una posibilidad desde los antecedentes que ha tenido el país frente al conflicto armado:

é la productividad que tiene la tierra en determinadas partes del país es inmensa, y hay mucha compañía extranjera, y muchos colombianos a través de determinadas sociedades, muchas personas de renombre público, que son 
PERCEPCIONES SOBRE LA MACROVICTIMIZACIÓN DE MAMPUJÁN Y SAN CAYETANO Y SU REPARACIÓN INTEGRAL EN EL MARCO DE LA LEY 975 DE 2005.

miembro de esas sociedades, y que les interesa más el enriquecimiento o el pequeño particular que el interés general de la comunidad, y por eso pudieron hacer masacres que se han producidoé (P6:10).

A su vez, observa como enseñanza que en el país existe divisiones políticas fuertes que no median sus diferencias con un discurso argumentativo, con la palabra, sino que lo llevan a la acción, generando violencia entre los sectores. Una solución que tienen algunas de estas personas es acabar con la vida del otro, cometiendo homicidios:

é que el nivel deee, como lo dijéramos, de fricción, o más que todo de, de división política que existe en Colombia es muy claro, acá por pensar de una manera de derecha o de izquierda lo tildan a uno, y la única solución que tienen las personas es simple y llanamente el acabar con la vida de la otra personaé (P6:11).

Otra enseñanza que ve el representante judicial LV del proceso es que existen dificultades interinstitucionales, desarticulación institucional, de trabajo en equipo para el bienestar de las víctimas del conflicto armado interno. Donde, por ejemplo, la Fiscalía General de la Nación presentó recelos para compartir información con los representantes judiciales de la Defensoría del Pueblo cuando se encontraban elaborando sus acciones para solicitar la reparación integral de las víctimas de Mampuján y San Cayetano:

é en lo que tiene que ver con el desarrollo del incidente concretamente con las entidades, que se necesita que haya una especie más de compromiso, sin querer que decir esto que, que se pongan previamente acuerdo de cómo van a hacer las diligencias, pero que el compromiso compartido de información por parte de las distintas entidades, por ejemplo la Fiscalía, por el mismo presupuesto que tiene, tiene una capacidad monstruosa de adquirir información, y de movilizarse, pero 
PERCEPCIONES SOBRE LA MACROVICTIMIZACIÓN DE MAMPUJÁN Y SAN CAYETANO Y SU REPARACIÓN INTEGRAL EN EL MARCO DE LA LEY 975 DE 2005.

una entidad como la Defensoría del Pueblo, es mínimo el presupuesto con que cuenta, y se trabaja siempre con las uñasé (P6:12).

Para entender mejor el contexto, según el mismo representante judicial, como enseñanza del proceso también está el que la reforma a la Ley de Justicia y Paz, es decir, la Ley 1592 de 2012, le arrebataba a las demás víctimas del conflicto armado interno la posibilidad de gozar de un incidente de reparación judicial integral en el marco de la Ley 975 de 2005. Desde la interpretación de los investigadores, más cuando esta reforma lo que buscaba era que la reparación integral quedara a cargo de la antigua Acción Social, hoy llamada Unidad de Atención y Reparación Integral a las Victimas (UARIV), adscrita al Departamento para la Prosperidad Social (DPS), dejando solo a las víctimas, básicamente, con la ñVerdadò y ñJusticiaò en el proceso de Justicia y Paz, generándose reparaciones (especialmente indemnizaciones) en Equidad. Para corroborar:

é ojalá este proceso de Mampuján no sea únicamente el de mostrar, ya que como vemos salió una ley que fue la 1592, que tumba todo lo que se ha logrado en materia de reparación a víctimas, y que en lugar de estar dando una imagen, de que Colombia efectivamente está comprometida con los temas de Derechos Humanos, lo que está es cercenando los derechos de las víctimas, y pone de, de relieve que 7 años después esa ley 975, no fue en pos de las víctimas sino en pos de los paramilitares desmovilizados, y 7 años después se dan cuenta del monstruo que creaban, porque lastimosamente a Mampuján lo ve como un monstruo y lo que el Estado colombiano quiere que se generen monstruos como esos, y consideran que simple y llanamente con dar, determinados montos, hasta 40 salarios 
PERCEPCIONES SOBRE LA MACROVICTIMIZACIÓN DE MAMPUJÁN Y SAN CAYETANO Y SU REPARACIÓN INTEGRAL EN EL MARCO DE LA LEY 975 DE 2005.

mínimos, tratándose delitos de homicidio ya están cumpliendo con esa obligación indemnizatoria, é (P6:13).

En resumidas cuentas, qué hubiera podido pasar a través de la Ley 1592 de 2012 con aquellas víctimas que iniciaron los procesos de Justicia y Paz desde varios años anteriores y que esperan una reparación judicial integral por este medio normativo (Ley 975 de 2005); aunque se sabe que nadie podrá ser reparado dos veces por el mismo hecho, basados en la Ley 1448 de 2011, articulo 20: ñPrincipio de prohibición de doble reparación y de compensación: La indemnización recibida por vía administrativa se descontará a la reparación que se defina por vía judicial; nadie podrá recibir doble reparación por el mismo conceptoò. Más cuando se sabía que las víctimas de Mampuján y San Cayetano recibieron sumas altas y justas de reparación (indemnización) en relación con los daños causados, lo cual va en contravía con la Ley de Víctimas y de Restitución de Tierras, Ley 1448 de 2011, debido a que repara (indemniza) teniendo en cuenta el hecho victimizante y no el daño, brinda una reparación en equidad. La reforma a la Ley 975 buscaba que las victimas recibieran una sola indemnización en Equidad por la Ley 1448, sin la posibilidad de ser descontado estos montos de una reparación judicial. Por ende, eran varios interrogantes que requerían en su momento acciones o estrategias desde la Rama Legislativa (Congreso de la República) y el Estado colombiano en general.

La reforma a la Ley de Justicia y Paz violaba un derecho fundamental constitucional colombiano y principio general, el de la Igualdad:

Constitución Política de Colombia de 1991, Artículo 13: Todas las personas nacen libres e iguales ante la ley, recibirán la misma protección y trato de las autoridades y gozarán de los mismos derechos, libertades y oportunidades sin ninguna discriminación por razones de sexo, raza, origen nacional o familiar, lengua, religión, opinión política o filosófica. El 
PERCEPCIONES SOBRE LA MACROVICTIMIZACIÓN DE MAMPUJÁN Y SAN CAYETANO Y SU REPARACIÓN INTEGRAL EN EL MARCO DE LA LEY 975 DE 2005.

Estado promoverá las condiciones para que la igualdad sea real y efectiva y adoptará medidas en favor de grupos discriminados o marginados.

Donde todas las victimas puedan gozar del mismo derecho y beneficio judicial respecto a la reparación integral. Si las víctimas de Mampuján y San Cayetano recibieron del proceso de Justicia y Paz una reparación integral y en Derecho, las demás víctimas del conflicto armado interno, que puedan enmarcarse en esta normatividad judicial, también deberían recibir dicha reparación y beneficios. Lo anterior pone de relieve, según el representante judicial LV, que alrededor de 7 años después de la Ley 975 de 2005, esta normatividad no fue creada a favor de las víctimas sino para el beneficio casi total de los postulados:

Decreto 4760 de 2005. Artículo 3. Lista de Postulados. (é ): Desmovilizados que manifestaron previamente y por escrito ante el Alto Comisionado para la Paz o al Ministro de Defensa, según se trate de desmovilizados colectivos o individualmente, su voluntad de ser postulados para acogerse al procedimiento y beneficios previstos por la Ley 975 de 2005 y declaren bajo la gravedad del juramento su compromiso de cumplimiento de los requisitos previstos en los artículos 10 y 11 de ésta, según corresponda. La elaboración de la lista de postulados en el proceso de Justicia y Paz se realizará, entre otras, con los nombres e identidades de los miembros de los grupos armados al margen de la ley que se hayan desmovilizado colectivamente de conformidad con la Ley 782 de 2002.

Habría que decir también que este mismo representante judicial percibe, gracias al proceso de Justicia y Paz adelantado con las víctimas de Mampuján y San Cayetano, entre otros, que el paramilitarismo en Colombia ha mutado, no ha desaparecido como lo dice el Estado colombiano, se denominan ahora Bandas Criminales (BACRIM), unas llamadas ñurabeñosò, otras ñRastrojosò, entre otros; lo cual requiere ajustes normativos para no dejar víctimas por fuera de 
PERCEPCIONES SOBRE LA MACROVICTIMIZACIÓN DE MAMPUJÁN Y SAN CAYETANO Y SU REPARACIÓN INTEGRAL EN EL MARCO DE LA LEY 975 DE 2005.

los beneficios o derechos de reparación integral, donde muchas de estas personas no han sido reconocidas como víctimas porque las normatividades, como la Ley 975 de 2005 y la Ley 1448 de 2011, no contemplan a estos grupos mutados como grupos armados organizados al margen la Ley en el marco del conflicto armado interno, negándoseles los beneficios normativos, a excepción de las víctimas de desplazamiento forzado dentro de la Ley de Victimas y de Restitución de Tierras, gracias al Auto 119 de 2013, que ordena la inclusión en el Registro Único de Víctimas (RUV) de las víctimas de desplazamiento forzado por BACRIM:

é considero que, el mismo proceso, este proceso de justicia y de paz, ha dejado claro que el paramilitarismo en Colombia no ha desaparecido, a mutado o se le ha cambiado de nombre, actualmente se les llama Bacrim, se les llama Urabeños, se les llama Rastrojo, pero es la misma situación de violencia que se está viviendo acá en Colombia, y está transmutando en otra serie de personas, entonces hasta el momento en que no haya un compromiso serio, por parte del gobierno, ya que todo este problema que se viene presentando es, en consecuencia yo creo que más del 80\% un problema de tierras, y problema de drogas,é (P6:14).

Como se ve, estos grupos armados ilegales, según el mismo representante judicial, también denominados grupos post desmovilización continúan operando en las zonas que fueron controladas por los paramilitares, sus objetivos, sus métodos, sus enemigos políticos y hasta la forma de operar son los mismos que empleaban los paramilitares antes de la aplicación de la Ley 975 de 2005, los cuales generan victimizaciones en un $80 \%$ por las tierras, buscando despojar o que abandonen las personas sus predios, atacando a los líderes de restitución de tierras y realizando alianzas con otros grupos armados para seguir explotando el negocio del narcotráfico (20\%). Es decir, no se evidencia un compromiso serio por parte del Estado colombiano para 
PERCEPCIONES SOBRE LA MACROVICTIMIZACIÓN DE MAMPUJÁN Y SAN CAYETANO Y SU REPARACIÓN INTEGRAL EN EL MARCO DE LA LEY 975 DE 2005.

intervenir estas mutaciones y problemáticas pensando en el beneficio de todas las víctimas de los diferentes hechos victimizantes.

\section{Sugerencias de los participantes}

El líder GP de Mampuján, le sugiere a las instituciones judiciales que se apersonen de las dificultades y realidades de las personas, de las víctimas del conflicto armado interno. Al igual, que detecten el daño causado en las victimas y para ello necesitan más contacto con las comunidades afectadas, teniendo en cuenta sus pretensiones de reparación, por ejemplo, para el cumplimiento y construcción de las medidas de reparación colectiva, donde se dialogue con mayor efecto, con el fin de propiciar los medios para generar restablecimientos de derechos en las víctimas. A saber:

é para los casos de las instituciones judiciales, creo que se tienen que apersonar más de las realidades de la gente, se tienen que apersonar más de las realidades de la gente, queee, en caso de Procuraduría Judicial que es quien representa las pretensiones colectivas eehh tiene que rozarse más con la gente, con las comunidades, a fin de que detecte realmente el daño que sufren las comunidades, é (P2:20).

Además, a los Magistrados o Jueces les sugiere seguir con el trabajo realizado, el cual es excelente y respetuoso: ñé uhmm, de los magistrados creo que no tengo nada que decir porque creo que hicieron un excelente trabajo, atendiendo primeramente a las víctimas, teniendo en cuenta las necesidades nuestras y tratándonos con respeto, é ò $(P 2: 21)$, a pesar de que existan opositores.

Sin embargo, a partir del líder TR de Mampuján, se agrega la importancia de que se tenga en cuenta no volver a generar dentro de los incidentes de reparación judicial, exhortos sino órdenes 
PERCEPCIONES SOBRE LA MACROVICTIMIZACIÓN DE MAMPUJÁN Y SAN CAYETANO Y SU REPARACIÓN INTEGRAL EN EL MARCO DE LA LEY 975 DE 2005.

directas que en realidad puedan contribuir a la reparación integral de las víctimas. Igualmente, le sugiere a los Magistrados o Jueces ser taxativos en este proceso, porque considera que no debería ser posible que unas personas que padecieron el flagelo del conflicto armado interno, como las víctimas de Mampuján y San Cayetano, que fueron privadas de sus derechos fundamentales, como: a vivir, de tener servicios de salud, de educación, de tener una vivienda digna; no sean reparadas integralmente antes que los postulados alias ñJuancho Diqueò y ñDiego Vecinoò salgan en libertad, antes de que cumplan sus penas en el marco de la Ley 975 de 2005, por eso ve tan importante ñé que los tiempos que pongan para el cumplimiento de las órdenes que se dan ahí sean inferiores a las penas que reciban los postuladosé ò (P3:25):

é Yo creo que una recomendación que se le puede dar a los magistrados, a los jueces, a quien toque fallar un proceso que tenga que ver con ley transicional, es que, mirando los antecedentes de esta sentencia que por favor traten de ser más taxativos, y no traten de dar, exhortos, sino que den en lo posible órdenes, porqueee, no es posible, que unas personas que fueron violadas en su derecho fundamental de tener la salud, de tener la educación, de tener una vivienda, dentro de un país que la guerra no ha cesado, dentro de un sistema que permite dar una pena alternativa a los victimarios, los victimarios salgan a las calles a gozar de su libertad y todavía los líderes de la población desplazada y de las comunidades sigan peleando por el cumplimento de las órdenes que dieron o de los exhortos que dieron en ese, en esa sentencia, entonces que sean cuidadosos de hacer sentencias, que pongan tiempos específicos inferiores a las penas,... $(P 3: 26)$. 
PERCEPCIONES SOBRE LA MACROVICTIMIZACIÓN DE MAMPUJÁN Y SAN CAYETANO Y SU REPARACIÓN INTEGRAL EN EL MARCO DE LA LEY 975 DE 2005.

De igual forma, el líder GP de Mampuján sugiere a la Fiscalía General de la Nación, pudiendo recaer a la Unidad de Justicia y Paz, ser más estricta y minuciosa con las investigaciones. La información y documentación que requieren deberían obtenerla de la fuente primaria que es la víctima, no de otras instituciones, como la antigua Acción Social, que pueden tener entre sus bases de datos, errores o no inclusiones de personas; para ello, propone que se generen bases de datos consolidadas y compartidas que sean única fuente de información de todas las instituciones, donde se hable en una misma línea, puesto que la proliferación de bases de datos de víctimas trae consigo errores procesales y, así, vulneración de derechos y victimizaciones secundarias. Para corroborar:

é Pienso que la, la Fiscalía tiene que ser másé hacer investigaciones a fondo, muy minucioso... antes que con las instituciones con las mismas víctimas; si por ejemplo la Fiscalía, tiene que, buscar una documentación para que la víctima sea ratificada como víctima, si se va a Acción Social sabemos que los sistemas no son completos, no todas las víctimas están registrada, y hoy un sistema dice que sí estás, pero si mañana lo necesitas para la ejecución de un proyecto posiblemente no estás, y la respuesta es que no estás y no estás o se borró del sistema, creo que es más confiable la versión de la víctima o de la comunidad que la versión de la institucionalidad, la idea también es que se puedan articular, creo que es uno de los aprendizajes, que Acción Social maneje un listado, la Fiscalía maneje ese mismo listado, la Personería maneje ese mismo listado, la Defensoría maneje ese mismo listado, que sea uno solo y no que haya celos institucionales, de que yo hago mi trabajo y esto lo tengo yo porque esto es para mí, sería bueno que al momento de pensar en las víctimas el trabajo sea articuladoé (P2:22). 
PERCEPCIONES SOBRE LA MACROVICTIMIZACIÓN DE MAMPUJÁN Y SAN CAYETANO Y SU REPARACIÓN INTEGRAL EN EL MARCO DE LA LEY 975 DE 2005.

Lo cierto es que, el representante judicial LV le sugiere a las instituciones más compromiso para atender a las víctimas del conflicto armado interno, donde trabajen mancomunada y articuladamente, con el compromiso de compartir información relevante para llevar este tipo de procesos judiciales en beneficio de las víctimas; sugerencia hecha, por ejemplo, a la Fiscalía General de la Nación, posiblemente, a la Unidad de Justicia y Paz, más cuando perciben que es una institución que tiene mayor capacidad económica y de adquisición de información, en comparación con la Defensoría del Pueblo, que cuenta con poco presupuesto. La desarticulación de las instituciones afecta a las víctimas del conflicto armado interno, sobretodo cuando buscan dilatar los procesos y evadir responsabilidades:

é en lo que tiene que ver con el desarrollo del incidente concretamente con las entidades, que se necesita que haya una especie más de compromiso, sin querer que decir esto que, que se pongan previamente acuerdo de cómo van a hacer las diligencias, pero que el compromiso compartido de información por parte de las distintas entidades, por ejemplo la Fiscalía, por el mismo presupuesto que tiene, tiene una capacidad monstruosa de adquirir información, y de movilizarse, pero una entidad como la Defensoría del Pueblo, es mínimo el presupuesto con que cuenta, y se trabaja siempre con las uñasé (P6:15).

Siguiendo esta misma corriente, un participante del grupo focal de San Cayetano sugiere a las instituciones - especialmente a las de control y seguimiento, infieren los investigadores -, hacer visitas constantes a las comunidades de víctimas de Mampuján y San Cayetano para hacer seguimiento a la evolución de sus procesos de reparación judicial integral, del cumplimiento del incidente de reparación dado en segunda instancia en el marco de la Ley de Justicia y Paz. Algunas víctimas ven necesario un acompañamiento constante de la institucionalidad, por 
PERCEPCIONES SOBRE LA MACROVICTIMIZACIÓN DE MAMPUJÁN Y SAN CAYETANO Y SU REPARACIÓN INTEGRAL EN EL MARCO DE LA LEY 975 DE 2005.

ejemplo, Fiscalía General de la Nación, u órganos de control como el Ministerio Público, infieren los investigadores, para verificar el cumplimiento de las órdenes y exhortos contenidos en el incidente de reparación dado en segunda instancia:

é Yo, yo diría que tenía que estar más, visitar más la evolución de nosotros, empaparse un poco más de la condición de nosotros, é entonces uno le diría a la institución, qué vengan a ver la condición cómo uno vive, que se enteren en realidad la condición de uno,é, que vayan, que vayan donde están las necesidades para que vean que sí es ciertoé (P9:17).

Ahora bien, el líder LM de San Cayetano, sugiere a las víctimas que no tienen vivienda propia y digna o que la perdieron por el hecho victimizante, que se dirijan sin pasividades a las Administraciones Municipales a solicitar subsidios de vivienda de interés social, más cuando son víctimas de estratos socioeconómicos bajos (1 ó 2); debido a que el Estado colombiano, como compromiso constitucional, consagrado en la Constitución Política de 1991, apoyan los investigadores, debe cumplir a partir del Art. 51. Todos los colombianos tienen derecho a vivienda digna: El Estado fijará las condiciones necesarias para hacer efectivo este derecho y promoverá planes de vivienda de interés social, sistemas adecuados de financiación a largo plazo y formas asociativas de ejecución de estos programas de vivienda. A saber:

é Los que no tienen vivienda la sugerencia es queé porque la vivienda no hace parte de reparación, o sea de indemnización, la vivienda ustedes saben que todos los colombianos que vienen en estrato 1 y 2 tenemos derecho a vivienda subsidiada por el gobierno, entonces hay que participar cómo? En el municipio, o sea hay que tener alianzas con los alcaldes para poder participar de los proyectos de vivienda de interés socialé (P4:21). 
PERCEPCIONES SOBRE LA MACROVICTIMIZACIÓN DE MAMPUJÁN Y SAN CAYETANO Y SU REPARACIÓN INTEGRAL EN EL MARCO DE LA LEY 975 DE 2005.

Al mismo tiempo, el representante judicial LV de las víctimas de Mampuján y San Cayetano, sugiere muy respetuosamente a las víctimas que recaiga, que la Ley 975 de 2005 no puede ser vista como un medio para superar las condiciones de pobreza, se debe recordar siempre que uno de los fines de esta Ley, aunque la mayoría de veces no se lleve a cabo, es lograr la reparación judicial integral de las víctimas del conflicto armado interno. Según él, muchas víctimas se volvieron ñvíctimas profesionalesò, es decir, se dedicaron a vivir de la compasión que puedan generar en otras personas, en otros entes, instituciones o funcionarios del Estado, con el argumento de estar buscando superar o sobrellevar las condiciones de pobreza, muchas veces sin padecerla; recordemos que la superación de la pobreza obedece a las políticas propias de un Estado Social de Derecho que el Estado colombiano no ha podido subsanar:

é Una cosa es reparar a una comunidad, a unas personas que han sido víctimas de la violencia, y otra cosa muy distinta es que las víctimas pretendan salir de la pobreza utilizando un proceso judicial, por un hecho del cual fue víctima indirecta, y lo que uno logró ver con ese primer incidente, es que como lo decía un compañero muchas víctimas se volvieron víctimas profesionales, es decir se dedicaron a vivir de la lástima, que puedan generar, en otras, en otras personas, en otros entes del Estado y en tal sentido considero que ese aspecto debe ser bastante revaluado porque lo que se trata es de reparar efectivamente el daño causado, pero no sacar de la pobreza porque el sacar de la pobreza obedece es a las políticas propias de un Estado social de derecho,é (P6:16).

Por otro lado, el líder TR de Mampuján sugiere a comunidades de víctimas y demás líderes de estas poblaciones, que estén adelantado un proceso judicial en el marco de la Ley de Justicia y Paz, que manejen la humildad y honradez en dicho proceso, a pesar de que existen funcionarios 
PERCEPCIONES SOBRE LA MACROVICTIMIZACIÓN DE MAMPUJÁN Y SAN CAYETANO Y SU REPARACIÓN INTEGRAL EN EL MARCO DE LA LEY 975 DE 2005.

públicos que no apuestan ni contribuyen al progreso y reparación integral de las víctimas. A su vez, mencionan la importancia de que los líderes operen transparentemente con las víctimas e instituciones buscando realmente la reparación integral de estos sujetos vulnerados, lo cual permite terminar con éxito los procesos:

é la recomendación a cualquier comunidad que está haciendo un proceso: la humildad, la honradez, nosotros hemos considerado que a pesar de que en este país hay injusticias, a pesar de que hay funcionarios públicos que no hacen apuesta al progreso social, que tienen alguna incapacidad administrativa, el detonante de algunos problemas que han tenido y que tendrán algunos líderes en la historia es también parte del comportamiento que cada uno de nosotros tenga, si nosotros somos honestos, si somos sinceros, si no nos tratamos de aprovechar de la situación con nuestros amigos que lideramos, o si no nos tratamos de aprovechar de las instituciones sino que hacemos unos procesos limpios, tenemos un noventa y tanto por ciento de posibilidades de terminar los procesos con éxito, entonces recomendaciones para nuestros amigos para que entremos a hacer procesos limpios, para que trabajemos transparentemente y para que nos ilustremos mucho en la exigibilidad de derechosé (P3:27).

A las víctimas del conflicto armado interno, el líder GP de Mampuján, les sugiere ser más atrevidas, adquirir información y conocimientos suficientes de las diferentes normatividades a las que acuden o pueden acudir para la defensa y reclamo de sus derechos. Deben, por ejemplo, sobrellevar los efectos limitantes del miedo para empezar o continuar con sus procesos judiciales, específicamente, con el proceso de Justicia y Paz, además, de confiar en los procesos de reintegración de los postulados, pero estando alertas: 
PERCEPCIONES SOBRE LA MACROVICTIMIZACIÓN DE MAMPUJÁN Y SAN CAYETANO Y SU REPARACIÓN INTEGRAL EN EL MARCO DE LA LEY 975 DE 2005.

é las víctimas tienen que ser atrevidas, romper el miedo, romper el miedo y también creerle digamos que a las personas que nos hicieron daño, si ellos dicen que no van a participar más de los hechos violentos, por lo menos creamos esa parte, creamos esa parte porque de la abundancia del corazón habla la voz... estando alertasé (P2:23).

También, una participante del grupo focal de San Cayetano considera importante que las víctimas y sus líderes tengan paciencia porque los procesos de Justicia y Paz son lentos, se dan por pasos, paulatinamente, pero deben ser activos, adquirir información o recibir asesoría normativa y trabajar en equipo con insistencia:

é Que tengan paciencia, y que tengan paciencia yé LUIS: Que sepan esperar. SEÑORA: Si, porqueé LUIS: Y que tal que ellos de pronto. SEÑORA: Que se informen bien. LUIS: Exacto. Que se informen bien, porque si hay veces así como aquí tenemos líderes, líder, hay personas que vienen de otra parte, buscando provecho de lo que es para nosotros. LUIS: Ajá. SEÑORA: Entonces, uno tiene que informarse bien para que no le metan... LUIS: Y si de pronto... SEÑORA: Viene algún vivo... (P9:18).

Por otra parte, otro participante del mismo grupo focal le sugiere a los postulados que el arrepentimiento por los hechos victimizantes causados con las poblaciones de Mampuján y San Cayetano y aparentemente demostrado dentro del proceso de Justicia y Paz adelantado con ellas, debió ser sincero y total. Deben arrepentirse por completo para que sientan y comprendan el dolor de estas comunidades:

é recuerden que los ojos de los hombre no los ven, pero Dios está viendo, cuando uno habla de arrepentimiento, tiene que el arrepentimiento tiene que ser total, 
PERCEPCIONES SOBRE LA MACROVICTIMIZACIÓN DE MAMPUJÁN Y SAN CAYETANO Y SU REPARACIÓN INTEGRAL EN EL MARCO DE LA LEY 975 DE 2005.

total. Ellos tienen que arrepentirse por completo, para sentir el dolor que sintió la comunidad, para sentir ese sufrimiento que ellos sintieron y en su más íntimo de su corazón querer, restaurarlo, ayudarlo, desde lo más íntimo,é (P9:19).

Y, así, puedan transformar sus vidas y, por ende, puedan apoyar efectivamente a la reparación integral de las víctimas y la judicialización de otros posibles responsables de la macrovictimización de Mampuján y San Cayetano que están en libertad; porque percibe que es posible que entre los postulados alias ñJuancho Diqueò y ñDiego Vecinoò puede existir alguno que haya decidido recibir una condena en el marco de la Ley de Justicia y Paz, con el fin de que con su silencio se esté beneficiando a un tercero o varios con poder seguir lucrándose ilegalmente; es decir, la sugerencia es que los postulados apoyen realmente en la construcción de la ñVerdadò del proceso de Justicia y Paz, toda la verdad de lo sucedido con la macrovictimización de Mampuján y San Cayetano:

é osea que una forma de manifestarse, que esas personas, que ellos hablaran sobre esas personas, pero nunca supimos sobre esoé Porque entonces, supongamos, yo soy ladrona y yo sé que usted se enojó conmigo y a mí me detienené BYRON: Ajá. SEÑORA: Y yo estoy pagando por mi condena y estoy patrocinando, que usted sigue haciendo. BYRON: Con mi silencio. SEÑORA: Con su silencia, claro. SEÑOR: Los postulados tienen que hablar. SEÑORA: Yo no estoy contenta con los resultados, no me siento***porque es que ellos, si ellos, dicen que verdad es *** Ellos tienen que decir a su verdad total ellos tienen que decir fulano, sutano, lo que haya sido, pero los que estaban con ellos de la comunidad, y así uno se siente satisfecho, porque, porque así uno sabe con quién lidia, porque así ***no sabemos quienes soné (P9:20). 
PERCEPCIONES SOBRE LA MACROVICTIMIZACIÓN DE MAMPUJÁN Y SAN CAYETANO Y SU REPARACIÓN INTEGRAL EN EL MARCO DE LA LEY 975 DE 2005.

Posteriormente, el líder GP de Mampuján, les sugiere a los representantes judiciales de víctimas de la Defensoría del Pueblo (a quien corresponda), ser más cuidadosos y responsables con la documentación y procesos de las víctimas:

é Yo creo que la Defensoría tiene que tener más cuidado con la documentación de las víctimas, eehhhé tratar deé de aunque somos víctimas y de pronto no estamos pagando nosotros, tener un respeto y seriedad con la documentación a fin de que se presenten efectivamente los documentos que la víctima provee,é $(P 2: 24)$.

No es justo que por errores, desinterés, olvidos, descuidos en la manipulación de los documentos se queden víctimas sin reparación integral, se queden por fuera de un incidente de reparación en el marco de la Ley de Justicia y Paz, aunque esto puede aplicarse a cualquier proceso con víctimas.

Entonces, los participantes al generar y exponer sus percepciones particulares durante la investigación, construyeron y expresaron a la vez percepciones sociales de las comunidades de Mampuján y San Cayetano, debido a que, como se dijo en la Revisión de la Literatura, cuando las personas (participantes de la investigación) hacen referencia a los objetos sociales (macrovictimización de Mampuján y San Cayetano y su incidente de reparación integral de Justicia y Paz), los clasifican, los explican y, además, los evalúan, es porque tienené (Montes et al., 2010) una percepción social de ese objeto. Sus percepciones individuales o particulares se convierten en percepciones sociales porque son compartidas por gran parte de la comunidad de Mampuján y San Cayetano y parte de la sociedad colombiana.

Cabe recordar aquí que, a partir de Montes et al. (2010), uno de los elementos importantes que definen a la percepción, es el reconocimiento de las experiencias cotidianas. El 
PERCEPCIONES SOBRE LA MACROVICTIMIZACIÓN DE MAMPUJÁN Y SAN CAYETANO Y SU REPARACIÓN INTEGRAL EN EL MARCO DE LA LEY 975 DE 2005.

reconocimiento es un proceso importante involucrado en la percepción, porque le permitió, por ejemplo, a los participantes de esta investigación evocar experiencias y conocimientos previamente adquiridos por esta macrovictimización y su incidente de reparación integral de Justicia y Paz, con los cuales compararon las nuevas experiencias, lo que les permitió identificarlas y aprehenderlas para interactuar con el entorno, con las consecuencias y cambios generados por la macrovictimización de Mampuján y San Cayetano y a la espera del cumplimiento de las medidas de asistencia y de reparación contenidas en la sentencia de segunda instancia. De esta forma, a través del reconocimiento de las características de los objetos se construyen y reproducen modelos culturales e ideológicos que permiten explicar la realidad con una cierta lógica de entre varias posibles, que se aprende desde la infancia y que depende de la construcción colectiva y del plano de significación en que se obtiene la experiencia y de donde ésta llega a cobrar sentido (Montes et al., 2010).

Estas personas conocen y expresaron la realidad que les circunda mediante explicaciones (percepciones) que extrajeron de los procesos de comunicación y del pensamiento social, respecto a la macrovictimización y la sentencia de reparación judicial integral de Mampuján y San Cayetano. Dichas percepciones, que también son sociales, a partir de Montes et al. (2010), se construyeron mediante: percepciones individuales o particulares compartidas, representaciones y valores, conocimientos y creencias (cultura), experiencia individual, experiencia compartida, hábitos adquiridos, comportamientos aprendidos y actitudes que tienen los pobladores (víctimas y líderes) de Mampuján y San Cayetano; también mediante la percepción que tiene la sociedad hacia estas personas, según algunas víctimas, incluyendo a los representantes judiciales, sobre lo que es un incidente de reparación en el marco de la Ley 975 de 2005 y sobre el historial de conflicto armado interno que ha tenido el país. 
PERCEPCIONES SOBRE LA MACROVICTIMIZACIÓN DE MAMPUJÁN Y SAN CAYETANO Y SU REPARACIÓN INTEGRAL EN EL MARCO DE LA LEY 975 DE 2005.

Es decir, estos juicios categoriales (percepciones) en ocasiones son compartidos por otras personas, por parte o una comunidad de forma general, generando con ello Percepciones Sociales. Por ello, el hecho de que haya existido una cantidad reducida de participantes dentro de la investigación en relación con la cantidad de los pobladores de ambas comunidades y que dentro de los estudios cualitativos, según Hernández et al. (2010), el tamaño de la muestra (en este caso Grupos de Participantes) no sea importante desde una perspectiva probabilística, debido a que el interés de los investigadores no era generalizar los resultados de su estudio a una población más amplia, sino profundizar sobre conceptos o percepciones de unos participantes; no le permite a esta investigación generalizar teorías que puedan replicarse de forma concreta en otras poblaciones víctimas, sin embargo, sus percepciones si pueden dar luces de lo que serían las Percepciones Sociales de estas comunidades (Mampuján y San Cayetano), porque entre ellos estuvieron personas que hacen parte de las mismas colectividades (víctimas y líderes: quienes guían y recopilan lo de sus liderados) y representantes judiciales, quienes por su experiencia pudieron dar información valiosa sobre las percepciones individuales o particulares y aquellas que comparten como sociedad víctimas de Mampuján y San Cayetano sobre sus macrovictimizaciones y el incidente de reparación judicial integral (Ley 975 de 2005). 
PERCEPCIONES SOBRE LA MACROVICTIMIZACIÓN DE MAMPUJÁN Y SAN CAYETANO Y SU REPARACIÓN INTEGRAL EN EL MARCO DE LA LEY 975 DE 2005.

\section{Conclusiones y Recomendaciones}

Gracias al análisis de los datos cualitativos, con ayuda de la organización de la información facilitada por el software Atlas. ti 6.2, se logró obtener doscientas catorce (214) Citas de los nueve (9) Documentos Primarios o transcripciones de las técnicas de recolección de información (Entrevistas Semiestructuradas y Grupos Focales), a saber: de P1:47 Citas (siendo el documento primario que más arrojó citas relevantes para la investigación), P2:24, P3:27, P4:21, P5:19, P6:16, P7:39, P8:01 (el de menos citas relevantes) y P9:20, las cuales fueron de interés para los investigadores porque respondian a los objetivos de la investigación y arrojaban información importante para dar a conocer a través de esta investigación; de las cuales se definieron diecinueve (19) Códigos o Categorías de análisis, en un principio como previas, las categorías 7 , $8,9,10,11,13$ y 14 debido a que respondían directamente a los objetivos de la investigación, y luego como emergentes, las demás categorías por la relación e importancia de la información que iba surgiendo para el análisis; al final, la suma de las categorías previas y emergentes arrojan el total de los Códigos utilizados en la investigación o temas de análisis y discusión.

Citas que se obtuvieron tras la indagacion de cuatro líderes de víctimas de Mampuján y San Cayetano, uno de ellos de este último corregimiento, quienes acompañaron a las víctimas durante todo el proceso de Justicia y Paz (Ley 975 de 2005) contra alias ñJuancho Diqueò y ñDiego Vecinoò y también son víctimas de estos postulados; dos representantes judiciales de la Defensoría del Pueblo y que participaron en el incidente de reparación, en calidad de representantes judiciales de las víctimas de ambos corregimientos y, que en el proceso apelaron la sentencia en primera instancia y culminaron con su participación en la sentencia de segunda instancia; y diecinueve víctimas de Mampuján y San Cayetano, nueve de Mampuján, víctimas de 
PERCEPCIONES SOBRE LA MACROVICTIMIZACIÓN DE MAMPUJÁN Y SAN CAYETANO Y SU REPARACIÓN INTEGRAL EN EL MARCO DE LA LEY 975 DE 2005.

Desplazamiento Forzado Urbano, siete, y rural dos, y diez de San Cayetano, también, víctimas de Desplazamiento Forzado.

Diecinueve (19) categorias o códigos que se obtuvieron por la concurrencia de las citas, a patir del Atlas. ti 6.2, en temas de análisis y discusión de este reporte de resultados de la investigación. Categorías obtenidas de nueve (9) Documentos Primarios, donde ambas contienen una cantidad de citas. De las cuales, se pudieron obtener, entre otros, resultados que indican, a partir de algunos participantes, que del incidente de reparación integral dado en segunda instancia, existe un alto incumplimiento de las medidas de Reparación Colectiva, de cumplimiento de las indemnizaciones y de víctimas satisfechas de Mampuján y San Cayetano con las indemnizaciones recibidas. Además, que la mayoría de los motivos de las victimizaciones por parte de los Grupos Armados Ilegales se debe a la apropiación ilegal de tierras y mucho menos al narcotráfico.

Ahora, se hace necesario recalcar que los resultados y discusiones de esta investigación se obtuvieron sólo a partir de las percepciones de los participantes, las cuales pueden tomarse como percepciones sociales de las comunidades de Mampuján y San Cayetano, y aplican hasta el momento en que se desarrollaron las técnicas de recolección de información, a partir de las cuales y respondiendo de forma concreta al objetivo general - cabe anotar que sólo se hará mención en esta parte conclusiva a las respuestas de las preguntas y objetivos de esta investigación de forma general, aunque existieron otros resultados y discusiones de suma importancia, se invita al lector a consultarlos de forma amplia en apartados anteriores - , se puede decir que varios participantes percibieron que no hubo una completa contribución del ñincidente de reparación integralò en el marco de la Ley 975 de 2005 a la reparacion integral de las víctimas de Mampuján y San 
PERCEPCIONES SOBRE LA MACROVICTIMIZACIÓN DE MAMPUJÁN Y SAN CAYETANO Y SU REPARACIÓN INTEGRAL EN EL MARCO DE LA LEY 975 DE 2005.

Cayetano. Es decir, las percepciones al respecto en los participantes estuvieron divididas, unos estuvieron en desacuerdo y otros estan conformes con los resultados de este incidente.

Lo que acontece es que, respondiendo de forma concluyente a los objetivos específicos de esta investigación, se puede decir que algunos participantes percibieron que faltaron por incluirse pretensiones de reparación integral de las víctimas de Mampuján y San Cayetano dentro del incidente de reparación dado en segunda instancia. Además de eso, se puede decir que no hay cumplimiento total, por parte de los postulados y por parte de la institucionalidad de las órdenes y/u exhortos emitidos por la Corte Suprema de Justicia en el fallo de segunda instancia frente a la reparación integral de las víctimas de Mampuján y San Cayetano, según algunos participantes. Lo cual no contribuye a la reparación integral de las víctimas.

A su vez, porque a partir de la intervención de algunos participantes, no se puede decir que hubo una completa satisfacción de las pretensiones de las víctimas de Mampuján y San Cayetano con el resultado del incidente de reparación dado en segunda instancia, precisando que las pretensiones a las cuales se hace referencia en este punto no están netamente ligadas con pretensiones de reparación, abarca un sin número de anhelos de las víctimas con el resultado del incidente de reparación dado en segunda instancia.

Lo que importa observar es que, a pesar que algunas víctimas de Mampuján y San Cayetano se sienten satisfechas con el proceso de Justicia y Paz o con los resultados del incidente de reparación integral dado en segunda instancia, existen otras que sienten insatisfacción de sus pretensiones.

Además de estas percepciones, existieron otras de los participantes sobre: las causas de la macrovictimización de Mampuján y San Cayetano y del Conflicto Armado Interno, también, de las revictimizaciones (victimizaciones secundarias) con las víctimas; sobre los daños ocasionados 
PERCEPCIONES SOBRE LA MACROVICTIMIZACIÓN DE MAMPUJÁN Y SAN CAYETANO Y SU REPARACIÓN INTEGRAL EN EL MARCO DE LA LEY 975 DE 2005.

por los hechos victimizantes y la macrovictimización de Mampuján y San Cayetano; los procesos jurídicos acertados y desacertados adelantados en el marco de la Ley de Justicia y Paz con estas víctimas; sentimientos presentes o generados en las víctimas de Mampuján y San Cayetano; y contribución y no contribución del primer incidente de reparación de Justicia y Paz para futuros procesos y la reparación integral de las víctimas de Mampuján y San Cayetano.

A su vez, se puede señalar como parte conclusiva que, los aportes o percepciones del representante judicial JS de las víctimas de Mampuján y San Cayetano están en contravía o discrepan con los del líder TR y un participante del grupo focal de Mampuján, respecto a que el incidente de reparación integral dado en segunda instancia sí satisface las pretensiones de las víctimas, donde el primero manifiesta que en su mayoría las pretensiones de reparación integral de estas personas fueron incluidas en este incidente, mientras que el segundo y tercero piensan que algunas víctimas, incluyéndose, no se sienten satisfechas cuando faltaron por contenerse pretensiones de reparación dentro de la sentencia de segunda instancia, tan importantes como el hecho de que las medidas de reparación integral debieron estas más ajustadas a la identidad de las comunidades, buscando la recuperación del tejido social, la recuperación cultural y de costumbres, o que dentro del incidente de segunda instancia debieron estar incluidas todas las víctimas, todos los hechos victimizantes para algunas víctimas, como el desplazamiento forzado, y todos los daños que se les causaron a estas personas, como pérdidas de bienes muebles e inmueblesé

Por ende, se hace necesario señalar que los beneficiarios del fallo y sus líderes, han adelantado acciones para alcanzar la reparación integral de todas las personas afectadas por la macrovictimización de Mampuján y San Cayetano: con empoderamiento y resiliencia de las víctimas, aprendizajes del proceso de Justicia y Paz o del incidente de reparación integral de 
PERCEPCIONES SOBRE LA MACROVICTIMIZACIÓN DE MAMPUJÁN Y SAN CAYETANO Y SU REPARACIÓN INTEGRAL EN EL MARCO DE LA LEY 975 DE 2005.

Mampuján y San Cayetano; entre otras. Lo anterior, muestra lo complejo de este tipo de percepciones u otras, las cuales pueden influenciar o estar afectando a los participantes de la investigación o a las mismas víctimas del conflicto armado interno, de tal forma, que presenten consecuencias psicológicas, físicas (corporales), sociales, económicas y familiares que los afecten tanto de forma individual como colectiva.

Es importante resaltar que algunos líderes manifestaron la importancia de que algunas de las personas que habían recibido la indemnización pudieran contar con un acompañamiento para invertir los recursos recibidos, dado que algunos dieron una utilización poco adecuada a los recursos, caso diferente el encontrado en San Cayetano en donde los investigadores pudieron constatar que con los recursos de la indemnización, las víctimas que en su mayoría eran mujeres, mejoraron las condiciones de sus viviendas, por ejemplo, cambiar el piso de tierra y poner piso de baldosa, construir algunas habitaciones o cambiar el tejado de las viviendas.

También resulta importante mencionar que en las expresiones de algunos participantes, se plantearon que para ellos sería muy frustrante que los postulados salieran libres después de haber cumplido los 8 años de cárcel y que aún quedaran pendientes elementos para el logro de su reparación integral, refiriéndose especialmente a los compromisos de las entidades gubernamentales para brindar las medidas de reparación colectiva a las que no les ven compromiso alguno para cumplir con sus obligaciones.

Por lo tanto, esta investigacion aporta a la psicología jurídica, en cuanto esta última trata de los supuestos psicológicos en que se fundamentan las leyes y quienes las aplican, bien sean juristas bien psicólogos, con el fin de explicar, predecir e intervenir (Martín, Palleja y Alonso, 2006), o es un área de la Psicología encargada de describir, explicar, predecir e intervenir sobre el 
PERCEPCIONES SOBRE LA MACROVICTIMIZACIÓN DE MAMPUJÁN Y SAN CAYETANO Y SU REPARACIÓN INTEGRAL EN EL MARCO DE LA LEY 975 DE 2005.

comportamiento humano que tiene lugar en el contexto jurídico, con la finalidad de contribuir a la construcción y práctica de sistemas jurídicos objetivos y justos.

Desde esta perspectiva, el comportamiento humano se concibe como un conjunto que incluye no solo la conducta fácilmente observable, sino también los procesos cognoscitivos y emocionales, y las creencias y actitudes de las personas. Interesan dentro de esta área, el comportamiento de diversos actores como los delincuentes, las víctimas, los administradores y procuradores de justicia, demandantes, demandados, testigos, guardias, policías y sociedad en general en el marco de la ley y de los sistemas de Justicia (Morales, y García, 2010).

Por consiguiente, las percepciones de los participantes de la investigacion sobre la macrovictimizacion y el incidente de reparación integral de Mampuján y San Cayetano, y todo lo que surge o surgió alrededor de éste, invitan a indagar y aplicar respectivamente, entre otras, sobre las consecuencias psicológicas (valoración del daño psicológico ${ }^{4}$ ) de las víctimas de Mampuján y San Cayetano y formas de intervención, teniendo como punto de partida sus percepciones, debido a que cómo conciban el entorno o los resultados del incidente de reparación integral en el marco de la la Ley de Justicia y Paz o los mismos hechos victimizantes, pueden generar un sin número de respuestas, que no siempre son convenientes o adaptativas para el sujeto, lo que obligaría, ademas, a revaluar la forma y efectividad de las diferentes normatividades.

Por otro lado, como sugerencias, se vio la necesidad de apoyar algunas generadas por participantes del proceso de investigación, entre ellas, que los postulados y las instituciones plasmadas con compromisos de reparación en los Resuelve, del incidente de reparación integral

${ }^{4}$ Realizado por un profesional con experticia en este campo de acción, es decir, por un Psicólogo Jurídico o Forense con conocimientos y experiencia, además, competencias suficientes. 
PERCEPCIONES SOBRE LA MACROVICTIMIZACIÓN DE MAMPUJÁN Y SAN CAYETANO Y SU REPARACIÓN INTEGRAL EN EL MARCO DE LA LEY 975 DE 2005.

dado en segunda instancia, cumplan con lo ordenado o exhortado, sin contratiempos, de forma rápida y sin revictimizar a las víctimas; necesitando para ello, competencias, asertividad, proactividad, responsabilidad, respeto, empeño, esmero, actitud, aptitud y voluntad para trabajar con y para víctimas del conflicto armado interno.

A su vez, que las instituciones judiciales se apersonen más de las dificultades y realidades de las personas, de las víctimas del conflicto armado interno, detectando con mayor rigurosidad el daño causado en estas personas y para ello, necesitan más contacto con las comunidades afectadas, teniendo en cuenta sus pretensiones de reparación y sus dificultades para recopilar las pruebas o documentos necesarios para llevar a cabo los procesos de Justicia y Paz.

También, se le sugiere a las instituciones más compromiso para atender a las víctimas del conflicto armado interno, donde trabajen con mayor rigor, mancomunada y articuladamente, con el compromiso de compartir información relevante para llevar a cabo este tipo de proceso judicial en beneficio de las víctimas y custodiando o cuidando la documentación o información de estas personas, esto último, en especial por lo sucedido con los representantes judiciales de la Defensoría del Pueblo al extraviar documentación de las víctimas, según algunos participantes. La desarticulación de las instituciones afecta a las víctimas del conflicto armado interno, más cuando buscan dilatar los procesos y evadir responsabilidades.

Por otro lado, se le sugiere a las instituciones u órganos de control, seguimiento y monitoreo como las del Ministerio Público, Procuraduría General de La Nación, Defensoría del Pueblo y Personerías, y a la Contraloría General de la Nación, hacer un seguimiento constante al cumplimiento de lo ordenado y exhortado en el incidente de reparación integral, de segunda instancia, de las víctimas de Mampuján y San Cayetano, y de ser necesario, generar las respectivas investigaciones y sanciones a quienes estén vulnerando, por omisión o acción, los 
PERCEPCIONES SOBRE LA MACROVICTIMIZACIÓN DE MAMPUJÁN Y SAN CAYETANO Y SU

REPARACIÓN INTEGRAL EN EL MARCO DE LA LEY 975 DE 2005.

derechos de las víctimas de estas comunidades o de otras que también estén adelantado procesos de Justicia y Paz o de otras normatividades como la Ley 1448 de 2011, entre otras.

Debido a que, como se ha visto, al parecer se necesita la presencia y acciones de estos órganos de control para poder que haya cumplimiento de los ñResuelveò del incidente de reparación integral de segunda instancia de las víctimas de Mampuján y San Cayetano, bien sea por parte de los postulados o la institucionalidad. Lo que interesa observar ahora es que, para las víctimas de Mampuján y San Cayetano o para otras que estén adelantando procesos de Justicia y Paz o de reparación vía administrativa (Ley 1448 de 2011), entre otras, se les sugiere solicitar sin temor y con asertividad, información constante sobre sus procesos y derechos, y apoyarse de los órganos de control, especialmente del Ministerio Público, para asesorarse y solicitar estos derechos en materia de atención, asistencia y reparación integral cuando se estén incumpliendo o existan irregularidades que no pudieron conciliarse. Las víctimas no deberían estar reclamando, sino recibiendo sin contratiempos las medidas de reparación integral, de asistencia, adecuada y respetuosa atención, buscando siempre evitar asistencialismo con esta población, generando liderazgos en estas personas y propiciándoles espacios de participación, donde sus voces ya no estén ñsilenciadasò y sean tenidas en cuenta en los procesos, ñhaciendo eco de las voces silenciadas...ò.

No es fortuito que a las instancias legislativas o competentes, se les sugiera analizar de forma más detallada y a favor de las víctimas, reformas normativas como la generada en su momento por la Ley 1592 de 2012, que privaba a las demás víctimas del conflicto armado interno y que venían adelantado este proceso judicial de Justicia y Paz, del derecho de gozar de una reparación judicial integral por esta normatividad, privándose el derecho fundamental constitucional de Igualdad. Su existencia y vigencia privaba a las demás víctimas de una 
PERCEPCIONES SOBRE LA MACROVICTIMIZACIÓN DE MAMPUJÁN Y SAN CAYETANO Y SU REPARACIÓN INTEGRAL EN EL MARCO DE LA LEY 975 DE 2005.

reparación integral en Derecho, dándola solo en Equidad, esta última, como la otorgada por la Ley de Víctimas y de Restitución de Tierras (Ley 1448 de 2011). Esta reconsideración, además, debería traer consigo cuestionamientos y cambios adecuados, respecto a los procesos de ñVerdadò y ñusticiaò de esta normatividad, que realmente contribuyan a la reparación integral de las víctimas.

Por su parte, se le sugiere a los postulados alias ñuancho Diqueò y ñDiego Vecinoò u otros postulados o desmovilizados, lograr de forma adecuada y satisfactoriamente la reintegración social y económica con la sociedad colombiana, incluyendo a las víctimas del conflicto armado interno, entre ellas, las de Mampuján y San Cayetano. Para ello, se hace necesario que culminen efectivamente sus procesos liderados por la Agencia Colombiana para la Reintegración (ACR), que no vuelvan a delinquir, ayuden a desmantelar otros grupos armados ilegales, aporten a la verdad ñealò de los hechos victimizantes para las víctimas y el sistema judicial, y propicien espacios de reconciliación y de reparación integral, donde las víctimas, la comunidad (sociedad) e instituciones estén inmersas.

Finalmente, después de visualizar claramente las dificultades para el cumplimento de los derechos adquiridos por parte de las víctimas de Mampuján y San Cayetano con el incidente de reparación integral dado en segunda instancia en el marco del proceso de Justicia y Paz, y al observar las victimizaciones secundarias que se están presentado con estas personas por parte de las instituciones y postulados, y estigmatizaciones por parte de la misma comunidad, es necesario preguntar nuevamente, citando desde aquí hasta el final del documento a Rodríguez (2014):

¿Cómo puede la psicología jurídica contribuir en la prevención de los efectos psicosociales de la victimización secundaria y al tiempo responder al cumplimiento de la justicia y de los derechos humanos? 
PERCEPCIONES SOBRE LA MACROVICTIMIZACIÓN DE MAMPUJÁN Y SAN CAYETANO Y SU

REPARACIÓN INTEGRAL EN EL MARCO DE LA LEY 975 DE 2005.

Para responder a este cuestionamiento, a continuación se proponen cinco fundamentos desde la psicología jurídica como alternativas para abordar las problemáticas desencadenadas por el conflicto armado interno colombiano, específicamente desde la victimización secundaria y el ejercicio de los derechos humanos.

El profesional en psicología jurídica tiene un gran campo de acción desde las diferentes instituciones encargadas de atender a las víctimas del conflicto armado como en organizaciones no gubernamentales que trabajan al servicio de los Derechos Humanos. Teniendo en cuenta sus áreas de aplicación podría desempeñarse como:

Asesor: de las víctimas a quienes puede dar orientación legal con respecto a las entidades competentes, instancias o rutas de atención que puede seguir para el restablecimiento de derechos. Por su parte, también puede asesorar a los profesionales de las instituciones para la toma de decisiones en los diferentes procesos que se adelantan con víctimas.

Consultor de la norma: el psicólogo jurídico puede asesorar a funcionarios de la rama legislativa y ejecutiva para la creación de políticas públicas que respondan a la atención de las víctimas, teniendo en cuenta, por ejemplo, investigaciones como esta donde se indagó las percepciones de las víctimas de Mampuján y San Cayetano frente al incidente de reparación de Justicia y Paz para que puedan hacer eco y repercusión en las decisiones legislativas, entre otras.

Perito: El psicólogo jurídico puede emitir informes periciales de las víctimas como punto de partida para la medida de rehabilitación dentro de la reparación integral que contempla la ley 1448 de 2011 o para el proceso judicial de la Ley 975 de 2005 en el incidente de identificación de afectaciones. 
PERCEPCIONES SOBRE LA MACROVICTIMIZACIÓN DE MAMPUJÁN Y SAN CAYETANO Y SU

REPARACIÓN INTEGRAL EN EL MARCO DE LA LEY 975 DE 2005.

Mediador: Con las víctimas se pueden adelantar procesos de mediación con el fin de hacer manejo de los conflictos antes de buscar resolución en instancias judiciales. Estos procesos contribuyen a la descongestión del aparato judicial, lo que conlleva a un beneficio de doble vía: por una parte las victimas podrán satisfacer con mayor efectividad sus necesidades y/o derechos, lo que a su vez generará una mejor percepción de la institucionalidad y minimizará la aparición de sintomatología psicológica que agravaría la salud mental. La segunda vía es que las instituciones tendrían menos ñhacinamientoòy una baja importante de casos que si se abordan preventiva y adecuadamente puede solucionarse en términos más sencillos, lo que permitiría priorizar la atención de aquellos casos que requieran un trato especial, al tiempo que los funcionarios también conseguirían adelantar su trabajo más eficazmente, disminuyendo la carga laboral y por ende el estrés y demás afectaciones, dado al contacto diario que tienen con las historias desgarradoras de los usuarios(as), lo que Smtih y Álvarez (2007), citados por Rodríguez (2014) desde el contexto costarricense pretenden establecer:

ñé ) cómo en la práctica, aparte de la víctima tradicional del delito, existe otra víctima silenciosa del proceso penal, constituido por el equipo de investigadores, fiscales, jueces y peritos, que día a día convive con el dolor ajeno. El problema se agrava por la carencia de conciencia y decisión política, sensibilidad por parte del sistema y jerarquías del Poder Judicial para conformar una oficina o entidad encargada de abordar preventivamente la problemática del empleado judicial, sino también porque respecto de la víctima del proceso, no se cumplen a cabalidad las garantías que se crearon en el Código Procesal Penal en cuanto a la atención integral que debe recibir una víctimaò. 
PERCEPCIONES SOBRE LA MACROVICTIMIZACIÓN DE MAMPUJÁN Y SAN CAYETANO Y SU

REPARACIÓN INTEGRAL EN EL MARCO DE LA LEY 975 DE 2005.

Es evidente que faltan criterios comprensivos para entender los procesos de victimización, por tanto es indispensable proporcionar capacitación al equipo de funcionarios que atienden a víctimas con el fin de sensibilizar frente a los efectos psicosociales de la misma, mostrando que minimizarlos y prevenir la aparición de la revictimización permite hacer más efectiva la reparación, cuidando la salud mental y salvaguardando los derechos humanos de los que son titulares todas las personas. Además es imperante, mejorar los canales de comunicación para que las víctimas conozcan la ruta de atención, sean atendidas sin que tengan que ir de un lugar a otro o recurrir a instancias legales para que se les preste un servicio que como se ha demostrado, son derechos que tienen por su calidad de ser humano y de víctima.

En definitiva, hay que reconocer que la psicología jurídica desempeña un papel primordial en el contexto colombiano al poder contribuir en el abordaje de complejas situaciones en donde el comportamiento de los individuos tiene implicaciones jurídicas, que para el interés en particular del presente son las víctimas del conflicto armado, dado las condiciones específicas en que ha evolucionado y se ha prolongado la violencia en el país. En esta área, la psicología jurídica tiene mucho que aportar en términos de prevención, atención y consultoría, empezando por el apoyo en la construcción de normas y políticas sociales, para que se materialice en su totalidad, es decir, lo que se plasme pueda llevarse a la realidad. 
PERCEPCIONES SOBRE LA MACROVICTIMIZACIÓN DE MAMPUJÁN Y SAN CAYETANO Y SU

REPARACIÓN INTEGRAL EN EL MARCO DE LA LEY 975 DE 2005.

\section{Referencias}

Acierno, R; Kilpatrick, D.G. y Resnick, H.S. (1999). Posttraumatic stress disorder in adults relative to criminal victimization: Prevalence, risk factors, and comorbidity. En P.A. Saigh y J.D. Bremner (Eds.). Posttraumatic stress disorder: A Comprehensive text. NeedhamHeights, MA. Allyn y Bacon, Inc.

Álvaro, J.L. y Garrido, A. (2003) Psicología Social: Perspectivas psicologías y sociológicas. España: Mc Graw Hill Interamericana de España. S.A.U.

Arce, R. y Fariña, F. (1994). El papel del psicólogo en la administración de Justicia. Nuevos horizontes. En Sobral, J., Arce, R., y Prieto, A. Manual de psicología jurídica. Barcelona, Buenos Aires, Mexico: Ediciones Paidos.

ATLAS.ti Scientific Software Development GmbH, Berlin (2003-2010). Todos los derechos reservados. Atlas. ti 6. Guía Rápida. Software for qualitative data analysis, management, and model building. Autor: Dr. Susanne Friese (Quarc Consulting). Consejero editorial: Sarah Matthews (ATLAS.ti GmbH). Realización técnica: Dr. Thomas G. Ringmayr (www.hypertexxt.com). Traducción: Toni Casasempere (www.cualsoft.com). Revisión: Sara Bordera \& Tim Vickers.

AUTO 119 DE 2013. República de Colombia; Corte Constitucional, Sala Especial de Seguimiento a la Sentencia T-025 de 2004 y sus autos de cumplimiento. Por medio del cual se hace seguimiento a las acciones adelantadas por el gobierno nacional para la superación del estado de cosas inconstitucional declarado mediante sentencia T-025 de 2004 en relación con el componente de registro y se dictan las medidas necesarias para mejorar la atención de la población desplazada por la violencia. Magistrado Ponente: LUIS ERNESTO VARGAS SILVA. Referencia: sentencia T-025 de 2004, autos 178 de 2005, 218 y 261 de 
PERCEPCIONES SOBRE LA MACROVICTIMIZACIÓN DE MAMPUJÁN Y SAN CAYETANO Y SU

REPARACIÓN INTEGRAL EN EL MARCO DE LA LEY 975 DE 2005.

2007 y 011 de 2009 (M.P. Manuel José Cepeda), 219 de 2011 y 052 de 2013 (M.P. Luis Ernesto Vargas Silva).

Baca, E, Cabanas, M.L. y Baca-García, E. (2003). El proyecto Fénix: un estudio sobre las víctimas del terrorismo en España. Resultados preliminares. En: Baca E, Cabanas ML (eds). Las víctimas de la violencia. Madrid: Estudios psicopatológicos. Triacastela. Instituto de Victimología. Fundación Archivos de Neurobiología, 139-185.

Banchs, M. (1986). Concepto de representaciones sociales: análisis comparativo. Revista costarricense de psicología (89). 27-40.

Braverman, M.T. (1999). Research on resilience and its implications for tobacco prevention. Nicotine and TobaccoResearch, 1, S67, S72.

Carrasco Perera (s.f.), Comentario al Art. 1106 del Código Civil, en los Comentarios al Código Civil dirigidos por M. Albaladejo.

Castañón Álvarez, M. J. (2012). Protección penal de las víctimas en los delitos de terrorismo (Doctoral dissertation, Universidad Complutense de Madrid).

Castilla del Pino, C. (2000). Teoría de los Sentimientos. Ensayo. TusQuets Editores.

CIE 10. Clasificación internacional de enfermedades, décima versión. Correspondiente a la versión en español de la ICD, siglas de ñnternational StatisticalClassification of Diseases and RelatedHealthProblemsò y determina la clasificación y codificación de las enfermedades y una amplia variedad de signos, síntomas, hallazgos anormales, denuncias, circunstancias sociales y causas externas de daños y/o enfermedad.

Clemente, A; Molero, R. y González, F., (2000). Estudio de la satisfacción personal según la edad de las personas. Universidad de Valencia. Anales de psicología, 2000, vol. 16, nº 2, 
PERCEPCIONES SOBRE LA MACROVICTIMIZACIÓN DE MAMPUJÁN Y SAN CAYETANO Y SU

REPARACIÓN INTEGRAL EN EL MARCO DE LA LEY 975 DE 2005.

189-198, (C Copyright 2000: Servicio de Publicaciones de la Universidad de Murcia. Murcia (España). ISSN: 0212-9728.

Código Penal Colombiano (Ley 599 de 2000).

Comité Internacional de la Cruz Roja (2010). Colombia: consecuencias humanitarias del conflicto armado en Colombia. Informe emitido el 22-04-2010. Consultado el 27 de octubre de 2013 en la URL: http://www.icrc.org/spa/resources/documents/report/colombia-reportintro-220410.htm

Compiani, M. F. (2001). Responsabilidad por daños colectivos. Revista Jurídica, 4, 67-82.

Constitución Política de Colombia de 1991.

Convención Americana sobre Derechos Humanos ï Pacto de San José (1969). Convención Americana sobre Derechos Humanos suscrita en la conferencia especializada interamericana sobre derechos humanos (B-32). San José, Costa Rica 7 al 22 de noviembre de 1969; ratificada por Colombia el 31 de julio de 1973 bajo la Ley Aprobatoria: Ley 16 de 1972, D.O. 33.780; Depositario: O.E.A. Consultado el 26 de octubre de 2013 en la URL: http://www.oas.org/dil/esp/tratados_B-

32_Convencion_Americana_sobre_Derechos_Humanos.htm

Corte Suprema de Justicia Sala de Casación Penal, República de Colombia (2011). Segunda Instancia 3454, Justicia y Paz, Edwar Cobos Téllez y Uber Enrique Banquez Martínez. Magistrados ponentes: María del Rosario González de Lemos. Aprobado Acta No. 139. Bogotá D.C., Abril veintisiete (27) de dos mil once (2011). La Corte resuelve el recurso de apelación interpuesto contra la sentencia parcial proferida por la Sala de Justicia y Paz del Tribunal Superior de Bogotá el 29 de junio de 2010, respecto de los postulados Edwar Cobos Téllez y Uber Enrique Banquez Martínez. 
PERCEPCIONES SOBRE LA MACROVICTIMIZACIÓN DE MAMPUJÁN Y SAN CAYETANO Y SU

REPARACIÓN INTEGRAL EN EL MARCO DE LA LEY 975 DE 2005.

Cuervo-Arango, M. A. (1993). La calidad de vida: Juicios de satisfacción y felicidad como indicadores actitudinales de bienestar. Por Aprendizaje. Revista de psicología social, 8(1), 101-110.Universidad Complutense de Madrid.

Declaración sobre los Principios Fundamentales de Justicia para las víctimas de delitos y del abuso del poder, adoptadas por la Asamblea General de las Naciones Unidas en su Resolución 4034 del 29 de noviembre de 1985.

Decreto 4760 de 2005. Artículo 3. Lista de Postulados. Por el cual se reglamenta parcialmente la Ley 975 de 2005. Decretado por el Presidente de la República de Colombia, en ejercicio de sus atribuciones constitucionales y legales, en especial de las conferidas por el artículo 18911 de la Carta Política y por la Ley 975 de 2005.

Domínguez, A. C. (2003). Conceptos fundamentales de Victimología. Instituto de victimología. Recuperado el, 15.

Doron, R. y Parot, F. (2007) Diccionario Akal de la Psicología. Madrid, España: Ediciones Akal S.A.

Dorsch, F. (1994) Diccionario de Psicología. Barcelona, España: Editorial Herder

Echeburúa, E; Paz de Corral y Amor, P.J. (2000). Tratamiento psicológico del trastorno de estrés postraumático. En J. Bobes, M. Bousoño, A. Calcedo y M.P. Gonzalez (Eds.). Trastorno de estrés postraumático. Barcelona. Masson.

Enrique Echeburúa, Paz de Corral y Pedro Javier Amor (2002). Evaluación del Daño Psicológico en las víctimas de delitos violentos. Universidad del País Vasco. ISSN 0214-9915 CODEN PSOTEG; Psicothema, Vol.14 Supl.

Esbec, E. (2000). Evaluación psicológica de la víctima. En E. Esberc y G. Gómez-Jarado. Psicología forense y tratamiento jurídico-legal de la discapacidad. Madrid. Edisofer. 
PERCEPCIONES SOBRE LA MACROVICTIMIZACIÓN DE MAMPUJÁN Y SAN CAYETANO Y SU

REPARACIÓN INTEGRAL EN EL MARCO DE LA LEY 975 DE 2005.

Fernández, F. M. (1999). Proactividad: el método científico de Karl Popper aplicado al futuro.Encuentros multidisciplinares, 1(3), 4.

Friese, S. (2010). Guía rápida Atlas. ti 6. Copyright (C) 2003-2010 porATLAS.ti Scientific Software Development GmbH, Berlin.

García, C. y Parra, G. (2013). El Daño Moral y a la Vida de Relación, y su aplicación en el sistema jurídico colombiano. Asesor académico: Hernández, H. Fecha de Publicación: 24 de enero de 2013. Tipo: Trabajo de Grado. Editorial: Universidad Industrial de Santander. Consultado el 10 de noviembre de 2013 en la URL: http://repositorio.uis.edu.co/jspui/handle/123456789/8251

García López, E. (2012). Fundamentos de psicología jurídica y forense. Mexico. Oxford University Press.

García-Peña Jaramillo, Daniel (2005). La Relación del Estado Colombiano con el Fenómeno Paramilitar: por el Esclarecimiento Histórico. Anal.polit.[online]. 2005, vol.18, n.53, pp.5876. ISSN 0121-4705. Consultado el 08 de noviembre de 2013 en la URL: http://www.scielo.org.co/pdf/anpol/v18n53/v18n53a04.pdf

Garmezy, N. (1991). Resilience in children's adaptation to negative life events and stressed environments. Pediatric Annals, 20, 459-466.

Garmezy, N. (1991). Resiliency and vulnerability to adverse developmental outcomes associated with poverty. American BehavioralScientist, 31, 416.430.

Goffman, E. (1963). Stigma: Notes on the Management of Spoiled Identity. Prentice - Hall.

Green, B.L. (1990). Defining trauma: terminology and stressor dimensions. Journal of Applied Social Psychology, 20, 1632-1642. 
PERCEPCIONES SOBRE LA MACROVICTIMIZACIÓN DE MAMPUJÁN Y SAN CAYETANO Y SU

REPARACIÓN INTEGRAL EN EL MARCO DE LA LEY 975 DE 2005.

Gutiérrez de Piñeres, Carolina; Botero Coronel, Elisa y Pérez, Carlos Andrés (2009). Revisión teórica del concepto de victimización secundaria. Liberabit, 15(1), 49-58. Consultado el 04 de noviembre de 2013 en la URL: http://pepsic.bvsalud.org/scielo.php?script=sci arttext\&pid=S172948272009000100006\&lng=pt\&tlng=es.

Gutiérrez, Francisco y Sánchez, Gonzalo (2006). ñ̃rologo, Nuestra guerra sin nombreò. Instituto de Estudios Políticos y Relaciones Internacionales (IEPRI). Nuestra guerra sin nombre. Transformaciones del conflicto en Colombia. Bogotá: Norma.

Hernández R., Fernández C. y Baptista M. (2010). Metodología de la Investigación, quinta edición. ISBN: 978-607-15-0291-9.

Hernández Sampieri, R., Fernández Collado, C., \&Baptista Lucio, P. (2006). Metodología de la investigación (4th ed.). México: McGraw-Hill.

Kühne, H.H. (1986). Kriminologie: Victimologie der Notzucht. JuristischeSchulung; 5:388-94.

LEY 1090 DE 2006. Ministerio de la Protección Social (Septiembre 06) del Congreso de Colombia. Por la cual se reglamenta el ejercicio de la profesión de Psicología, se dicta el Código Deontológico y Bioético y otras disposiciones.

Ley 1448 de 2011 (junio 10). Por la cual se dictan medidas de atención, asistencia y reparación integral a las víctimas del conflicto armado interno y se dictan otras disposiciones. Diario Oficial No. 48.096 de 10 de junio de 2011. Congreso de la República de Colombia.

Ley 1592 del 03 diciembre de 2012. "Por medio de la cual se introducen modificaciones a la ley 975 de 2005 "por la cual se dictan disposiciones para la reincorporación de miembros de grupos armados organizados al margen de la ley, que contribuyan de manera efectiva a la 
PERCEPCIONES SOBRE LA MACROVICTIMIZACIÓN DE MAMPUJÁN Y SAN CAYETANO Y SU REPARACIÓN INTEGRAL EN EL MARCO DE LA LEY 975 DE 2005.

consecución de la paz nacional y se dictan otras disposiciones para acuerdos humanitarios" y se dictan otras disposiciones". Congreso de la República de Colombia.

Ley 446 de 1998 (Julio 7). Diario Oficial No. 43.335 de 8 de julio de 1998, Por la cual se adoptan como legislación permanente algunas normas del Decreto 2651 de 1991, se modifican algunas del Código de Procedimiento Civil, se derogan otras de la Ley 23 de 1991 y del Decreto 2279 de 1989, se modifican y expiden normas del Código Contencioso Administrativo y se dictan otras disposiciones sobre descongestión, eficiencia y acceso a la justicia. Artículo 16: Valoración de daños. Parte II DE LA EFICIENCIA EN LA JUSTICIA, TITULO I, NORMAS GENERALES. Consultado el 27 de octubre de 2013 en la URL: http://www.secretariasenado.gov.co/senado/basedoc/ley/1998/ley_0446_1998.html

Ley 80 de 1993. Numeral 3 del Art. 32: Contrato de prestación de servicios.

Ley 975 de 2005. ñPor la cual se dictan disposiciones para la reincorporación de miembros de grupos armados organizados al margen de la ley, que contribuyan de manera efectiva a la consecución de la paz nacional y se dictan otras disposiciones para acuerdos humanitariosò. Congreso de Colombia. Reglamentada parcialmente por los Decretos Nacionales 4760 de 2005, 690, 2898 y 3391 de 2006.Fecha de expedición: 25 de julio de 2005. Fecha de entrada en vigencia: 25 de julio de 2005. Medio de Publicación: Diario Oficial 45980 de julio 25 de 2005.

López, C., y Sevillano, O. (2008). Balance político de la parapolítica. Cor-65.

Martín-Baró, I. (2003). Poder, ideología y violencia. Madrid, Editorial Trotta. S.A.

Martín, E. G., Palleja, J. M., y Alonso, C. H. (2006). Psicología jurídica.

Masón, A. (2000). Artículo: La crisis de seguridad en Colombia: causas y consecuencias Internacionales de un estado en vía de fracaso. Tema: La "Crisis" Colombiana: Causas y 
PERCEPCIONES SOBRE LA MACROVICTIMIZACIÓN DE MAMPUJÁN Y SAN CAYETANO Y SU

REPARACIÓN INTEGRAL EN EL MARCO DE LA LEY 975 DE 2005.

Repercusiones Externas e Internas. Universidad de los Andes; Colombia Internacional; ISSN (versión en línea): 1900-6004. (pp.82-102). Consultado el 23 de octubre de 2013 de la URL: http://colombiainternacional.uniandes.edu.co/view.php/372/1.php

Masten, A.S. (1999). Resilience comes of age: Reflections on the past and outlook for the next generation of research. En M.D. Glantz y J.L. Johnson (Eds.), Resilience and development. Positive life adaptations (pp.281-296). Nueva York: Kluwer Academic/Plenum Press.

Medellín, C. y otros. (2000). Lecciones del Derecho Romano. 14 Edición. Santa Fe de Bogotá, Temis, p.206.

Merleau-Ponty, (1985) Fenomenología de la percepción, Editorial: Planeta-Agostini. Barcelona, 1985. $469 \mathrm{p}$

Montes, A., Cordero, E., Acuña, M., Peláez, M, Matienzo, L. y Villiarolo, P. (2010). Análisis de conocimientos y percepciones sociales sobre doping y prevención, en deportistas de córdoba (argentina) y su abordaje preventivo. Trabajo de investigación. Directora: Dra. Elsa Clara Corbella. Agencia Mundial Antidopaje (WADA). Comité de Educación. Formato de Aplicación a Subvenciones a Investigaciones en Ciencias Sociales. Córdoba, Argentina.

Morales, L. y García, E. (2010). Psicología Jurídica: quehacer y desarrollo. Artículo de reflexión sobre temática original y asociada a investigación. Divers.: Perspect. Psicol. / ISSN: 17949998 / Vol. 6 / No 2 / 2010 / pp.237 ï 256.

Muñoz, J. (2005). Análisis cualitativo de datos textuales con Atlas. ti 5. Universidad Autónoma de Barcelona. Noviembre, Versión 3.03.

Onwuegbuzie, A. J., Dickinson, W. B., Leech, N. L. y Zoran, A. G. (2011). Un marco cualitativo para la recolección y análisis de datos en la investigación basada en grupos focales. Artículo. Paradigmas, 3, 127-157. Consultado el 03 de noviembre de 2013 en la URL: 
PERCEPCIONES SOBRE LA MACROVICTIMIZACIÓN DE MAMPUJÁN Y SAN CAYETANO Y SU REPARACIÓN INTEGRAL EN EL MARCO DE LA LEY 975 DE 2005.

https://www.google.com.co/\#q=Seg\%C3\%BAn+Barbour+(2007)\%2C+en+un+grupo+focal $\% 2 \mathrm{C}+\mathrm{o}+\mathrm{tambi} \% \mathrm{C} 3 \% \mathrm{~A} 9 \mathrm{n}+\mathrm{conocido}+\mathrm{como}+$ grupo+de+enfoque $\% 2 \mathrm{C}+\mathrm{m} \% \mathrm{C} 3 \% \mathrm{~A} 1 \mathrm{~s}+\mathrm{all} \% \mathrm{C} 3$ $\% \mathrm{~A} 1+\mathrm{de}+$ hacer+las+mismas+preguntas+a+varios+participantes $\% 2 \mathrm{C}+$ su+objetivo+es+gener $\underline{\operatorname{ar}+y+a n a l i z a r}+$

Oviedo, G. (2004). La definición del concepto de percepción en psicología con base en la teoría Gestalt. Revista de estudios sociales, ISSN-e 0123-885X, № .18, pp.89-98. Consultado el 15 de noviembre de 2013 en la URL: http://dialnet.unirioja.es/servlet/articulo?codigo=2349282

Pacto Internacional de Derechos Económicos, Sociales y Culturales (1966). Adoptado y abierto a la firma, ratificación y adhesión por la Asamblea General en su resolución 2200 A (XXI), de 16 de diciembre de 1966. Entrada en vigor: 3 de enero de 1976, de conformidad con el artículo 27.Ratificado por Colombia el 29 de octubre de 1969 bajo la Ley Aprobatoria: Ley 74 de 1968, D.O. 32.681; Depositario: O.N.U. Consultado el 26 de octubre de 2013 en la URL: http://www2.ohchr.org/spanish/law/cescr.htm

Pérez, C. (2013). Marcando al delincuente: estigmatización, castigo y cumplimiento del derecho. D. R. (C) 2013. Universidad Nacional Autónoma de México-Instituto de Investigaciones Sociales. Revista Mexicana de Sociología 75, núm. 2 (abril-junio, 2013): 287-311. México, D.F. ISSN: 0188-2503/13/07502-05.

Pilonieta, A. S. (2002). Dispositivos de empoderamiento para el desarrollo psicosocial. Univ. Psychol Pontificia Universidad Javeriana, Bogotá (Colombia), 1(2), 39-48.

Pizarro Leongomez, Eduardo (2004). Una democracia asediada: balance y perspectiva del conflicto armado en Colombia. Bogotá: Norma.

Presentación - filología (s.f.), Pregrado en Letras: Filología Hispánica. Consultado el 02 de julio de 2013 en la URL:http://www.google.com.co/\#output=search\&sclient=psy- 
PERCEPCIONES SOBRE LA MACROVICTIMIZACIÓN DE MAMPUJÁN Y SAN CAYETANO Y SU

REPARACIÓN INTEGRAL EN EL MARCO DE LA LEY 975 DE 2005.

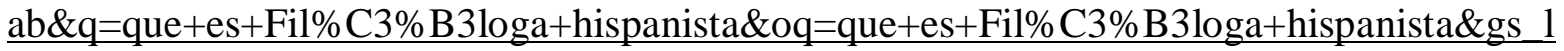

$=$ hp.3...338.1440.0.2034.7.6.0.0.0.4.690.2972.2-1j0j2j3.6.0...0.0.0..1c.1.17.psy-

ab.6bAPEZk4OXE\&pbx=1\&bav=on.2,or.r_qf.\&bvm=bv.48572450,d.eWU\&fp=419483f13

$\underline{0 \mathrm{~d} 74 \mathrm{~d} 38 \& \text { biw }=1366 \& \mathrm{bih}=667}$

Prieto, M. y March, J. (2002). Paso a paso en el diseño de un estudio mediante grupos focales. INVESTIGACIÓN CUALITATIVA. Aten Primaria, 15 de abril. (p.366). Consultado el 01 de junio de 2013 de la URL: http://www.elsevier.es/sites/default/files/elsevier/pdf/27/27v29n06a13029750pdf001.pdf

Protocolo Adicional a los Convenios de Ginebra del 12 de agosto de 1949 relativo a la protección de las víctimas de los conflictos armados sin carácter internacional (Protocolo II) (1949). Este Convenio fue aprobado en Colombia mediante la disposición 58 transitoria de la Constitución Política y promulgado mediante el Decreto $\underline{509}$ de 1996, publicado en el Diario Oficial No. 42.746 de 18 de marzo de 1996. Consultado el 26 de octubre de 2013 en la URL: http://www2.ohchr.org/spanish/law/protocolo2.htm

Pynoos, R.; Sorenson, S. y Steinberg, A. (1993). Interpersonal violence and traumatic stress reactions. En L. Goldberger y S. Breznitz (Eds.). Handbook of stress: Theoretical and clinical aspects (2a ed.). New York. Free Press.

Quisbert, E. (2010). Apuntes De Derecho Procesal Civil Boliviano. Sucre, Bolivia. Arte (C) ApoyoGraficoÊ . Derechos Reservados. Consultado el 07 de junio de 2014 en la URL: http://jorgemachicado.blogspot.com/2009/11/dpc19.html\#sthash.jxDNpf33.dpuf

Ramírez, Socorro (2006). ñActores europeos ante el conflicto colombianoò. Instituto de Estudios Políticos y Relaciones Internacionales (Iepri). Nuestra guerra sin nombre. Transformaciones del conflicto en Colombia. Bogotá: Norma. 
PERCEPCIONES SOBRE LA MACROVICTIMIZACIÓN DE MAMPUJÁN Y SAN CAYETANO Y SU

REPARACIÓN INTEGRAL EN EL MARCO DE LA LEY 975 DE 2005.

Resolución No 008430 de 1993. Por la cual se establecen las normas científicas, técnicas y administrativas para la investigación en salud. Ministerio de Salud, resolución del 04 de octubre. República de Colombia.

Rodríguez, L. (2014). DERECHOS HUMANOS EN VICTIMAS DEL CONFLICTO ARMADO: UNA MIRADA DESDE LA PSICOLOGÍA JURÍDICA. Publicado el 01 de enero de 2014. Consultado el 11 de abril de 2014 en la URL: http://psicologiajuridica.org/archives/4558\#comments

San Pedro, P. (2006). El Individuo como agente del cambio: El proceso de empoderamiento. Desarrollo ñEn Perspectiva, (1).

Sánchez, A. (2003). La evaluación psiquiátrica de las víctimas. En: Baca E, Cabanas ML (eds). Las víctimas de la violencia. Madrid: Estudios psicopatológicos. Triacastela. Instituto de Victimología. Fundación Archivos de Neurobiología, 1117-38.

Sobral, J., Arce, R., y Prieto, A. (1994). Manual de psicología jurídica. Barcelona, Buenos Aires, Mexico: Ediciones Paidos.

Tamarit, J.M. (2006). La Victimología: cuestiones conceptuales o metodológicas. En: Baca Baldomero E, Echeburúa Odriozola E, Tamarit Sumilla JM. Manual de Victimología. Tirant Lo Blanch. Valencia, 2006.

Torrealba, F. (s.f.). Artículo: La pérdida de Oportunidad o Chance.

Tribunal Superior del Distrito Judicial de Bogotá Sala de Justicia y Paz (2010). Magistrada Ponente: Uldi Teresa Jiménez López. Radicación: 110016000253200680077. Postulados: Edwar Cobos Téllez y Uber Enrique Banquéz Martinez. Delito: Homicidio agravado y otros. Procedencia: Fiscalía 11 Unidad Nacional de Justicia y Paz. Decisión: Sentencia. Bogotá D.C., veintinueve (29) de junio de dos mil diez (2010). 
PERCEPCIONES SOBRE LA MACROVICTIMIZACIÓN DE MAMPUJÁN Y SAN CAYETANO Y SU

REPARACIÓN INTEGRAL EN EL MARCO DE LA LEY 975 DE 2005.

Valencia Agudelo, G. (2009). La economía frente al conflicto armado interno colombiano, 19902006. Perfil De Coyuntura Económica, O(8). Consultado el 25 de octubre de 2013 en la URL:

http://aprendeenlinea.udea.edu.co/revistas/index.php/coyuntura/article/view/2321/1893

Van Zyl, P. (2008). Promoviendo la justicia transicional en sociedades post-conflicto. Serie justicia transicional-Memoria histórica Verdad, memoria y reconstrucción. Estudios de caso y análisis comparado. Centro Internacional para la Justicia Transicional (ICTJ), 14-45.

Vargas Melgarejo L (1995) Los colores lacandones: una estructura sobre percepción visual. México. Tesis. Presentada Escuela de Antropología. p.115.

Villanueva, F. V. (2004). La responsabilidad civil objetiva del médico y daño moral. Revista CONAMED, 9(2), 14-21.

Vivas, J., Comesaña, A. y Vivas, L. (2007). Evaluación de las redes semánticas de conceptos académicos en estudiantes universitarios. Psico-USF, v. 12, n. 1, pp.111-119, jan./jun. 2007. Consultado el 12 de junio de 2014 en la URL: http://pepsic.bvsalud.org/pdf/psicousf/v12n1/v12n1a13.pdf

Wilkinson, S. (2004). Focus group research. En D. Silverman (ed.), Qualitative research: Theory, method, and practice (pp.177-199). ThousandOaks, CA, EE. UU.: Sage. 
PERCEPCIONES SOBRE LA MACROVICTIMIZACIÓN DE MAMPUJÁN Y SAN CAYETANO Y SU

REPARACIÓN INTEGRAL EN EL MARCO DE LA LEY 975 DE 2005.

\title{
APÉNDICES
}

\section{Apéndice A. Modelo consentimiento informado participantes}

\author{
UNIVERSIDAD SANTO TOMAS \\ MAESTRIA EN PSICOLOGIA JURIDICA \\ Consentimiento para participar en Investigación
}

Título: Percepción de las víctimas y sus representantes, frente al incidente de reparación a las víctimas de Mampuján y San Cayetano en el marco de la ley de justicia y paz

Lugares de Estudio: Bogotá D.C., Mampuján y san Cayetano, Departamento de Bolívar.

Llevado a Cabo por: Luis Alberto Bonilla Cárdenas, Jhon Byron Tamayo Vera.

Directora: Dra. Ángela Tapias Saldaña

Introducción: El presente documento es proveer toda la información a los posibles participantes en la investigación, que pueda afectar su decisión de participar o no en la misma, las personas que la realizan se encuentran en condiciones de responder cualquier pregunta que usted tenga, es importante que lea de manera detenida el presente documento y haga todas las preguntas que considere necesarias, antes de decidir si desea participar en la investigación. Si decide participar en ella, los investigadores le solicitaran que firme el presente consentimiento del cual le será proporcionada una copia.

Propósito de la Investigación: Esta investigación trata sobre la percepción de ustedes como víctimas o representantes judiciales frente al incidente de reparación de las víctimas de Mampuján y San Cayetano en el marco de la ley de justicia y paz.

El propósito de este estudio es establecer sí el incidente de reparación de Mampuján y San Cayetano contribuyó a la reparación integral de las víctimas. Para ello, se harán preguntas sobre las pretensiones de reparación de las víctimas, así mismo, se indagará sobre los elementos que permitan identificar si fueron satisfechas dichas pretensiones.

Si usted decide participar en este estudio se le solicitará lo siguiente:

Representante Judicial

- Se le solicitará su participación en una entrevista semi-estructurada con los investigadores.

- $\quad$ La entrevista tendrá una duración entre una y dos horas.

- Se harán preguntas relacionadas con las pretensiones de las víctimas y si fueron satisfechas; el cumplimiento por parte de los perpetradores y de la institucionalidad de las ordenes emitidas por la corte suprema de justicia en el fallo de segunda instancia.

- $\quad$ Con su consentimiento verbal y escrito, la entrevista será grabada en audio.

Víctimas

Líderes Comunitarios de Mampuján y San Cayetano:

- Se le solicitará su participación en una entrevista semi-estructurada con los investigadores. 
PERCEPCIONES SOBRE LA MACROVICTIMIZACIÓN DE MAMPUJÁN Y SAN CAYETANO Y SU REPARACIÓN INTEGRAL EN EL MARCO DE LA LEY 975 DE 2005.

- $\quad$ La entrevista tendrá una duración entre una y dos horas.

- $\quad$ Se harán preguntas relacionadas con sus pretensiones y si fueron satisfechas.

- $\quad$ Con su consentimiento verbal y escrito, la entrevista será grabada en audio.

Víctimas de Mampuján y San Cayetano

- $\quad$ Se les solicitará su participación en Grupos Focales desarrollados por los investigadores.

- $\quad$ Los grupos focales tendrán una duración entre una y dos horas.

- $\quad$ Se harán preguntas relacionadas con sus pretensiones y si fueron satisfechas.

- $\quad$ Con su consentimiento verbal y escrito, esta técnica de recolección de información será grabada en audio.

Utilización de la información que proporcione: Esta información será utilizada para la Realización de la tesis de los investigadores, la cual es requisito para optar por el título de Maestría en psicología Jurídica. También puede ser utilizada para otras publicaciones de los investigadores, participación en congresos, seminarios, simposios u otros eventos de carácter académico y público.

Riesgos por participar en el Estudio: Aunque existen posibles riesgos por la participación en la presente investigación, los investigadores velarán por darle el mejor uso a la información, no obstante un posible riesgo, sería la divulgación de información sensible obtenida de las entrevistas semi-estructuradas y los grupos focales, particularmente su usted da permiso para utilizar su nombre en la investigación. Otro posible riesgo es que la información puede perderse o ser robada.

Posibles beneficios del estudio: Un posible beneficio de este estudio podría ser darles mayor visibilidad a sus posiciones sobre los resultados del incidente de reparación a las víctimas de Mampuján y San Cayetano, de igual forma, este estudio puede tener efectos a nivel de representaciones sociales y en el aparato judicial, frente a los actuales incidentes de reparación que se adelantan y que se adelantarán en el marco de la Ley de Justicia y Paz.

Participación Voluntaria: su participación es completamente voluntaria y usted está en libertad de retirarse en cualquier momento, usted también puede negarse a responder a cualquier pregunta planteada por los investigadores. El hecho de negarse o dejar de participar en este estudio, no afectará su relación con los investigadores, con su directora y con la Universidad Santo Tomás. Usted no recibirá ningún tipo de compensación económica por su participación en la investigación.

Contactos del Estudio: Antes, durante y después del estudio usted se puede contactar con los investigadores:

Luis Alberto Bonilla Cárdenas

Teléfono Móvil: XXXXXX

Correo electrónico: XXXXXX 
PERCEPCIONES SOBRE LA MACROVICTIMIZACIÓN DE MAMPUJÁN Y SAN CAYETANO Y SU REPARACIÓN INTEGRAL EN EL MARCO DE LA LEY 975 DE 2005.

John Byron Tamayo Vera Teléfono Móvil: XXXXXX

Correo electrónico: XXXXXX

Si usted tiene preguntas acerca de sus derechos o si tiene algún descontento con cualquier parte de este estudio, puede contactar anónimamente si así lo desea a la Directora de la tesis. Dra. Ángela Tapias, al siguiente correo electrónico: XXXXXX.

En constancia de sus deseo de participar en la investigación:ÒPercepción de las víctimas y sus representantes, frente al incidente de reparación a las víctimas de Mampuján y San Cayetano en el marco de la Ley de justicia y pazò se firma el presente consentimiento informado a los

días del Mes de de 2012.

Firma

Nombre:

Tipo de participante

Representante judicial

Líder Comunitario

Víctima 
PERCEPCIONES SOBRE LA MACROVICTIMIZACIÓN DE MAMPUJÁN Y SAN CAYETANO Y SU REPARACIÓN INTEGRAL EN EL MARCO DE LA LEY 975 DE 2005.

\section{Apéndice B. Preguntas guías de las técnicas de recolección de información}

A continuación, se presentan las preguntas que sirvieron de guía para el desarrollo de las entrevistas semiestructuradas a los líderes de las víctimas y a sus Representantes Judiciales, así como las preguntas que se aplicaron a las víctimas en el marco del desarrollo de los grupos focales.

Preguntas guía realizadas a los líderes de las víctimas de Mampuján y San Cayetano a través de esta entrevista semiestructurada:

Nombre completo:

Cédula de ciudadanía:

Estudios realizados:

Edad:

Género:

Comunidad de víctimas que representó:

1. ¿Usted fue víctima de los hechos ocasionados por los postulados?

2. ¿Usted se convirtió en líder de las víctimas de su comunidad antes o después de los hechos victimizantes? Explique su respuesta

3. ¿Cuál fue su papel como líder de las víctimas de su comunidad en el incidente de reparación integral?

4. ¿Cree que faltaron pretensiones de las víctimas por incluir en el incidente de reparación?

5. ¿Cree que la sentencia de segunda instancia del incidente de reparación integral a las víctimas de su comunidad llenó las expectativas de estas? Explique su respuesta

6. ¿Considera que se logró la reparación integral de las víctimas de su comunidad con el fallo de la segunda instancia establecido por la Corte Suprema de Justicia?

7. ¿Encontró dificultades o falencias en el proceso del incidente de reparación integral a las víctimas de su comunidad adelantado en el marco de la Ley de Justicia y Paz? Explique su respuesta

8. ¿Considera que hubo cumplimiento por parte de los postulados de las órdenes emitidas por la Corte Suprema de Justicia en el fallo de segunda instancia en relación a su comunidad? Explique su respuesta

9. ¿Considera que hubo cumplimiento por parte de la institucionalidad de las órdenes emitidas por la Corte Suprema de Justicia en el fallo de segunda instancia en relación a su comunidad? Explique su respuesta

10. ¿Encontró dificultades o falencias en el incidente de reparación integral a las víctimas de su comunidad en relación con las pretensiones de estas? ¿Cuáles?

11. ¿Cree que las pretensiones de las víctimas de su comunidad fueron satisfechas con el resultado del incidente de reparación dado en la segunda instancia?

12. ¿Qué enseñanzas le dejó el haber participado en el primer incidente de reparación integral en el marco de la ley 975 de 2005 ?

13. ¿Qué enseñanzas cree que le dejó a su comunidad el haber participado en el primer incidente de reparación integral en el marco de la ley 975 de 2005 ? 
PERCEPCIONES SOBRE LA MACROVICTIMIZACIÓN DE MAMPUJÁN Y SAN CAYETANO Y SU REPARACIÓN INTEGRAL EN EL MARCO DE LA LEY 975 DE 2005.

14. ¿Qué sugerencias puede darle al sistema judicial, instituciones, representantes judiciales, víctimas y demás líderes de víctimas a partir de los procesos adelantados en el primer incidente de reparación integral en el marco de la ley de Justicia y Paz?

15. ¿Usted cree que la ley de Justicia y Paz sirvió para satisfacer las pretensiones de las víctimas?

16. Si las victimas ya recibieron la reparación integral, ¿ésta cumplió con el objetivo o destino que tenía?

Preguntas guía realizadas a los representantes judiciales de las víctimas de Mampuján y San Cayetano a través de esta entrevista semiestructurada:

Nombre completo:

Cédula de ciudadanía:

Estudios realizados

Edad:

Género:

Comunidades de víctimas que representaron:

1. ¿Considera que se logró la reparación integral de las víctimas con el fallo de la segunda instancia establecido por la Corte Suprema de Justicia? Explique su respuesta

2. ¿Encontró dificultades o falencias en el incidente de reparación integral a las víctimas de Mampuján y San Cayetano en relación con sus pretensiones? ¿Cuáles?

3. ¿Considera que hubo cumplimiento por parte de los postulados de las órdenes emitidas por la Corte Suprema de Justicia en el fallo de segunda instancia? Explique su respuesta

4. ¿Considera que hubo cumplimiento por parte de la institucionalidad de las órdenes emitidas por la Corte Suprema de Justicia en el fallo de segunda instancia? Explique su respuesta

5. ¿Cree que las pretensiones de las víctimas de Mampuján y San Cayetano fueron satisfechas con el resultado del incidente de reparación dado en la segunda instancia?

6. ¿Cree que faltaron pretensiones de las víctimas por incluir en el incidente de reparación?

7. ¿Qué enseñanzas le dejó el haber participado en el primer incidente de reparación integral en el marco de la ley 975 de 2005 ?

8. ¿Qué sugerencias puede darle al sistema judicial, instituciones, demás representantes judiciales, victimas y líderes de victimas a partir de los procesos adelantados en el primer incidente de reparación integral en el marco de la ley de Justicia y Paz?

9. ¿Usted cree que la Ley de Justicia y Paz sirvió para que las víctimas sean reparadas de manera integral?

Preguntas guía realizadas a las víctimas de Mampuján y San Cayetano a través de los Grupos Focales:

Nombre completo:

Cédula de ciudadanía:

Estudios realizados:

Edad:

Género: 
PERCEPCIONES SOBRE LA MACROVICTIMIZACIÓN DE MAMPUJÁN Y SAN CAYETANO Y SU

REPARACIÓN INTEGRAL EN EL MARCO DE LA LEY 975 DE 2005.

Hecho (s) victimizante (s):

Comunidad:

1. ¿Consideran que el incidente de reparación integral contempló todos los hechos victimizantes, daños o perjuicios de los cuales ustedes fueron víctimas?

2 ¿Creen que faltaron pretensiones de ustedes como víctimas por incluir en el incidente de reparación?

3 ¿Ustedes se sienten satisfechos con las órdenes emitidas por la Corte Suprema de Justicia en el fallo de segunda instancia en cuanto a su reparación integral? ¿Por qué?

4 ¿Cómo fueron cumplidas las órdenes emitidas por la Corte Suprema de Justicia en el fallo de segunda instancia en cuanto a su reparación integral por parte de los postulados y de las instituciones?

5 ¿Se sienten satisfechos con la manera en que los postulados y las instituciones cumplieron las órdenes emitidas por la Corte Suprema de Justicia en el fallo de segunda instancia en cuanto a su reparación integral? Explique su respuesta

6 A partir de lo que vivieron en el incidente de reparación, ¿qué sugerencias puede darle al sistema judicial, instituciones, representantes judiciales, líderes de víctimas y demás víctimas a partir de los procesos adelantados en el primer incidente de reparación integral en el marco de la ley de Justicia y Paz?

7 ¿Ustedes creen que la Ley de Justicia y Paz ha sido un instrumento efectivo para lograr la reparación integral de las víctimas? 
PERCEPCIONES SOBRE LA MACROVICTIMIZACIÓN DE MAMPUJÁN Y SAN CAYETANO Y SU REPARACIÓN INTEGRAL EN EL MARCO DE LA LEY 975 DE 2005.

\title{
Apéndice C. Modelo consentimiento informado digitadora
}

\author{
UNIVERSIDAD SANTO TOMAS \\ MAESTRIA EN PSICOLOGIA JURIDICA
}

Consentimiento informado para el digitador(a) encargado(a) de hacer la transcripción de las técnicas de recolección de información.

Título de la investigación: Percepción de las víctimas y sus representantes frente al incidente de reparación a las víctimas de Mampuján y San Cayetano en el marco de la ley de justicia y paz Lugares de Estudio: Bogotá D.C., Mampuján y San Cayetano, Departamento de Bolívar. Llevado a Cabo por: Luis Alberto Bonilla Cárdenas, Jhon Byron Tamayo Vera.

Directora: Dra. Ángela Tapias Saldaña

Introducción: El presente documento es proveer toda la información al digitador encargado de hacer la transcripción de las técnicas de recolección de información (audios): ñgrupos focalesò y ñentrevistas semiestructuradasò, de los participantes víctimas de Mampuján y San Cayetano y sus representantes judiciales del incidente de reparación en el marco de la Ley de Justicia y Paz, con el fin de que pueda aceptar o no el trabajo de transcripción y se comprometa con la confidencialidad de la información, salvaguardando la identidad de los participantes y asegurando la no utilización indebida de la información y sin autorización de los investigadores.

Si decide participar en la transcripción de los audios, los investigadores le solicitarán que firme el presente consentimiento del cual le será proporcionada una copia.

Propósito de la Investigación: Esta investigación trata sobre la percepción de las víctimas o representantes judiciales frente al incidente de reparación de las víctimas de Mampuján y San Cayetano en el marco de la ley de justicia y paz.

El propósito de este estudio es establecer sí el incidente de reparación de Mampuján y San Cayetano contribuyó a la reparación integral de las víctimas. Para ello, se harán preguntas sobre las pretensiones de reparación de las víctimas, así mismo, se indagará sobre los elementos que permitan identificar si fueron satisfechas dichas pretensiones y conocer de parte de las victimas el cumplimiento de las ordenes realizadas por la Corte Suprema de Justicia a los postulados y la institucionalidad.

Si usted decide participar en este estudio con la transcripción de los audios, se le solicitará lo siguiente:

- Expresar verbalmente su intención de participar con la transcripción, lo cual en ningún momento lo hace autor, coautor o integrante de la investigación.

- Se comprometa con la confidencialidad de la información, salvaguardando la identidad de los participantes y asegurando la no utilización indebida de la información y sin autorización de los investigadores.

- Firmar el presente consentimiento informado del cual le será proporcionada una copia 
PERCEPCIONES SOBRE LA MACROVICTIMIZACIÓN DE MAMPUJÁN Y SAN CAYETANO Y SU REPARACIÓN INTEGRAL EN EL MARCO DE LA LEY 975 DE 2005.

Utilización de la información que proporcione: Esta información será utilizada para la Realización de la tesis de los investigadores, la cual es requisito para optar por el título de Maestría en psicología Jurídica. También puede ser utilizada para otras publicaciones de los investigadores, participación en congresos, seminarios, simposios u otros eventos de carácter académico y público.

Posibles beneficios del estudio: Un posible beneficio de este estudio podría ser darles mayor visibilidad a las posiciones de las víctimas o sus representantes judiciales sobre los resultados del incidente de reparación a las víctimas de Mampuján y San Cayetano, de igual forma, este estudio puede tener efectos a nivel de representaciones sociales y en el aparato judicial, frente a los actuales incidentes de reparación que se adelantan y que se adelantarán en el marco de la Ley de Justicia y Paz. Específicamente, para el digitador un beneficio visible es el de poder recibir una remuneración por el trabajo de transcripción de los audios.

Participación Voluntaria: su trabajo como digitador encargado de la transcripción de los audios, es completamente voluntario y usted está en libertad de retirarse en cualquier momento de esta actividad.

Contactos del Estudio: Antes, durante y después del estudio usted se puede contactar con los investigadores:

Luis Alberto Bonilla Cárdenas

Teléfono Móvil: XXXXXX

Correo electrónico: XXXXXX

Jhon Byron Tamayo Vera

Teléfono Móvil: XXXXXX

Correo electrónico: XXXXXX

En constancia de su deseo de trabajar como digitador encargado de hacer la transcripción de los audios de la investigación: ñPercepción de las víctimas y sus representantes, frente al incidente de reparación a las víctimas de Mampuján y San Cayetano en el marco de la Ley de justicia y pazò, se firma el presente consentimiento informado a los __ días del Mes de de 2013.

\section{Firma}

Nombre completo:

C.C.

Teléfono:

Correo electrónico: 